for

\title{
Research Facility Access $\&$ Science Education
}

October 1994

Principal Investigators

Dr. S. Peter Rosen, Dean

College of Science

University of Texas at Arlington

and

Dr. Vigdor L. Teplitz, Chair

Physics Department

Southern Methodist University

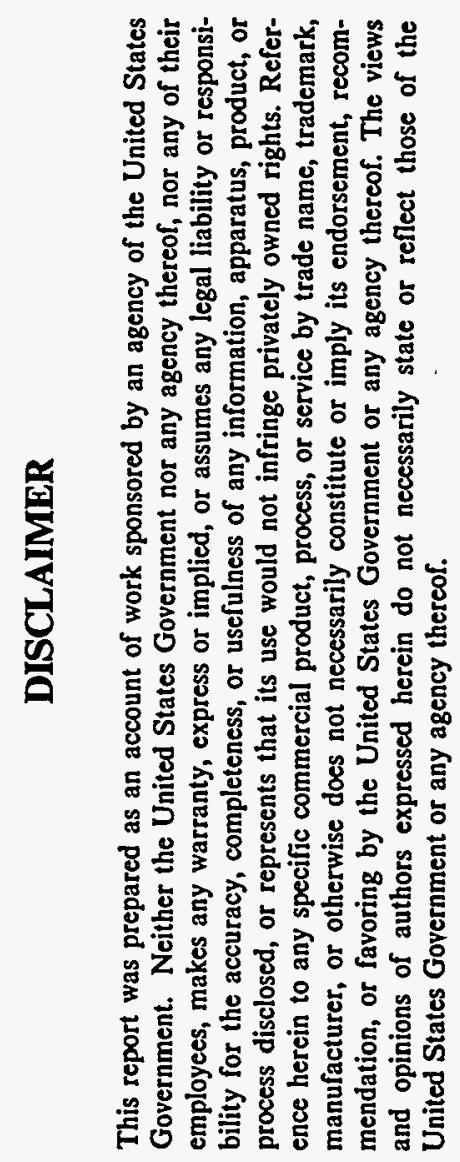

Project Director

Dr. Jane Armstrong 
The following is a list of persons who have given their valuable time and insights as a part of our:

\section{ADVISORY BOARD}

Science Education Committee

\section{COMMITTEE CHAIRMAN}

Dr. Bill Baker, Professor of Chemistry, University of Texas, Arlington, TX

\section{MEMBERS}

Dr. Manuel Berriozábal, Coordinator, TEX PREP, and Professor of Mathematics, University of Texas, San Antonio, TX

Nan Broussard, Director, Eisenhower Mathematics and Science Higher Education Grants Program, Texas Higher Education Coordinating Board, Austin, TX

Jim Collins, Director of Science, Texas Education Agency, Division of Curriculum Development, Austin, TX

Dr. Norman Hackerman, President Emeritus, Rice University and Chairman, Scientific Advisory Board, The Welch Foundation

Sonia Hernandez, Education Director, Governor's Policy Council, Office of the Governor, Austin, TX

Dr. Robert James, Director, Texas Alliance for Science, Math \& Technology, Texas A\&M University, College Station, TX

Karen Johnson, Director of University Research, Texas Instruments, Dallas, TX

Dr. Joe Lagowski, Professor of Chemistry, University of Texas, Austin, TX

Honorable Penny Reddington, County Judge, Ellis County, Waxahachie, TX

Evelyn Restivo, 1994 Tandy Technology Scholar and Chemistry and Physics Teacher at Maypearl ISD, Maypearl, TX 


\section{ADVISORY BOARD}

\section{R\&D Infrastructure Committee}

\section{COMMITTEE CHAIRMAN}

Dr. Charles Tapp, Director of Quality Improvement, Sandia National Laboratories, Albuquerque, NM

\section{MEMBERS}

Andy Blanchard, Director of Space Technology \& Research Center, Houston Advanced Research Center, The Woodlands, TX

Michael Brown, Owner, Cognitive Training Associates, Waxahachie, TX

Ed Casteel, Public Affairs Executive, Rockwell International, Richardson, TX

Jan Collmer, Owner, Collmer Semi-Conductor, Dallas, TX

Al Hampton, State Coordinator, TAME Inc., University of Texas, Austin, TX

Dr. Dennis Judd, Professor or Physics, Prairie View A\&M University, Prairie View, TX

Jack Kilby, Past Director of Research Labs, Texas Instruments, National Inventors Hall of Fame, and National Medal of Science, Dallas, TX

Mike Lockerd, Manager of External Research and University Strategies, Texas Instruments, Dallas, TX 75265

John Mills, Advanced Research \& Robotics Institute, University of Texas at Arlington, Fort Worth, TX

Bill Stotesberry, GTT Communications, Austin, TX

Dr. Bob Webb, Professor of Physics, Texas A\&M University, College Station, TX

Dr. Jane Winer, Dean, College of Arts \& Sciences, Texas Tech University, Lubbock, TX 


\section{Table of Contents}

Table of Contents

1.

1.1.

1.2.

1.3.

2.

2.1.

2.1.1.

2.1.2.

2.1.3.

2.2 .

3.

3.1.

3.2 .

3.2.1.

3.2.2.

3.2.3.

3.2.4.

3.3.

3.3.1.

3.3.1.1

3.3.1.2

3.3.1.3

3.3.1.4

3.3.1.5

3.3.1.6

3.3.1.7

3.3.2.

3.3.2.1

3.3.2.2

3.3.2.3

3.3.2.4

3.3.3.

3.3.4.

3.3.5.

3.3.6.

3.3.7.

3.4 .

3.4.1.

3.4.2.

3.4.2.1
Executive Summary

Science Education/CyberScience Coalition

R\&D Facility Access Program

Findings \& Recommendations

Background \& Organization of Study

Overview

Study Goal \& Mission

Detailed Study Objectives

Affirmative Action

Study Management

Science Education Program

Introduction: Scientific Inquiry as a Life Skill

Definition of Need

Advisory Board's Science Education Subcommittee

Survey of Math \& Science Education Programs in Texas

Science Education Workshop

CyberScience Survey of Science Teachers

CyberScience Coalition

CyberScience Education Enhancement Center

Computer Literacy Training for Teachers

Teachers/Students/Classrooms On-Line

TAME Collaboration

Science Education Equipment Lending Pool

Software on Science (SOS) Clearinghouse

Student Internship Opportunities

School Administrator /School Board Seminars on Connectivity

Connectivity Resource Center

Technology Deployment Services

Technology Maintenance Services

CyberScience Digital Data Repository

Digital Libraries

iv

1

1

4

4

7

Educational Technology Test Beds 32

A Community Resource for Workforce Development 33

Executive Institute on Educational Technology 33

Business Relationships 34

University Relationships $\quad 35$

Financial Considerations 35

Budget Projections by Cost Center - CyberScience Coalition 36

Sources of Funds

Federal Funding 
State Funding

Summary Recommendations

4.1. R\&D Facilities Access Program

4.2.

4.2.1.

Original SSC Assets

R \& D Infrastructure Market Survey

R\&D Market Survey Results

Stratified Survey Results

Market Potential

Follow-up

4.4 .

R\&D Infrastructure Workshop

51

4.5 .

4.5.1.

4.5.2.

4.5.3.

Existing Regional University R\&D Shop Facilities

51

Anticipated Availability of SSC Assets

High Performance Computing Center

Information Technology

Mechanical shops

53

4.5.4.

4.5.5.

4.5.6.

4.6 .

4.6.1.

Cryogenics and Magnet Development

53

Electronics

54

Data Acquisition

54

Viable Services: Academic/Small Business R\&D Facility

Access Program

54

Academic/Small Business R\&D Facility Access Program

55

4.6.2.

4.6.3.

4.7.

4.7.1. R\&D Equipment Loan Program

Conferences and Collaborative Outreach Activities

Financial Considerations

Cost \& Competitiveness

4.7.2.

Pricing

58

4.7.3.

Budget

58

4.7.4.

Sources of Funds

61

4.8 .

5.

Recommendations

61

R\&D Training Activities

63

5.1.

Endorsement of Other EOI Projects

5.2 .

5.3.

5.4 .

6.

Manufacturing Technology Deployment Center TEEX/ARRI

63

Recommendation

64

Summary \& Recommendations

65

6.1.

Introduction

65

6.2.

6.3.

6.3.1.

Summary Description

65

Management

Academic/Small Business R\&D Facilities Access Program

68

6.3.2.

CyberScience Education Programs

68

6.4 . Interim Period

68

6.5 .

Recommendations

70

7. Summary Budget Requirements $\quad 72$

8. Appendices $\quad 73$

Appendix A Survey of Texas Universities and Colleges 73

Appendix B Science Education Workshop Agenda 
Appendix C Cyberscience Science Teacher Survey 80

Appendix D "Riding The Internet" 84

Appendix E Equipment For Science Education Lending Pool $\quad 85$

Appendix F Detailed Descriptions of SSC Assets/Capabilities 86

F.1.

F.2.

F.2.1.

F.2.2.

F.2.3.

F.3.

F.3.1.

F.3.2.

F.3.3.

F.4.

High Performance Computing and Communications

86

Information Technology

Voice Systems

86

Data Network 87

Audio-Visual . $\quad 87$

Mechanical shops , $\quad 88$

- Machining Capabilities . 88

Welding Capability $\quad 89$

Quality Control $\quad 89$

Cryogenics 89

F.5. Magnet Fabrication v 89

$\begin{array}{lll}\text { F.6. } & \text { Electronics } & 90\end{array}$

$\begin{array}{lll}\text { F.6.1. } & \text { VLSI design and testing } & 90\end{array}$

$\begin{array}{lll}\text { F.6.2. } & \text { Board level systems } & 90\end{array}$

F.6.3. RF capabilities $\quad, \cdots, 91$

F.6.4. Test \& Measurement 91

F.7. Data Acquisition 91

Appendix G R\&D Market Survey Results $\quad 93$

Appendix H R\&D Market Survey Information Requests 94

Appendix I Electronics Equipment Anticipated to be Available 96

Appendix J Machine Shop Equipment Anticipated to be Available $\quad 97$

Appendix K R\&D Infrastructure Workshop Agenda $\quad 99$

Appendix L HARC-C: Image Compression Software 101

Appendix M PowerKids' Power OS 103

Appendix N Letter of Support from Globe Project 104 


\section{1.. Executive Summary}

This UTA/SMU project definition study describes critical customer services and research programs which draw upon SSC assets to meet regional needs in two major components:

- $\quad$ Science Education

- Academic/Small Business R\&D Facility Access

The location of the SSC in Texas constituted a significant stimulus to R\&D. activities in Texas, encouraging new initiatives in high energy physics, as well as stimulating other areas of physics and related sciences.

An important aspect of maximizing the utility of the investment in the SSC should be to re-allocate SSC assets in ways that maintain that momentum. This study addresses several ways to achieve that end, extending benefits to all of physics, the sciences in general and particularly, to science education.

\subsection{Science Education/CyberScience Coalition}

Just as information technology has become an integral tool for the practicing mathematician, engineer or scientific researcher, it now also belongs in our science and math classrooms as a day-to-day tool in the hands of our students and teachers. Advances in hardware capabilities, user interface, and software technology allow students to use computers as transparent extensions of their . hands and minds to explore the world around them.

In the CyberScience Coalition, we propose to use TENET, THEnet, Internet and information technology as primary catalysts to involve scientists and engineers in the enhancement of science education. We believe:

- Integral use of information technology will impact the value of student experiences and result in a broader range of students excelling in science and mathematics literacy;

- Offering learners more relevant and meaningful learning environments will result not only in greater mastery of concepts but also a better appreciation of the value science and mathematics in solving real world problems; and finally, that

- Teachers and students must use today's leading edge information tools if they are to invent and apply tomorrow's problem solving technology. 
The CyberScience Coalition is proposed as a new connectivity mechanism involving:

- Technical components continuing as part of the reconfigured Texas Laboratory,

- Public schools and regional service centers,

- 2 and 4-year degree-granting academic institutions,

- State and federal agencies,

- Professional societies,

- Businesses and industries, as well as

- Foundations, community organizations

and others concerned with educational reform.

Furthermore, the CyberScience Coalition is designed to involve these interested constituents in building a sustainable base for the application of telecommunications technologies to science and math education.

Texas' core industry bases, from oil to electronics to agriculture, all have a continuing demand for a science literate workforce. In addition to involving key industry representatives as members of our advisory board, exploratory discussions with representatives from internationally recognized firms such as Texas Instruments, Rockwell International, Apple Computers and E-Systems, indicate an interest and willingness on the part of industry to participate in the formation of the CyberScience Coalition. Letters of Support will be provided as an appendix, delivered under separate cover.

For organizational and management purposes, the CyberScience Coalition will be divided into four components, addressing the following program needs. With appropriate funding, components 1 and 2 describe program elements for which we can begin immediate delivery.

1. Science Education Enhancement Center, providing:

- Computer Literacy Training for Teachers

- Lab Equipment Lending Pool

- Students/Classrooms On-line

- School Administrator Seminars

- Software on Science (SOS) Clearinghouse

- Student Internship Opportunities

2. Connectivity Support Center

- Technology Deployment Services

- Technology Maintenance Services 
- Internet Data Repository/Gateway for Science Education Users (NII/WWW/Mosaic)

- Digital Libraries

- Linkages with International Educational Communities, beginning with Mexico

In a survey of Texas science teachers conducted for this study, $89 \%$ of respondents reported that their classrooms are not connected to a network, $69 \%$ felt that they had "zero" or "weak" networking skills, and $90 \%$ wanted to learn more via a variety of training vehicles.

According to a 1993 national survey, $80 \%$ of the installed base of computers in American elementary and secondary schools are essentially incapable of supporting multimedia graphical applications; presently, only Apple Macintoshes and IBM compatible 386s or $486 \mathrm{~s}$ are capable of supporting the higher level applications which facilitate teaching good science visually.

Almost all of the Macintoshes, PCs, PowerBooks/portables, workstations, servers and computer peripherals currently a part of the SSC Laboratory inventory can meet the higher level applications criteria and could be very efficiently used in a Texas outreach program that will also coincide with the national agenda for improving the use of NII and telecommunications technologies in classrooms .

A critical feature of the CyberScience Coalition is the use of this current SSC inventory of appropriate computer hardware and peripherals (Current inventory indicates as many as 2925 Macs/PCs, 906 workstations and 9375 various peripherals available) to link Texas science teachers on to Internet as part of the Connectivity Resource Center efforts.

Using the rural community science classrooms in South Texas, East Texas and West Texas as a priorities, demonstration models and test beds can be established in ways that allow successful approaches to be cost-efficiently replicated both nationally, and eventually in Mexico.

Components 3 and 4 describe research program elements that are needed to build sustainable, on-going research efforts that feed cutting edge technology back into the front-line programs, such as those outlined in points 1 and 2 above. Investments of seed dollar funding are necessary to initiate research programs such as the following:

3. Educational Technology Research Group

- Technology Test Beds

- Learning Styles Research

4. Workforce Development Research Group 
- Data Base on Workforce Needs and Skill Assessments for Science and Engineering

- Executive Institute for Advancement of Science Education

\subsection{R\&D Facility Access Program}

No one university or small business has all of the state-of-the-art equipment, or adequate space to carry out all the work it might wish to undertake. A market survey conducted as part of this project definition study has determined that interest in shared-use access to SSC assets was highest for high performance computing. In order to demonstrate the true need for sustained access to this high priority asset, we propose to manage a fund which provides subsidized access and use of high performance computing and available shop capabilities for users from all Texas universities, national labs, and small high-tech industries, with special emphasis on efforts that facilitate equitable access for minorities and females.

The mission for the proposed Academic/Small Business R\&D facility Access Program is to provide a broad array of state-of-the-art technical services in one central location to serve the research and development communities in universities and in high-tech enterprises in Texas. This program will enhance many universities' abilities to collaborate in forefront research projects, will allow industries to develop their ideas more economically, and can interface efficiently with the on-going scientific programs remaining as a permanent part of the Texas Laboratory.

For organizational and management purposes, the R\&D Facility Access Program will include the following components:

- $\quad$ R\&D Facility Access Fund;

- $\quad$ R\&D Lab Equipment Lending Pool; and

- Stand-Alone Electronics and Machine Shops, if necessary.

\subsection{Findings \& Recommendations}

After careful study and consideration, with input from an especially helpful and experienced Advisory Board, the following recommendations are made as a part of this UTA/SMU project definition study:

A A critical service niche in science education has been identified which uses existing SSC computing assets to support science education by 
providing on-going teacher enhancement on the use of computers and connectivity resources on a daily basis in science classrooms.

For science education, the project has definite uses/needs for pieces of SSC equipment, including almost all of the Macs/PCs/workstations $(3500+)$ as well as permanent staff, budget and facility space, independent of any other technical and/or high performance computing elements which may continue to exist.

An outreach program will be implemented to loan SSC/DOE computer workstations to schools and to provide expertise to "information-poor" school districts in Texas to enable them to connect to the NII. Ownership would be retained by the CyberScience Connectivity Resource Center, which will also maintain the computers and networking hardware.

In addition to providing all available Macs, Pcs, workstations and computer peripherals available for the enhancement of science education, the Department of Energy can leverage both their education and research dollars well by providing:

1) Immediate start-up funding of $\$ 1.6 \mathrm{M}$ direct costs for the 1995 and \$1.7M direct costs for 1996; and

2) Base line support of $\$ 1 \mathrm{M}$ direct costs for each of the subsequent three years, plus leadership assistance in securing long-term selfsustaining research funding and development activities for the CyberScience programs during the first five years of operation.

B Use of the SSC assets will be maximized by the establishment and funding of an Academic/Small Business R\&D Facility Access Fund, a service program to provide universities and small businesses in Texas (and if feasible the region) with access to the electronic and machine shops and parallel computing capabilities that are retained at the site.

The mission of the proposed Academic/Small Business R\&D Facility Access Program is to provide a broad array of state-of-the-art technical services and training in one central location to serve the research and development communities in universities and in high-tech enterprises in Texas, relating to all branches of physics. This service program will enhance the abilities of universities, most especially undergraduate and minority institutions, and small businesses to participate in leading research collaborations, to establish new ties with one another, and could contribute to the economic feasibility of new idea development.

Twenty percent (20\%) of the Academic/Small Business R\&D Facility Access Fund will be prioritized for minority and/or female users, or project teams involving minorities and/or females in principal roles. 
The Department of Energy (DOE) should finance this Academic/R\&D Facility Access Program at an annual amount of $\$ 2 \mathrm{M}$ per year over the next 5 years in order to provide those in both the scientific and regional business communities with a different, yet on-going, R\&D stimulus similar to that which might have been anticipated to exist due to the existence of the SSC Laboratory in Texas. Five years' cumulative direct costs requested from DOE for the R\&D Facilities Access Fund and minimal Fund administration total $\$ 12.5 \mathrm{M}$, and five years' cumulative direct costs for the R\&D Equipment Lending Program total \$1.8M.

C Training needs for R\&D technicians, as well as for production technicians, were also investigated during this project definition study; however, our evidence suggests that other DOE-funded studies, specifically those led by industry-driven Texas Manufacturing Technology Center (TMTC) and its proposed Inland Regional Technical Institute, as well as by the Texas Engineering Extension Service (TEEX)/UTA's Automated Robotics Research Institute, are competent endeavors perhaps better suited to this task, and as such, are endorsed and supported to meet training needs.

D Our project has identified no justifiable needs for the Central Facility (CF), in and of itself, but does have facility space needs which could be met by allocation of space either at CF or N-15, depending on what and where other technical and/or high performance computing elements will continue to exist on a long-term basis.

E To prevent a loss of continuity between completion of this study and implementation of defined projects, the CyberScience Coalition and the Academic/Small Business R\&D Facility Access Program, we recommend that modest funds be made available immediately for program development work to continue. To support base line program development activities would require approximately $\$ 30,000$ per month plus indirect costs; funds requested represent direct costs to support four program development and technical staff, appropriate administrative support, and basic travel and operating expenses. 


\section{Background \& Organization of Study}

\subsection{Overview}

As Congress voted to terminate the Superconducting Super Collider (SSC) Laboratory in October of 1993, the Department of Energy was encouraged to maximize the benefits to the nation of approximately $\$ 2$ billion which had already been expended to date on its evolution.

Having been recruited to Texas from other intellectually challenging enclaves around the world, many regional scientists, especially physicists, of course, also began to look for viable ways to preserve some of the potentially shortlived gains made by Texas higher education in anticipation of "the SSC era."

In fact, by November, 1993, approximately 150 physicists and engineers from thirteen Texas universities and the SSC itself, had gathered on the SMU campus to discuss possible re-uses of the SSC assets. Participants at that meeting drew up a petition addressed to the state and federal governments requesting the creation of a Joint Texas Facility for Science Education and Research. The idea was to create a facility, open to universities and industry alike, which would preserve the research and development infrastructure and continue the educational mission of the SSC.

Shortly thereafter, in December of 1993, Texas Governor Ann W. Richards appointed a committee of distinguished citizens, chaired by Jess Hay, to review the SSC situation and to make recommendations for state action. At the request of the Hay Committee, the National Research Council (NRC) quickly assembled a panel of National Academy members to visit the SSC, and provide technical advice. Advice from the NRC group included retention of a core group of scientists; maximizing uses for the high performance computing capabilities, and encouragement for evolution of some "joint facility supporting science education and research."

The Hay Committee made three recommendations to the Governor in February, 1994:

- $\quad$ Retain a core group of scientists and engineers to maintain the viability of complex SSC facilities and to develop alternative uses for them;

- Establish (or was it authorize) a research agency to direct the work of the core group; and

- Focus initial efforts on regional centers for superconductivity, highperformance computing, and medical technology. 
In addition, the Hay Committee recommended that the SSC site be restored to its native Blackland Prairie condition.

While these recommendations were being developed, the Department of Energy (DOE) issued a call for "Expressions of Interest" for use of SSC assets and established a procedure for reviewing formal proposals. DOE also entered into negotiations with the State of Texas, represented by the Texas National Research Laboratory Commission (TNRLC), to determine what compensation should be given the State in return for its approximate $\$ 539 \mathrm{M}$ already contributed in land acquisition costs, as well as facilities, to the SSC Laboratory endeavors.

Outcome of these parallel processes consisted of an agreement between the State and DOE, which was announced in July, 1994, and two specific sets of project definition studies regarding alternative uses of the SSC assets:

SET 1 evolved under the leadership of the TNRLC:

- Regional Medical Technology Center (RMTC)

- Applied Superconductivity \& Cryogenics Technology Center (ASCTC)

- Southwest Center for Computing; Information and Learning (SCCIL)

- Blackland Prairie Restoration Project (BPRP)

SET 2 consisted of several of the expressions of interest (EOI's) originally requested by and subsequently funded directly by DOE:

- Joint Texas Facility Supporting Research, Training and Science Education (UTA/SMU)

- Inland Regional Industrial Technology Institute (TSTC)

- Manufacturing Deployment Center (TEEX/ARRI)

- Minority Institution Network Access to the Central Computing Facility (PVAMU)

- $\quad$ Measurement of Velocity of Light in a Magnetic Field (JPL) and in a Strong Magnetic Field (Colorado State U.)

- Cryogenic Helium Gas Convection Research (Yale/Duke/U of Oregon)

- Geotechnical Facility for Environmental Research at the SSC Site in Texas (LBL)

This document, is the final report for the project definition study regarding the "Joint Texas Facility Supporting Research, Training and Science Education, " one of those EOI's funded directly by DOE as a part of SET 2.

One of the underlying tenets of this project definition study is that the sharing of resources is inherently more economical than duplication. For 
example, it is assumed that the required computer support is supplied by a dedicated High Performance Computer Center, and that the shops are actually maintained by a primary user. Leading candidates to serve as primary technical users of the facility include:

RMTC. The Regional Medical Technology Center (RMTC) will include both a proton cancer therapy facility and a radioisotope production facility. Having already passed DOE peer review, as well as state endorsement, the RMTC is well on its way to receiving appropriations to formalize its existence.

ASCTC. Functioning as the Applied Superconductivity and Cryogenics Technology Center (ASCTC), the magnet complex can become a national center for the development of superconducting magnets for many different purposes, ranging from highly specialized "one-of-a-kind" magnets to magnets for magnetic levitation. Such a center can be of great service to the nation by helping superconductivity become an economically viable technology with widespread applications.

Under the terms of the preliminary agreement between the State and DOE, the superconducting magnet complex will become the property of the State. It is the most up-to-date facility of its kind in the country with the capacity to cable and wind the highly specialized wire alloys that become superconducting at liquid helium temperatures. It also has a very large capacity to produce liquid helium and is fully equipped to design, fabricate, and test superconducting magnets of all shapes and sizes. One obvious use of the complex in the field of High Energy Physics is the development and fabrication of special magnets for the Large Hadron Collider (LHC), an accelerator about one-third the energy of SSC which is likely to be built in Europe in the next ten years. Indeed the National Research Council panel emphasized in its report that this could provide the basis for a United States contribution to the LHC.

BPRP. The Blackland Prairie Restoration Project proposes restoring approximately 6,000 acres of endangered prairie ecosystem at the former site of the Superconducting Super Collider (SSC). The restoration project is proposed to be an integrated land management system compromised of restored tall grass prairie together with approximately 150 acres of riparian woodlands and associated wetlands. Park programs will be phased in as the area of land restored to Blackland Prairie increases. Educational, recreational and interpretive programs will be instituted gradually. It is proposed that educational programs could target students who are interested in actually working on the restoration project, or host science class field trips to observe the restoration process. The proximity of the SSC land to Waxahachie and the Dallas and Fort Worth Metropolitan areas suggests that the park could support a strong educational program that targets elementary, middle, and high school students in these areas. 
SCCIL. The Southwest Center for Computing, Information \& Learning (SCCIL) recommends that the computing networking and many other SSC resources be used to create a regional center which would be a major regional node on the National Information Infrastructure (NII), a large data repository and a high performance computing center. The use of technology to deliver education, particularly with an emphasis on science education through a proposed on-site school as well as through interaction with the CyberScience Coalition science education initiative, will be an important strategy with which our project definition will collaborate and compliment.

At the time of SSC funding termination in October of 1993; the "SSC assets" included about 2000 highly skilled staff members, several large buildings, and much sophisticated equipment. Inevitably the staff, the single most valuable asset, has all but evaporated during the past year as the scientists, engineers and technicians at the SSC Laboratory have moved on to other jobs and other careers, many out of state and/or the country.

The physical facilities remaining consist of a partially completed 600 million electron volts $(\mathrm{MeV})$ linear accelerator, a complex of superconducting magnet laboratories and helium liquifiers, and an enormous 525,000 square feet central facility building. The central facility (CF), totally wired and networked for modern electronic communication, houses state-of-the-art engineering shops, offices, a library, and a massively parallel computer farm.

The most versatile of SSC assets, and possibly the most fragile, is the collection of computer hardware assembled at the SSC laboratory, including personal computers and work stations. As the centerpiece for a node on the National Information Infrastructure, these resources could enable education in Texas to join in the cyberspace revolution that is sweeping through our society, and to develop educational programs based on them serve as a model for duplication in other places, in addition to benefiting Texans.

The ability to access large databases, to connect students in one location with master teachers and researchers at the other end of the world, and to eventually create interactive simulations of key scientific experiments will open up vast new possibilities for science education, many of them not even imaginable today.

Use of the SSC site and SSC assets provides a unique opportunity to realize the goals envisioned in Joint Texas Facilities Project. Conceived as a collaboration involving relevant state agencies, universities and forwardlooking industries, the Joint Texas Facility for Science Education and Research would receive technical leadership from scientists and engineers who are thoroughly versed in the developing lines of their fields, and who have the flexibility to adapt to changing scenarios. With state endorsement and support, such a facility could earn the respect of both industrial and political communities and provide an effective interface between them and the 
technical community. As noted by the National Research Council panel, the path for providing shared academic access to these R\&D facilities will not be easy, but it is well worth exploring.

\subsubsection{Study Goal \& Mission}

Study Goal: To provide realistic advice and recommendations for using SSC Assets to enhance science research, education and economic competitiveness in Texas.

Study Mission: To study the benefits and costs of including the following broad, Texas outreach programs as permanent parts of whatever science/physics facility evolves at Waxahachie, Texas.

\subsubsection{Detailed Study Objectives}

During the course of this study, we have researched and analyzed the proposed purposes, benefits and costs of the elements of a Joint Texas Facility for Support of Research, Training and Science Education. The objectives of such a Facility would include: science education, particularly teacher enhancement, precollege instruction assistance, and intern activities; and infrastructure support for Texas physics research in areas of machine shops, electrical and electronic shops, engineering design, and training programs in these areas. The goal would be to provide new resources, not to compete with existing facilities. Special attention would be paid to full participation by minorities and women and predominantly minority institutions.

For science education, the objectives were examine the feasibility to:

- Develop and manage teacher enhancement programs;

- $\quad$ Support efforts by Texas schools in K-8 in all sciences and at the high school level in physics;

- Conduct undergraduate, graduate, and postdoctoral activities at the site;

- Manage appropriate intern activities at the site for students and teachers.

Regarding infrastructure support for Texas physics research, the objectives were to investigate the feasibility of a facility which could:

- $\quad$ Provide machine shops, electrical and electronic shops, engineering design expertise, CAD/CAM facilities, and other related infrastructure elements for physics research in Texas, basic and applied, in universities and industry; 
- Develop and conduct, in cooperation with industry, appropriate training programs in the broad areas of mechanical and electrical engineering shops that would constitute the core of the research infrastructure support.

- Operate so as to supplement institutional infrastructure for those challenges requiring resources not available at individual institutions and companies;

- $\quad$ Facilitate cooperation among multiple Texas institutions and companies in responding jointly to major technical challenges; and

- $\quad$ Seek to maintain a balance among different parts of physics that would furnish appropriate support to various sub fields, taking into account national and state priorities as well as advancement of the field.

In pursuing both science education and infrastructure initiatives, the project would be defined in such a way as to meet the following common objectives:

- Work in close coordination with the other specific on-site uses selected for development;

- $\quad$ Structure operations and activities such as to encourage and to promote participation of women and minorities and minority-serving institutions;

- Attempt to ensure maximum exploitation for technical training, teacher enhancement, and other educational programs of its research infrastructure activities;

- Attempt to ensure that its activities utilize the best in educational technology and pedagogic research and practice; and

- Structure its activities so as to reinforce and enhance existing efforts in education and research.

\subsubsection{Affirmative Action}

Insufficient participation by women and minorities is a problem in physics at the national, state and local levels. A major objective of JTF must be to ensure that its programs are designed, to the maximum extent possible, to aid in addressing that problem. A variety of appropriate features have been incorporated into the programs defined in this study. These include:

- Twenty per cent (20\%) of the Academic/Small Business R\&D Facility Access Fund will be prioritized for minority and/or female users, or project teams involving minorities and/or females in principal roles. This could be particularly important in facilitating research at minority institutions which tend to be very limited in infrastructure assets to support faculty creativity; and 
- Intern arrangements for minority and female high school students. A working arrangement in this area, with TEXPREP is under discussion with its director, who sits on the advisory board of this study, as discussed in section 3.3.1.6;

- Special efforts in staffing. To this end, the advisory board for this study contains several minority and/or women who are well qualified to aid in identifying suitable candidates;

- Workshops with those in Texas with expertise in fostering women and minorities to identify further programs for collaboration. The object would be to augment the many efforts in this area being made by people and organizations around the State and to avoid duplicating such efforts or competing with them.

\subsection{Study Management}

The organization of the Study consisted of the following elements:

A Full Time Director. Dr. Jane Armstrong was recruited and served as Project Director for the Study. Prior to initiating her consulting practice in 1990, Dr. Armstrong served as Vice President for Strategic Development for the Houston Advanced Research Center, a university research consortium. Having worked in the field of university research program development and technology ventures for approximately 15 years, Dr. Armstrong is familiar with Texas education and research programs as well as with SSC historical evolution.

Administrative Support to the Staff. Rebekah DeLaughter, a journalism graduate from University of Texas at Austin and former employee of the SSC Technical Publications Division, provided key facilitating skills in the position of Project Coordinator.

Knowledgeable SSC staff. The SSC lab technical division has provided staff assistance from the following individuals: Kate Morgan; Dr. Jheroen Dorenbosch; Dr. Georges Jamieson; Linda Walling, as well as various administrative staff, where needed.

Consultants. External advice and expertise were provided by Dr. Dan Howard; Dr. J. E. Gonzales; Bill Stotesbery; Dr. Ron Johnson; and Dr. Lynne Bowers.

Market Research. Both staff time and specialized assistance were devoted to this important element. Dr. Dan Howard, chair of Southern Methodist University's College of Business Marketing Department, worked with project staff to complete market survey research for research and development infrastructure and training issues, while Dr. J.E. Gonzales, Texas Center for 
Educational Research with the Texas Association for School Boards provided data tabulation and analysis of survey information solicited from physics and biology teachers in Texas.

The R\&D infrastructure study attempted to ensure objectivity of market research into use of SSC assets for infrastructure for R\&D. Dr. Daniel Howard; Chair of Southern Methodist University's College of Business marketing department, whom the Principal Investigators never met, was selected on advice of the dean of the college of business. Dr. Howard is a recognized national expert in his field. He has consulted on marketing for such major firms as Airco Electronic Gases, Honeywell, Prudential, JC Penney, and the May Company. Dr. Howard is making use of technical advice from study staff, developed a survey instrument and managed its execution. Dr. Howard analyzed the responses and wrote a report independently without staff assistance.

Workshops. Two workshops, one on educational aspects, and one on research infrastructure elements, were held early in the Study to ensure maximum participation in formulating detailed questions to be studied and in answering those questions.

Advisory Board. A committed group of leaders from industry, education and government were involved as "working" advisors during the evolution of our project definition study (See Advisory Board Directory in beginning of document). In order to adequately address all of the relevant questions and issues, the Advisory Board was divided into two subcommittees: one for R\&D Infrastructure, chaired by Dr. Charles Tapp, Director of Quality Improvement at Sandia National Laboratories; and a second for science education, chaired by Dr. Bill Baker, Professor, University of Texas at Arlington. Advisory Board members were included in both workshops and two board meetings, as well as one-on-one interaction as needed in order to meet the deliverables of the study in a timely fashion.

Volunteers. The concept for this proposal traces back to a statewide meeting of physics faculty at Southern Methodist University in October, 1993. At that meeting an informal organization was created, co-chaired by the Principal Investigators and Dr. Richard Wigmans, Bucy Professor of Physics at Texas Tech University. Many of the more than 100 members of the organization participated in one or more of the workshops or as individual resources, and that participation was used as a measure that plans drafted during the Study are truly responsive to Texas science needs, and to physicists in particular.

Interface with Parallel Studies. Both formal and on-going informal arrangements with parallel DOE and TNRLC studies of on-site uses of SSC assets were utilized wherever possible, to avoid unnecessary duplication and to share relevant information. 


\section{Science Education Program}

\subsection{Introduction: Scientific Inquiry as a Life Skill}

For the past several years, committees from both the National Academy of Sciences and the American Association for the Advancement for Science (AAAS) have debated and highlighted the urgency for developing a scienceliterate citizenry.

The SSC was the first national laboratory to include the creation of an international science education program as part of its original mission. In light of the current circumstances, a reconstituted, reinvigorated science education initiative remains a compelling need, both on a state and national basis.

The process of scientific inquiry, more commonly known as "problemsolving, " is a critical life-skill. In addition to encouraging talented students to become scientists and engineers, concentrated efforts must be made to infuse science awareness, appreciation, inquiry and understanding into classroom activities so that students are effectively prepared to solve problems, make decisions and perform successfully as they enter the global workplace.

What is this process of scientific inquiry? Exploration of questions, critical data collection and analysis, plus working together to share ideas and information freely with each other and team-members, or to use modern instruments and technologies to extend intellectual capabilities.

As we analyzed what "SSC Assets" might truly be fortuitous in a reconfigured science education initiative, we realized that we had several elements of a very exciting, cutting edge science education effort right at our fingertips. . . scientists. . . their favorite tools, computers. . . and connectivity to the world via a national information infrastructure.

\subsection{Definition of Need}

A four-pronged approach was used in reviewing existing science education programs and in identifying specific niche services which might use specific SSC assets to be both collaborative and mutually beneficial to all involved:

- Advisory Board Science Education Subcommittee

- Review of College of Education Math/Science Programs in Texas 
- Science Education Workshop

- CyberScience Survey of Science Teachers

\subsubsection{Advisory Board's Science Education Subcommittee}

To examine, document and address the compelling need for science-literate citizens, principal investigators invited participation of key representatives from industry, public schools, the scientific arenas and the local community to serve on a Science Education Subcommittee and an Advisory Board to provide guidance and advice in fulfilling the following charge:

CHARGE: To examine and make recommendations regarding cost-effective activities, structure, operation, and possible funding sources of an on-going educational outreach effort to strengthen and enhance Texas science education initiatives utilizing existing SSC assets, including:

- On-going science teacher enhancement;

- Programs involving university, industry and government to strengthen science appreciation, understanding and awareness for all students in Texas schools;

- Intern activities for teachers \& students of science; and

- $\quad$ Network access to TENET, Internet, interactive computer-aided instruction and technical library holdings

Members of the Advisory Board's Science Education Subcommittee represent a vast array of expertise, as well as interest in the issues surrounding science education, including a member of both the academy of science and the academy of engineering who currently chairs the scientific advisory board for a major foundation; director of the math and science Eisenhower Grants programs for the Texas Coordinating Board for High Education; a 1994 Tandy Scholar (100 teachers recognized nationally); director of university research liaison for a Fortune 100 electronics firm; president of a small business providing skill assessment and interactive training packages for federal contracts; university leaders in science education and information technology; director of a large DOE-funded, minority-targeted math/science preparation program; key community leaders; and science education director for the Texas Education Agency; as well as general participation from advisory board members serving on the R\&D Infrastructure subcommittee. These individuals are identified at the beginning of the document. 


\subsubsection{Survey of Math \& Science Education Programs in Texas}

According to the administrator responsible for Eisenhower Grants for math and science education programs at the Coordinating Board for Higher Education in Texas, a directory of math and science education programs available from/delivered by Texas colleges and universities does not currently exist. As part of our study, therefore, letters were sent to Deans of Education at all Colleges and Universities in Texas, requesting descriptive information regarding their on-going efforts in these areas. Follow-up phone calls were made during the last two weeks in October 1994, to make sure that the survey data included in appendix $\mathbf{A}$ was as complete as possible given our time frame for data collection.

Seventeen universities responded to the survey with descriptions of their science education and teacher enhancement. The major thrusts of these programs are the enhancement of teaching skill, knowledge of subject matter, and the development of new courses and curricula. Five of these institutions emphasize the development of teaching technology and only one mentions networking. Two universities mention summer programs for elementary and high school students.

Computer literacy and connectivity training for teachers appear not to have been emphasized in these programs and so there exists a clear need and important niche for the aims of the CyberScience Coalition. Several institutions have expressed great interest in joining this effort.

\subsubsection{Science Education Workshop}

The Science Education Workshop was held Thursday, September 1, 1994 at Southern Methodist University (Agenda is available in Appendix B). Approximately 65 educators and industry representatives attended the daylong event. Topics of discussion included the settlement between the U.S. Department of Energy and the State of Texas, an overview of the Joint Texas Facility Project and other collaborations including reports from the Regional Medical Technology Center, the Southwest Center for Computing, Information \& Learning, and the Inland Regional Industrial Technology Center.

Kate Morgan and Dr. Jane Armstrong described the evolution of a CyberScience Coalition and how it might involve SSC assets, as well as connectivity to scientists and engineers in the enhancement of science education.

Keynote presentations were made by Lourdes Monteagudo, Executive Director of the Teachers' Academy for Math and Science at the Illinois 
Institute of Technology, and by Lauren Williams, Director for the VISION . program of the Triangle Coalition for Science and Technology Education.

Breakout sessions provided opportunities for the following topics to be discussed:

- What are the currently connectivity, equipment and training needs to link science teachers onto TENET and/or InterNet? with other scientists?

- $\quad$ Are there ways: to integrate workplace skill requirements into curriculum modules that teach TAAS science essential elements?

- Could the Coalition development process avoid duplication of efforts?

- Are there suggestions for clarifying the scope, priorities, research opportunities or funding scenarios for the CyberScience Coalition?

Connectivity was identified as a primary barrier to science teachers, inhibiting science classroom participation in educational opportunities becoming available via TENET and Internet. Workshop leaders were encouraged to move ahead quickly with the proposed survey of science teachers to measure the extent of the needs to be filled by a coalition effort delivering computer literacy training, services and support in ways that complement other science education programs.

\subsubsection{CyberScience Survey of Science Teachers}

Intended to measure the computing capabilities and connectivity of science classrooms in Texas, the CyberScience Survey was designed by Project Director, Dr. Jane Armstrong, and one of the project's advisory board members, Evelyn Restivo, a 1994 Tandy Scholar who teaches physics and chemistry at Maypearl ISD, and was reviewed by a workshop session during the Science Education Workshop.

The CyberScience survey was sent by mail to two teacher groups in Texas: the Physics Teachers Association of Texas $(n=265)$; and the Texas Association of Biology Teachers $(n=630)$ The survey sample therefore totaled: 895.

Respondents returned surveys directly to the Texas Center for Educational Research (TCER) which had agreed to participate in the study by providing independent data entry, quality assurance, and data analysis. TCER is a subsidiary of the Texas Association of School Boards (TASB).

From an adjusted response rate calculated to be $27 \%$, (240 completed returns received out of the 895 sent), the following relevant findings can be summarized:

1. Computers in the Classroom 
- $69 \%$ have some kind of computer(s) in their classrooms;

- $95 \%$ use some sort of technology for their Science and Math classes ranging from TV to software: $34 \%$ used TV; and 61\% used some combination of TV, CD-ROM, databases, and software; and

- $86 \%$ would like to add computers to their science classrooms.

2. Network Connections in the Classroom

- $89 \%$ of the respondents indicated that their science classrooms are not connected to a network, by virtue of having no phone or modem; and

- $89 \%$ of students did not have access to networks from the classroom.

3. Computers at Home

- $85 \%$ of science teachers have computers at home; and

- half of the respondents have access to networks from their homes; of those that did, $28 \%$ accessed TENET.

4. Training Needs

- 69\% felt they had "zero" or "weak" networking skills;

- $90 \%$ wanted to learn more via one or more of the training services listed;

- $79 \%$ of respondents indicated that they thought their schools would pay release time for them to attend training session; and

- $86 \%$ would attend a training class that was provided free of charge on a weekend.

5. About the Respondents

- All are on mailing list of either Texas Association of Physics Teachers or Texas Association of Biology Teachers;

- $60 \%$ are female;

- $44 \%$ are between the ages of $40-50 ; 92 \%$ between the ages $30-60$;

- $90 \%$ are white; and

- $50 \%$ teach at the 10 th-12th grade levels.

A copy of the CyberScience Survey instrument, as well as a complete report of findings prepared by Dr. J.E. Gonzalez for the Texas Center for Educational Research, can be found in Appendix C. 
Massachusetts Institute for Technology (MIT) students now need an Internet account to get a dorm room; Stanford students use Internet to register for classes; and University of California at Berkeley students are e-mailing their professors via Internet, rather than trying to catch them during office hours. "Ability to Internet" may soon become the latest screening device for determining who "surfs" up the ladder of life-long learning and employability.

Actually, the evolution of Internet is so inherently "science driven" that we do our science students a great disservice if we do not quickly provide them with not only exposure to its existence, but expertise in its use as a dynamic new "tool of the trade" in scientific inquiry. Originally developed as a way for scientists in the defense communities to communicate, Internet now has about 20 to 30 million active users and that number is said to be growing at the rate of approximately 160,000 per month.

The newest information service on Internet is definitely "science driven" World-Wide Web, a hyper-text based client/server system was primarily developed by scientists at CERN European Particle Physics Laboratory. In addition, the most popular WWW client for Windows is Mosaic, developed at the National Center for Super computing Applications (NCSA) at the University of Illinois at Champagne-Urbana.

What are the roles for our national information infrastructure (NII) and related educational technology in addressing the challenges of science and mathematics education reform? An often repeated phrase is let's do science and mathematics not learn about science and mathematics. Many educators have found that today's information technologies (computers) have become important tools in addressing the objectives of reform movements.

Just as information technology has become an integral tool for the practicing mathematician, engineer or scientific researcher, it now also belongs in our science and math classrooms as a day-to-day tool in the hands of our students. Advancements in hardware capabilities, user interface, "and software technology allow students to use computers as transparent extensions of their hands and minds to explore the world around them.

In the CyberScience Coalition, we propose to use TENET, Internet and information technology as a primary catalyst to involve scientists and engineers in the enhancement of science education. We believe that the integral use of information technology will impact the value of student experiences and result in a broader range of students excelling in science and mathematics literacy. 
Offering learners more relevant and meaningful learning environments will result not only in greater mastery of concepts but also a better appreciation of the value science and mathematics in solving real world problems. Teachers and students must use today's leading edge information tools if they are to invent and apply tomorrow's problem solving technology.

The CyberScience Coalition is proposed as a new connectivity mechanism involving:

- Technical components continuing as a part of the reconfigured Texas Laboratory;

- 2 and 4-year educational institutions and universities;

- $\quad$ State and federal agencies;

- Professional societies;

- Businesses and industries; and

- Foundations, community organizations and others concerned with educational reform.

Furthermore, the CyberScience Coalition is designed to involve these interested constituents in building a sustainable base for the application of telecommunications technologies to science and math education.

For organizational and management purposes, the CyberScience Coalition services will be divided into four components, addressing the following program needs. With appropriate funding, components 1 and 2 describe program elements which can begin immediate delivery.

1. Science Education Enhancement Center, providing

- Computer Literacy Training for Teachers

- Lab Equipment Lending Pool

- Students/Classrooms On-line

- School Administrator Seminars

- Software on Science (SOS) Clearinghouse

2. Connectivity Support Center

- Technology Deployment Services

- Technology Maintenance Services

- Internet Digital Data Repository for Science Education Users (NII/WWW/Mosaic)

- Digital Libraries

- Linkages with International Educational Communities, beginning with Mexico 
The immediate services will be organized, administered and delivered in ways that are measurably tied to:

- national education goals

- Texas Assessment of Academic Skills (TAAS)

- Benchmarks for Literacy as defined by AAAS

Using the rural community science classrooms in South Texas, East Texas and West Texas as a priority, demonstration models and test beds can be established in ways that allow successful approaches to be cost-efficiently replicated both nationally, and particularly in Mexico.

Components 3 and 4 describe research program elements that are needed to build sustainable, on-going research efforts that feed cutting edge technology back into the front-line programs, such as those outlined in points 1 and 2 above. Investments of seed dollar funding are necessary to initiate research and human resource development programs such as the following:

3. Educational Technology Research Group

- Technology Test Beds

- Learning Styles Research

4. Workforce Development Research Group

- Data Base on Workforce Needs and Skill Assessments for Science and Engineering

- Executive Institute for Advancement of Science Education

\subsubsection{CyberScience Education Enhancement Center}

Initially, the CyberScience education enhancement center will be comprised of the following initiatives:

- Computer Literacy Träining for Teachers

- Lab Equipment Lending Pool

- $\quad$ Students/Classrooms On-line

- School Administrator Seminars

- Software on Science (SOS) Clearinghouse

- $\quad$ Student Internship Opportunities

\subsubsection{Computer Literacy Training for Teachers}

At the Science Education Workshop (see section 3.2.3), connectivity was identified as a primary barrier to science teachers, inhibiting science classroom 
participation in educational opportunities becoming available via TENET and Internet.

A resulting survey of science teachers to measure the extent of the needs to be filled by a coalition effort delivering computer literacy training, data services and on-line support discovered the following :

- $\quad 69 \%$ felt they had "zero" or "weak" networking skills;

- $\quad 90 \%$ wanted to learn more via one or more of the training services listed;

- $\quad 79 \%$ of respondents indicated that they thought their schools would pay release time for them to attend training session; and

- $86 \%$ would attend a training class that was provided free of charge on a weekend.

There are many well researched and equally well documented reasons to provide computer literacy training to teachers in general, and to science teachers in particular. Connectivity, and networking skills are an emerging skill set for science teachers, however, and information regarding effective ways to integrate and/or InterNet learning opportunities into the classroom are paving the way for a whole new array of educational resources to be incorporated into ANY classroom or learning environment. For detailed information regarding InterNet learning resources, please see "Riding the Internet Schoolbus: Places to Visit and Things to Do," Technology \& Learning, October 1994, provided in Appendix D.

A teacher with sound basic computer skills can make immediate and concrete contributions to a scientific project, and can quickly become a valued asset in the research at hand rather than an initial burden. Connectivity is one of the long term benefits that will empower the teacher to remain an active partner in learning and problem-solving, to collaborate with other teachers of science in the development of lessons, and to stay abreast of developments both in science and in pedagogy.

The computer literacy training and connectivity components of this project definition study are designed to allow each teacher to follow a course of instruction that is tailored to his or her individual level of competency and individual schedule. The CyberScience Education Enhancement Center will be available to teachers after classes and classes are also planned for weekends.

Maximum use will be made of interactive software that can assess skill level and deliver course modules at the appropriate level, allowing teachers to progress at their own rates of interest and learning. Using an innovative new learning operations management system, called Power OS, and client/server technology, many Macintoshes will access a central data base of courses so that from each individual learning station a teacher can access the 
full range of courses taught at the CyberScience Education Enhancement Center.

In addition, a computer coach will provide instruction and be available to answer questions. Formally structured classes will be offered for teach introductory courses and other courses where high demand makes classroom teaching an economical approach. Topics for these formal courses are introductory computer skills and networking skills. A basic curriculum of introductory computer skills, networking to learning resources, curriculum authoring tools and data base manipulation will be included in initial offerings.

Experienced science teachers who have completed initial course offerings will be considered as candidates to serve as Computer Coach/Trainers in subsequent summers or weekends. They may also contribute by helping teach computer courses or by staffing a hot-line/e-mail to provide assistance to the CyberScience Education Enhancement Center clients. All science teachers who participate in one or more of the center's programs will be encouraged to maintain their involvement in the Center's programs and to continue their exploitation of the Center's facilities to network with other science professionals around the country.

The immediate services will be organized, administered and delivered in ways that are measurably tied to:

- National education goals;

- Texas Assessment of Academic Skills (TAAS); and

- Benchmarks for Literacy as defined by AAAS.

\subsubsection{Teachers/Students/Classrooms On-Line}

According to a 1993 national survey, $80 \%$ of the installed computers in American elementary and secondary schools are essentially incapable of supporting multimedia graphical applications. Only that part of the base of current classroom computers made of Apple Macintoshes (10\%) and IBM compatible $386 \mathrm{~s}$ or $486 \mathrm{~s}(8 \%)$ is capable of supporting the higher level applications which facilitate teaching good science visually.

ALMOST ALL of the Macintoshes, PCs, PowerBooks/portables, workstations, servers and computer peripherals currently a part of the SSC Laboratory inventory meet the higher level applications criteria and could be very efficiently used in a Texas out-reach program which will also coincide with the national agenda for improving the use of NII and telecommunications technologies in classrooms (Currently, SSC inventory indicates as many as 2925 Macs/PCs, 906 workstations and 9375 various peripherals available). 
An outreach program will be implemented to loan SSC/DOE hardware to schools and to provide expertise to "information-poor" school districts in Texas to enable them to connect to the NII. Ownership would be retained by the CyberScience Connectivity Resource Center, which will also maintain the computers and networking hardware.

Using the rural community science classrooms in South Texas, East Texas and West Texas as a priorities, demonstration models and test beds can be established in ways that allow successful approaches to be cost-efficiently replicated both nationally, and particularly in Mexico.

\subsubsection{TAME Collaboration}

The Texas Alliance for Minorities in Engineering, Inc. (TAME) which had its beginning in 1976, is a non-profit 501(c)(3) organization whose main objective is to increase the numbers of minorities and women in the engineering and science professions. Headquartered in Austin, Texas, TAME and its 20 alliances work cooperatively with Texas school systems (K-12), colleges and universities community organizations, state and local government agencies and private industries to sponsor and conduct programs and activities that will enhance student preparation in mathematics and science and that will motivate them to choose careers in science and engineering.

The proposed CyberScience Coalition and its CyberScience Education Enhancement Center offers both a means and a mechanism to assist TAME in its efforts to provide programs and activities for students and teachers of math and science education in areas such as the following:

- On-going math and science teacher enhancement workshops;

- Deployment of teacher workstations and student workstations to science education classrooms in ways that connect them to learning resources via the InterNet and the growing information superhighway;

- Increased access to state-of-the-art science, math and engineering educational materials; and

- Workshops for school administrators, parents and community.

The TAME alliances in Dallas (DAME) and Waco (representing over 10,000 minority students in the area) are extremely interested in the development of this project due to the close proximity of the proposed CyberScience Education Enhancement Center headquarters in Waxahachie, and have expressed interest in becoming leaders in defining ways that these services may be of immediate assistance to enhance some of their on-going activities and programs. 
As the practice of science becomes increasingly technical, effective teaching of science must have access to sophisticated equipment for demonstration and training. Often, however, it is impractical, if not simply economically unfeasible, for smaller schools to maintain an adequate selection of expensive equipment. As part of fulfilling its mission to function as an education resource, the Office of Education of the SSC assembled a collection of science education materials that were intended for loan to area teachers. This collection includes oscilloscopes, digital volt meters, motorized telescopes, videos, CD-ROMs, and a library of books, demonstration materials and kits of all kinds. A complete listing of the collection is provided in Appendix E.

The CyberScience Education Enhancement Center proposes to support the original intended use of these materials by making them available to be checked out on loan by various area science teachers. If resources permit, it would be very useful to incorporate a delivery service or to establish satellite locations to provide good access to the materials for a greater number of teachers. Resources must also be committed to maintain the collection and to augment its equipment as needed.

\subsubsection{Software on Science (SOS) Clearinghouse}

The Science Education Enhancement Center will seek out, review, "house" and support a clearinghouse of on-line deliverables for science education. Led by committees of science education experts/scientists, invited leadership for the charter technical task forces are proposed to include:

\section{SOS Clearinghouse Technical Advisory Council}

Co-Chairs: Dr. Robert Beck Clark, Texas A\&M University and Dr. Tom O'Cuma, Lee College

Physics, interim chair: Dr. Richard Olenick, University of Dallas

Chemistry, interim chair: Dr. Joe Lagowski, University of Texas at Austin

Biology, interim chair: Dr. Dr. Curtis Chubb, University of Texas Southwest Medical Center at Dallas

Math, interim chair: yet to be identified

Social Sciences, interim chair: Dr. Jane Winer, Texas Tech University

The primary role of the SOS Clearinghouse is to reduce the gap between "what is used" and "what quality software is available" for teachers in classrooms. As the Software On Science (SOS) Clearinghouse begins to 
function with intensity, appropriate life-long learning and professional development workshops will be delivered on an on-going basis in order to fill a dynamic need for interactive, on-line instructional capabilities which are to be teacher tools for enhancing classroom learning.

\subsubsection{Student Internship Opportunities}

The environment which affords teachers a learning experience in real-world science is equally valuable to allow students to experience the excitement of science. Two types of student involvement are envisioned: individual internships and classroom activities. We envision two kinds of internships, on-site and off-site.

With regard to on-site internships, we believe that the scope of the Blacklands Prairie Project and the Regional Medical Technology Center would eventually permit a program involving on the order of 20 high school students for a ten week summer period. Such a program would, of course, depend on acceptance by the management of those programs. The budget for such a program has not been included in our baseline calculations.

With regard to off-site internships, we envision that the CyberScience Education Enhancement Center would be in regular contact with well over 100 academic and industrial users around the State. Thus, one could plan on a program of 50 internships using these connections. By placing students in their local areas, room, board, and travel would be eliminated from the budget, and it is possible to envision stipends as low as $\$ 2000$ for a ten week period. In many cases, the entity at which the student is placed might contribute toward that stipend.

There is sufficient detail involved in recruiting and making arrangements for such a program involving on the order of 70 students that we estimate a requirement for one junior FTE of additional staff.

A significant portion of the Internship Program would be devoted to minority students and women. There is a very successful Texas program of summer workshops for minority students under the direction of Dr. Manuel Berriozábal, called TEXPREP. Students who have been through that program by the beginning of their junior or senior year of high school would be prime candidates for the internship program the following summer. This program would, on the one hand, keep up the student's momentum in technical accomplishment. On the other hand, selecting from the most promising of the students engaged in the TEX PREP program would guarantee to the host units interns "pre-tested" to be most apt to succeed in a summer program. 
In conjunction with Texas Association of School Boards, the CyberScience Coalition will develop and host regular seminars for public school administrators, school board members and interested community leaders and parents regarding connectivity topics related to public school implementation and cost-efficiency for educational technology.

\subsubsection{Connectivity Resource Center}

Given the continued existence of a high performance computing center and the preservation of the existing ESNET connections and associated equipment which have been an integral part of the SSC high performance computing program efforts, SSC computing and network assets could serve as an effective, convenient resource to promote the rapid, efficient, and effective introduction of the NII into K-12 schools.

The goal of the Connectivity Resource Center is to provide the necessary resources to Texas educators to foster effective student use of the NII (Internet) in Texas public schools.

Using the Texas rural community science classrooms in South Texas, East Texas and West Texas as a priorities, demonstration models and test beds can be established in ways that allow successful approaches to be cost-efficiently replicated state-wide, nationally, and particularly in Mexico.

The connectivity resource center will be used as a central Internet distribution site for educational software and computer hardware (loan of computers, modems, printers etc.). A massive storage system will be created to "mirror" files (or whole sites) that are frequently accessed by schools. A request for a file located in Europe, for example, by a student at a school connected to our network would result in a copy of that file being placed in our storage system. Subsequent requests for this file by any person connected to our site would result in the local copy being accessed and not the overseas one. This feature is extremely important since secondary school students do not have the option of working at non-peak hours. Also important is the fact that if the bottleneck is at the source end (overloaded server), then no increase bandwidth can improve access times.

Such a storage system would allow faster access to files and decreased load on the InterNet links to Europe or other heavily used sites in this country. All of this activity would be transparent to the user. There would be no need for the user to change the address of the requested file. Software will automatically seek out and update files during non-peak hours. Also software would detect cases where files must be accessed live (for example weather satellite pictures 
which change several times per hour). Inherent in this system is the ability to prevent access to certain sites or sections of sites (always a concern to parents and school administrators). Resource Center computing staff would be heavily involved in cooperative efforts with other NII nodes to develop improved networking software to improve "peak hour" use of the Internet.

Present network links will be upgraded to T3 or ATM to provide the necessary bandwidth for this activity. Much of this capability exists today but special tailoring for educational purposes would be needed. All public domain software would be freely available to anyone and this site would become a major educational NII node.

An outreach program will be implemented to loan SSC/DOE hardware to schools and to provide expertise to "information-poor" school districts in Texas to enable them to connect to the NII. Ownership would be retained by the CyberScience Connectivity Resource Center, which will also maintain the computers and networking hardware.

Targeting science classrooms in East Texas, South Texas and West Texas rural regions will enable many minority students to participate in information rich learning environments usually available to schools with large education technology budgets.

\subsubsection{Technology Deployment Services}

An outreach program will be implemented to loan SSC/DOE hardware to schools and to provide expertise to "information-poor" school districts in Texas to enable them to connect to the NII. Ownership would be retained by the CyberScience Connectivity Resource Center, which will also maintain the computers and networking hardware.

The office of technology deployment services will provide necessary resources for schools that need help to connect to the Internet and/or the CyberScience Digital Data Repository.

Existing SSC/DOE computer equipment will be loaned to schools to enable connectivity. Initially the primary recipients of this equipment will be rural science classrooms.

The CyberScience school connectivity program requires several components:

1) Building Administrator/Principal must attend a School Administrator Seminar;

2) Science Teacher must complete core courses for CyberScience Computer Literacy, or test out; 
3) Phone-jack, modem and dial-up connection services must be installed in the designated science classroom;

4) Teacher station will be located in the science classroom, have access to Internet and the CyberScience Digital Data Repository via the 1-800 \# and dial-up connectivity and be staffed by a CyberScience trained teacher; and

4) Student computer stations in the science classroom will be connected to Internet and the CyberScience Digital Data Repository via the LAN.

In order for a school to receive equipment on loan and to participate in the CyberScience Coalition programs, the local campus is required to pay for, or to request a CyberScience School Scholarship to cover costs of a LAN-phone jack in the science classroom; schools must agree to pay for local phone line charges on a regular basis, as well as science teacher's tuition to annual teacher enhancement workshop.

\section{Teacher Stations in the Classrooms}

Much has been written about the failure of many teachers to integrate technology into their teaching practices even though access was provided to their students with laboratory or check out CPUs. The Apple Classroom of Tomorrow (ACOT) research found that teachers need to personally experience the benefits of computer technology before they grasp its power for their students.

Despite new "ease of use" features, a significant effort and sacrifice of personal time is required to master today's information technology. It is understandable that teachers. are unwilling to dedicate the time and energy required unless they have convenient access to a computer assigned to just them. In a recent Electronic Learning issue focused on "A Computer on Every Teacher's Desk, " many testimonials were given to support the notion that successful adoption of technology required a teacher station.

Evidence shows that even one computer, in the classroom, permanently assigned to the teacher effects the quality of instruction. Like doctors, plumbers, or electricians, teachers need a tool box for their profession. Teachers are information professionals and require tools and skills for access, manipulation, and communication of information on a daily basis.

\section{Classroom Student Research Stations}

Research has shown that the culture of the classroom can only be changed when technology is easily accessible by students at all times. While this could be interpreted as one CPU per student, this is rarely required or even desired. One of technologies surprising benefits is support of collaborative learning environments. 
Instructional research indicates that learning should be social to be meaningful. In addition, collaborative skills for problem solving have been identified as critical for success in most careers.

Five to six student learning stations per classroom is often a critical mass for a positive impact on instructional methods. With technology in the classroom, students can use discipline specific tools as an integral part of their research on a daily basis.

Empowered with technology, individuals learn to rely on student stations for information access, computation, problem solving, producing reports and presentations, and for collaboration. The result can be a dramatic change in motivation, a shift from knowledge transfer mode by the teacher to a knowledge construction mode by the students.

\subsubsection{Technology Maintenance Services}

A major obstacle to Internet connectivity for many schools is simply the lack of trained people who know how to "wire up" a school or school district. The resource Center would make available such trained persons to local school districts and would offer training to their permanent networking staff.

Center staff will maintain, service and upgrade computer equipment. There will be an on-site electronic shop for repair and upgrade of computer equipment. Software will also be maintained and upgraded as necessary. A database will be created to provide information on product reliability, repair history, and usefulness in an educational environment. This will allow schools to make hardware and software purchasing decisions based on experience in a school environment.

\subsubsection{CyberScience Digital Data Repository}

A major obstacle to Internet use in a school setting is that the Internet is often slow during peak hours. Some "interesting" sites even limit access during peak (i.e. school hours) times. A solution to this obstacle is to provide large amounts of storage at one location that is used to "mirror" interesting sites. This storage would be "dynamic" in the sense that request for files would result in a copy of that file being placed on a local disk. Subsequent requests for that file would result in the local file being made available. this would reduce traffic on the out-of-state InterNet links and provide faster access to information. Sites that "refuse" service during peak hours would be automatically queried at later times and the requesting student or teacher notified when the file became available. 
Existing software already permits much of this to be done. For example, automatic downloading of selected files at midnight from heavily used sites is simple. However, effective use of these concepts will require new software tools and this center will become a major developer of NII related software and collaborate in development of NII policies related to K-12 use of the Internet. It will be especially important to ensure that copies of files are kept current. Some files are updated every time a request is made. Such files can not be stored locally. The "connectivity software" will need to be able to distinguish these cases from cases where file are updated only infrequently.

The repository concept will evolve with time. It is important that the repository function to enhance the use of the Internet and not just become another bottleneck. It is also unclear whether schools should connect only through this site or whether it should be optional. This needs to be decided in conjunction with TENET administrators and advice from the Texas Education Agency, after initial operation has started since operating experience will help answer the question.

\subsubsection{Digital Libraries}

In addition to the "automatic repository" described above, there will be a digital library of information deemed to be of value to K-12 schools. Repository information will be automatically stored by software.

Digital Library information will be selected by professional educators and will be supported by the center. Support will include providing assistance in using stored educational programs, cataloging the contents of the library, and providing a database so users can share information about their experience using items in the Digital Library.

Access to library volumes which have been converted to digital storage would also greatly enhance limited library holdings for science education in many rural communities.

\subsubsection{Educational Technology Test Beds}

The use of SSC assets to foster science teacher computer literacy and to put SSC/DOE workstations in science classrooms can be done in a way that not only improves classroom connectivity, but also creates a controlled environment for testing technology advances which can' aid, improve or increase cost efficiency for providing similar connectivity on a scalable basis for other communities and classrooms, especially with the focus on rural delivery systems inherent in this project definition study. 
For science education initiatives, we will create research efforts designed to provide leadership in delivering the latest science education technology products to CyberScience NII research test-beds comprised of participating science classrooms in Texas, through a public/private partnership effort called the CyberScience Coalition (Appendices L \& M).

- HARC.C Data Compression Technology (patents pending): Houston Advanced Research Center

- APPLE Internet Tools: Apple Computers

- NIH Imaging Software / University of Arizona, Center for Imaging in Education

- $\quad$ PowerOS, VerCom Systems (software protection pending)

- $\quad$ Learning Styles Research, utilizing psychometric tools such as Kolbe Cognitive Index and Dunn, Dunn \& Price's Learning Styles Inventory

\subsubsection{A Community Resource for Workforce Development}

$\neg$ The Texas Council on Workforce and Economic Competitiveness issued "The Changing World of Work: A Strategic Plan for Building a World-Class System for Workforce Education and Training," in June 1994. As a critical element of goal four, the Council recommends establishment of a "skill standards and certification system for literacy/basic education, workforce skills and occupational areas."

The opportunity exists using digital data storage capabilities resident as part of a functioning High Performance Computing Center to define "workforce needs and skill assessments for science and engineering" and to construct data resource information storage and retrieval processes which can be shared with staff at the Texas Education Agency to guide evolution of Texas Assessment of Academic Skills (TAAS) for Science, and to provide the basis for student awareness programs regarding careers in science and engineering.

The education survey that is described in section 3.2.4 of this report establishes the need for enhancing the computer skills of science teachers. Several other sources establish a very similar need for enhancing both basic computer skills and more specific job skills in the general population. Designed to provide such training for science teachers, this facility is equally well-equipped to meet training needs of the private sector.

\subsubsection{Executive Institute on Educational Technology}

Increasingly, leaders of business, industry and government are called upon to commit corporate staff and/or funds to support education initiatives -- often math and science education initiatives 
For many of the executives who are most likely to be key decision-makers, however, the plethora of educational technology applications and approaches which they might be asked to support, or acquire, can be vastly different than those they encountered in their own educational experiences. Even for scientists and engineers.

Computers, software and connectivity tools are advancing so rapidly that educators - much less executives - struggle to stay current with the best educational applications.

In addition, experts estimate that perhaps half of the information learned by freshmen engineers (maybe scientists too) is obsolete by the time that they graduate. Over 1000 books are published every day, and the growth of international information networks is exponential. Yet new demands on management for teaming and coaching roles leave less time for staying current. Most of today's executives did not receive their education in a computer literate environment.

The Executive Institute on Science Education is designed to fulfill a two-fold purpose for busy executives:

- To provide intense, hands-on briefings and experiences regarding stateof-the-art educational technology and performance evaluations for science education initiatives; and

- To highlight recent advances in science, information technology, engineering or technology tools for human resource management which would of benefit to them in fulfilling their corporate management responsibilities.

The Executive Institute will conduct short, 2 or 3 day symposia for executives in a relaxed learning environment which provides on-going insights into individualized learning styles through a variety of technology applications and experiences.

The SSC Central Facility connectivity capabilities can serve as a primary base; other sites can be added in an evolutionary fashion. Other than initial startup funding to draft curriculum and generate initial marketing activities, this program is anticipated to become self-supporting within 1 to 2 years of implementation, if the SSC facility infrastructure (meeting rooms, computers, office space, LAN's, etc.) continue to be available. Fees for participation would range from $\$ 1000$ to $\$ 2000$ for such a symposium and 50 to 100 could be accommodated at each session. 


\subsubsection{Business Relationships}

Texas' core industry bases, from oil to electronics to agriculture, all have a continuing demand for a science literate workforce. In addition to involving key industry representatives as members of our advisory board, exploratory discussions with representatives from internationally recognized firms such as Texas Instruments, Rockwell International, Apple Computers and ESystems, indicate an interest and willingness on the part of industry to participate in the formation of the CyberScience Coalition. Letters of Support will be provided as an appendix, delivered under separate cover.

\subsubsection{University Relationships}

As university deans of education were contacted regarding the existence of math and science education initiatives on their campuses, many became so enthused about the project that we were defining, that they were singularly encouraging regarding the need to infuse Internet connectivity into rural Texas science classrooms and were eager to foster existence of the CyberScience Coalition. We anticipate similar responses from Deans of Science and Engineering, as well as university faculty in general. Letters of Support will be provided as an appendix, delivered under separate cover.

In addition, colleges, universities and technical training facilities may want to prepare "home page" information on their educational opportunities for display to students via the CyberScience Digital Data Repository.

\subsection{Financial Considerations}

After careful study and consideration, with input from an especially helpful and experienced Advisory Board, the following recommendations are made as a part of this UTA/SMU project definition study:

A A critical service niche in science education has been identified which uses existing SSC computing assets to support science education by providing on-going teacher enhancement on the use of computers and connectivity resources on a daily basis in science classrooms.

For science education, the project has definite uses/needs for pieces of SSC equipment, including almost all of the Macs/PCs/workstations $(3500+)$ as well as permanent staff, budget and facility space, independent of any other technical and/or high performance computing elements which may continue to exist. 
An outreach program will be implemented to loan SSC/DOE computer workstations to schools and to provide expertise to "information-poor" school districts in Texas to enable them to connect to the NII. Ownership would be retained by the CyberScience Connectivity Resource Center, which will also maintain the computers and networking hardware.

In addition to providing all available Macs, Pcs, workstations and computer peripherals available for the enhancement of science education, the Department of Energy can leverage both their education and research dollars well by providing:

1) Immediate start-up funding of $\$ 1.6 \mathrm{M}$ direct costs for the 1995 and \$1.7M direct costs for 1996; and

2) Base line support of $\$ 1 \mathrm{M}$ direct costs for each of the subsequent three years, plus leadership assistance in securing long-term selfsustaining research funding and development activities for the CyberScience programs during the first five years of operation.

\subsubsection{Budget Projections by Cost Center - CyberScience Coalition}

Budget projection spreadsheets are presented under the following Table. 


\subsubsection{BUDGET PROJECTIONS BY COST CENTER - CYBERSCIENCE COALITION}

ADMINISTRATION
Executive Director, CyberScience Coalition
Administrative Assistant
Receptionist
Subtotal
$\quad$ Fringe Benefits @ $30 \%$
Personnel Total
Travel
Equipment
Materials \& Supplies
Facilities Space Rental
Other--Miscellaneous
$\quad$ Total

\begin{tabular}{rrrrrr} 
\% FTE & 1995 & 1996 & 1997 & \multicolumn{1}{l}{1998} & \multicolumn{1}{c}{1999} \\
& & & & & \\
1.00 & $\$ 85,000$ & $\$ 89,250$ & $\$ 93,713$ & $\$ 98,398$ & $\$ 103,318$ \\
1.00 & $\$ 25,000$ & $\$ 26,250$ & $\$ 27,563$ & $\$ 28,941$ & $\$ 30,388$ \\
1.00 & $\$ 15,000$ & $\$ 15,750$ & $\$ 16,538$ & $\$ 17,364$ & $\$ 18,233$ \\
\hline 3.00 & $\$ 125,000$ & $\$ 131,250$ & $\$ 137,813$ & $\$ 144,703$ & $\$ 151,938$ \\
& $\$ 37,500$ & $\$ 39,375$ & $\$ 41,344$ & $\$ 43,411$ & $\$ 45,581$ \\
\cline { 2 - 6 } & $\$ 162,500$ & $\$ 170,625$ & $\$ 179,156$ & $\$ 188,114$ & $\$ 197,520$ \\
& $\$ 10,000$ & $\$ 10,000$ & $\$ 10,000$ & $\$ 10,000$ & $\$ 10,000$ \\
& $\$ 15,000$ & $\$ 15,000$ & $\$ 15,000$ & $\$ 15,000$ & $\$ 15,000$ \\
& $\$ 15,000$ & $\$ 15,000$ & $\$ 15,000$ & $\$ 15,000$ & $\$ 15,000$ \\
& $\$ 4,000$ & $\$ 4,000$ & $\$ 4,000$ & $\$ 4,000$ & $\$ 4,000$ \\
& $\$ 10,000$ & $\$ 10,000$ & $\$ 10,000$ & $\$ 10,000$ & $\$ 10,000$ \\
\hline 3.00 & $\$ 216,500$ & $\$ 224,625$ & $\$ 233,156$ & $\$ 242,114$ & $\$ 251,520$
\end{tabular}

W SCIENCE EDUCATIONENHANCEMENT CENTER

Program Director, Science Ed Enhancement Cl

Administrative Assistant

CyberScience Coach/Trainers (6)

4 FTE for M-F classes in summers

2 FTE for S/S classes year-round

SOS MultiMedia Curriculum Specialist

Lab Equipment Clerk

Subtotal

Fringe Benefits @ $30 \%$

Personnel Total

Travel

Equipment

Materials \& Supplies

Facilities Space Rental 3800sq FT @ $\$ 10 / \mathrm{sq} \mathrm{ft}$

Other--Phone \& Miscellaneous

Total

\begin{tabular}{rrrrrr}
1.00 & $\$ 50,000$ & $\$ 52,500$ & $\$ 55,125$ & $\$ 57,881$ & $\$ 60,775$ \\
1.00 & $\$ 25,000$ & $\$ 26,250$ & $\$ 27,563$ & $\$ 28,941$ & $\$ 30,388$ \\
& & & & & \\
1.00 & $\$ 30,000$ & $\$ 31,500$ & $\$ 33,075$ & $\$ 34,729$ & $\$ 36,465$ \\
2.00 & $\$ 60,000$ & $\$ 63,000$ & $\$ 66,150$ & $\$ 69,458$ & $\$ 72,930$ \\
1.00 & $\$ 40,000$ & $\$ 42,000$ & $\$ 44,100$ & $\$ 46,305$ & $\$ 48,620$ \\
1.00 & $\$ 20,000$ & $\$ 21,000$ & $\$ 22,050$ & $\$ 23,153$ & $\$ 24,310$ \\
\hline 7.00 & $\$ 225,000$ & $\$ 236,250$ & $\$ 248,063$ & $\$ 260,466$ & $\$ 273,489$ \\
& $\$ 67,500$ & $\$ 70,875$ & $\$ 74,419$ & $\$ 78,140$ & $\$ 82,047$ \\
\hline & $\$ 292,500$ & $\$ 307,125$ & $\$ 322,481$ & $\$ 338,605$ & $\$ 355,536$ \\
& $\$ 10,000$ & $\$ 10,000$ & $\$ 10,000$ & $\$ 10,000$ & $\$ 10,000$ \\
& $\$ 25,000$ & $\$ 25,000$ & $\$ 25,000$ & $\$ 25,000$ & $\$ 25,000$ \\
& $\$ 25,000$ & $\$ 25,000$ & $\$ 25,000$ & $\$ 25,000$ & $\$ 25,000$ \\
& $\$ 38,000$ & $\$ 38,000$ & $\$ 38,000$ & $\$ 38,000$ & $\$ 38,000$ \\
& $\$ 5,000$ & $\$ 5,000$ & $\$ 5,000$ & $\$ 5,000$ & $\$ 5,000$ \\
\hline & $\$ 395,500$ & $\$ 410,125$ & $\$ 425,481$ & $\$ 441,605$ & $\$ 458,536$
\end{tabular}


CONNECTIVITY RESOURCE CENTER

Program Director, Connectivity Resource Ctr

\begin{tabular}{rrrrrr} 
\% FTE & 1995 & 1996 & 1997 & \multicolumn{1}{l}{1998} & 1999 \\
& & & & & \\
1.00 & $\$ 60,000$ & $\$ 63,000$ & $\$ 66,150$ & $\$ 69,458$ & $\$ 72,930$ \\
1.00 & $\$ 25,000$ & $\$ 26,250$ & $\$ 27,563$ & $\$ 28,941$ & $\$ 30,388$ \\
2.00 & $\$ 50,000$ & $\$ 52,500$ & $\$ 55,125$ & $\$ 57,881$ & $\$ 60,775$ \\
2.00 & $\$ 50,000$ & $\$ 52,500$ & $\$ 55,125$ & $\$ 57,881$ & $\$ 60,775$ \\
1.00 & $\$ 50,000$ & $\$ 52,500$ & $\$ 55,125$ & $\$ 57,881$ & $\$ 60,775$ \\
1.00 & $\$ 40,000$ & $\$ 42,000$ & $\$ 44,100$ & $\$ 46,305$ & $\$ 48,620$ \\
\hline 8.00 & $\$ 275,000$ & $\$ 288,750$ & $\$ 303,188$ & $\$ 318,347$ & $\$ 334,264$ \\
& $\$ 82,500$ & $\$ 86,625$ & $\$ 90,956$ & $\$ 95,504$ & $\$ 100,279$ \\
\hline & $\$ 357,500$ & $\$ 375,375$ & $\$ 394,144$ & $\$ 413,851$ & $\$ 434,543$ \\
& $\$ 25,000$ & $\$ 25,000$ & $\$ 25,000$ & $\$ 25,000$ & $\$ 25,000$ \\
& $\$ 100,000$ & $\$ 100,000$ & $\$ 100,000$ & $\$ 100,000$ & $\$ 100,000$ \\
& $\$ 15,000$ & $\$ 15,000$ & $\$ 15,000$ & $\$ 15,000$ & $\$ 15,000$ \\
& $\$ 27,500$ & $\$ 27,500$ & $\$ 27,500$ & $\$ 27,500$ & $\$ 27,500$ \\
& $\$ 17,500$ & $\$ 17,500$ & $\$ 17,500$ & $\$ 17,500$ & $\$ 17,500$ \\
& $\$ 3,000$ & $\$ 6,000$ & $\$ 12,000$ & $\$ 24,000$ & $\$ 24,000$ \\
& $\$ 12,000$ & $\$ 12,000$ & $\$ 12,000$ & $\$ 12,000$ & $\$ 12,000$ \\
$500 / y \mathbf{r}:$ & $\$ 125,000$ & $\$ 125,000$ & $\$ 125,000$ & $\$ 125,000$ & $\$ 125,000$ \\
& $\$ 10,000$ & $\$ 10,000$ & $\$ 10,000$ & $\$ 10,000$ & $\$ 10,000$ \\
\hline & $\$ 692,500$ & $\$ 713,375$ & $\$ 738,144$ & $\$ 769,851$ & $\$ 790,543$
\end{tabular}

\section{PROGRAM DEVELOPMENT EFFORTS}

Faculty Director,Ed Technology Research

Faculty Director, Workforce Development

Faculty Director, Executive Institute

Subtotal

Fringe Benefits $30 \%$

Personnel Total

Travel

Equipment

Materials \& Supplies

Facilities Space Rental 2850sq FT @\$10/sq ft

Other--Phone \& Miscellaneous Total

\begin{tabular}{rrrrrr}
0.50 & $\$ 40,000$ & $\$ 42,000$ & $\$ 44,100$ & $\$ 46,305$ & $\$ 48,620$ \\
0.50 & $\$ 40,000$ & $\$ 42,000$ & $\$ 44,100$ & $\$ 46,305$ & $\$ 48,620$ \\
1.00 & $\$ 80,000$ & $\$ 84,000$ & $\$ 88,200$ & $\$ 92,610$ & $\$ 97,241$ \\
\hline 2.00 & $\$ 160,000$ & $\$ 168,000$ & $\$ 176,400$ & $\$ 185,220$ & $\$ 194,481$ \\
& $\$ 48,000$ & $\$ 50,400$ & $\$ 52,920$ & $\$ 55,566$ & $\$ 58,344$ \\
\hline & $\$ 208,000$ & $\$ 218,400$ & $\$ 229,320$ & $\$ 240,786$ & $\$ 252,825$ \\
& $\$ 25,000$ & $\$ 25,000$ & $\$ 25,000$ & $\$ 25,000$ & $\$ 25,000$ \\
& $\$ 15,000$ & $\$ 15,000$ & $\$ 15,000$ & $\$ 15,000$ & $\$ 15,000$ \\
& $\$ 25,000$ & $\$ 25,000$ & $\$ 25,000$ & $\$ 25,000$ & $\$ 25,000$ \\
& $\$ 28,500$ & $\$ 28,500$ & $\$ 28,500$ & $\$ 28,500$ & $\$ 28,500$ \\
& $\$ 18,000$ & $\$ 18,000$ & $\$ 18,000$ & $\$ 18,000$ & $\$ 18,000$ \\
\hline & $\$ 319,500$ & $\$ 329,900$ & $\$ 340,820$ & $\$ 352,286$ & $\$ 364,325$ \\
20.00 & $\$ 1,624,000$ & $\$ 1,678,025$ & $\$ 1,737,601$ & $\$ 1,805,856$ & $\$ 1,864,924$
\end{tabular}




\subsubsection{Sources of Funds}

The ability to utilize SSC assets to create the CyberScience Coalition programs outlined creates an unheralded opportunity to build a significant, competitive NII training/demonstration site for education, technology test beds for improving cost-effectiveness and efficacy of this new learning paradigm, and a major Internet accessed, digital data repository supporting science education.

Costs associated with initialization of these efforts can be significantly reduced by naming the CyberScience Coalition, or its parent organization, as custodian of all of the current SSC inventory of appropriate computer hardware and peripherals (Current inventory indicates as many as 2925 Macs/PCs, 906 workstations and 9375 various peripherals available) to train and link Texas science teachers on to Internet, including access to the CyberScience Data Repository.

By invoking section 2 of Executive Order no. 12821, IMPROVING MATHEMATICS AND SCIENCE EDUCATION IN SUPPORT OF THE NATIONAL EDUCATION GOALS, the Department of Energy(DOE) could:

1. Vest the CyberScience Coalition, or its parent organization, with the responsibility for transfer excess education-related equipment (referenced in the above paragraph) to Texas schools in support of math and science education, and

2. Fund training and training assistance to recipients of education-related a Federal equipment to ensure that the equipment will be used to its fullest capability.

Discussions have already been initiated to start the process for a proposal to be submitted for matching funds to the Texas State/Federal Matching Pool, thus leveraging the immediate impact of such action by DOE in beginning immediate delivery of CyberScience services.

Long-term, CyberScience programs can generate funding through a variety of vehicles:

1. Federal Funding for NII, networking/connectivity research, and related science education initiatives.

2. State funds through new legislative appropriations;

3. User fees generated from tuition/registration/nominal subscription fees for training and resource services.

4. CyberScience Coalition Membership Fees from private sector. 
5. Public school commitments of future Technology Allotment Funds.

\subsubsection{Federal Funding}

Federal funding opportunities are emerging on several fronts, and are summarized most succinctly in "Putting the Information Infrastructure To Work: Report of the Information Infrastructure Task Force Committee on Applications and Technology," prepared by the Department of Commerce (NIST), Summer 1994:

"The Department of Commerce provides support and direct funding for telecommunications infrastructure planning and development, and plans to support improvements in workplace training using the NII. Commerce's National institute of Standard and Technology supports standards development.

The Department of Defense provides lifelong education and training to hundreds of thousands of military personnel. It supports R\&D for education and training and is expected to transfer knowledge and software to schools and non-Defense workplaces under its Dual-Use and Technology Reinvestment programs. The Department of Defense Dependents Schools are expected to serve as a testbed for new applications.

The Department of Education advocates for the needs of all learners in the development of the NII. The Department is the principal source of Federal support for distance learning, via the Star Schools Program. In FY 1995, the Department will also support applications and programming development, pilot projections, teacher networks, research, and planning grants to states and districts.

The Department of Energy is in the forefront in the development and use of information technologies, such as high performance computing, high speed networking, data storage and data bases, and other information services and system integration technology. The Department is developing $\mathrm{K}-12$ computing and communications applications that support a new learning paradigm and take advantage of the regional presence and capabilities of the Department's laboratories. Emphasis is placed on reaching a broad range of students, including women and underrepresented minorities. The Department will initiate pilot projects that have scalability as an important characteristic so that schools can bridge the period until network and system costs decline to the point that the education establishment can take over this support. Another key technology initiative is the development of digital libraries that will enable users speedy and economical access to Energy information over an electronic data highway. 
The Department of Labor has direct and indirect interaction with employers, workers, business and labor organizations, and other government entities and administers most Federal training programs. The Department hopes to use the NII to enhance the skills, education and training of the American workforce.

The National Aeronautics and Space Administration continues to build on its HPCC program, its aeronautics and space science research and engineering missions, and its existing education outreach infrastructure to facilitate the general development of the NII to support mathematics, science, and engineering education in K-12 education. this program consists of pilot projects at 7 NASA Centers involving many of their local schools and school districts. The goal of the $\mathrm{K}-12$ effort will be to produce and distribute curriculum materials to a very broad user community over the Internet. A video is in production in cooperation with the Department of Education to provide guidance on appropriate steps for implementing Internet access and utilization in the classroom. NASA continues to operate and improve. its "Spacelink" computer information system for the education community, principally teachers and students.

The National Science Foundation supports research on digital libraries for capturing, categorizing, and organizing data of all forms (text, images, sound, speech) in electronic form to allow utilization of networked databases distributed around the nation and the world. A networking infrastructure for education program will establish test beds and implement prototypes that explore the role of electronic networks in support of reformed education. The NSF will also support the development of national facilities and centers such as NSFNET, High Performance Computing and Communications Centers and National Challenge Centers needs to support the research, education and training activities required to broaden the impact of NII.

In addition, the High-Performance Computing and Communications initiative, an interagency effort under the aegis of the Office of Science and Technology Policy, includes several components that directly support the development of NII uses for education, training, and lifelong learning. These include:

- The National Research and Education Network (NREN). The NREN will establish a very fast communications infrastructure for research and educational use. NREN efforts include increasing the availability of advanced network products and services at affordable cost to research and education communities.

- Information Infrastructure Technology and Applications (IITA). This component supports the development of software, interfaces, and tools necessary for the educational use of the NII, including access to digital libraries." 
Several specific funding opportunities for the CyberScience programs are already identified on the immediate horizon; work to generate proposals must begin shortly for the following:

- expression of interest letter already submitted in conjunction with Texas A\&M University regarding GLOBE project (Appendix N);

- NSF Program Solicitation: Networking Infrastructure for Education Supplements, New Projects and Planning Grants;

- NSF Program Solicitation: Rural Systemic Initiatives in Science, Mathematics and Technology Education;

- NSF Institute for Science Education;

- NTIA, Department of Commerce: National Telecommunications and Information Infrastructure Assistance Program (TIIAP).

\subsubsection{State Funding}

Prepared by Texas' Comptroller of Public Accounts, the Texas Department of Information Resources and the General Services Commission, the Texas Telecommunications Strategic Plan (September 1994) hones in on the critical funding issues for educational connectivity that our project definition study is designed to address for science education efforts:

"Existing services tend to be community based pilot projects that do not achieve a critical mass of users for any one service. Costs have been a major obstacle, given the chronic budget pressures confronting schools and the lack of predictable costs associated with educational networking. Cost is the key reason that data networking in the educational community has trickled down slowly from the major universities to other four-year schools and then two year schools, with the K-12 schools and public libraries still lagging.

"The Technology Allotment Fund provides money that regional service centers may apply to the K-12 schools if a plan is submitted for technology integration. The amount of $\$ 30$ per child is based upon the average daily attendance of the school district. This fund is a start, but Texas schools need a plan for a continued investment in the underlying infrastructure which includes the transmission facilities, equipment and programs for curriculum development."

Bottom line, the DOE can leverage dollars well by supporting the CyberScience programs for the first five years of operation. 


\subsection{Summary Recommendations}

- A critical service niche in science education has been identified which uses existing SSC computing assets to support science education by providing on-going teacher enhancement on the use of computers and connectivity resources on a daily basis in science classrooms.

For science education, the project has definite uses/needs for pieces of SSC equipment, including almost all of the Macs/PCs/workstations $(3500+)$ as well as permanent staff, budget and facility space, independent of any other technical and/or high performance computing elements which may continue to exist.

An outreach program will be implemented to loan SSC/DOE computer workstations to schools and to provide expertise to "information poor" school districts in Texas to enable them to connect to the NII. Ownership would be retained by the CyberScience Connectivity Resource Center, which will also maintain the computers and networking hardware.

- In addition to providing all available Macs, Pcs, workstations and computer peripherals available for the enhancement of science education, the Department of Energy can leverage both their education and research dollars well by providing:

1) Immediate start-up funding of \$1.6M for 1995 and \$1.7M for 1996; and

2) Base line support of $\$ 1 \mathrm{M}$ for each of the subsequent three years, plus leadership assistance in securing long-term self-sustaining research funding and development activities for the CyberScience programs during the first five years of operation. 


\section{R\&D Facilities Access Program}

Most of the future scientific projects proposed for retention at the former SSC site will require highly specialized technical support. Whether building an accelerator for medical use or completing a cryogenic research center, many technically complex components are not always available off-the-shelf, and their on-site design and timely production can contribute to the overall success of the programs. At this writing, it is anticipated that a Regional Medical Technology Center, High Performance Computing Center, and an Applied Superconductivity and Cryogenics Technology Center will be developed from. SSC assets, and that the current electronics and machine shop equipment and facilities will be maintained to support these three major activities.

The sophisticated electronic and machine shops and parallel computing capabilities of the SSC Laboratory significantly contributed over time to the research efforts of over 100 universities. Because of the highly specialized technical staff and equipment needed for physics-related $R \& D$, most universities do not have all of the state-of-the-art equipment needed or adequate space to carry out all of their work. Also, specialized skills and equipment may only be needed for a short time. These limitations also apply to small businesses for which it is not economical feasible to retain highly specialized technical staff and facilities to cover all areas of potential development.

Use of the SSC assets will be maximized by the establishment and funding of a service program to provide universities and businesses in Texas (and if feasible the region) with access to the electronic and machine shops and parallel computing capabilities that are retained at the site. The mission of this proposed program is to provide a broad array of state-of-the-art technical services and training in one central location to serve the research and development communities in universities and in high-tech enterprises in Texas, relating to all branches of physics. This service program will enhance the abilities of businesses, most especially undergraduate and minority institutions, and small punishes to participate in leading research collaborations, to establish new ties with one another, and could contribute to the economic feasibility of new idea development.

The level of need and feasibility of a service program to provide universities and businesses in Texas with access to SSC assets retained on site were investigated using an independently contracted market mail-in survey, survey follow-up, university/industry workshop and a telephone survey of existing university $R \& D$ shop facilities. The results, conclusions drawn and recommendations are discussed below. 


\subsection{Original SSC Assets}

At the time of cancellation of the SSC, parts of the project were in fairly advanced stages of completion, while others had hardly started. A large fraction of the tangible assets that were in place in 1993 are still available and are described below.

The SSC assets are located at two building sites near Waxahachie. The larger site is located a few miles from I35E, the main Texas north-south corridor and one mile north of US 287 . This 42 -acre site has excellent accessibility by road and is adjacent to a railroad. The Central Facility at this site is a 550,000 square feet building with 100,000 square feet of warehouse space and 160,000 square feet of laboratories and mechanical shops. The remaining 290,000 square feet are used as offices, conference rooms, computer rooms and a food service area. Machine shops and assembly areas are organized in 10 high bays with crane capacities varying from 3 to 25 Tons. Some of the cranes also serve covered loading docks. Electrical power of up to $15,700 \mathrm{kVA}$ is available, as well as low conductivity cooling water and compressed air. Nine computer rooms provide uninterrupted power Supply (UPS) capability.

The Central Facility houses an excellent technical library. It has a collection of 10,000 books and 700 journals. The main collection areas are physics, accelerator theory, design and construction and magnet technology. Supporting collections cover computing, software engineering, mathematics, science education, EH\&S, and Total Quality Management (TQIM).

The second site, called N15, is located 6 miles west from I35E on FM 1446. It has several industrial buildings with a total area of 90,000 square feet. They house cryogenics facilities, as well as the magnet construction and testing laboratories.

The SSC sites contain assets in the following major areas: 1) High performance Computing and Communications; 2) Information Technology; 3) Mechanical Shops; 4) Cryogenics; 5) Magnet Fabrication; 6) Electronics; and 7) Data Acquisition. Each of these assets are described in greater detail in Appendix F.

Briefly, the SSC High Performance Computing Center provides 12,000 MIPS computing power on a UNIX workstation farm. A total of 120 workstations are organized in groups that are tightly coupled by optical fibers and Ethernet. Voice communications includes 10,000 connections and the buildings are connected with T1 lines. On-site networking is primarily via Ethernet. SSC assets at the Central Facility include extensive video teleconferencing and video production capabilities 
The mechanical shops include CAD/CAM and over 150 major pieces of machining equipment and a complete welding facility. Precision instruments are available for quality control. The cryogenics facility houses the world's largest cryogenic capability. The magnet fabrication facility is equipped to design and produce superconducting and resistive dipoles and more complex magnets, including two 25 ton cranes and fully automated cablers, winders and a 16 meter long shell welding press. The specialized electronics shops can handle analog and digital design, surface mount, programmable logic, RF and high power.

\section{2. $\quad$ R \& D Infrastructure Market Survey}

A market survey was conducted to measure marketplace needs for equipment and services developed using existing assets of the Superconducting Super Collider near Waxahachie, Texas. The entire document is included in Appendix G. The study objective was to determine the types of equipment/services with the highest demand and the characteristics of the groups with the greatest needs.

The survey sample of 2505 was comprised of Texas physicists, half the technology firms in Texas, and deans of schools of science of Texas universities. Five-hundred forty-two usable surveys were returned for a response rate of $21.6 \%$. The response rate for the sub-samples is given in the table below. An assessment of possible sample bias was conducted and not supported. The response rates for the survey were judged to be adequate for making population generalizations.

\begin{tabular}{ccccc}
\hline Sample & physicists & firms & deans & total \\
\hline $\mathbf{N}$ & 1044 & 1330 & 131 & 2505 \\
usable survey & 341 & 177 & 24 & 542 \\
response rate & $32.7 \%$ & $13.7 \%$ & $18.3 \%$ & $21.6 \%$ \\
\hline
\end{tabular}

\subsubsection{R\&D Market Survey Results}

Seven assets were described for possible use high performance computing, information technology, mechanical shops, cryogenics, magnet fabrication, electronics and data acquisition. Most respondents $(65.7 \%)$ indicated a willingness to use at lease one asset for either research or training purposes. The use of assets for both research and training was most common (35.4\%), followed by research use $(23.1 \%)$ and training use $(6.8 \%)$.

Estimates of high performance computing use for research ranged from 40.2 $45.8 \%$ of the respondents. Estimated utilization of the information technology, mechanical shops, electronics and data acquisition assets ranged 
(over two measures) from $26.6-31.8 \%$ and $27.5-34.7 \%$ of the respondents. Estimated use of the cryogenics and magnet fabrication assets were lowest and ranged (over two measures) from $8.2-11.9 \%$ and $10.0-12.5 \%$ of the respondents.

Estimates of asset usage for training purposes revealed a ranking similar to research although the anticipated usage levels were lower. High performance computing was ranked first (33.3\% of the respondents), followed by information technology, electronics and data acquisition (average of 25.5\%), mechanical shops (16.6\%) and cryogenics and magnet fabrication (usage of $10.1 \%)$.

The manner in which assets would be utilized was examined. Across assets in general, use of assets for design, as opposed to fabrication, was preferred. There was about equal interest in having design and fabrication done by Facility personnel as to having it done by the respondent's employees, using SSC assets. However, for the mechanical shops support by Facility personnel was most desired.

The extent of asset usage was examined. Respondents estimated using the high performance computing asset on average of 16.26 weeks annually. Information technology had the next highest average estimate (11.87 weeks). Small differences were observed for remaining assets and ranged from 7.95 to 9.86 weeks.

Data were obtained on annual rental costs for comparable assets if Facility use was not provided. Those estimates varied widely and ranged from $\$ 152,714$ for magnet fabrication to $\$ 39,111$ for data acquisition. A mid-range estimate of $\$ 91,065$ was provided for high performance computing.

\subsubsection{Stratified Survey Results}

Results were stratified by employment group. Corporate respondents anticipated less research and training use on every asset than university respondents. Nevertheless, $50.8 \%$ of the corporate respondents still indicated use of at least one asset in the Facility for either research or training purposes. Higher percentages of both university faculty/staff (78.6\%) and deans (83.4\%) provided such indications.

Corporate respondents estimated fewer weeks (9.14 wk.) of high performance computing use than either university faculty/staff (19.27 wk.) or deans ( 16.53 wk.). Estimates on remaining assets were not significantly different across groups. Thus, although the fraction of the corporate population expected to utilize Facility assets may be less than the fraction of university population, the extent (amount) of usage is likely to be similar between customers from both groups on most assets. 
Estimated annual rental costs revealed substantially higher estimates by corporate respondents, relative to university faculty/staff, for most assets. However, faculty/staff indicated higher estimates of magnet fabrication costs.

Data were stratified by principal orientation and area of specialization for the Texas physicist sub-sample. The intent was to identify groups with the highest likelihood of using Facility assets. A higher likelihood of asset use for research was found for respondents with experimental, design or training orientations. A higher likelihood of asset use for training was found for respondents with experimental or training orientations.

Higher anticipated asset use for research was indicated for the following specializations: astrophysics, biophysics, high energy physics, nuclear physics, physics of beams, superconductivity and mechanical engineering. Higher anticipated asset use for training was indicated for the following specializations: astrophysics, biophysics, condensed matter, high energy physics, nuclear physics and superconductivity. In general, the higher asset use among these target specializations was reflected in both higher percentages of respondents and a higher number of weeks of usage. The target specializations also estimated higher annual rental costs across assets.

Data were stratified by type of business for corporate respondents. The intent was to identify businesses with the highest likelihood of using Facility assets. For research purposes, those target businesses were as follows: computers, parts and equipment, electrical equipment and components, industrial chemicals, drugs and medicines, plastic and synthetic materials, optical and medical instruments and other. For training purposes, the target businesses were as follows: computers, parts and equipment, electrical equipment and components and aircraft and parts.

Data were stratified by respondent responsibilities for making decisions on use of the Facility assets. Respondents with sole decision making responsibilities were found to be less likely to utilize the assets, relative to other levels of responsibility.

Analyses were conducted to determine if the asset wage results varied by the number of miles from respondent workplace to Waxahachie, Texas. They did not. One possible explanation is that respondents anticipate use of the Facility assets for non-routine and specialized projects.

Analyses were conducted to determine if the asset usage results varied by annual corporate revenues. The highest revenue group (greater than $\$ 400$ million) was more likely than other groups to indicate use of the high performance computing, cryogenics, magnet fabrication, information technology and data acquisition assets for research purposes; and the high performance computing and magnet fabrication assets for training purposes. 
Finally, analyses were conducted to determine if asset usage varied as a function of the amount of externally funded research obtained by universities. Results revealed a consistent tendency for greater asset use (for both research and training purposes) at universities with high external funding.

\subsubsection{Market Potential}

The total market (dollar revenue) potential for use of the SSC assets within the proposed Facility can be estimated as a function of four parameters. Costs of renting comparable assets elsewhere were judged to be a reasonable equilibrium market entry price. These annual rental cost figures for each asset were adjusted to reflect the proportion of a year involved in asset use.

These figures were then multiplied by the estimated total number of potential users. This number of "potential users" was defined by: (A) current APS members principally employed by Texas universities; and (B) the number of technology firms in Texas; it was assumed that "companies, "rather than employees within those firms, would purchase Facility access. This number of "potential users" $(A+B)$ was 3322. Finally, these figures were multiplied by estimates of the population proportions likely to utilize the assets. Using this equation [(annual rental costs) $\times$ (percent year in use) $x$ ( $N$ of potential users) $x$ (percent of population expected to use)], the estimated market potential for the assets is as follows:

\begin{tabular}{cc}
\hline Asset & Maximum Market Potential \\
\hline High Performance Computing & $\$ 31,430,403$ \\
Information Technology & $\$ 10,587,645$ \\
Mechanical Shops & $\$ 4,088,928$ \\
Cryogenics & $\$ 4,458,312$ \\
Magnet Fabrication & $\$ 6,988,784$ \\
Electronics & $\$ 9,177,146$ \\
Data Acquisition & $\$ 5,868,921$ \\
\hline
\end{tabular}

Across assets, the total market potential is $\$ 72,600,139$. These figures should be regarded as an upper limit. Two major factors were not taken into consideration in this estimate, namely the availability of comparable assets elsewhere, and the tendency to quote rental costs for more assets than are actually needed by a potential user.

Differences in assumptions in the development of the market potential parameters can greatly affect the resulting estimates. In the analyst's view, the market potential estimates are best regarded as exactly that -- market potential. They represent optimistic projections of what might be obtained in 
the absence of limiting circumstances (e.g., the need to provide a price discount significantly lower than competitors to attract customers, the resistance of key decision makers to use of assets at the Facility etc.). In general, the possibility that respondents' statements of "intended" (or expected) use of assets may overstate their "actual" use needs to be considered when interpreting the market potential figures.

For the purpose of this study, we will assume that the scale of operations should be governed by the "optimistic" numbers for market potential that were generated by the market research, divided by at least ten to take into account the cautionary notes that accompany those estimates.

In addition, we are assuming that as with any start-up operation, this is not an immediate projection of revenue, but what might be possible given a quality management, marketing and sales force to identify and reach customer demands.

\subsubsection{Follow-up}

Respondents to the survey could request to be contacted for further information (See Appendix $\mathrm{H}$ ). Currently we are contacting respondents that requested information. Some preliminary results of this effort indicate:

- The value of requested services is indeed lower than is indicated by the quoted equivalent rental value of the asset;

- High expectations exist about the skills and expertise of the personnel remaining at the SSC; and

- Capabilities and expertise at the SSC do not always provide a good match with the needs of the potential users.

This confirms that marketing potential estimates may indeed be high. However, we also find that:

- A large unsatisfied need for computing exists in the Texas academic community; and

- Some of the needs of small and medium size businesses coincide well with the capabilities at the SSC.

The large need for computing in the physics community was already well established. The HPCC was made available to High Energy Physics users in March 1993 and has since been used at near saturation levels. 
The Research Infrastructure Support Workshop was held August 30, 1994 at the Superconducting Super Collider Central Facility (See Appendix K). Approximately fifty people from industry and higher education attended the half-day event. Topics of discussion included the settlement between the U.S. Department of Energy and the State of Texas, an overview of the Joint Texas Facility Project and other collaborations including reports from the Regional Medical Technology Center, the Southwest Center for Computing, Information \& Learning; and the Inland Regional Industrial Technology Center, and a tour of the Super Collider's machine and tooling shops.

In addition, breakout sessions gave attendees opportunities to provide input on the following topics:

- What specialized equipment and expertise are necessary at such a common research facility?

- What potential price levels would stimulate sustainable usage?

- What is the availability/demand for trained technicians to support

$R \& D$ at Universities? to support on-site technical programs? to support corporate R\&D labs?

As intended, the presentation and ensuing workshop breakout sessions fostered a mood of collegiality in addressing the difficult issues associated with reapportionment of current SSC assets. During the wrap-up sessions, discussions and summary comments vacillated between enthusiasm for using the facilities to benefit $R \& D$, and pessimism regarding short-term sources of funding necessary to demonstrate long-term viability.

\subsection{Existing Regional University R\&D Shop Facilities}

In order to gauge the needs for mechanical and electronic shop facilities by research personnel in the local area and over a broader region (Texas), a survey of such facilities already in place was conducted. The scope of the survey was confined to all colleges and universities in the local area, the larger universities (especially those granting M.S. and Ph.D. degrees) state wide, and selected companies in the local area. The survey was conducted by telephone.

Although the survey was designed to question all colleges in the area, it soon became apparent that eliminating community colleges (two-year junior colleges) from the list would be necessary. It was found that the instructors at the community colleges generally do not engage in research. Teaching is the 
prime objective at community colleges and instructors have heavy teaching loads. In general all laboratory facilities are intended for instruction. Three (3) of the approximately sixteen (16) community college in the area were surveyed.

At the smaller colleges and universities (student populations of 3,000 or less) the faculty are interested or engaged in research. There are however no dedicated shop facilities at these institutions. Researchers generally collaborate with others at larger universities or research laboratories and use the facilities at these larger institutions.

Among the educational institutions in the area only the larger universities (student populations of up to 27,000) have mechanical and electronic shop facilities. Typically the mechanical shop will have 1,000 to $5,000 \mathrm{sq}$. ft. with one or two machinists/technicians. The shop will contain 1 to 3 milling machines and 1 to 5 lathes. These machines may have numerical readout but are not numerically controlled. Other equipment typically includes drill presses, band saws, grinders and may or may not include welding and sheet metal equipment. These shops do not have CAD capabilities. Similarly the electronic shops are rather basic facilities with one or two engineers/technicians. At these shops they have the capability to design and build boards and systems but rarely using CAE tools. Test equipment includes oscilloscopes, meters, power supplies but not in general more sophisticated equipment such as spectrum analyzers, network analyzers, etc.

\subsection{Anticipated Availability of SSC Assets}

The assets described in the previous sections are not at all guaranteed to be available. Moreover, efficient access for small users is only possible for those facilities that are already operated for other major clients. Large scale operations will depend critically on the outcome of other re-use studies. Clearly, a phase of extensive coordination will be needed after submittal of the other studies. Below we list the expected modes of operation for the different assets mentioned in the market survey.

\subsubsection{High Performance Computing Center}

The High Performance Computing Center (HPCC) will likely remain available at the SSC site. Initial operation will be provided by a very small crew. Most of the HPCC income is projected to be generated by medium and large commercial users.

The TNRLC proposal for HPCC includes several major upgrades: additional clusters; a Massively Parallel Processor, and huge mass storage devices. 
Services will be extended with software development capabilities in areas of visualization, data retrieval, parallel computing etc. Software development will be done in collaboration among in-house engineers, academic experts and industry.

Additional upgrades could be implemented as necessary to meet the everincreasing computing needs of academic and small business users.

\subsubsection{Information Technology}

Currently some information technology services remain available to cover the SSC's internal needs for communication. Manpower is scarce; however, a large amount of equipment is available, such as servers and network equipment.

The TNRLC proposal for the HPCC includes planned upgrades in the information technology area. For example, improved external links will be provided to increase communication bandwidth. Extensive synergy is expected with proposed educational and training activities. For example, high-tech classrooms and computing infrastructure can be used for training in software engineering, communications and computing, mechanical CAD, electronics CAD and, as mentioned in section 3 of this study, for improving teachers' computing proficiency.

\subsubsection{Mechanical shops}

The mechanical shop at the N15 site is part of the assets that become property of Texas and will be available for shared use. However, as machining was coordinated between shops in the Central Facility and N15, the N15 shop does not cover the full range of capabilities.

The TSTC and TEEX/ARRI studies propose additional activities at the site related to conventional and advanced machining applications. Such programs would provide first class opportunities for shared facilities access.

\subsubsection{Cryogenics and Magnet Development}

The TNRLC project definition study entitled, "Applied Superconductivity and Cryogenics Technology Center," proposes to continue operations of the cryogenics and magnet assets at N15, with a strong emphasis on business incubation. The ASCTC study includes provision of access to the facilities for academic and small business users. This study proposes to refer any 
university or small business interests in cryogenics and magnet development to the ASCTC program, as long as it continues in operation at the site.

\subsubsection{Electronics}

Activities in the electronics area are planned under the TSTC project definition study entitled, "Inland Regional Industrial Technology Institute," ranging from silicon chip fabrication, clean-room services and surface mount technology, to more conventional through-hole printed circuit boards.

Implementation of the TSTC project would permit shared use access to a wide range of electronics technologies and expertise. Under the current settlement terms, however, hardly any of the electronics assets will become Texas property.

\subsubsection{Data Acquisition}

Under the settlement between DOE and Texas, the majority of the data acquisition assets at the SSC remain DOE property. No major local use or user has been identified yet. Also, much of this equipment is highly specific to High Energy Physics experiments. Several requests have been received by DOE for re-deployment of these assets in HEP Laboratories, where they could be put to good use. Re-establishing a DAQ effort at the SSC would require an investment of a few million dollars for equipment and newly hired and trained engineers.

\subsection{Academic/Small Business R\&D Facility Access Program}

The R\&D Infrastructure Market Survey and survey follow-up, R\&D Infrastructure Workshop, and the telephone survey of existing university R\&D shop facilities carried out during the course of this study and described above, combined with information gleaned from parallel SSC asset studies supported by DOE indicate that there is an unfulfilled need for additional computing facilities for the Texas academic community and that some of the needs of academe, as well as small high-tech businesses in Texas can be met by access to the SSC assets.

It is currently assumed that a Regional Medical Technology Center, High Performance Computing Center, and an Applied Superconductivity and Cryogenics Technology Center will be developed from SSC assets, and that the current electronics and machine shop equipment and facilities will be maintained to support these three major activities. Based upon this 
assumption, it is recommended that these facilities have both their dedicated operational mission and a service mission. The service mission will include the science education program, described in section 3 above, and an Academic/Small Business R\&D Facility Access Program.

For organizational and management purposes, the R\&D Facility Access Program will include the following components:

- $\quad$ R\&D Facility Access Fund;

- $\quad$ R\&D Lab Equipment Lending Pool; and

- Stand-Alone Electronics and Machine Shops, if necessary.

\subsubsection{Academic/Small Business R\&D Facility Access Fund}

Many opportunities in physics-related $R \& D$ require resources in staff and equipment that are larger than a single institution is able to commit. But formidable difficulties to inter-institutional collaboration can exist. In 1990, the principle investigators of this study learned of these difficulties first hand as founders of the Physics Association of North Texas; the objectives of this organization is to foster cooperative activities and communication. An Academic/Small Business R\&D Facility Access Fund will aid physics-related R\&D in Texas universities and industries by not only providing needed facilities and expertise, but by fostering patterns of cooperation and by facilitating unique and otherwise difficult research collaboration.

The basic concept for an Academic/Small Business R\&D Facility Access Fund is to provide R\&D equipment and services too specialized and/or too expensive for individual institutions to provide independently. For example, experimental apparatus can be designed and/or constructed on-site and utilized at the home institution or some other experimental site. A central facility for these purposes is cost effective, avoids unnecessary duplication, and encourages new collaborative R\&D initiatives. An investigator would submit a budget and a short proposal describing his/her needs. The proposal would be reviewed and funds/credit extended for use of the facility.

\subsubsection{R\&D Equipment Loan Program}

In the course of the R\&D Infrastructure Workshop conducted as a part of this study (see section 4.3 above), a suggestion was made that R\&D in Texas would benefit greatly from an equipment loan program that would provide for limited time use of SSC equipment at off-site locations. This suggestion runs counter to the thrust of the present study, that is on-site uses of the SSC assets. Nevertheless, a limited loan program for specific equipment might be feasible 
and would be consistent with the overall objective of maximizing the utility of SSC assets.

Additionally, a loan program could make a large difference in the capacity of smaller institutions to carry out sophisticated experiments and consequently could contribute greatly to the research programs of predominately undergraduate and/or minority institutions and small businesses. Investigators would be able to propose research to federal funding agencies with budgets based on the availability of the equipment.

The loan program could provide a service for short-term experiments that need sophisticated electronics equipment. Equipment could be made available to experimenters to use off-site for a specified period of time. A loan program would not be advisable for machine shop equipment due to its large size or for computer equipment due to the facility of accessing additional computing power through Internet connections.

A reasonable estimate of the size for the equipment pool for the loan program would be $10 \%$ of the SSC electronic equipment. As a rough estimate, the present electronics store is valued at $\$ 25 \mathrm{M}$, so that the Loan Program store would be valued at $\$ 2-3 \mathrm{M}$ in value and consist of 100-150 items with useful lifetimes of about six to ten years.

The R\&D Equipment Loan Program would be managed similar to a competitive grants program, with the applicant providing a description of the planned use for review. The major elements of cost for the program would include: 1) the equipment, 2) a staff member to supervise, store, maintain, transport, and process requests for the equipment, 3) insurance costs, and 4) maintenance and provisions for loss and uncovered damage to equipment. A storage room will be needed for the equipment. We are assuming that transportation and insurance costs will be borne by the borrower.

\subsubsection{Conferences and Collaborative Outreach Activities}

The Physics Association of North Texas has successfully arranged conferences and workshops. Sharing the financial burden made a scale of activity possible that could not have been easily attempted by an individual institution. At the same time, the organization suffered from being decentralized.

The Academic/Small Business R\&D Facilities Access Program could, in many cases, provide that centralization and the expertise that comes with experience. In addition, this program could assist physics departments and industrial R\&D units in their efforts to increase professional interaction and community awareness by joint sponsorship of lectures and related programs, for example a newsletter. Initially, only a part-time staff member would be required for these activities; especially if volunteer leadership and guidance is 
also provided by an organization such as the Physics Association of North Texas.

\subsection{Financial Considerations}

The concept of providing universities and small businesses involved in physics-related R\&D with access to the High Performance Computing Center and the electronics and machine shops retained on the SSC site is supported by the findings of this study.

\subsubsection{Cost \& Competitiveness}

Use of the infrastructure and equipment already in place at the SSC avoids the costs of constructing and equipping a new facility. A reduction in cost is assumed when existing facilities are shared by many users. Operational costs for the Regional Medical Technology Center, High Performance Computing Center, and the Applied Superconductivity and Cryogenics Technology Center will not increase significantly if the service mission, namely, the science education program and the R\&D facility access program is implemented. More specifically, pooled resources will yield a reduction in cost for the businesses and educational institutional served and an increase in competitiveness for the small businesses involved by:

- Possible use of excess capability of the facilities with a dedicated mission.

- Synergy of R\&D activities with training and educational activities at the site. Small, challenging projects can serve as training for students and interns.

- Collaboration of universities and small businesses with other hightech companies. Small production projects can be handled by the aggressive small businesses involved, for example, in the business incubator established by the Applied Superconductivity and Cryogenics Technology Center. These companies are expected to be very efficient and the universities and other small R\&D businesses seeking access to the former SSC facilities will provide these companies with an early set of challenging clients.

- Joint ventures between industry, state and federal institutions and academia. Some of the high-tech challenges identified by the academic and small business users will lead to collaborative projects. All parties involved may contribute funds, hardware, software and expertise to create alpha- and beta-test sites to prove and demonstrate the feasibility of leading edge technologies. 


\subsubsection{Pricing}

The proposal for this project definition study was based upon the following two assumptions for R\&D facility access:

1) REQUIRED COMPUTER SUPPORT WILL BE SUPPLIED BY A DEDICATED HIGH PERFORMANCE COMPUTER CENTER (HPCC) TECHNICAL USER.

In keeping with these assumptions, the Academic/Small Business R\&D Facility Access Fund is proposed as a mechanism which permits and facilitates access by these important user communities in an efficient, easily managed, low-overhead process that allows the HPCC and technical applications centers to concentrate on their primary technical functions.

Presently, the high performance computing center is marketing cpu cycles at a maximum rate of $\$ 4 / \mathrm{cpu}$ hour for small users. Billing algorithms for use of electronics shops and machine shops are currently under development by the project definition study groups proposing to become the primary technical users of the shop equipment.

In both billing circumstances, the Academic/Small Business R\&D Facility Access Fund anticipates paying similar rates for uses by its scientific user community; budget projections have been prepared accordingly.

\subsubsection{Budget}

In drawing up an illustrative budget, for the R\&D Facility Access Program, there are two top-level decisions to be made: (1) the relative apportionment among the four areas covered in the baseline program (HPCC, Infotech, Mechanical Shops, and Electronics Shop); and (2) the overall scale of the effort.

The first decision is relatively easy. One can use directly the ratios computed from the market potential estimates in the Market Survey. These are derived from respondents estimates of the cost of securing comparable assets elsewhere. Alternatively, one can begin with respondents estimates of time of use and compute values based on SSC Laboratory costs in delivering the service. The two methods agree roughly. The result is about $70 \%$ of the budget should be devoted to computer-based services and about $30 \%$ should be devoted to shop services.

The scale of the Program is the more difficult decision. It is clear that the cautionary factors identified in the Market Survey require it be considerably 
below the maximum $\$ 70 \mathrm{M}$. It is also clear that in starting such a program, it is preferable to err on the side of caution, rather than on the side of optimism. It is also important that the scale of the program clearly be practical. After considerable study and consultation, a judgment was made that a total program on the order of $\$ 2 \mathrm{M} /$ year meets these criteria and the budget has been scaled based on this assumption.

A projected budget for the Academic/Small Business R\&D Facility Access Fund is presented in the table below. Its most important feature is the $\$ 2 \mathrm{M}$ R\&D Access Fund. This, based on the 70/30 split would be used to "purchase" from the operating entities of the computing and shop facilities $\$ 1.4 \mathrm{M}$ and $\$ 0.6 \mathrm{M}$ of computer and shop services. The computer services would be split among large jobs, small jobs and information technology. Large jobs would naturally take the majority of the CPU-hours while choosing among small jobs and information technology proposals would take the majority of the peer review effort. The shop services would be split among mechanical shops, electronics shops and engineering design. While a significant amount of work was done by this study on incremental costs of the various services as a basis for the bottom line budgeting, that work is not presented here. The scale of shop services provided, with a roughly even split between electronics and mechanical, would be on the order of fifty jobs of each sort per year.

The R\&D Equipment Lending Program is budgeted here separately from the Educational Equipment Lending Program; actual operations will be integrated.

An estimate of the value of the SSC assets, computers and shop equipment, that would be required to support operations at the scale selected, $\$ 4 \mathrm{M}$, is given. Illustrative tables of equipment are given in Appendices I and J. With the concept of operations selected, this equipment is covered under the requests from the primary operators of the facilities involved.

At this writing, it appears relatively certain that there will be continued operation of computing facilities. However, timing and extent of shop services is in much more doubt. We have therefore prepared a budget for the shop portion of the R\&D Access program as a "stand alone facility" without the advantages of the $\$ 0.6 \mathrm{M}$ being incremental to functioning shops, but with the same scale of operations. It should be noted that the cost is about $50 \%$ higher. We believe that this provides some measure of the efficiencies inherent in the incremental, shared use concept proposed.

Finally, we note that one can deduce from the stand alone shop budget that a bare-bones, low budget partial infrastructure operation could be run on the basis of strictly user-supplied operation of machine shop assets; such an operation would eliminate the salary items except for security and operations supervision. 


\begin{tabular}{|c|c|c|c|c|c|}
\hline R\&D FACILITY ACCESS & FTE & 1995 & 1996 & 1997 & 1998 \\
\hline \multicolumn{6}{|l|}{ PERSONNEL } \\
\hline Access Fund Program Director & 1.00 & $\$ 60,000$ & $\$ 61,800$ & $\$ 63,654$ & $\$ 65,564$ \\
\hline Administrative Assistant & 1.00 & $\$ 25,000$ & $\$ 25,750$ & $\$ 26,523$ & $\$ 27,318$ \\
\hline FRINGE BENEFITS @ 30\% & & $\$ 25,500$ & $\$ 26,265$ & $\$ 27,053$ & $\$ 27,865$ \\
\hline \multicolumn{6}{|l|}{ CONSULTANTS - Peer Review } \\
\hline $12 @ \$ 1000$ ea & & $\$ 12,000$ & $\$ 12,000$ & $\$ 12,000$ & $\$ 12,000$ \\
\hline TRAVEL & . & $\$ 10,000$ & $\$ 8,000$ & $\$ 8,000$ & $\$ 8,000$ \\
\hline \multicolumn{6}{|l|}{ EQUIPMENT } \\
\hline Office Equipment & & $\$ 10,000$ & $\$ 2,000$ & $\$ 2,000$ & $\$ 2,000$ \\
\hline R\&D-Facility Access Fund & & $\$ 2,000,000$ & $\$ 2,200,000$ & $\$ 2,420,000$ & $\$ 2,500,000$ \\
\hline \multicolumn{6}{|l|}{ FACILITIES/SPACE RENTAL } \\
\hline Administrative Offices/600SQFT & & $\$ 6,000$ & $\$ 6,000$ & $\$ 6,000$ & $\$ 6,000$ \\
\hline MATERIALS \& SUPPLIES & & $\$ 10,000$ & $\$ 10,000$ & $\$ 10,000$ & $\$ 10,000$ \\
\hline TOTAL & & $\$ 2,158,500$ & $\$ 2,351,815$ & $\$ 2,575,229$ & $\$ 2,658,746$ \\
\hline R\&D EQUIPMENT LENDINGG & FTE & 1995 & 1996 & 1997 & 1998 \\
\hline \multicolumn{6}{|l|}{ PERSONNEL } \\
\hline Equipment Lending Clerk & 1.00 & $\$ 30,000$ & $\$ 30,900$ & $\$ 31,827$ & $\$ 32,782$ \\
\hline FRINGE BENEFITS @ $30 \%$ & & $\$ 9,000$ & $\$ 9,270$ & $\$ 9,548$ & $\$ 9,835$ \\
\hline EQUIPMENT maintenance \& upgrade & des & $\$ 300,000$ & $\$ 300,000$ & $\$ 300,000$ & $\$ 300,000$ \\
\hline FACILITIES/SPACE RENTAL/800 sc & sqft & $\$ 8,000$ & $\$ 4,000$ & $\$ 4,000$ & $\$ 4,000$ \\
\hline MATERIAL \& SUPPLIES & & $\$ 3,000$ & $\$ 3,000$ & $\$ 3,000$ & $\$ 3,000$ \\
\hline TOTAL & & $\$ \$ 350,000$ & $\$ 307,000$ & $\$ 307,000$ & $\$ 307,000$ \\
\hline JTF R\&D program total & & $\$ 2,508,500$ & $\$ 2,658,815$ & $\$ 2,882,229$ & $\$ 2,965,746$ \\
\hline SSC ASSETS from DOE & & $\$ 4,000,000$ & & & \\
\hline
\end{tabular}

\begin{tabular}{|c|c|c|c|c|c|}
\hline STAND-ALONE SHOPS BUDGE & FTE & 1995 & 1996 & 1997 & 1998 \\
\hline PERSONNEL & & & & & \\
\hline Shop Supervisor & 1.00 & $\$ 60,000$ & $\$ 61,800$ & $\$ 63,654$ & $\$ 65,564$ \\
\hline Machinists $3 @ 45 k$ & 3.00 & $\$ 135,000$ & $\$ 139,050$ & $\$ 143,222$ & $\$ 147,518$ \\
\hline Electronics Engineers $4 @ 55 \mathrm{~K}$ & 4.00 & $\$ 220,000$ & $\$ 226,600$ & $\$ 233,398$ & $\$ 240,400$ \\
\hline FRINGE BENEFITS @ 30\% & & $\$ 124,500$ & $\$ 128,235$ & $\$ 132,082$ & $\$ 136,045$ \\
\hline \multicolumn{6}{|c|}{ EQUIPMENT maintenance \& upgrades } \\
\hline Machining Equipment ${ }^{-}$ & & $\$ 25,000$ & $\$ 25,000$ & $\$ 25,000$ & $\$ 25,000$ \\
\hline Electronics & & $\$ 150,000$ & $\$ 150,000$ & $\$ 150,000$ & $\$ 150,000$ \\
\hline \multicolumn{6}{|l|}{ FACILITIES /SPACE RENTAL: } \\
\hline Machine Shops 10,000 sqft & & $\$ 100,000$ & $\$ 100,000$ & $\$ 100,000$ & $\$ 100,000$ \\
\hline Electronics Shops 8000 sqft & & $\$ 80,000$ & $\$ 80,000$ & $\$ 80,000$ & $\$ 80,000$ \\
\hline TOTAL & & $\$ 479,500$ & $\$ 483,235$ & $\$ 487,082$ & $\$ 491,045$ \\
\hline
\end{tabular}




\subsubsection{Sources of Funds}

We have identified three basic sources of funds for the proposed access program: federal, state, and private. Federal funds are available through the High Performance Computing and Communications (HPCC) Program in which the following federal agencies participate:

ARPA, NSF, DOE, NASA, NIH, NOAA, EPA, ED.

The total budget of these agencies for the fiscal year FY 94 is $\$ 938 \mathrm{M}$ and the proposed budget for FY 95 is $\$ 1,155 \mathrm{M}$.

In addition to the HPCC program, we anticipate that other programs within these agencies could be sources of funds for our program. In NSF, for example, efforts to direct research into strategic areas could support our efforts to bring together university researchers and small businesses to develop new enabling technologies and new products. Similarly, programs in DOE directed towards Technology Transfer could support interactions with various National Laboratories.

At the State level, there exists the Texas State Matching Pool, which provides funds to match federal and other dollars brought into the state through programs in state and private entities. Thus it is anticipated that some portion of federal support for this program might be matched on a one-to-one basis by the state.

In summary, we propose that DOE finance an Academic/Small Business R\&D Facility Access Fund at an annual amount of $\$ 2 \mathrm{M}$ per year over the next 5 years in order to provide those in both the scientific and regional business communities with a different, yet on-going R\&D stimulus similar to that which might have been anticipated to exist due to the existence of the SSC Laboratory in Texas.

Not only is demand for this level of support demonstrated by our market survey (See Appendix G), but we also suggest that twenty percent (20\%) of the Academic/Small Business R\&D Facility Access Fund be prioritized for minority and/or female users, or project teams involving minorities and/or females in principal roles.

\subsection{Recommendations}

- The mission of the proposed Academic/Small Business R\&D Facility Access Program is to provide a broad array of state-of-the-art technical services and training in one central location to serve the research and development communities in universities and in high-tech enterprises in Texas, relating to all branches of science. This service program is expected to enhance the abilities of universities, most 
especially undergraduate and minority institutions, as well as small business, to participate in research collaborations, to establish new ties with one another, and to contribute to long-term state and national economic competitiveness.

- Use of the SSC assets will be maximized by the establishment and funding of an Academic/Small Business R\&D Facility Access Fund, a service program to provide universities and small businesses in Texas (and if feasible the region) with access to the electronic and machine shops and parallel computing capabilities that are retained at the site.

- Twenty percent (20\%) of the Academic/Small Business R\&D Facility Access Fund will be prioritized for minority and/or female users, or project teams involving minorities and/or females in principal roles.

- The Department of Energy (DOE) should finance an Academic /R\&D Facility Access Program at an annual amount of $\$ 2 M$ per year over the next 5 years in order to provide those in both the scientific and regional business communities with a different, yet on-going, R\&D stimulus similar to that which might have been anticipated to exist due to the existence of the SSC Laboratory in Texas. Five years' cumulative direct costs requested from DOE for the R\&D Facilities Access Fund and Fund administration total $\$ 12.5 \mathrm{M}$, and five years' cumulative direct costs for the R\&D Equipment Lending Program total \$1.8M. 


\section{R\&D Training Activities}

\subsection{Endorsement of Other EOI Projects}

Although training needs for $R \& D$ technicians were investigated during this project definition study, evidence suggests that other DOE-funded repurposing projects, specifically those led by Texas State Technical College (TSTC) and by the Texas Engineering Extension Service (TEEX)/UTA's Automated Robotics Research Institute, are competent endeavors which should be endorsed and supported to meet training needs which might arise.

\subsection{Manufacturing Technology Deployment Center TEEX/ARRI}

Manufacturing companies must face increasingly fierce competition in the global market. "The U.S. share of world production has declined from about $50 \%$ in 1955 to about 15\% today." Because this is the case, it is crucial that immediate steps be taken to assist small manufacturers in improving their effectiveness and competitiveness, and to help them safeguard against failure. The result of the feasibility study conducted by the Advanced Robotics Research Institute (ARRI) and the Texas Educational Extension Service (TEEX) shows that the most logical, productive, and financially advantageous applications of the SSC facility to be the development of a Manufacturing Technology Deployment Center (MTDC). The MTDC will contain the following applications:

- $\quad$ Product Development Center

- Business Incubator/Accelerator

A Product Development Center is an industry driven facility that provides services to facilitate the process of product development for the manufacturing community. Included in the services to manufacturers by such a center are a comprehensive approach to prototype design and fabrication, a concurrent design of product and manufacturing processes, and market research.

A business Incubator/Accelerator is also an industry driven facility that allows start-up companies to use shared facilities to develop products and processes, and allows them to initiate low rate production. 
The Manufacturing Technology Deployment Center (MTDC) is a privatepublic partnership between industry, academia, and government that will enhance global economic competitiveness of small and medium size manufacturers in a five state region (Texas, New Mexico, Oklahoma, Arkansas, and Louisiana) through industry driven training and education, technical assistance, and the deployment of clean, agile, environmentally conscious, and energy efficient manufacturing technologies that reside in the DOE, other federal laboratories, regional universities and colleges.

\subsection{Texas State Technical College Initiative}

The Teaching/Learning Factory and Technology Training Center of TMTC's Inland Regional Industrial Technology Institute (I-RITI) will interactively function as a support mechanism to prepare R\&D and production technicians. In this effort, industry-driven TMTC will link resource partners, TSTC Waco, state and regional universities, and other R\&D laboratories at IRITI to:

- Integrate the teaching environment with the manufacturing environment for rapid applications of technology through experiential learning; and

- Link technical, engineering, and management education in applied projects that integrate newer design, manufacturing and management technology for opportunities that teach "real time" concurrent engineering.

\subsection{Recommendation}

- $\quad$ Although training needs for R\&D technicians were investigated during this project definition study, evidence suggests that other DOE-funded repurposing projects, specifically those led by Texas State Technical College (TSTC) and by the Texas Engineering Extension Service (TEEX)/UTA's Automated Robotics Research Institute, are competent endeavors which should be endorsed and supported to meet training needs which might arise. 


\section{Summary \& Recommendations}

\subsection{Introduction}

This section summarizes the chief elements of the project definition study funded and undertaken as the "Texas Joint Facility Supporting Research, Training and Science Education," as the detailed in sections 3-5 above. Recommendations concerning management are made in section 6.3.; while recommendations concerning activities in the interval between completion of the study period on October 31, 1994 and the time at which Texas and DOE finalize their arrangements for what will continue as functioning components long-term. Section 6.5 contains other recommendations.

\subsection{Summary Description}

This project definition study was undertaken based upon the following assumptions:

- $\quad$ Maximum use should be made of existing tangible SSC assets; a minimum of acquisition of new equipment or construction should be required.

- The operations concept should minimize duplication of services and resources already provided by other institutions; areas of overlap are desirable only where significant deficiencies exist.

- Where possible, use should be made of intangible SSC assets.

- Other, technical uses of SSC assets will be selected for primary funding as on-going technical components. These are likely to include design and construction of an accelerator for medical therapy and research and radioisotope production as well as the Blacklands Prairie recovery project. Other uses, such as physics experiments using SSC assets, cryogenics work, and superconductivity, and the high performance computer center are possible. Academic and small business users will be able to share facilities with those selected and to draw, even if in limited amounts, on the expertise of their personnel.

- The concept of operations must be broad enough so as to benefit, not just the local region, but the entire state, and possibly be expandable beyond state borders to be of service in a still broader region.

Within these bounding assumptions, the projects defined by this study, in outline, include the following: 
- $\quad$ Computer Literacy for science teachers and science education programs whose core is maximal exploitation of the personal computers, work stations, mass storage capabilities and connectivity access assembled by SSC. These would be used both on-site and in Texas schools. The programs of section 3 are designed to use that asset to position science teachers in Texas to make maximum use of the rapidly growing pool of educational resources available on, and from, computers and networked connections of computers.

- Intern activities for teachers and students drawing on both on-site activities related to other uses of SSC assets selected and off-site activities. The Science Education Enhancement Center will be in a unique position to facilitate such off-site internships in view of the unique lines of communication it will develop with a variety of $R \& D$ activities in Texas through its infrastructure arm.

- $\quad$ An Academic/Small Business R\&D Facility Access Fund, which will aid physics-related R\&D in Texas universities and industries by providing access to infrastructure facilities and expertise in a variety of areas, including computing, information technology, machine shops, electronic shops, advanced engineering and design capabilities. These infrastructure activities will ensure that the benefits from SSC shop and related assets will extend to $R \& D$ throughout the State and not be limited to the local region and the specific technical SSC asset uses selected.

- Long-term, elements of the CyberScience Coalition would compete for funding for its programs from federal and other funding agencies. In time, the majority, if not the entirety, of its educational activities could be so funded.

- At a measured pace, the Academic/Small Business R\&D Facility Access Fund would assist the reconfigured TNRLC to move to essentially fullfunding of its infrastructure support activities, as modes of operation for best serving the needs of a variety of types of users throughout the State were developed.

- Both the CyberScience Coalition and the Academic/Small Business R\&D Facility Access Fund are designed to ensure that the uses of SSC assets, tangible and intangible, are distributed throughout Texas as broadly as possible to the people -- science students, teachers, and researchers in schools, colleges, universities, and industries - best equipped to benefit from such use.

\subsection{Management}

The reconfiguration, and resulting management structure, of the present Texas National Research Laboratory Commission (TNRLC) as the designated 
asset management organization is anticipated to have a major influence on recommendations regarding specific management structures for the Academic/Small Business R\&D Facilities Access Program and the CyberScience Education Programs.

Since a TNRLC reconfiguration has not yet been completed by the state legislature, the discussion below is limited to management philosophy issues and internal operating issues related to the two programs which are defined in this study.

Members of the Advisory Board should represent universities and small businesses who have vested interests in use of the facilities. Independent peer reviewers should be used at least annually to evaluate specific fund disbursements.

The nature of this effort makes it a prime candidate for the developing concept of "virtual organization." In this management approach, each activity or "cost center" has a managing program director and an allocated resource level. The Program Director then has responsibility for assembling the "virtual organization" that will define and deliver the cost center's services, as well as for supervising its execution -- rather than assigning portions of the activity to various units of the parent organization. The members of the virtual organization can come from inside or outside the parent organization. The virtual organization exists for the life of the particular activity. The people involved in the activity report to the manager with respect to it -- although they may also be involved in more than one business line, or cost center, at a time - rather than to someone supervising their participation in various diverse activities.

This project management style is particularly suited to the proposed activities. The nature of the project staff will vary depending on how best to meet human resource needs; options for filling positions include staff, participating faculty and others.

The virtual organization approach to internal management is psychologically particularly suitable in this case. Both education and science are fundamentally dependent to a much greater degree than many other human activities on the judgment, creativity and enthusiasm of their practitioners. The same attributes are needed for those who would support, facilitate and enhance these activities. Putting responsibilities in the hands of individual managers of talent, rather than in an organizational matrix, is clearly the preferable route for attracting, retaining and most fully exploiting the capable people the education and research programs will need to succeed. 

Personnel requirements for the Academic/Small Business R\&D Facilities Access Programs are designed to be nominal. An Access Fund Program Director will work with members of an unpaid, appointed Advisory Board to design and implement a simple application and peer review process in the administration of the Fund to provide timely access to high performance computing capabilities, as well as access to available electronics and machine shops. The Access Fund Program Director will supervise an Administrative Assistant and an Equipment Lending Clerk, who will handle daily responsibilities for the R\&D Lab Equipment Lending Program.

Space requirements for the R\&D Facilities Access Fund and the R\&D Equipment Lending program total less than 1500 square feet.

\subsubsection{CyberScience Education Programs}

Personnel requirements for the CyberScience Coalition education programs include an Executive Director, Program Directors for both the Science Education Enhancement Center and the Connectivity Resource Center, and Faculty Directors for program development initiatives in the areas of Educational Technology Research, Workforce Development and the Executive Institute. Faculty Directors are anticipated to be joint employees with a coalition member university; such joint appointment might also be true of the Executive Director. As currently projected, a total of 20 FTEs are necessary to provide the science education and connectivity services as defined in this study. Space requirements for these programs are projected to total approximately 10,200 square feet.

Due to the evolving technical and research components of the CyberScience Education Programs, this effort might well be considered as a separate technical application center, akin to the other technical EOIs and TNRLC projects. As such, it too might be a candidate for external contractual management by joint venture groups. If that were to occur, however, budget figures presented herein must be adjusted to include some negotiated indirect costs, since only direct cost figures have been outlined in this document.

\subsection{Interim Period}

To prevent a loss of continuity between completion of this study and implementation of the defined projects, the CyberScience Coalition and the Academic/Small Business R\&D Facility Access Fund, we recommend that 
modest funds be made available, starting immediately. The program of work during this period would include the following:

- Pursuit of funding opportunities, for the defined project activities; submission, where appropriate, of non-binding letters of intent, and preparation of elements of full proposals for immediate use in the event of a favorable decision.

Such activity is particularly important for the educational arm. There are specific programs in this area already announced and more are expected. A small, near-term investment is important in keeping open as many options as possible and in ensuring that well though out proposals could be submitted rapidly.

- Identification of specific R\&D Facility Access needs in the first year of operation. Such an effort now, even at a low level, would capitalize on the wide distribution of the market research survey. Potential users who requested follow up information at study completion would be contacted. A general mailing could solicit candidate projects in the event of favorable action. Working with those most interested would permit generation of detailed operational procedures beyond the scope of the present study.

- Maintenance of open lines of communication developed in the course of the present study. The study has been in contact with a wide variety of individuals and institutions which have expressed interest in using and/or supporting the projects defined in this study. Interim activity would keep open those contacts, eliminating needless duplicative efforts to re-establish them in the event of a favorable decision after a lengthy hiatus. These include educational organizations, staff members of such organizations, and teachers; they include industrial and academic scientists; and they include those participating in the other studies.

To support baseline program development activities such as those described above would require approximately $\$ 30,000$ per month plus indirect costs; funds requested represent direct costs to support four program development and technical staff, appropriate administrative support, and basic travel and operating expenses. The present study grant could, we believe, serve for the administrative entity for the interim effort. Effort in the interim period would be augmented by supervision and assistance by the Principal Investigators on the present study. It could also be augmented by participation by various physicists and others, around the State, who have taken an active interest in the Joint Texas Facilities concept and its objectives since before the November, 1993, meeting at Southern Methodist University cited in Section 2. Most importantly, efforts in this period would be augmented by members of the Advisory Board, who have expressed a willingness remain constituted and to meet a limited number of times, as 
needed, in connection with maintaining present momentum during an . interim period.

\subsection{Recommendations}

After careful study and consideration, with input from an especially helpful and experienced Advisory Board, the following recommendations are made as a part of this UTA/SMU project definition study:

A A critical service niche in science education has been identified which uses existing SSC computing assets to support science education by providing on-going teacher enhancement on the use of computers and connectivity resources on a daily basis in science classrooms.

For science education, the project has definite uses/needs for pieces of SSC equipment, including almost all of the Macs/PCs/workstations $(3500+)$ as well as permanent staff, budget and facility space, independent of any other technical and/or high performance computing elements which may continue to exist.

In addition to providing all available Macs, Pcs, workstations and computer peripherals available for the enhancement of science education, the Department of Energy can leverage both their education and research dollars well by providing:

1) Immediate start-up funding of $\$ 1.6 \mathrm{M}$ direct costs for the 1995 and \$1.7M direct costs for 1996; and

2) Base line support of $\$ 1 \mathrm{M}$ direct costs for each of the subsequent three years, plus leadership assistance in securing long-term self-sustaining research funding and development activities for the CyberScience programs during the first five years of operation.

B Use of the SSC assets will be maximized by the establishment and funding of a service program to provide universities and small businesses in Texas (and if feasible the region) with access to the electronic and machine shops and parallel computing capabilities that are retained at the site.

The mission of the proposed Academic/Small Business R\&D Facility Access Program is to provide a broad array of state-of-the-art technical services and training in one central location to serve the research and development communities in universities and in high-tech enterprises in Texas, relating to all branches of physics. This service program will enhance the abilities of universities, most especially 
undergraduate and minority institutions, and small businesses to participate in leading research collaborations, to establish new ties with one another, and could contribute to the economic feasibility of new idea development.

Twenty percent (20\%) of the Academic/Small Business R\&D Facility Access Fund will be prioritized for minority and/or female users, or project teams involving minorities and/or females in principal roles.

The Department of Energy (DOE) should finance this Academic/R\&D Facility Access Program at an annual amount of $\$ 2 \mathrm{M}$ per year over the next 5 years in order to provide those in both the scientific and regional business which might have been anticipated to exist due to the existence of the SSC Laboratory in Texas. Five years' cumulative direct costs requested from DOE for the R\&D Facilities Access Fund and minimal Fund administration total $\$ 12.5 \mathrm{M}$, and five years' cumulative direct costs for the R\&D Equipment Lending Program total $\$ 1.8 \mathrm{M}$.

C Training needs for R\&D technicians, as well as technicians for production, were also investigated during this project definition study; however, our evidence suggests that other DOE-funded studies, specifically those led by Texas Manufacturing Technology Center (TMTC) and its proposed Inland Regional Technical Institute, as well as by the Texas Engineering Extension Service (TEEX)/UTA's Automated Robotics Research Institute, are competent endeavors perhaps better suited to this task, and as such, are endorsed and supported to meet training needs.

D Our project has identified no justifiable needs for the Central Facility, in and of itself, but does have facility space needs which could be met by allocation of space either at Central Facility or N-15, depending on what and where other technical and/or high performance computing elements will continue to exist on a long-term basis.

E The N15 shop capabilities should be augmented with a small set of equipment from the Central Facility. A list of machine shop equipment anticipated to be available for use is given in appendix $\mathrm{I}$. The total value of the listed equipment is about $\$ 250,000$. Most of the equipment listed in the appendix is also requested by other re-use studies; some is associated with the Linac and becomes Texas property. 


\subsection{SUMMARY BUDGET REQUIREMENTS - Direct Costs}

$\begin{array}{llllll}\% \text { FTE } & 1995 & 1996 & 1997 & 1998 & 1999\end{array}$

CYBERSCIENCECOALTION

\begin{tabular}{|c|c|c|c|c|c|c|}
\hline Administration & 3.00 & $\$ 216,500$ & $\$ 224,625$ & $\$ 233,156$ & $\$ 242,114$ & $\$ 251,520$ \\
\hline Science Education Enhancement Cente & 7.00 & $\$ 395,500$ & $\$ 410,125$ & $\$ 425,481$ & $\$ 441,605$ & $\$ 458,536$ \\
\hline Connectivity Resource Center & 8.00 & $\$ 692,500$ & $\$ 713,375$ & $\$ 738,144$ & $\$ 769,851$ & $\$ 790,543$ \\
\hline Program Development & 2.00 & $\$ 319,500$ & $\$ 329,900$ & $\$ 340,820$ & $\$ 352,290$ & $\$ 364,330$ \\
\hline Total & 20.00 & $\$ 1,624,000$ & $\$ 1,678,025$ & $\$ 1,737,601$ & $\$ 1,805,860$ & $\$ 1,864,929$ \\
\hline
\end{tabular}

N

ACADEMIC/SMALL BUSINESS

R\&D FACILTTY ACCESS PROGRAMS

R\&D Facility Access Fund

$2.00 \quad \$ 2,243,500 \quad \$ 2,351,815 \quad \$ 2,575,229 \quad \$ 2,658,746 \quad \$ 2,662,369$

R\&D Equipment Lending Program

$1.00 \quad \$ 389,000 \quad \$ 347,170 \quad \$ 348,375 \quad \$ 349,616 \quad \$ 352,212$

Total

$\begin{array}{llllll}3.00 & \$ 2,632,500 & \$ 2,698,985 & \$ 2,923,604 & \$ 3,008,362 & \$ 3,014,581\end{array}$

GRAND TOTAL

$23.00 \quad \$ 4,256,500 \quad \$ 4,377,010 \quad \$ 4,661,205 \quad \$ 4,814,222 \quad \$ 4,879,510$ 


\section{Appendices}

\section{AppendixA Survey of Texas Universities and Colleges}

\section{Science Education and Teacher Enhancement programs at Texas Colleges and Universities}

Baylor University

- Programs aimed at improving teaching skills of teachers already in the field using state-of-the-art technology but finding resources is a problem.

- Collaboration between Baylor and the Holmes Group - a Professional Development elementary school in Waco.

East Texas State University

- Physics Department holds workshops for middle school and elementary school teachers to enhance their skills in teaching physics. Currently, to encourage participation, graduate credit is given, tuition is paid for the teacher, a stipend is paid, and teachers are given materials to use in their classroom.

- Has received Eisenhower funds in the past and anticipates requesting additional funds in the future.

Houston Baptist University

-Eisenhower grant to teach bilingual elementary teachers physical science with emphasis on chemistry-training, books \& materials-3 graduate hours credit for participating teachers

Rice University

-Model Science Laboratory - funded by $\$ 6$ million dollar NSF grant and approx. $\$ 6$ million in corporate donations - operated under the auspices of the Rice University Center for Education. Aimed at retraining inner-city middle school teachers in science education. 
Sam Houston State University

-Very large year-round, graduate program where teachers develop curriculum to take to their classroom.

-Developing programs with area school districts to monetarily reward teachers who pursue an advanced degree.

-Would like to see state-wide ISD networked so teachers (especially rural) can communicate and share information, and expose students to technology. Need resources such as computers and training to do so.

Southwest Texas State University

- Science departments use educational grants to provide graduate-level courses in physics, biology and chemistry specially designed for teachers - especially middle-school level teachers

-They also sponsor an 180-hour (3 credit hours graduate credit) course called "Southwest Wild", which is a field ecology class

-In addition they do workshops to provide in-service training for teachers

Southwestern University

-Education department has required education courses in process (emphasizing discovery and inquiry to develop curiosity) as well as content courses for science education

- Have applied for several NSF and Eisenhower grants to develop science enrichment programs but they weren't funded

-They have an Eisenhower grant to work with area teachers for mathematics enrichment

-There are no initiatives from the Science Departments for science education

Texas A\&M University - Kingsville

-In collaboration with the Region II Education Service Center, they sponsor an Eisenhower Mathematics and Science Program to provide in service training to secondary teachers of mathematics (grades 7-12). The programs are summer institutes ranging from 9 to 15 days. Instruction is based on the premise that teachers teach in the way they were taught--therefore 
participants are taught by using hands-on activities, large and small group settings, lecture and discussion. Manipulatives and graphing calculators are employed extensively as tools for learning and teaching mathematics. Cooperative learning techniques are a major focus.

Texas A\&M University

- Currently writing a 5-year grant proposal to the NSF for an initiative to restructure Middle Grades (6-9) for the State of Texas. The goals of the proposal will be to create instructional materials and to develop and pilot new science courses.

Texas Christian University

- NSF multiple year grant focusing on teacher enhancement in teaching math and science in the elementary school (year-round program). Teachers from area schools meet every week during the school year with TCU professors for exploratory exercises in science and math. During the summer area elementary students are invited to participate in science/math activities. Major goal is to improve teaching of math and science by promoting and enhancing teachers knowledge and understanding of math and science.

- Grant sponsored by Southwest Education Development Laboratory--goal is to enhance science instruction in upper elementary and middle school classroom through use of technology and community resources.

Texas Tech University

Certifications programs in science and mathematics including graduate study.

-Minority Mathematics and Science Education Cooperative" (Eisenhower grant)--involves faculty members of two elementary schools in Lubbock. Also developing Science I curriculum materials.

-Eisenhower-funded program in mathematics education for area $\mathrm{K}-6$ teachers.

- Summer program in science and mathematics for junior high school students.

- Hosts large area science fair each year. 
- Grants from Hughes Foundation for outreach to area biology teachers

- Clark Scholars Program supports high-ability high school junior and senior students to work in research project with faculty member for 8 weeks in summer (students come from all over nation)

Texas Women's University

-Graduate level hands-on course for elementary teachers to develop materials and ideas in science and mathematics

Trinity University

- Program funded by TEA and administered by Centers for Teacher Enhancement. Program is in its 5th year and in San Antonio involves 2 middle and 2 elementary schools. Interactive TV and video, computers, TENET training and Satellite are used. Technology is the theme.

University of Houston

-Program funded by NSF titled "Great Investigations for 6 th Grade Science". Program involves 6 school districts in Houston and 21 teachers. Program aimed at developing a new approach to teaching science through new curriculum, upgrading teachers technology knowledge by providing software training (limited classes mainly teach how to use spreadsheets).

University of North Texas

-Operates the Science and Mathematics Academy for 11-12 grade academically gifted students

-Working to establish the High Performance Learning Center at the SSC which will include virtual science laboratories placed around the state, development of curriculum and instruction materials emphasizing the use of technology, plus extensive distance-learning and professional development activities relating to science education.

University of Texas at Arlington

-Year-round program of enhancement for Math teachers. Texas Instruments supports program and distinguished Chair to lead program. 
University of Texas at Austin

- Extensive Masters and Doctoral programs in science education

-?? grant outreach programs (still waiting for info) 


\title{
Appendix B Science Education Workshop Agenda
}

\author{
A WORKSHOP \\ Hughes Trigg Student Center, Ballrooms C \& W \\ Southern Methodist University \\ Thursday, September 1, 1994 \\ AGENDA
}

8:30 a.m. Welcome \& Overview of Settlement between Texas and DoE Peter Rosen

$8: 45$

Overview of JOINT TEXAS FACILITY Study

Vic Teplitz

9:00

Concept for CYBERSCIENCE COALITION

Kate Morgan

Jane Armstrong

Mission: to involve active research scientists and

engineers in the enhancement of science education

$9: 30$

OTHER PROJECT STUDIES--SOURCES FOR SCIENTIST INVOLVEMENT

- Regional Medical Technology Center

Ben Prichard

-Applied Superconductivity \& Cryogenics Ctr.

Adnan Yucel

-Southwest Ctr. for Computing, Information \& Learning

Dave Gurd

-High Performance Learning Center

Kathleen Holmes

-Manufacturing Technology Deployment Center

Mike Huddleston

-Minority Institution Network

Dennis Judd

$10: 30$

BREAK

$10: 45$

MORNING BREAKOUT SESSIONS

A $\cdot$ Promenade A

Jane Armstrong/Kate Morgan

What are the current connectivity, equipment and training needs to link science teachers onto TENET and/or InterNet? with other scientists?

B •Promenade B

Michael Brown 
Are there ways to integrate workplace skill requirements into

curriculum modules that teach TAAS Science essential elements?

11:45 a.m. LUNCH

1:00 p.m. SAMPLE ORGANIZATIONAL MODELS

-TEACHERS' ACADEMY FOR MATH AND SCIENCE

Illinois Institute of Technology, Chicago Lourdes Monteagudo

-TRIANGLE COALITION FOR SCIENCE \& TECHNOLOGY EDUCATION

College Park, Maryland Lauren Williams

2:00 p.m. AFTERNOON BREAKOUT SESSIONS

C-Atrium C Robert James

Could the coalition development process avoid duplication of efforts?

D.Atrium D William B. Baker

Are there suggestions for clarifying the scope, priorities, research opportunities OR funding scenarios for the CYBERSCIENCE COALITION?

3:00 BREAK

3:30 _ REPORTS FROM SESSIONS

4:00 WAYS TO STAY INVOLVED 


\title{
Appendix C CyberScience Science Teacher Survey
}

Final Report to the

Joint Texas Facility Project Supporting Research Training \& Science Education

on the findings of the

\section{CyberScience Coalition Survey}

October 13, 1994

\author{
J. E. Gonzalez, Ph.D. \\ Texas Center for Educational Research
}

P.O. Box 2947

Austin, TX 78768

512.467-0222

The Texas Center for Educational Research (TCER) was contacted by Dr. Jane Armstrong, on September 16th, regarding participation in the CyberScience Coalition Survey. TCER agreed to participate in the study and provide data entry, quality assurance, and data analysis. Preliminary findings were presented to the Joint Texas Facility Project Supporting Research Training \& Science Education advisory group on October 11th, at Dallas, Love Field, Texas. This report constitutes the final report to the advisory group and is due on October 14th. All project materials will be returned to Dr. Armstrong on October 17th.

The CyberScience Coalition Survey which was developed by Dr. Armstrong and her staff, was mailed to two teacher groups in Texas: the Physics Teachers Association of Texas ( $n=265)$; and the Texas Association of Biology Teachers $(n=630)$. The survey sample therefore totaled: 895 . The cut-off date for responding to the survey was midnight on October 3rd. Respondents returned surveys directly to TCER. The survey response flow was steady from $9 / 26$ through $10 / 7$ as shown in Table 1 . No surveys have been received by TCER since $10 / 7$. 
Table 1

CyberScience Coalition Survey Response Flow

\begin{tabular}{ccc}
\hline Date & Number & Sum \\
\hline $9 / 26$ & 9 & 9 \\
$9 / 27$ & 6 & 15 \\
$9 / 28$ & 14 & 29 \\
$9 / 29$ & 15 & 44 \\
$9 / 30$ & 43 & 87 \\
$10 / 3$ & $\quad \therefore 8$ & 175 \\
$10 / 4$ & & 198 \\
$10 / 5$ & 23 & 217 \\
$10 / 6$ & 19 & 229 \\
$10 / 7$ & 12 & 245 \\
\hline
\end{tabular}

After review of the materials received by TCER, it was found that five (5) surveys, although returned to TCER, had not been completed at all by the respondents. These surveys were therefore removed from the statistical database, reducing the total number of responses to 240 . With the adjusted number of responses totaling 240; the adjusted response rate was calculated to be $27 \%$.

If it can be assumed that the sample is representative of teachers in these two science groups, a margin of error can be calculated based on estimates of the size of the population of interest, and the number of respondents. Utilizing formulas found in W. G. Cochran (1977), Sampling Techniques, 3rd ed. pp. 75-76; the estimated adjusted margin of error for the CyberScience Coalition Survey is $\pm 7 \%$.

\section{C.1. Findings}

\section{C.1.1. Computers in the Classroom:}

Respondents indicated that the average science class size was 27 (std. $=6.84$; range: 2-55). The average number of computers in science classrooms was 3 (std.=4.25;range: 1-32). 166 respondents (69\%) indicated that they had computers in their classrooms; of these computers: $27 \%$ were IBM, $14 \%$ were Apple, and $18 \%$ were Macintosh (10\% of respondents also indicated that they had different combinations of computers in their classrooms). 122 respondents $(52 \%)$ indicated that they had printers in their classrooms; $36 \%$ of 
which were dot matrix printers. 93 respondents indicted that they could get their computers repaired.

95\% of respondents indicated that they utilized some sort of technology for their Science and Math classes ranging from TV to software: $34 \%$ used TV; and $61 \%$ used some combination of TV, CD-ROM, databases, and software. $66 \%$ of respondents indicated that there were computer labs that they did not have access to. $86 \%$ of respondents indicated that they would like to add computers to their science classroom. By brand; $42 \%$ of respondents indicated they preferred Macintosh, $11 \%$ preferred IBM, and $46 \%$ listed some combination of computers for their classroom.

\section{C.1.2. Network Connections in the Classroom:}

$89 \%$ of respondents indicated that they were not connected to a network, by virtue of having no phone or modem. The question regarding modem speed was moot, as $89 \%$ of respondents indicated they did not know, the question did not apply to them, or they simply did not respond to this item. (A followup question regarding network connection speed resulted in a similar response; as $87 \%$ indicated they did not know, the question did not apply to them, or they simply did not respond to this item.) However, in terms of connectivity, $70 \%$ of respondents indicated that they had access to: TENET (45\%) and Internet (10\%). $89 \%$ of students, however, did not have access to networks from the classroom. This was verified in a follow-up question where respondents indicated that $92 \%$ of students did not have an e-mail address. Of 240 respondents, only 51 listed an e-mail address.

\section{C.1.3. Computers at Home:}

$85 \%$ of respondents indicated that they had computers at home; $46 \%$ were IBM users and 22\% were Macintosh users. Half of the respondents did not have access to networks from their homes; of those that did, $28 \%$ accessed TENET. In a follow-up question regarding e-mail addresses, only 39 respondents listed an e-mail address.

\section{C.1.4. Training Needs:}

$69 \%$ of respondents had "zero" or "weak" networking skills. However, respondents were willing to learn, as $90 \%$ listed the type of training or help they would like to receive; ranging from the use of telephone hotlines to extensive training. $79 \%$ of respondents indicated that they thought their schools would pay release time for them to attend training session; and $86 \%$ 
indicated that they thought they would attend a training class that was . provided free of charge on a weekend.

\section{C.1.5. About the Respondents:}

Sixty percent of survey respondents were female; $44 \%$ were between the ages of $40-50$ (92\% between the ages of 30-60). The majority of respondents (90\%), were white; and $50 \%$ taught at the 10th-12th grade levels. $30 \%$ of respondents taught at a 4A school (schools with a student enrollment between 715 and 1,599); $25 \%$ taught at a $5 \mathrm{~A}$ school (schools with a student enrollment greater than 1,600); and 16\% taught at a $3 \mathrm{~A}$ school (schools with a student enrollment between 295 and 714). 


\section{Appendix D "Riding The Internet"}

See attached document 
Appendix E Equipment For Science Education Lending Pool

See attached document 


\section{Appendix F Detailed Descriptions of SSC Assets/Capabilities}

\section{F.1. High Performance Computing and Communications}

The SSC High Performance Computer Center was established for the simulation of SSC physics experiments and the design of the accelerator systems. It provides 12,000 MIPS computing power on a UNIX workstation farm. A total of 120 workstations are organized in groups that are tightly coupled by optical fibers and Ethernet. Several types of stations are used, such as Hewlett Packard 9000/735s, SUN SPARC 10s, and Silicon Graphics SGI 4D/360s. Each station has at least $64 \mathrm{MB}$ RAM and 1 GByte disk. Four SGI Challenge $\mathrm{L}$ file servers provide an additional 160 GBytes disk space. Two Summus STL-2300-12 tape robots are used for archiving.

The center is being used for technical and scientific applications, and is easily accessible via Internet. All computer equipment is housed in secure, air conditioned and fire proof computer rooms.

The workstations in the farm normally run in course grain parallelism and are available for batch and interactive use. Batch queuing is provided using distributed operating systems like NQS. Applications that require fine grain parallelism can run under the Parallel Virtual Machine operating system. The large amount of disk space allows use of advanced distributed databases and information retrieval systems. Due to its modular architecture the system is easily upgradable and expandable. It can be used as test bed for emerging hard and software technologies and new interoperability concepts.

The center has an Intel iP860 Hypercube with 64 tightly connected nodes. It can be used for massively parallel scientific and technical applications in areas of image processing, ray tracing, climatology and hydro-dynamics, etc.

\section{F.2. Information Technology}

The SSC has excellent internal and external communications infrastructure. Extensive capabilities in areas of data processing, networking and multimedia make an ideal facility to develop and exploit the emerging information technologies. 
Each SSC office has at least 4 connections for phone and data. Voice communication relies on AT\&T PBX equipment able to serve 10, 000 connections. Redundant long distance links are available and buildings are connected with TI lines. Pagers are also available and radio links assure contact with mobile crews.

\section{F.2.2.}

Data Network

On-site networking is typically done using Ethernet. Ethernet concentrators are in secure equipment rooms. They are wired by fiber or copper to routers, connected on a fiber backbone. The different buildings are linked using T1 connections. Software for network monitoring and management is installed throughout.

The internal networks connect thousands of PCs, Macintoshes and workstations. Tens of servers are installed throughout the facility and used for name-servers, file servers, databases, compute servers,...centralized plotting, mail distribution, backup and interactive information retrieval.

Wide Area Network connections with regional and national networks are assured by three T1 links. The site is directly connected to the Texas Higher Education network (THEnet) and ESnet, and has access to Internet and Texas Education network (TEnet). Several workstations are set up as servers for the Word Wide Net. The excellent bandwidth of the connections and the availability of powerful servers, ample mass storage and the High Performance Computer Center make the site very attractive for information storage, interactive retrieval, and 'distance learning'.

\section{F.2.3. - Audio-Visual}

The SSC laboratory has extensive experience with video teleconferencing. Several complete systems currently support connections with, for example, the National Laboratories, universities in the US, and sites in Italy and Japan. More primitive, multi-party, global video-conferencing between workstations is now possible using Internet.

Sophisticated video production capabilities include pre-production planning, script writing, professional camera teams, videotaping and post-production editing. They are used for documentation, instruction, information, training, public awareness and educational purposes. 
The SSC has professional still-camera equipment and photo lab equipment . with a throughput of up to 360 prints per hour. High resolution color scanners are used for digitization. Software is installed for digital image treatment. Part of the photographic collection is accessible via Internet.

An integrated publishing system allows for the conversion of various word processing standards and computer assisted translation. Document control systems are accessible via the network. A complete publishing department can handle document preparation and high throughput printing.

\section{F.3. Mechanical shops}

Most of the mechanical shop capabilities are located at the Central Facility. The shops have the personnel and equipment to manufacture hardware and instrumentation for a wide range of applications. Shop capabilities include machining, forming, fabrication, welding and assembly processes and specialized techniques for the production of a wide variety of prototype components, systems and experiments.

CAD/CAM program systems provide the capability to take ideas from concept through drawing directly into the proper machine language for the individual machines with Computer Numerical Control (CNC).

\section{F.3.1. Machining Capabilities}

Most conventional equipment has the ability to attain a tolerance level of $0.025 \mathrm{~mm}(0.001 ")$, while some of the more sophisticated CNC units reach $0.002 \mathrm{~mm}(0.0002 ")$. Most machine tools have the capability of reading in metric or English units.

The shops contain over 150 major pieces of equipment. Machining capabilities include: lathes with working envelopes of 24 " swing and $60^{\text {" }}$ length, fully programmable milling machines, a planer that can handle work pieces of up to 144" length, and a 6" by $18^{\prime \prime}$ grinder which can satisfy exceptional surface finish requirements. In addition, there is a CNC turning/milling center that swings a maximum diameter of 18 ". It has a 16 position automatic tool changing magazine, all tool position are live and can operate in the horizontal or vertical position. Parts of up to 39 " length can be machined. All function are controlled by microprocessor to within 0.001 degree. 
The welding shop capability includes the equipment to perform a complete range of welding procedures and techniques i.e. Gas Tungsten Arc Welding (TIG), Gas Metal Arc Welding (MTG), Shielded Metal Arc Welding (SMAW). The shop fabricates complex structural and tubing configurations in a variety of materials. It also has the capability to perform soldering, brazing and cutting with oxy-acetylene and plasma systems.

TIG machines are used for the complex and delicate welding of thin wall $0.005^{\prime \prime}$ thick stainless steel bellows. Welders are certified to perform vacuum tight and pressure welds to level 3 standards. The scope of the welding capabilities is expanded to provide for the welding of dissimilar materials.

\section{F.3.3. $\quad \therefore$ Quality Control}

Testing and inspection capabilities cover a wide assortment of precision measurements. The QA group has sophisticated equipment, such as: CNC optical comparators, CNC coordinate measuring machines, a dead weight tester, a vacuum gauge calibration system, a super-micrometer and a laser alignment system.

\section{F.4. Cryogenics}

The cryogenics facility is located at the N15 site east from I35. It houses the world's largest cryogenic capability. Three helium refrigerators each provide $4000 \mathrm{~W}$ cooling at $4.5^{\circ} \mathrm{Kelvin}$ and $37 \mathrm{~g} / \mathrm{s}$ liquefaction. A smaller refrigerator cools $500 \mathrm{~W}$ at $4^{\circ} \mathrm{K}$. Large 40,000 liter dewars intrinsically handle sudden, major load upsets.

The facility is designed to provide maximum flexibility and to handle the requirements of multiple large or small-scale loads. Automatic control is implemented to improve system efficiency and quick turnaround. The large cooling power provides a unique opportunity to create a world-class $1.8 \mathrm{~K}$ super-fluid helium facility. It can also be used for testing at intermediate temperatures.

\section{F.5. Magnet Fabrication}

The magnet development and test laboratories at the N15 site are dedicated to the advancement of superconducting devices and the associated manufacturing technologies. They are equipped to design and produce 
superconducting and resistive dipoles and more complex magnets. Magnets . of up to 16 meters in length can be built and tested in-house. The capabilities of staff and facilities have been demonstrated by the successful manufacturing of the world's premier superconducting magnets.

The site has 47,000 square feet of mechanical shops, served by two 25 Ton cranes. The buildings provide a quasi clean room environment for the specialized equipment used for magnet construction, such as fully automated cablers, cable wrappers and wedge wrappers; gantry style coil winders for coils of 2-16 meter length; and curing and collaring presses with up to 300 Tons per foot capacity. A 16 meter long shell welding press allows for fully automated TIG welding.

The magnet laboratories also provide CAD/CAM, factory simulation software, sophisticated general purpose machining equipment and Quality Control inspection. Cryogenic and a warm test stand are used for precision magnetic measurements.

\section{F.6. Electronics}

Ten specialized laboratories at the SSC are equipped for research, development and production of electronics and data acquisition systems. All have excellent connectivity to the network. Some of the shops have special high power provisions, while others are RF shielded for ultra-sensitive measurements. The electronics shops can handle analog and digital design, surface mount, programmable logic, RF and high power.

\section{F.6.1. VLSI design and testing}

Computer Aided Design software is available for design of analog and digital chips. Simulation at chip level is done using HSpice, for analog electronics, and VERILOG, VHDL for digital, behavioral simulation. A 100-channel 100 $\mathrm{MHz}$ pin-by-pin digital chip tester is used for IC verification. Combined with analog digital test \& measurement equipment it can be used for the evaluation of mixed analog/digital designs.

\section{F.6.2. Board level systems}

Electronics capabilities meet a wide range of requirements in the areas of low noise, low power, radiation hardness, digital signal processing, VME, VXI, and system design. Alternative CAD software is available for design, simulation, layout and production of board level systems of varying complexity and functionality. E-size plotters and copiers are available for 
documentation. State-of-the-art programmers are available for PALs, FPGAs, EPROMs and ROM.

Prototype fabrication and small scale production are possible using throughhole mounting and infra-red refold surface mount soldering systems with automated component placement, cleaning and Quality Control. A sheet metal workshop is used for the production of chassis and rack assemblies.

\section{F.6.3. : RF capabilities}

Extensive capability has been developed in the area of Radio Frequency design and testing. A 5300 square feet facility specializes in testing of high power RF equipment. It has a separate 3-phase, $1000 \mathrm{kVA}$ power feeds that provide 16$20 \mathrm{kV}$ DC output power. Low conductivity cooling water is available at more than 1000 gallons/minute.

A second 5000 square feet RF shielded room specializes in low level RF testing. Capability also exists for high precision impedance testing of RF structures.

\section{F.6.4. Test \& Measurement}

All laboratories are well equipped with up-to-date measurement equipment, such as network analyzers, spectrum analyzers, oscilloscopes, sweepers, synthesizers and state analyzers. Extensive capability exists for measurements beyond $1 \mathrm{GHz}$ and in the $430 \mathrm{MHz}$ and $60 \mathrm{MHz}$ ranges. Much of the equipment is computer controlled via GPIB, VME or VXI.

Electronics Quality Assurance is provided by the metrology/calibration laboratory that serves as a standard reference traceable to NIST. The laboratory is designed to perform incoming inspection, periodic calibration and repairs of the electronic equipment used at the SSC.

\section{F.7. Data Acquisition}

Extensive capability and expertise are available in the area of data acquisition, readout and control. Numerous real-time multi-processor systems have been developed, based on VME and VXI. Large setups are normally controlled by UNIX workstations, while agile small scale readout systems are based on Macs or PCs running LabView. Expertise is available with real-time UNIX operating systems like VxWorks and Lynx. 
Specialized evaluation and test equipment exists for network and for high bandwidth connection studies. Experience with measurement, control, readout and digital signal processing allows for the design of small or high bandwidth systems with throughputs of up to $40 \mathrm{~GB} / \mathrm{s}$.

A large pool of commercial modular NIM, CAMAC, GPIB, VME and VXI test and measurement equipment is available to tackle the most difficult control and readout problems. 
Appendix G R\&D Market Survey Results

PLEASE REFER TO ATTACHED DOCUMENT 


\section{Appendix H R\&D Market Survey Information Requests}

In responding to the R\&D Market Survey, the following individuals expressed an interest in being contacted regarding future uses of the SSC assets:

- David Alexander, President, S-Tel Corporation, Mineral Wells, TX

- $\quad$ Ralph G. Beil, Marshall, TX

- Dr. Gregory A. Benesh, Associate Professor of Physics, Baylor University, Waco, TX

- $\quad$ P. R. Brooks, Chemistry Department, Rice University, Houston, TX

- John Gostroot, President, EGC Corporation, Houston, TX

- D. M. Dalton, Sr., President, Dalton Tool Inc., Austin, TX

- $\quad$ Albert L. Ford, Professor of Physics, Texas A\&M University, College Station, TX

- Harold Garner, McDermott Center, University of Texas Southwest Medical Center, Dallas, TX

- Edwin C. Hodges, President, Q-Systems International, Inc., Arlington, TX

- G. W. Hoffmann, Professor of Physics, University of Texas at Austin, Austin, TX

- Michael Isichenko, Research Fellow, Fusion Research Center, University of Texas at Austin, Austin, TX

- Joe Loya, Academic Budget Officer, University of Texas at San Antonio, San Antonio, TX

- $\quad$ George Mallard, Linguistic Products, The Woodlands, TX

- Dr. William H. Marlow, Texas A\&M University, College Station, TX

- Dr. Hans-Jocken Trost, Department of Physics, Texas A\&M University, College Station, TX

- $\quad$ Larry Milligan, Director of Engineering, AVO International, MultiAmp Division, Dallas, $\mathrm{TX}$

- Dr. Chau Nguyen, SBC Consulting, Houston, TX

- Dr. B. Paul Padley, Rice University, Houston, TX

- Mark G. Raizen, Assistant Professor, Department of Physics, University of Texas at Austin, Austin, TX 
- . Dr. A.K. Ray, Professor of Physics, University of Texas at Arlington, Arlington, TX

- Herbert Ruek, Senior Member of Technical Staff, NEC America, Inc., Irving, TX

- Michael Schermer, President, Consulting Partners, Inc., Dallas, TX

- Charles F. Squire, Houston, TX

- Dr. James Stevenson, Concordia Lutheran College, Austin, TX

- Dr. Jon Hamilton, Concordia Lutheran College, Austin, TX

- $\quad$ P. C. Sundt, Metrix Instrument Co., Houston, TX

- Dr. John Taboado, President, Taboada Research Instruments, San Antonio, TX

- Dr. Richard Wigmans, Professor of Physics, Texas Tech University, Lubbock, TX

- $\quad$ B.H. Wildenthal, University of Texas at Dallas, Richardson, TX

- Liqiu Yang, Department of Chemistry, University of Houston, Houston, TX 


\section{Appendix I Electronics Equipment Anticipated to be Available}

To provide electronics services the following equipment is requested to be available:

- $\quad$ SSC-SYS-S033: Electronics Test and Measurement System. Test and measurement equipment and specialized test personnel are often underutilized in academic groups and small businesses. This system allows provision of test services in a cost effective way, while optimizing the use of these SSC assets.

- $\quad$ SSC-SYS-S059: Low level RF (Global) Crate and Modules System. This equipment is well fit to serve as loan equipment.

- $\quad$ SSC-SYS-S067: Metrology/Calibration Laboratory. Only about one third of the equipment in this system is needed to provide a state of the art Metrology and Quality Assurance service to academic users and small businesses. This is another example of a capability that small groups can not afford to set up themselves. JTF can provide such services in a cost effective way while optimizing use of this SSC asset.

- $\quad$ SSC-SYS-S085: Test Beam Tracking R\&D Equipment. This is a fully configured data acquisition, ideal for short term detector tests that are typically done by small academic groups.

- SSC-SYS-S097: Muon R\&D Equipment. This system mainly consists of modular test and measurement equipment typically used in physics research.

- $\quad$ SSC-SYS-S111: Physics Department Electronics R\&D Laboratory. This system provides full capability for electronics prototype production.

- UNIX software licensed to the SSC for Board and Chip design and simulation.

Current replacement value of this equipment is on the order $\$ 2 \mathrm{M}$. 


\section{Appendix J Machine Shop Equipment Anticipated to be Available}

Equipment requested to be transferred from the Central Facility to complete the machine shop capabilities at N15.

\begin{tabular}{|c|c|c|c|}
\hline Item & \multicolumn{2}{|l|}{ Usage } & \multirow{2}{*}{$\begin{array}{l}\text { Comments } \\
\text { TO REPLACE THE BETEN 1/4" } \\
\text { MACHINE NOW MDL. }\end{array}$} \\
\hline $\begin{array}{l}\text { ATLANTIC 1/2" } \\
\text { SHEER }\end{array}$ & METAL CUTTING LARGE & CAPACITY. & \\
\hline ATLANTIC DIES & \multicolumn{3}{|c|}{ SPARE DIES FOR ATLANTIC PRESS } \\
\hline ATLANTIC BRAKE & \multicolumn{3}{|c|}{ BRAKE FOR MATERIAL BENDING } \\
\hline ROTEXPUNCH & \multicolumn{3}{|l|}{ METAL PUNCH } \\
\hline ROTEX PUNCH & \multicolumn{3}{|l|}{ METAL PUNCH } \\
\hline MILLER 350 & \multicolumn{3}{|l|}{ WELDER } \\
\hline MILLER 350 & \multicolumn{3}{|l|}{ WELDER } \\
\hline ULTRA AIR & \multicolumn{3}{|l|}{ FUME COLLECTOR } \\
\hline ULTRA AIR & \multicolumn{3}{|l|}{ FUME COLLECTOR } \\
\hline MILLER 451 & \multicolumn{2}{|l|}{ MIG WELDING } & MEDIUM DUTY MIG WELDER \\
\hline $\begin{array}{l}\text { THERMAL } \\
\text { DYNAMICS CUTTER }\end{array}$ & \multicolumn{3}{|r|}{ MEDIUM DUTY PLASMA CUTTER } \\
\hline $\begin{array}{l}\text { KELLENNBURER } \\
\text { GRINDER }\end{array}$ & \multicolumn{2}{|l|}{ ĠRINDER } & ID-OD GRINDER \\
\hline BRIDGEPORT - & \multicolumn{2}{|l|}{ MILLING MACHINE } & SERIES I MILLING MACHINE \\
\hline BRIDGEPORT : & \multicolumn{2}{|l|}{ MILLING MACHINE } & SERIES I MILLING MACHINE \\
\hline BRIDGEPORT & \multicolumn{2}{|l|}{ MILLING MACHINE } & $\begin{array}{l}\text { SERIES II VERTICAL MILLING } \\
\text { MACHINE WITH CNC }\end{array}$ \\
\hline & \multicolumn{2}{|l|}{ SANDBLASTER } & GLASS BEAD SANDBLASTER \\
\hline - & \multicolumn{3}{|l|}{ TUBING CUTTER } \\
\hline MAZAK & \multicolumn{2}{|l|}{ MILLING MACHINE } & 5-AXIS MAZAK MILL WITH CNC \\
\hline ROBOFILL 6000 & \multicolumn{2}{|l|}{ WIRE CUTTING } & $\begin{array}{l}\text { CNC WIRE CUTTER TO CUT METAL } \\
\text { LAMINATIONS }\end{array}$ \\
\hline MILLER 200 & \multirow{2}{*}{\multicolumn{2}{|c|}{$\begin{array}{l}\text { WELDER } \\
\text { WELDÉR }\end{array}$}} & PORTABLE WELDERS \\
\hline MILLER 300 & & & PORTABLE WELDERS \\
\hline & \multicolumn{3}{|l|}{ SPOT WELDER } \\
\hline & \multicolumn{2}{|l|}{ ROD OVENS } & $\begin{array}{l}\text { TO REMOVE MOISTURE FROM } \\
\text { WELDING RODS }\end{array}$ \\
\hline & \multicolumn{2}{|l|}{ POSITIONER } & USED FOR HOLDING WORK PIECES \\
\hline LEBLOND 15" & \multicolumn{2}{|l|}{ LATHE } & $\begin{array}{l}\text { LATHE WITH LARGE CENTER HOLE } \\
\text { CLEARANCE }\end{array}$ \\
\hline STOCK & \multicolumn{2}{|l|}{ WIRE AND ROD STOCK } & $\begin{array}{l}\text { CONSUMABLE WELDING ROD AND } \\
\text { WELDING WIRE STOCK }\end{array}$ \\
\hline OPTICAL & \multicolumn{2}{|l|}{ OPTICAL COMPARATOR } & FOR INSPECTION \\
\hline ALCATEL & \multicolumn{2}{|l|}{ LEAK CHECKER } & VACUUM LEAK CHECKING \\
\hline ALCATEL & \multicolumn{2}{|l|}{ LEAK CHECKER } & VACUUM LEAK CHECKING \\
\hline CECOR & \multicolumn{3}{|l|}{ OIL CLEANER } \\
\hline
\end{tabular}




\title{
Appendix K R\&D Infrastructure Workshop Agenda
}

\author{
TEXAS JOINT FACILITY PROJECT \\ R\&D INFRASTRUCTURE SUPPORT WORKSHOP
}

Tuesday, August 30, 1994

Auditorium, SSC Central Facility

AGENDA

1:00 p.m.

WELCOME \& REVIEW OF SSC SETTLEMENT PROCESS

Dr. Peter Rosen, Dean of Science, UT Arlington

1:20 p.m.

OVERVIEW OF JOINT FACILITY STUDY (UTA/SMU)

FYI on activities included in proposal

-market research progress

Dr. Vigdor Teplitz, Physics Dept. Head, SMU

1:30 p.m. OPPORTUNITIES FOR COLLABORATION/OTHER STUDIES

-Regional Medical Technology Ctr.

Ben Prichard

--Applied SuperConductivity \& Cryogenics Ctr.

G.T. Mulholland

-Manufacturing Technology Deployment Ctr.

Mike Huddleston, TEEX

-Inland Regional Industrial Technology Ctr.

Phil Gray, Waco TSTC

-Southwest Ctr. for Computing, Information \& Learning

Dave Gurd, TNRLC

2:00 p.m.

TOUR OF FACILITIES 
3:00 p.m.

WORKSHOP BREAKOUT SESSIONS

A- Auditorium

Mike Lockerd, VP at TI

How do we determine what specialized equipment and expertise (not available at home institutions) are necessary at such a common research facility?

B- Lapostolle Room Jheroen Dorenbosch, SSC

What potential price levels would stimulate sustainable usage? How do other shared use facilities generate revenue?

C. Meson Room Jane Armstrong

How do we assess the availability/demand for trained technicians to support R\&D at universities? to support on-site technical programs? corporate R\&D labs?

4:00 p.m.

SESSION REPORTS/FEEDBACK \& DISCUSSION

Auditorium

4:30 p.m.

PRIORITIES \& OPPORTUNITIES

Auditorium

evolution of action plan 


\title{
Appendix L HARC-C: Image Compression Software
}

\author{
A breakthrough in Compression Performance and Quality \\ Non confidential Summary
}

\section{L.1. The challenge}

A new industry is emerging to provide Information-on Demand. This information consists of customized news, weather, sports, and entertainment programming, as well as educational, financial, medical and employment services, Information-on Demand requires the rapid search, sort, storage, transfer and display of information. The delivery of large amounts of timecritical information drives the continuing demand for automated digital processes and for compression software appropriate for image, text, sound and motion. This arena defines the Houston Advanced Research Center (HARC) Information Technologies Initiative.

\section{L.2. The current situation}

While text files can be compressed to a high level and yet comply with quality standards, picture files often suffer from such compression methods. A number of solutions to image compression are currently implemented with impressive results, but require a hardware implementation. The remarkable thing about HARC-C is that it matches or exceeds these impressive results but in software.

\section{L.3. HARC-C Compression}

HARC is enabling the "information highway" through its timely research in wavelet image compression -- a technique that permits very large compression ratios while maintaining excellent image quality standards. The new software have the effect of increasing picture traffic on the information highway.

The compressed images reduce the bandwidth requirements for interactive use of both still and motion pictures. The Houston Advanced Research Center is ready to release its new compression software under the name of HARC-C. Our digital future will be filled with pictures as well as with text because of HARC-C. 
HARC-C Compression:

- exceeds JPEG and MPEG (II) standards in both performance and quality for both still and motion pictures.

- achieves a minimum ratio of 30:1 in still image without visible artifacts or visible loss.

- exceeds MPEG standards in video compression on an R3000 processor with 24 bit, real-time expansion at a rate of 30 frames per second (frame compression at 10:1).

- $\quad$ achieves 100:1 compression ratios for black and white (no gray scale) images with minimum loss.

Areas to benefit significantly from HARC-C software include

- image archives for cultural, educational, scientific, medical, financial and military applications

- image transmission, interactive communications, publishing and "ondemand" programming.

- image capture, scanning, duplication and synthetic image generation. 


\section{App.M PowerKids' Power OS}

Power OS is the operating system developed to manage and control several learning CPUs. Power OS includes bar code log on technology, curriculum control and maintenance, systems networking, participant time and advancement monitoring.

Power OS was developed by and is the property of VerCom Systems, Inc. Designed to allow the use of off the shelf educational software as well as specially developed and integrated software, Power OS is the operations shell in which other programs will be allowed to run. This will allow teachers to control and monitor curriculums for each child on an individual basis regardless of the computer on which the child is working.

Power OS collects data on each session as a child uses the computer. This information includes how long the child was on the computer, the software used by the child, the time spent using each software, and the number of levels advanced in particular programs.

Power OS logon technology is based on bar code readers. Each student receives a bar code sticker which can be placed on a notebook, etc. When the child is ready to log on they will run a bar code reader over their bar code. Thus, the computer will recognize who is logging on and will bring up a personal information screen, containing a picture of the child, other personal information and a personal mail information box.

From this personal information screen, students are able to enter into the mail mode to send or read mail, or to enter their individualized curriculum/software availability screen. The curriculum screen indicates what levels the student has completed in each software program available, as well as what new areas or software are available to the child. From the curriculum screen each student is able to self direct his/her personal area of study during a session. 
App. N Letter of Support from Globe Project

See attached document 


\section{Riding the Internet Schoolbus: Places to Visit and Things to Do}

\section{Hooked up}

to the Internet?

Not sure what

to do next?

Here's a sampling

of activities,

projects, and

resource hot-

spots to get you in gear

\section{APPENDIX D}




\section{By Odvard Egil Dyrli}

$\mathbf{T}$ here is so much for students and teachers to do educationally through the Internet-the giant telecommunications "network of networks" linking computers in every continent-that giving introductory travel instructions is like trying to summarize vast libraries on a single index card. Newspapers, magazines, and television networks now devote continuing attention to the Internet and its educational benefits, and schools everywhere are scrambling to get access anyway they can-through colleges and universities, state computer-education networks, regional service providers, and commercial service resellers. (For an introduction to the Internet and what it means to schools, see "The Internet: Bringing Global Resources to the Classroom," Technology \& Learning, October, 1993.) The U.S. federal government and a growing number of states are making commitments to getting all $\mathrm{K}-12$ schools online, but many educators may be asking themselves, "What do we do once we get there?" What follows is a sampling of educationally valuable Internet sites, all verified, plus everything you need to know to get there and to navigate once you've arrived.

\section{Levels of Internet Service}

How much you will be able to take advantage of the tools and resources offered by the Internet depends on the level of service that you have. All Internet connections offer basic electronic mail-e-mail-service directly, or through a "gateway" from a commercial network such as America OnLine, CompuServe, eWorld, or Prodigy. More advanced service consists of TELNET, whereby you can log in from your computer to use a computer at a remote location in the world; and FTP ("file transfer protocol"), through which you can bring copies of electronic resources back to your home machine.

If you can TELNET and FTP, you will also be able to use search and browsing tools such as Archie, Gopher,
Veronica, WAIS, and WWW. These allow you to search vast resource networks, or be more directed in your browsing. However. in order to use these tools easily, and to use the new interactive hypermedia tools such as Mosaic, a powerful information gathering application that uses HyperCardlike buttons to link you to worldwide sites within a single document, you need special service that links your computer directly to the Internet (see sidebar on levels of connection).

\section{What You Can Do \\ Through E-Mail}

Tremendous educational benefit can be gained simply by using e-mail to reach around the world. This is by far the most common use of the Internet, and all you need, once you have e-mail access to the Internet. is the identification name and e-mail address of the person or group you wish to contact (for example, this writer is DYRLI@UCONNVM.UCONN.EDU). The following are examples of activities that you and your students can do. These are starting points, and the addresses given will put you in touch with specific projects, or with people who can help you organize your own.

Write to the White House: The President and the Vice-President have several e-mail boxes. as do a growing number of members of Congress. Although the volume of mail received at the White House requires "automatic" initial replies, the response is immediate and includes ways for you to get more information and electronic publications. The addresses PRESIDENT@WHITEHOUSE.GOV and VICE-PRESIDENT@ WHITEHOUSE.GOV will get your e-
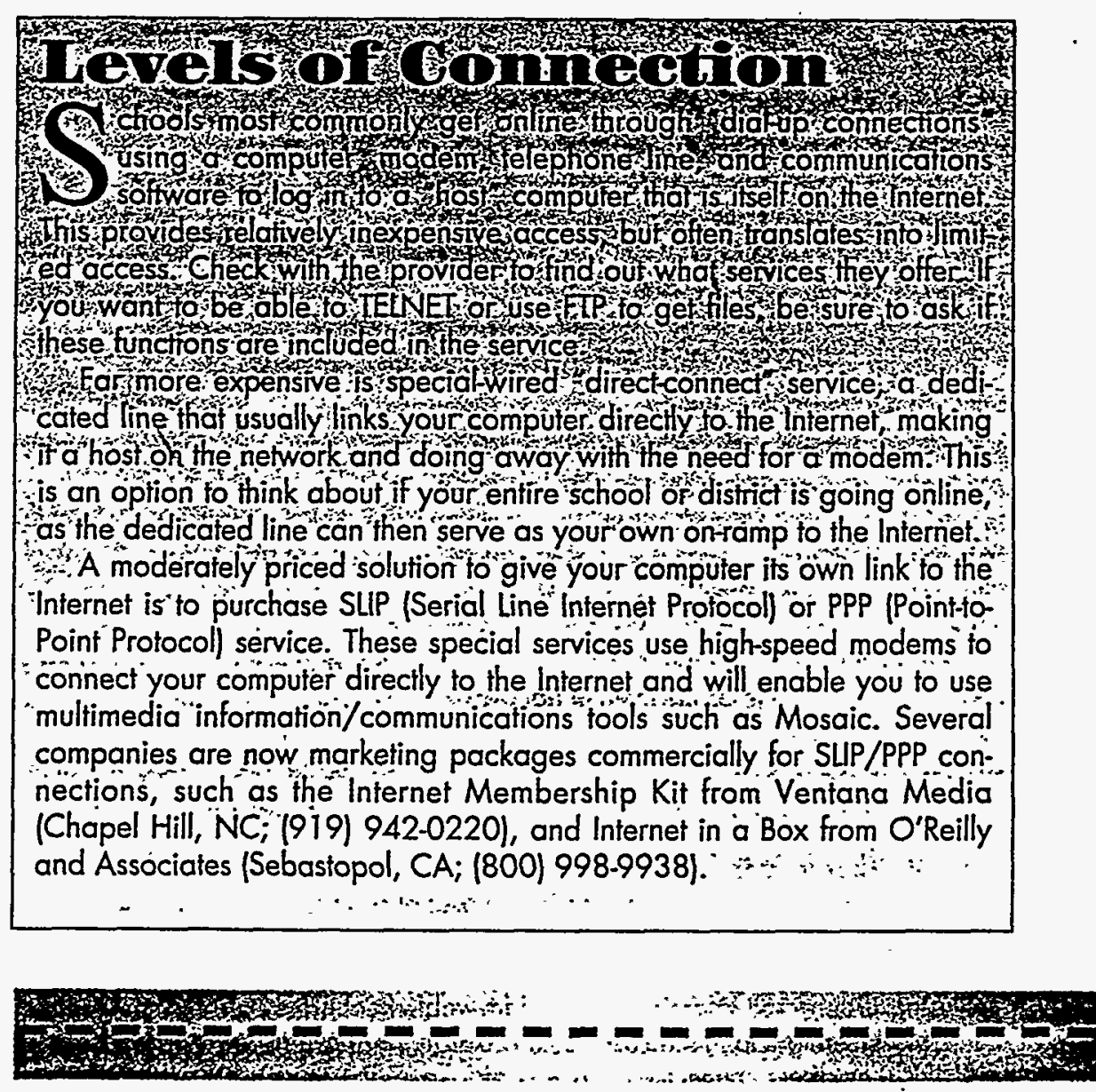
mail delivered.

\section{Exchange Keypal Messages:}

Keypals - the electronic version of penpals-can be teacher-to-teacher, student-to-student, or class-to-class. Exchanging keypal messages provides students with outstanding opportunities for writing in real contexts, and is an effective way to learn firsthand about other communities and countries. For example. Joan Clifford and Laura Peterson in Reading, MA, use the Internet to let their eighth-grade French I students hone new language skills and exchange cultural information with peers at the Lycée Romain Rolland in Clichy, France. Similarly, Nancy
Moorhead's special education students at the Homer Drive Elementary School in Beaumont. TX, developed their map skills and learned about Asian culture by exchanging e-mail with a class in Hong Kong. In fact, KIDLINK is a global keypal network for students age 10-15. To join. send e-mail to LISTSERV@VMI.NODAK.EDU (see subscription instructions in the Discussion Group portion of this article).

\section{Work With Electronic Mentors:} Electronic mentors are subject matter experts who volunteer to work closely with classes or individuals online, typically on a particular project. Judi Harris, Director of the Electronic

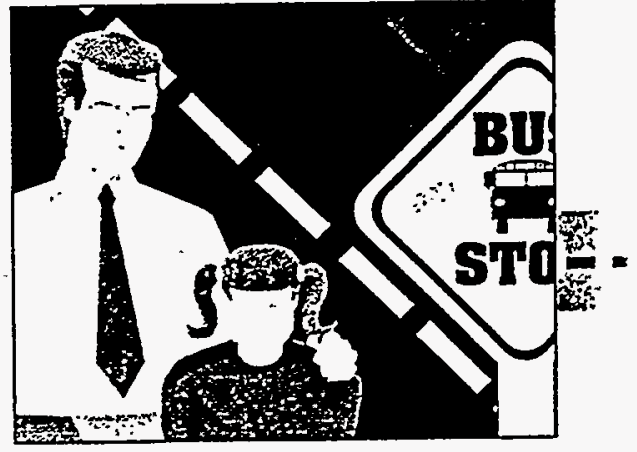

Emissary Project at the University of Texas, has matched numerous $\mathrm{K}-12$ classes with mentors throughout the United States, to help with student research in disciplines such as Constitutional law, ancient Greek liter-

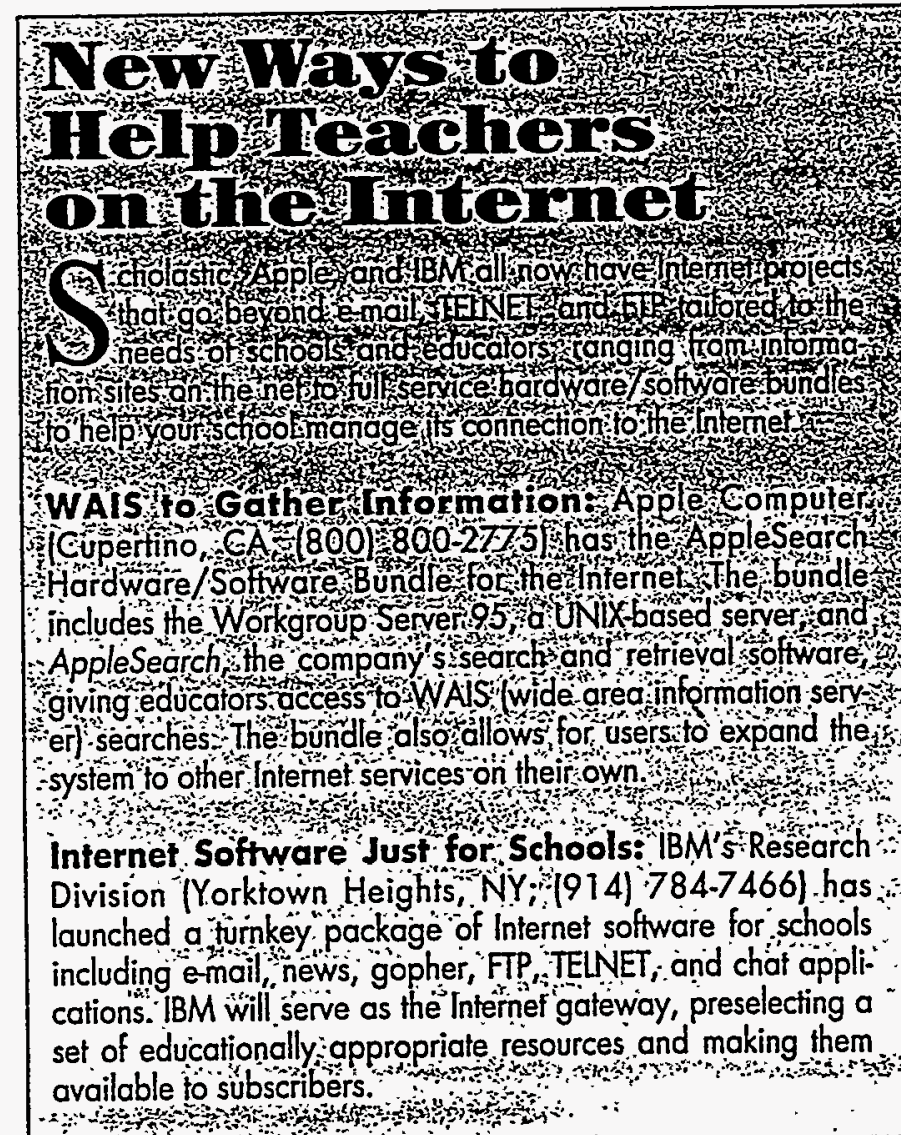

Lesson Planning Resources and More: Need a crosscurriculum lesson plan built around science themes? Want some ideas for ways to make the most of seasonal activities? One place to look is Scholastic Network's (New York, NY; (212) 343-6898) Scholastic Internet Center, available on the net using Gopher or WWW (world wide web). Reach the center by entering hitp://scholastic.com: 2005 if you have a SLIP, PPP, or direct connection and Mosaic. To reach them -through Gopher,-set gopher.to scholastic.com. and change the

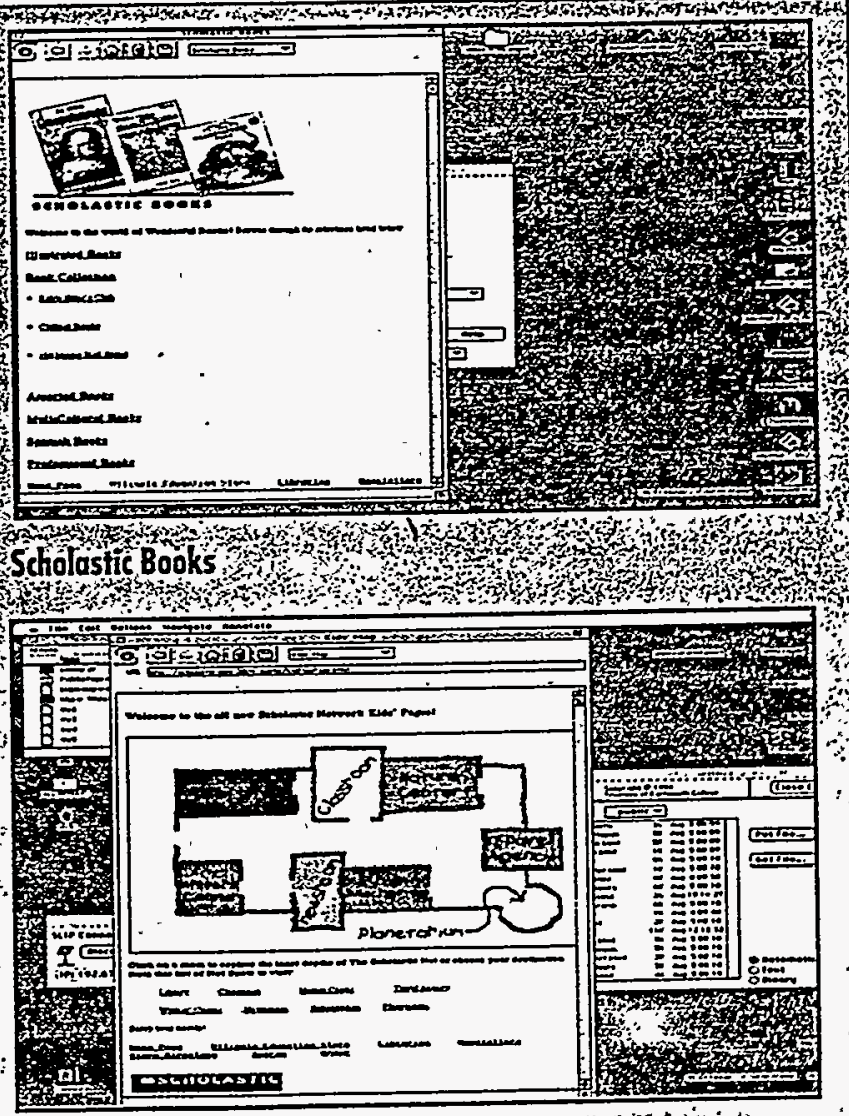

Kids' Page ép

PORT to 2003 or

Scholastic is also working on making its Scholastic Network available through the Internet, with new features like "Internet Field Trips." Each month resources related to a theme such as space exploration will be grouped logether, establishing an easy "pathwoy" for teachers to get relevant. information quickly. 
ature, and life support in space. E-mail Harris at JBHARRIS@TENET.EDU for more information.

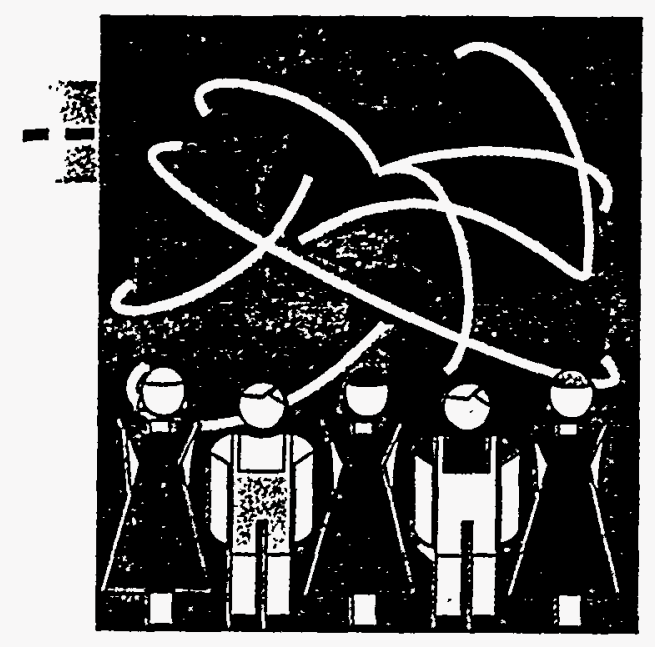

Work on Cooperative Projects: One of the most valuable uses of Internet telecommunications is for students to work collaboratively on projects with other students in distant locations, perhaps contributing information to a centralized database. For example, Nina Hansen's class at the Timothy Edwards School in South Windsor, CT, got fascinating results from their Save the Beaches project, in which over 500 surdents in the United States, Brazil, Canada, Costa Rica, Denmark, and Portugal analyzed local beach litter. For information about this project, contact Nina Hansen (AHANSEN@ UHAVAX.HARTFORD.EDU).

\section{Go on Electronic Expeditions:} Participating electronically in actual events as they take place is an exciting way for students to experience tive unknown vicariously. Recent projects in which students received periodic Internet reports-and exchanged messages-include the Iditarod dog sled race in Alaska, a four-person bike journey in Africa, a multi-national trek across the Arctic Ocean, and an expedition to the Antarctic. Where on the Globe Is Roger?, a project currently underway, follows the adventure trip of a retired Marine Corps pilot traveling by truck from South America to Southeast Asia. For information, contact the Global SchoolNet Foundation
(WHERE_IS_ROGER@BONITA. CERF.FRED.ORG).

\section{Communicate Across Age}

Groups: Telecommunications is a unique vehicle for multi-age projects that benefit both older and younger students. An example is the Ask a Young Scientist program. in which Kurt Grosshans's advanced-placement students from Christiansburg High School in Christiansburg, VA, research and answer science questions for elementary school students and teachers. Elementary school teachers can send email to APSCICHS@RADFORD. VAK12ED.EDU with up to five questions per single message. Similar projects include older students responding to "Dear Santa" letters from primary students, and Big Brother/Big Sister email contacts with younger children with disabilities.

Do Research Online: The Internet has put new research tools into the hands of students and teachers, even

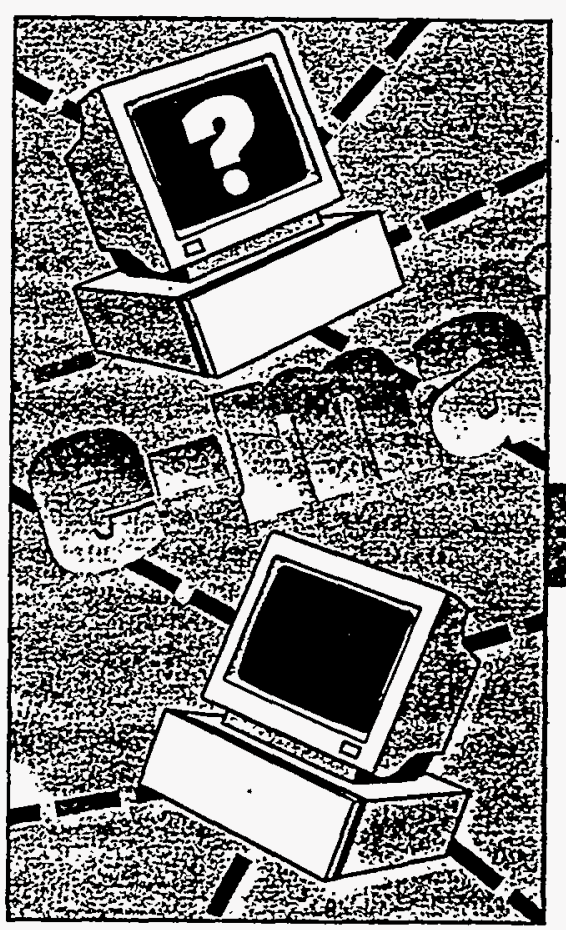

through e-mail. For example, the

AskERIC project is an Internet-based question-answering service for educators that searches resources from the 16 national ERIC (Educational Resource Information Center) Clearinghouses. and delivers an array of information relevant to questions asked. To try it out, send your question to ASKERIC@ ERICIR.SYR.EDU and expect a reply within 48 working hours.

Publish Electronically: Thanks to e-mail, special project reports done by students, teachers. and professional associations can be made available easily to a national and even international online audience. There are a number of messages sent to discussion groups that generously offer to share such resources. For example, if you would like an e-mail copy of the "Telecommunications: Ideas. Activities, Resources" booklet for teachers, send a request to Dr. Ann E. Barron of the University of South Florida (BARRONA@MAIL. FIRN.EDU).

\section{Get Copies of Documents:}

Although most electronic documents, such as articles, guides, and information lists, are obtained through FTP or TELNET tools, many locations will also allow you to request specific documents by e-mail. As an example, try sending e-mail to the Merit Network Information Center in Michigan at the address NIC-INFO@NIC.MERIT. EDU (leave the "name" and "subject" lines blank) and simply write the oneword message HELP in order to receive introductory telecommunications information. 
services, ask questions, propose online projects, seek keypals, and become part of cooperative programs for teachers and students-and all of this goes on as an extended form of e-mail.

Groups range from the scholarly to the recreational to even the frivolous, and joining is usually free. List members receive all of the electronic mail. that anyone sends to the group, and you can simply read messages, "lurking" as it's called, until you decide to respond to either a person or the entire list. (Warning: Do not use an automatic message response key unless you want everyone in the discussion group to read your message.) For example, Lynnette Braunhardt's seventh-grade students in the Mansfield Middle School in Mansfield, CT, discovered the power of discussion groups when one student posted a question on St. Francis of Assisi to a Medieval History group, and three British professors responded, giving the student detailed information for a report.

Listed below are three valuable general interest discussion groups recommended for teachers. All three are "moderated," which means that messages are reviewed before they are distributed (un-moderated groups let messages go through automatically). Each of these group addresses a variety of issues relevant to educators, and most people find that by joining one or two of the groups, they have more than enough information to keep them upto-date.

KIDSPHERE at the University of Pittsburgh tends toward discussion of elementary education (joining address: KIDSPHERE-REQUEST@VMS.CIS. PITT.EDU).

\section{EDTECH at Michigan State}

University often has more of a secondary education focus (joining address: LISTSERV@MSU.EDU).

EDNET at the University of Massachusetts covers topics of interest to all educators (joining address: LISTSERV@NIC.UMASS.EDU).
To join, leave the Name: and Subject: parts of your e-mail blank, and send the following message, inserting the group name and your own name (the e-mail program will send your electronic address): SUBSCRIBE group-name your-name, (e.g., SUB-
SCRIBE EDTECH ODVARD EGIL

DYRLI). Subscription requests for the last two groups are handled by a common list management program called "Listserv," which fulfills requests such as subscribing or unsubscribing without human intervention, so instructions

\section{A F $\mathrm{S}$} ew Worcs on Tavgationand uscape ure, it's great cruising the net, looking of the wonderful bits and bytes of information. Butjir's easy to overextend yourself and feel lost even as you sit in your ówn home or classsoom. Here are some tips for a-smoother ride... When you to tave oround the world using you computer and TELNET occasionally you will gef into a jom where you ore left with blank screen, and entering the usual question mark forthelp doesn'tend up heforng at all if this hap

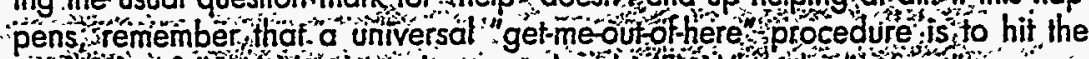
escape key followed by the tight square bracket lols Whenthe promptoppears,

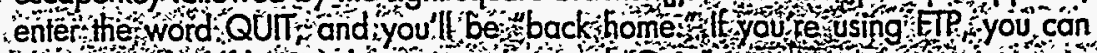
exticate yourself by simply'entering the word "Quit ow It Speking of IP the sites discussed in this article are socalled anonymous

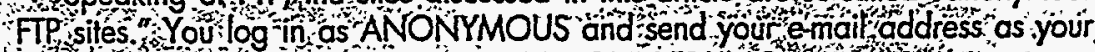

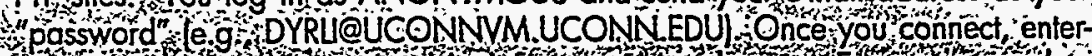

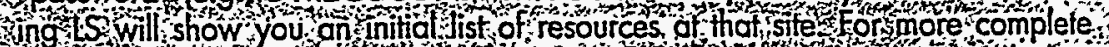

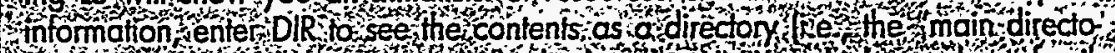

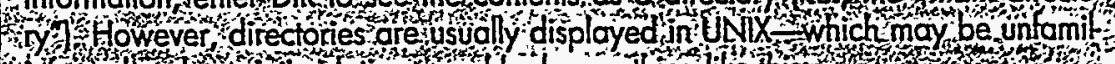

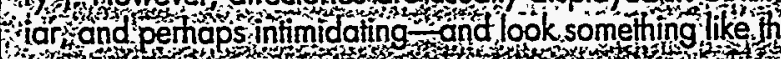

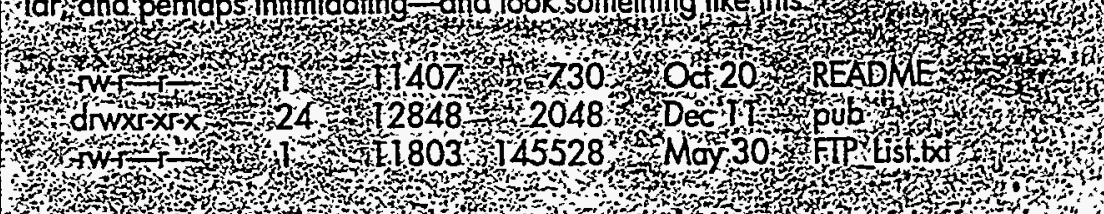

When you see such a directory, all you need to know is that if the first charater of eoc ch line is a letter, then the file tite at the far night is a directory loub is a

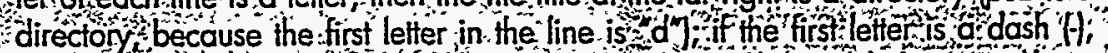
then the title at the for right is probably a file The numbers in the center column llef of the datel describe the size of the file in bytes a good woy to determine if you have room for it on your machine, $\therefore$ To change to any listed sub-directory (look at the public directory pub first), enter $C D$ and the directory's name; e.g.; CD PUB isthen you can enter $L$ or:DIR again to see its confents. You can do the same thing to continue traveling farther down into sub-directories, or go back up by entering CD followed by a space and two dots (CD ..). If you get lost among the directories but don't want simply to quit, use $C D$ / to return to the directory where you begond s. When you find a text file that you, want the file name has either the extension of text or txt or no extensionl, you can bring a copy back to your host machine. To get o copy of the file, enter the name exactly as it appears in the directory - upper case, lower case, dots and dashes-followed by what you want to name the file when it arrives: For example, to get the file above listing FTP sites around the world, you could enter: GET FTP List.txi myitp text (which means "bring the FTP list.txt file to my computer, and give, it the name myttp.text"). Notice that when using GET, the words in the file name must be joined with dols, as they are here.

Since you cannot read oxt file before transferring it to your computer, you may first want to get any README files in a directory, which are usually guides to the contents (also helpful are FAQ files- "frequently asked quejstions"). Once a file has been transferred you can read it using yoür word processor, edit it, and make printed copies as you wish. 
must be written in a way that the program can interpret. In contrast, the Kidsphere subscription requests are read by real people, so you can be less formal (e.g., "Please add my name to the Kidsphere list, and thanks a lot!").

When you get notice that. you have been added to a list-anywhere from within minutes to several days lateryou will receive information describing how the group operates. Save these instructions-either on disk and/or printed out on hardcopy so you will know, for example, how to get off the list during vacation breaks and other useful information. You may well find yourself receiving scores of messages each day, so try to process your mail daily, making copies of what you want and deleting the rest.

\section{TELNETing}

\section{to Remote Computers}

If you have a connection that offers TELNET service, you and your students will be able to log-in to computers around the world that offer such access. To do so, you simply enter TELNET and the address (e.g., TELNET NEWTON.DEP.ANL.GOV). When you "arrive" at a site, you will usually be presented with menus directing you to places to visit. The following are some examples of TELNET sites that teachers and students will find particularly valuable.

\section{Argonne National Laboratory in Illinois runs a special NEWTON bul- letin board for teachers and students. Of special interest is the Ask a} Scientist service, where users can leave questions and get answers back from scientists at the laboratory. To take part, TELNET NEWTON.DEP.ANL. GOV (and log in as BBS).

Cleveland Freenet is the flagship of the user-friendly "freenet" electronic information systems supported by the National Public Telecommunications Network (NPTN). Academy One, found in the Schoolhouse (the site is set up as "buildings" in a community) houses a variety of educational resources, including online projects in

\section{Vis-Ed Educational Software}

Vis-Ed's software materials are offered in a number of titles for high school and college level academics. These materials stem from our educational flash card sets that we have produced for over $\mathbf{4 0}$ years!

Each software application contains a variety of learning methods (tutor. quiz. lesh, game) and multimedia features (text, hypertext. color graphics. animated messages, audia and more) and is available on $3 \psi_{2}^{\circ}$ or $54_{4}^{\circ}$ disks.

Alditional software sets will continue to be released by Vis-Ed including various titles in math. science, medicine, social studies. SAT preps husiness. more foreign languages, and others.

For information contact: Visual Education Association 581 W. Leffel Lane

P.O. Box 1666

Springfield, OH $\$ 5501$

Call $1-800-243-7070$ or

FAX 513-324-5697

Vis:-

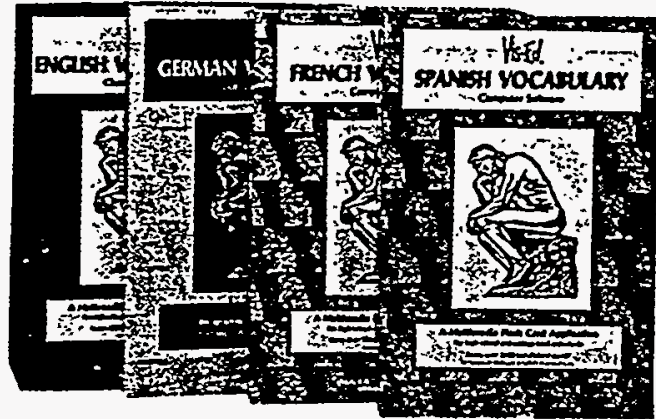

CIRCLE 67 ON FREE INFORMATION CARD
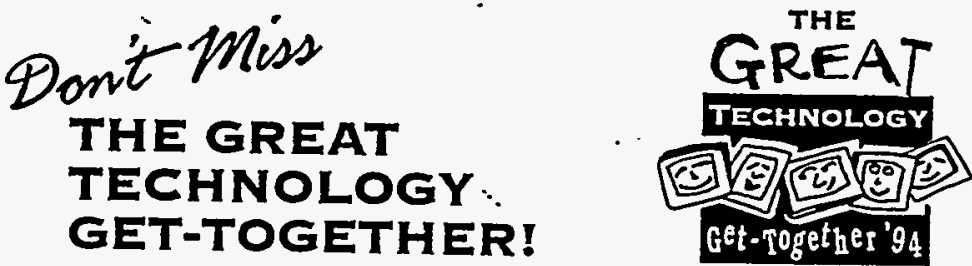

THE GREAT TECHNOLOGY GET-TOGETHER 1994 brings the future of educational technology to you. Discover innovative new ways to integrate technology into kids' lives. Be inspired by educational technology leaders and colleagues. Explore the exhibit hall and talk to technology experts.

\section{THE GREAT TECHNOLOGY GET-TOGETHER features:}

- over 25 inNovative pre-conference workshops

- more than 100 inspirational general sessions

- the latest SOFTWARE AND HARDWARE available for schools

Spotight sessions will feature industry leaders, such as Therese Mageau and Karen Peterson. Hear them discuss the trends influencing the future of educational technology in schools.

CALL 612/638-8780 TO REGISTER for the iniovative pre-conference workshops and the informative general sessions. Hurry! Space is limited. Don't miss this TECHNOLOGY GET-TOGETHER. It's going to be GREAT!

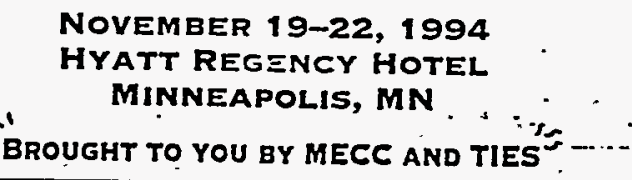




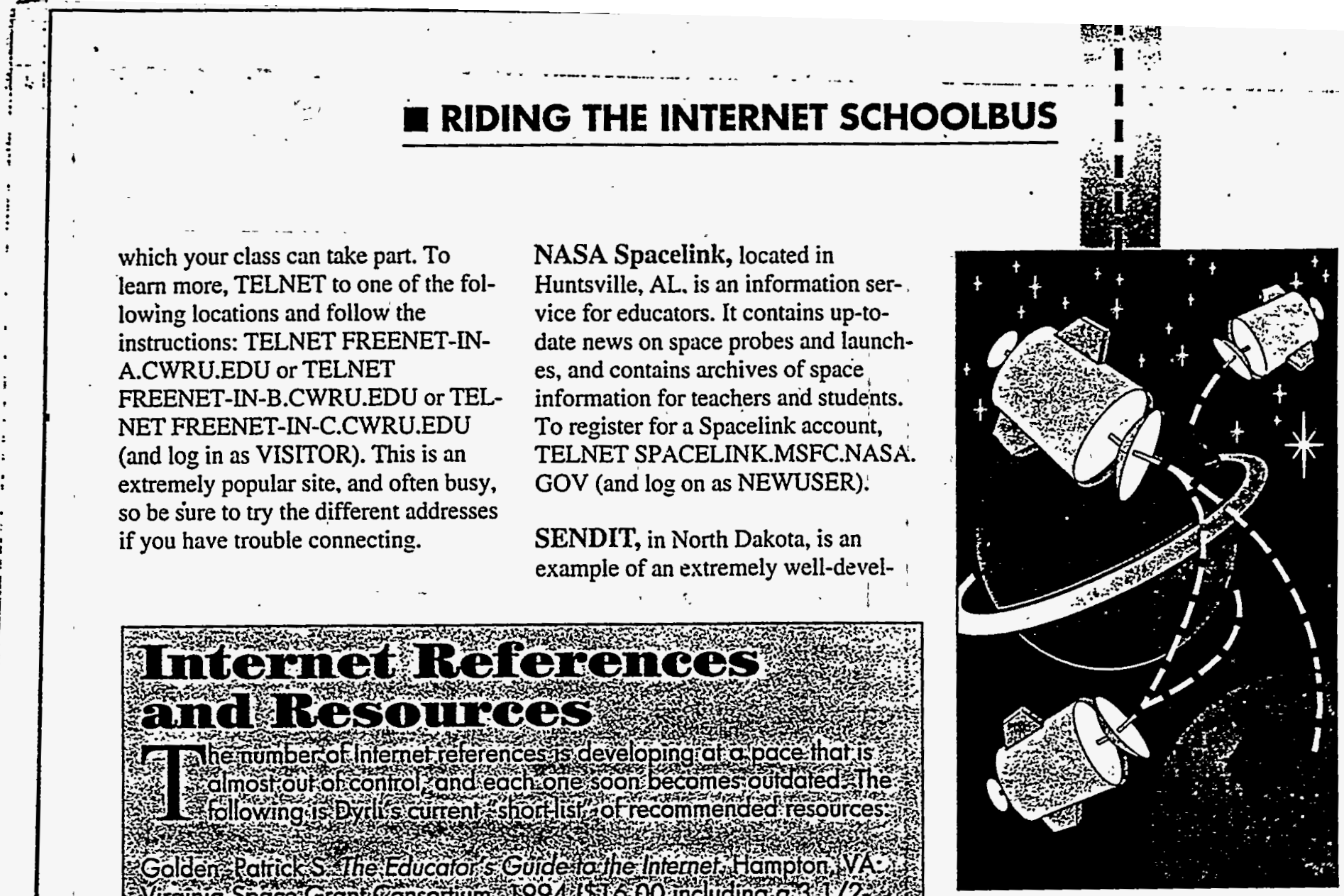

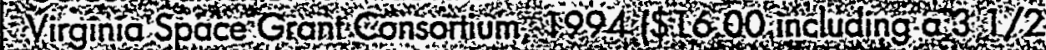

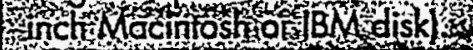

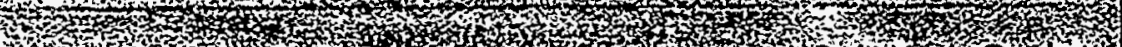

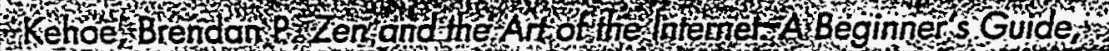

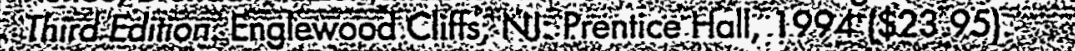

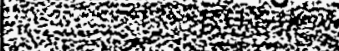

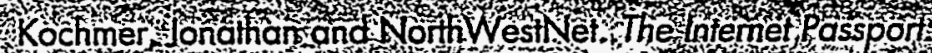

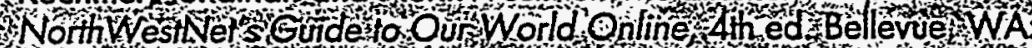

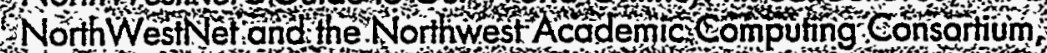

Inc $1993(\$ 29 ; 25)^{3}$

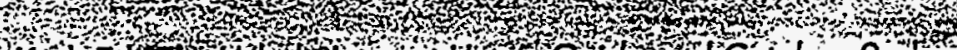

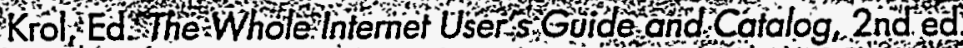

Sebastopol GA GO'Reilly and Associates 1994 (\$24.95)

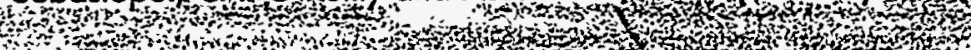

LaQuey, Tracy, with Jeanne C Ryder The Tnternet Companion: $A$

Beginner's Guide to Global Networking Reading $M A$-Addison-

Wesley, T993 1 12.951. $\therefore$ - $\quad \therefore$.

Tennant, Roy, et al Crossing the internet Threshold: An Instructional

Handbook, 2nd ed. Berkeley, CA Library Solutions Press, 1994

(\$45.001.

Other recommended resources: NASA has an 11 -minute video for presentations outlining the benefits of the Internet for schools. Global Quest: The Internet in the Classroom costs $\$ 18.50$-handling and shipping included-from NASA CORE; Lorain Eounty Joint Vocational School, 15181 Route 58 South, Oberlin, $\mathrm{OH} 44074$; (216) 774-105i, ext. 293. The tape can be duplicated for free at any NASA Teacher Resource Center.

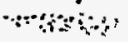

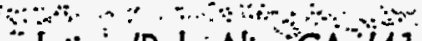$$
\therefore \rightarrow
$$

The Computer Learning Foundation (Palo Alto, $\mathrm{CA}$; (415) 327-3347)

has a wide range of books on the Internet worth looking into, many

geared toward educators.

oped state network devoted specifically to $\mathrm{K}-12$ education telecommunications. It makes available a host of valuable resources for teachers and students, such as the K12NET USENET newsgroups, that your local service provider might not offer.'Educators from any state can connect with SENDIT when they TELNET SENDIT.NODAK.EDU ( $\log$ in as BBS and use the password SENDIT2ME).

University of Massachusetts/Amherst K-12 Information System, developed to advance $\mathrm{K}-12$ education in Massachusetts schools, offers a wealth of teacher resources. Through it, you can access other Internet services and read postings, or messages, from USENET newsgroups. To try. it out, TELNET K12.UCS.UMASS.EDU (and $\log$ in as GUEST).

Weather Underground at the University of Michigan is an extremely popular TELNET destination for checking up-to-date weather reports and forecasts for major cities throughout the United States. To get there, TELNET MADLAB.SPRL.UMICH. EDU 3000 (be sure to include the required 3000 "port number"). 


\section{Bringing Worldwide \\ Resources to Your \\ Classroom With FTP}

FTP is an advanced service (if you can TELNET, you can probably FTP) that lets you log on to "FTP sites" around the world, search through the available resources-including reports, articles, magazines, photographs, film clips, and software-and bring copies back to your computer electronically. For the purposes of this article we will discuss transferring text only.

The following are examples of useful resources for K-12 teachers that you can get from popular FTP sites. To use the service, simply enter FTP and the address (e.g. FTP

CSD4.CSD.UWM.EDU). Be aware that the letters FTP are part of some of the addresses. You will also find hundreds of additional files at each of these sites that you may wish to take a look at as well, since part of the fun is in the discoveries you make. Getting any README files can be a great time saver.

The "Yanoff List" is a comprehensive guide to FTP, TELNET, and Gopher sites around the world. Compiled and updated by Scott Yanoff, the list is available at many FTP locations. One to try is FTP CSD4.CSD.UWM.EDU and look for the file inet.services.txt in the pub subdirectory.

The "December Guide," written by John December, is one of the best guides to information sources and services on the Internet, including online publications and recommended FTP sites. FTP FTP.RPI.EDU and get the file internet-cmc in the sub-directory pub/communications.

The "Teacher Contacts" Files contain introductory messages from $\mathrm{K}$ 12 teachers who have Internet access, and are therefore useful directories for finding keypals. The alphabetized files are compiled and updated by Sally Laughon (LAUGHON@VTVMI.CC.

$\therefore \quad$ VT.EDU), and are being revised as the

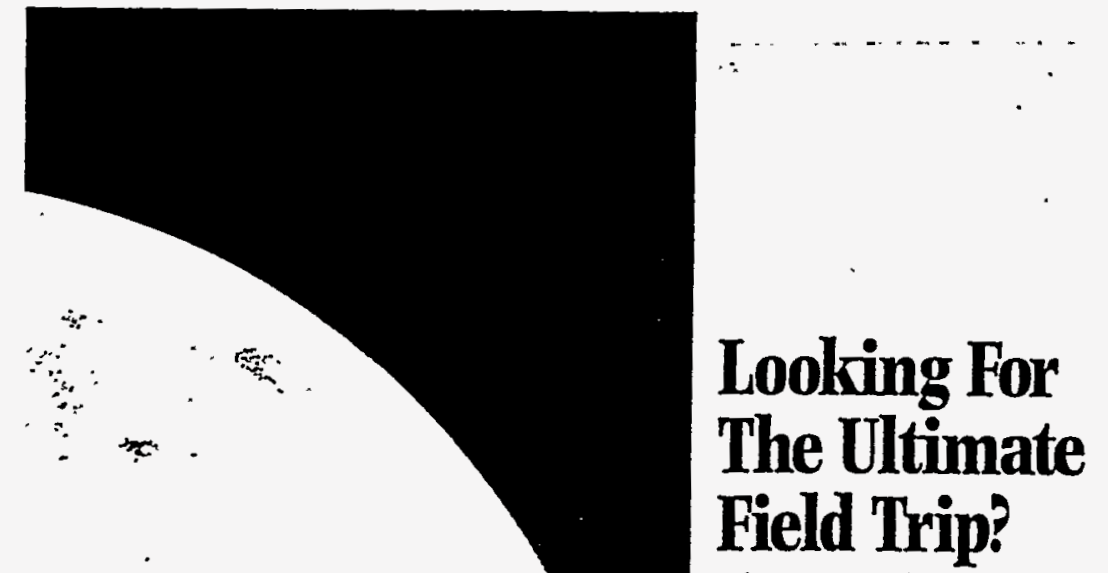

It begins in Littleton, Colorado with a $31 / 2$ day training program at the J.C. Sparkman Center for Educational Technolog: With the knowledge and skills to tap into the information superhighway, limitless possibilities unfold. (Imagine taking fourth graders on a free video tour through outer space, or introducing your Spanish class to a high school in Guadalajara via cable.)

1995 Teacher Grants All expense paid grants are available to teachers in schools within most $\mathrm{TCl}$ service areas for this remarkable training program as a result of donations raised through $\mathrm{TCl}$ " "Electronic Field Trip" promotion. Contact your school district for details. And begin the ultimate field trip yourself.

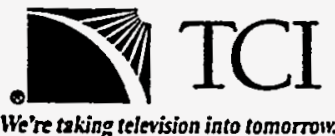

We're taking television into tomorrow.

J. G. SPARKHAH geHtER FOR EDUGATIONAL TEGHHOLOGY

CRCIE 38 ON FREE INFORMATION CARD
Get your own for just $\$ 14$ (eight big issues).

\section{Call now.. $1 \cdot 800 \cdot 543 \cdot 4383$}

CIRCIE 82 ON FREE INFORMATION CARD

TECHNOLOGY O' LEARNING OCTOBER 199439 


\section{RIDING THE INTERNET SCHOOLBUS}

"People Contacts Database." FTP

FTP.VT.EDU and look in the $p u b / k 12$ sub-directory for the files with teacher.contacts in the name.

The Merit Network Information Center (NIC) Files contain a selection of Internet guides and references, including online versions of popular books like Internet Basics, Zen and the Art of the Internet, and There's Gold in Them Thar Nenvorks. FTP

NIC.MERIT.EDU and start by getting the "readme" file named

"INDEX.introducing.the.internet" in the introducing.the.internet sub-direc-

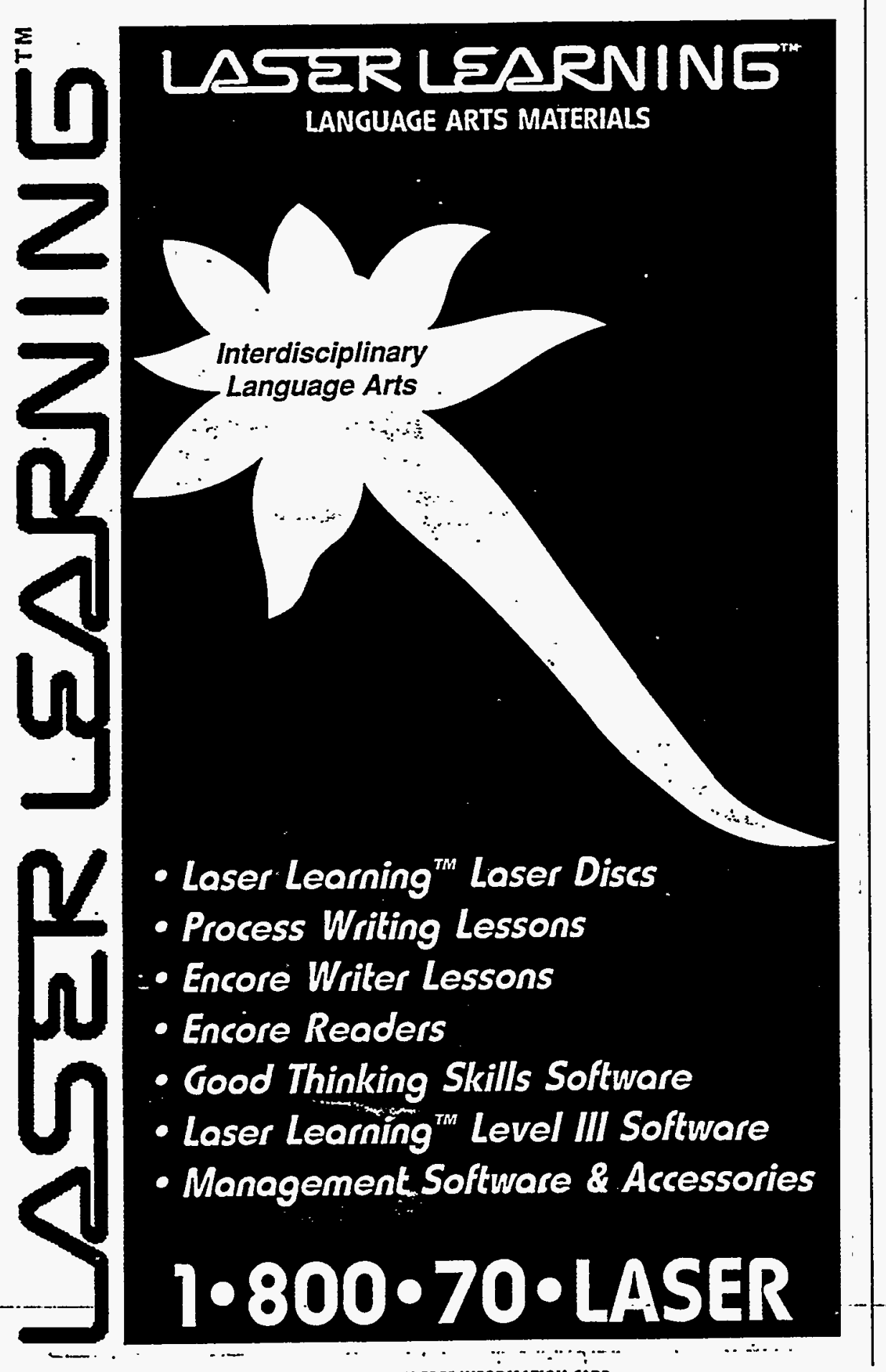

tory. Also look for lists of discussion groups at this site.

\section{EDNET Educator's Guide to}

E-Mail Lists is a useful guide for educators at all levels-K-12 up through the university - that simplifies the job of finding education-related $e$ mail lists. FTP NIC.UMASS.EDU and look in the publednet sub-directory for the educatrs.lst file name.

The National Center for Technology Planning (NCTP) Files at Mississippi State University are listed in a directory of technology plans from school systems nationwide, as well as related documents that may be helpful for local planning efforts. FTP RA.MSSTATE.EDU and look in the pub/archives/nctp sub-directory.

The "SURAnet Guide to Selected Internet Resources" is an Internet user's guide that covers network navigation tools and information resources in major fields of study. FTP

FTP.SURA.NET and look in the subdirectory pub/nic for the infoguide.<month $>-<$ year $>$ files.

The "Internet Resource Directory (IRD)" Files are valuable resources with lists of FTP sites, discussion groups, and TELNET sites of interest to K-12 educators. FTP VIRGINIA. EDU and look in the pub/IRD directory for the IRD files.

The Internet as we know it today is a worldwide grass-roots collaboration that exemplifies a spirit of cooperation among thousands of volunteers who freely share their talents, time, and resources. People can now communicate easily with others anywhere on the globe, and share personally in news as it happens. It's time to get your schoolbus onto the Internet and show your students the world.

Odvard Egil Dyrli, a contributing editor of Technology \& Learning, is Professor Emeritus of Education at The University of Connecticut, and CoDirector of the Technology \& Learning Professional Development Institute. 


\section{APPENDIXE}

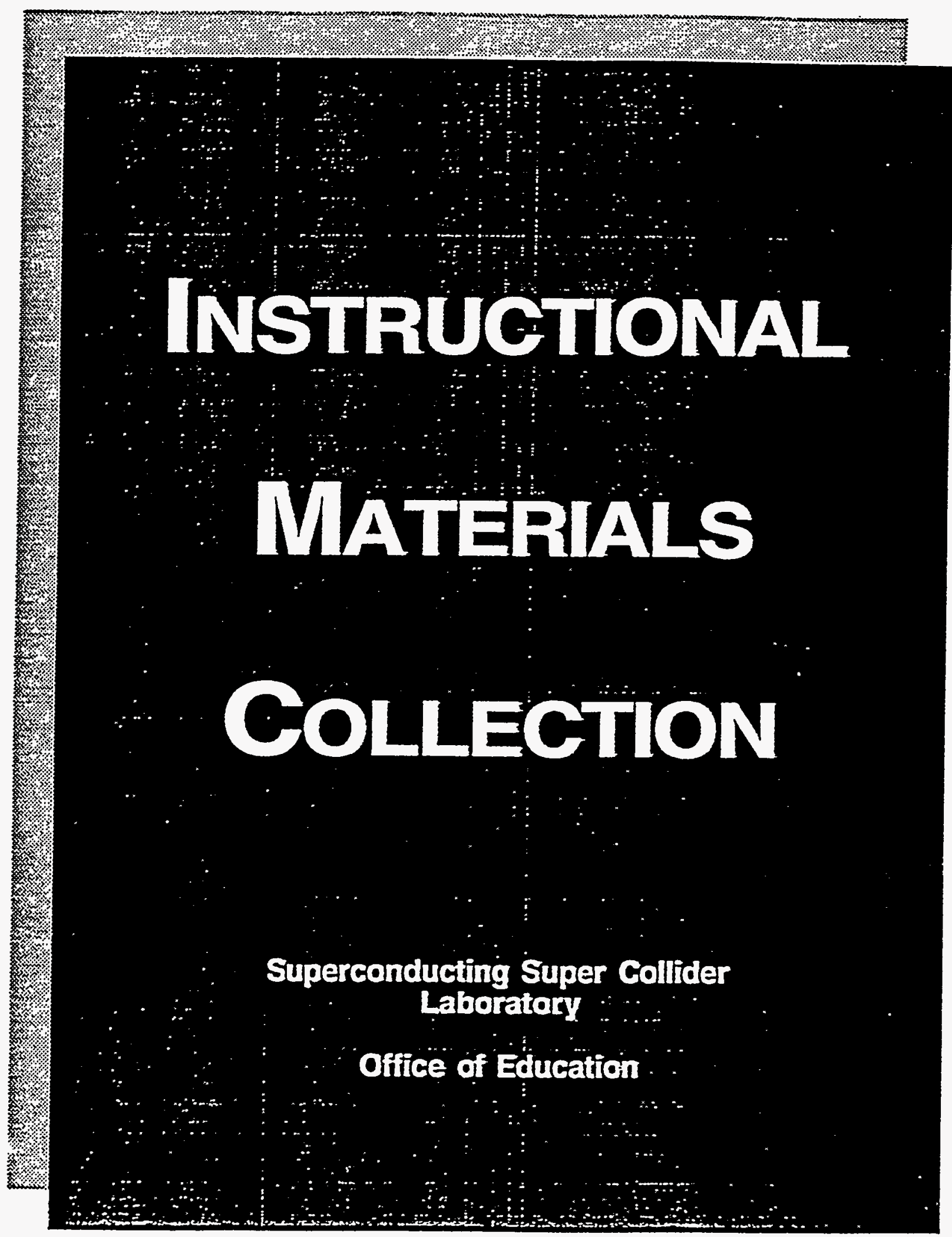

F:sised $7 / 8 / 93$ 


\section{INSTRUCTIONAL MATERIALS COLLECTION}

Air Track and Gliders

Alnico Block Magnets

Bicycle Wheel Gyroscope

Blackboard Mechanics System Set

Celestron Ultima \& Schmidt Cassegrain Telescope

Capsela Scientific Motorized Gearing System

Chaos Demonstration Package

Decimeter Metric System Game

Demonstration Motor and Generator

Dewar

Digital CCD Imaging Camera

Digital Multimeter

Discharge Electrode

Dual Trace Oscilloscope

Electric Circuit Kit

Electromagnetic Demonstration Apparatus

Electronic Circuits and Electromagnetism Kit

Electrostatic Generator

Elementary Science Kit

ELF Meter

Faraday's Electromagnetic Induction

Floating Magnet Demọnstration

Galvanometer and DC Volt-Ammeter

Gauss/Tesla Meter, Hand-Held Digital

General Purpose Oscilloscope

Hi-Strength Magnetizer with Keeper Set

Holography Kit, Sandhox (Metrologic)

How Strong is a Magnet?
Intermediate Science Equipment Kit

Large Cloud Chamber, Diffusion

Laser, Helium/Neon (Metrologic)

Laser Lissajous Figure Apparatus

Levitation Demonstration Kit

Magnet Model, Projection Type

Magnetic Earth Model

Magnetic Effect of Current

Metre Stick Optical Bench, with Accessories

Millikan Apparatus

Newtonian Demonstrator

Parabolic Collision Apparatus

Pith Ball Electroscope

Portable Demonstration/Fume Hood

Potential-Kinetic Energy Tracks

Power Supply

Power Supply, DC, Dual Station

Random Molecular Motion Demo Kit

Resistivity/Persistent Current Lab Kit--Model 1000

Ripple Tank/ Wave Generator

Rotating Stool

Scattering Apparatus

Sine/Square Wave Generator

Speed of Light Laser Video Kit

Student Laser $0.8 \mathrm{~mW}$ Modulated

Student Laser, $0.8^{\prime} \mathrm{mW}$ Unmodulated

Student Laser $2.0 \mathrm{~mW}$ Unmodulated

Suburian Vacuun l'ump 


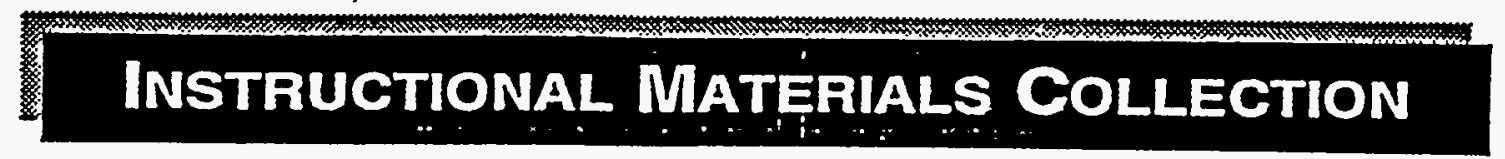

The Physics of Toys Demonstration Set

Three-Dimensional Magnetic Field Model

TS-24 Registered Software License

TS-24 Student Workbooks, The Hands-On Universe

TS-24 Viewgraph Presentation Kit 


\section{INSTRUCTIONAL MATEAIALS COLLECTION}

\section{Item Name \\ Quantity \\ Supplier \\ Description}

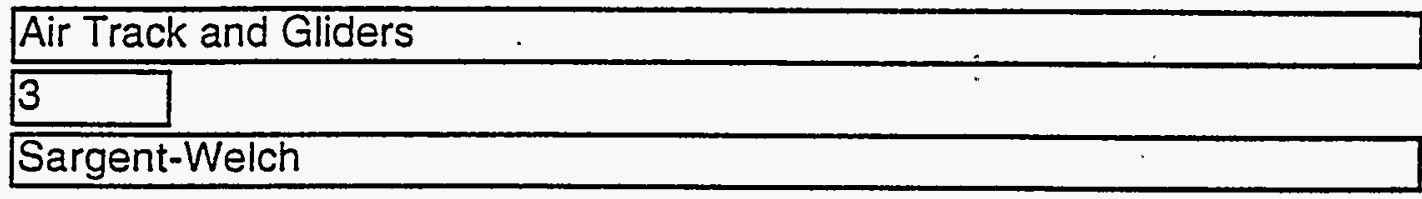

Provides the ideal medium for studying the motion and collision of bodies and the conservation of momentum. Friction is essentially nonexistent and all motion is confined to just one dimension making analysis quite simple. In addition it can be made gently concave for studies of periodic motion. The track comes complete with an illustrated student manual.

\section{Item Name \\ Quantity \\ Supplier \\ Description}

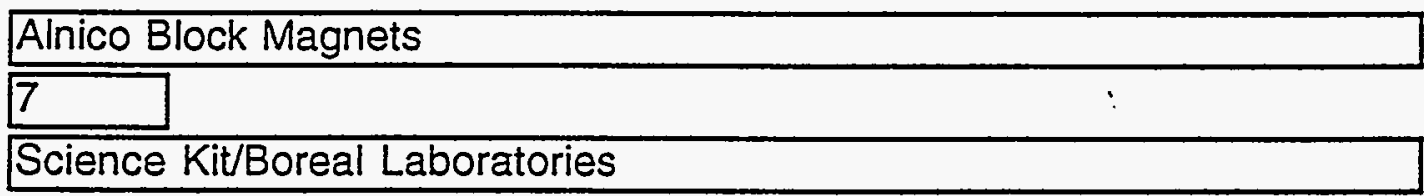

Two Alnico magnets having extremely high strength for their size. 


\section{INSTHUCTIOTIAL MATHRIALS COLLECTION}

\section{Item Name \\ Quantity \\ Supplier}

Description

Item Name

Quantity

Supplier

Description

Bicycle Wheel Gyroscope

2

Science Kit \& Boreal Laboratories

Enlist your more muscular students in using out Bicycle Wheel Gyroscope; they are often convinced they can "muscle" where it doesn't want to go. To their surprise, it will usually "muscle" them.

To make it, we start with a large diameter 26" steel bicycle wheel running on ball bearings. On it we mount a heavy solid rubber tire to guarantee a large moment of inertia in the wheel. To each end of the axle, we fasten a handle with an eye at the end. The mass distribution is such that one push of the hand provides enough spin to the wheel to display all the properties of gyroscope. Once spinning, the entire wheel can be suspended by one end of the horizontal axle. Let a student sit on a freely rotating stool and watch them try moving the wheel. Ask a student to hold the spinning wheel and rapidly walk around the corner. Students will be surprised by the results but impressed by the consistency. The Bicycle Wheel Gyroscope coupled with the Rotating Stool can give students experience in rotational mechanics.

\section{Blackboard Mechanics System Set}

2

Pasco Scientific

A Blackboard Mechanics system can enliven your lectures with easy to setup, informative mechanics demonstrations. Your lecture diagrams become actual demonstrations of physical principles. You no longer just draw a lever, pulley, or inclined plane, then tell your students what the forces would be. Instead you put the lever, the pulley, or the inclined plane right on the board, hang the weights, attach the scale, and let the students see the results. And since your experimental,surface is the blackboard, you can write explanations right next to the setup, so you loose none of the descriptive advantages of a diagram. Using Blackboard Mechanics is almost faster than drawing, and so much more impressive. 


\section{INSTRUCTIONAL MATEMIALS COLLECTION}

\section{Item Name \\ Quantity \\ Supplier}

Description

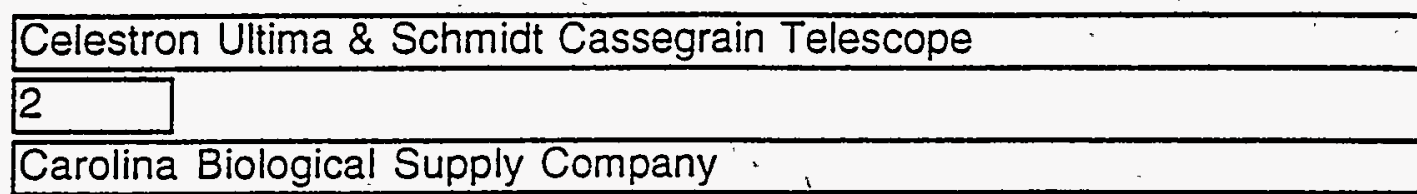

Unsurpassed optical excellence with an 8" aperture and a focal length of $2032 \mathrm{~mm}(\mathrm{f} / 10)$. The swing-through fork mount has slow motion controls and 7.54" diameter Byers worm gear drive. The mirrors are Starbright coated for the brightness images of any available $8^{\prime \prime}$ telescope. The cordless, quartz electronic drive system eliminates the need for separate power requirements. Comes with sealed rechargeable lead acid batteries good for 500 charges (recharge from AC or DC current): large RA ( $\left.8.75^{\prime \prime}\right)$ and DEC (d.13") circles; $8 \times 50$ finderscope with polar alignment reticle for straight through or right-angle viewing; $30-\mathrm{mm}$ Plossl eyepiece (68, 1.25"); $7-\mathrm{mm}$ orthoscopic eyepiece (290X, 1.25"), multicoated prism star diagonal (1.25"); heavy duty wedge with latitude scale; deluxe latitude adjuster; bubble level; accessory tray; and adjustable metal tripod with $2^{n}$ diameter, rubber coated legs, includes deluxe foam-fitted carrying case.

\section{Item Name \\ Quantity \\ Supplier}

Description
Capsela Scientific Motorized Gearing System 2

Carolina Biological Supply Company

The 25 lesson, illustrated Teacher's Manual contains easy-to-follow teachers notes, overviews, and student handout masters to help children solve the mystery of how and why things work. It provides a hands-on, minds-on learning experience in a format that children find challenging and fun. They simply snap together the interchangeable parts to build innovative land-and-water-working 'models like a vacuum cleaner that cleans a hydrojet car, a geared down cruising submarine; a chain-driven mini cycle, a revolving tower and more (over 140 in all). The physical science 'concepts of force, work, energy, momentum; machines, electricity, and fluids become simplified as the children observe the principles in action. Lessons can be taught independently or grouped. One kit per class is recommended. Accepted by the National Science Teachers Association. 


\section{INSTRUCTIONAL MATERIALS COLLECTION}

\section{Item Name \\ Quantity \\ Supplier \\ Description}

Chaos Demonstration Package

2

Science Kit/Boreal Lab

Is it possible that patterns may exist in seemingly random events such as weather systems and modeling population biology? Now you can easily explore these questions by plotting patterns in seemingly random behavior with this comprehensive package. Developed by Dr. Kriebel, a widely published and respected authority on the applications of Chaos Theory, the Chaos Demonstration Package brings this new and exciting concept to life for your students. Using the precision waterwheel system, our exclusive Chaos Demonstration Package offers you a simple way to demonstrate Chaos Theory using materials designed specifically for grades 9 and up. All the background material required for you to become an expert in this field is provided. . The package includes: a color videotape and video manuscript that covers the concept of chaos and chaotic systems; and a computer laboratory program (both IBM and Apple versions) that demonstrates and allows you to plot your own data for several standard chaotic functions (Lorenz attractor, Rossler attractor and Innictir funntinnl Samnlo data and a manulal with antivitioc and

\section{Item Name \\ Quantity \\ Supplier}

Description

\section{Decimeter Metric System Game}

\section{3}

Science Kit/Boreal Lab

Decimeter teaches the commonly used units of the system with questions involving everyday shopping situations. It also gives practice in simple math. Players move around a colorful board which presents and reinforces the concepts. There are separate decks of question cards which allow beginning and advanced players to participate together. Included are a game board, dice, 60 centimeter cubes, question cards and chance cards for both beginning and advanced players, instructions, and an answer key. For two to six players, middle school and junior high. 


\section{INSTRUGTIONAL MATERIALS COLLEGTION}

\section{Item Name \\ Quantity \\ Supplier}

Description

\section{Demonstration Motor and Generator}

3

Science Kit/Boreal Lab

Effective classroom demonstrations of electromagnetism, polarity of coils, the right-hand rule, dynamos, and series-connected and shuntwound motors are at hand with this extra large $(42 \times 15 \times 34 \mathrm{~cm}$ high) model. Students easily see the relative positions of the armature, large magnets, commutator, brushes, and terminals. Two coils are painted red and two are painted green to help students distinguish magnetic poles. Add a galvanometer and students understand how a dc generator operates. Made of heavy steel on a cast metal base for years of durable service.' With instructions. Note: Requires a $6 \mathrm{~V}$ battery or power supply for operation.

\section{Item Name \\ Quantity \\ Supplier}

Description

\section{Dewar}

5

Cryofab

Ideal for short-term storage and handling of liquid nitrogen, argon or oxygen: The vessels have a long flexible spout to facilitate pouring and to increase thermal efficiency. All containers are equipped with aluminum dust cap with vent hole. They are portable and easy to handle. 


\section{INSTHUCTIONAL MATERIALS CÖLLECTION}

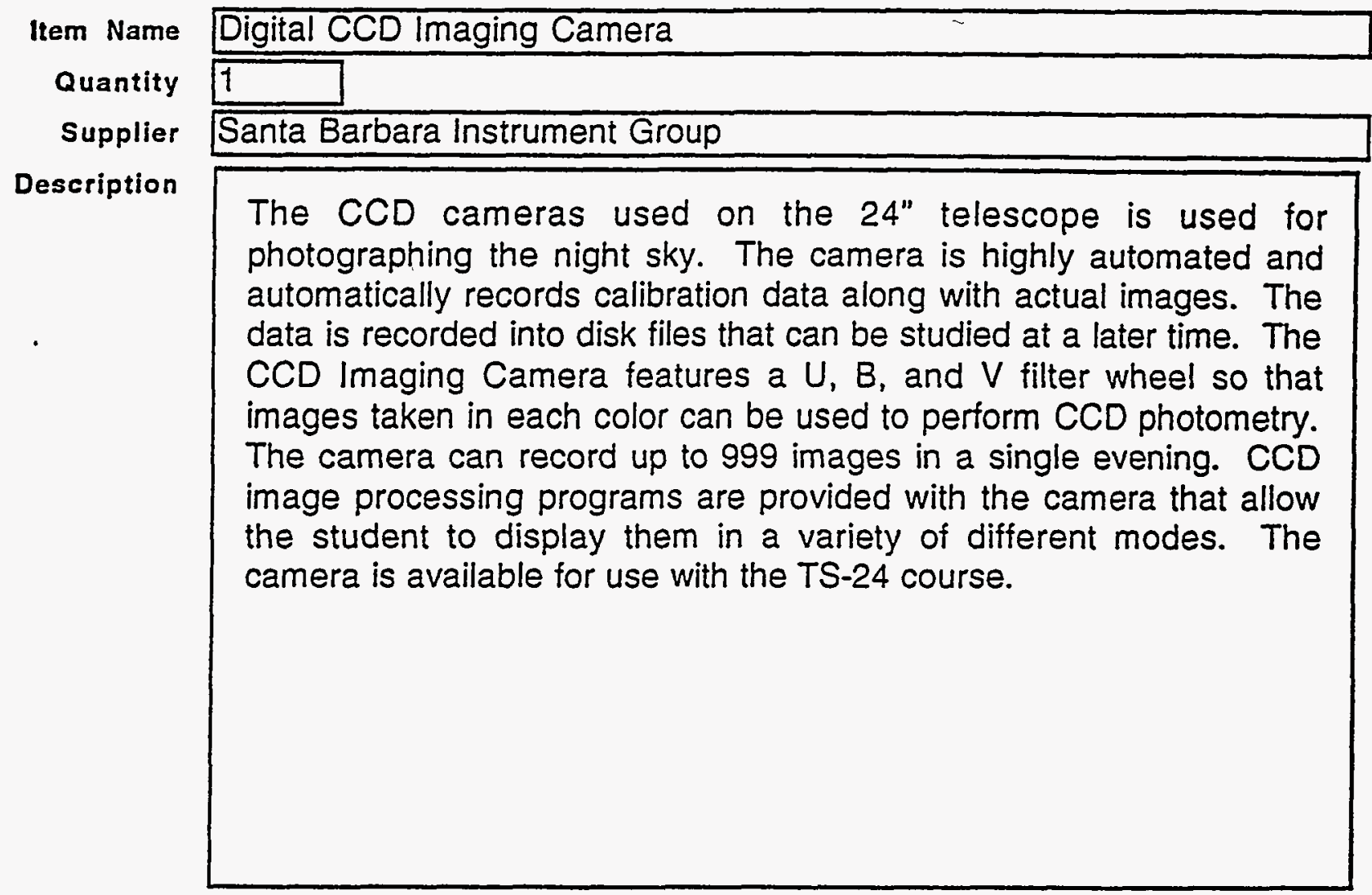

$\begin{aligned} & \text { Item Name } \text { Digital Multimeter } \\ & \text { Quantity } 4 \\ & \text { Supplier Sargent-Welch }\end{aligned}$

Description

You can measure just about anything with this new digital multimeter. It offers a grand total of 28 ranges in 9 different functions and all for a surprisingly low price. Values being measured are displayed by the 3-1/2 digit LCD in 1/2" high numerals along with both the function and units. In addition any one reading can be held in display after removing the probes. The unit is fully overload protected up 1000 VDC and fused for anything in excess. In addition the unit is equipped with a tilt stand for convenience and two 1-meter long probes with fully sheathed clips for high voltages. The multimeter comes with a $9 \mathrm{~V}$ battery, a thermocouple with a 30" cable for temperature, and complete instructions. It operates for 200 hours on an alkaline battery and gives a "Lo Bat" indication when less than $20 \%$ useful life remains. 


\section{INSTRUCTIÖNAL MATERIALS CÓLLECTION}

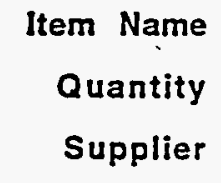

Description

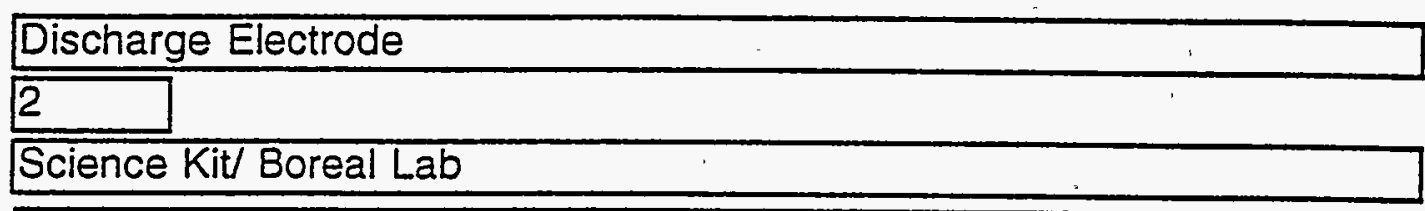

Easily and safely discharges an electrostatic generator. A polished aluminum sphere, $10.5 \mathrm{~cm}$ in diameter, is mounted on a $40 \mathrm{~cm}$ insulated lucite rod. A flexible wire lead has a banana plug at one end and a clip on the other for attaching to the base of the generator. The Discharge Electrode is to be used with the Electrostatic Generator (Van de Graaff).

\section{Item Name \\ Quantity \\ Supplier \\ Description}

\section{Dual Trace Oscilloscope}

5

Goldstar-Science Kit/Boreal Lab

A flexible sensitive $20 \mathrm{MHz}$ dual trace oscilloscope. It is compact, lightweight, simple to use, and well suited for high school and.college laboratory applications. It features single or dual channel operation, $x-y$ mode, and $z$-axis. The CRT screen is glare-free pale blue with an internally lit $8 \times 10$ red graticule. The graticule's overall dimensions are $76 \times 95 \mathrm{~mm}$. The scope comes with two 10:1 and 1:1 switchable probes and a complete operating manual. 


\section{INSTHUCOTIONAL MATERIALS COLLECTION}

\section{Item Name \\ Quantity \\ Supplier \\ Description}

Electric Circuit Kit

1

Sargent-Welch

Practical circuit-building experience is achieved quickly, conveniently, and with complete safety by the beginner who uses this set. It teaches how to construct common series and parallel circuits and clearly shows the correspondence between schematic circuit diagrams and actual working circuits. Nonhazardous low voltage (6.3 volts $A C$ ) power is provided by a step-down transformer operated from line voltage.

A sturdy pegboard panel with rubber feet serves as the base on which circuits are to be constructed. An assortment of 24 connecting wires with clips at each end is provided. A box of five fuses and instructions for carrying out six basic exercises are included.

\section{Item Name \\ Quantity}

Supplier

Description
Electromagnetic Demonstration Apparatus

2

Sargent-Welch

Many striking demonstrations of the magnetic effects of both alternating and direct current can be performed with this apparatus. Each demonstration can be set up quickly and easily, and most of the effects are simple to explain. All have important commercial applications. 


\section{INSTRUCTIONAL MATEGIALS COLLECTION}

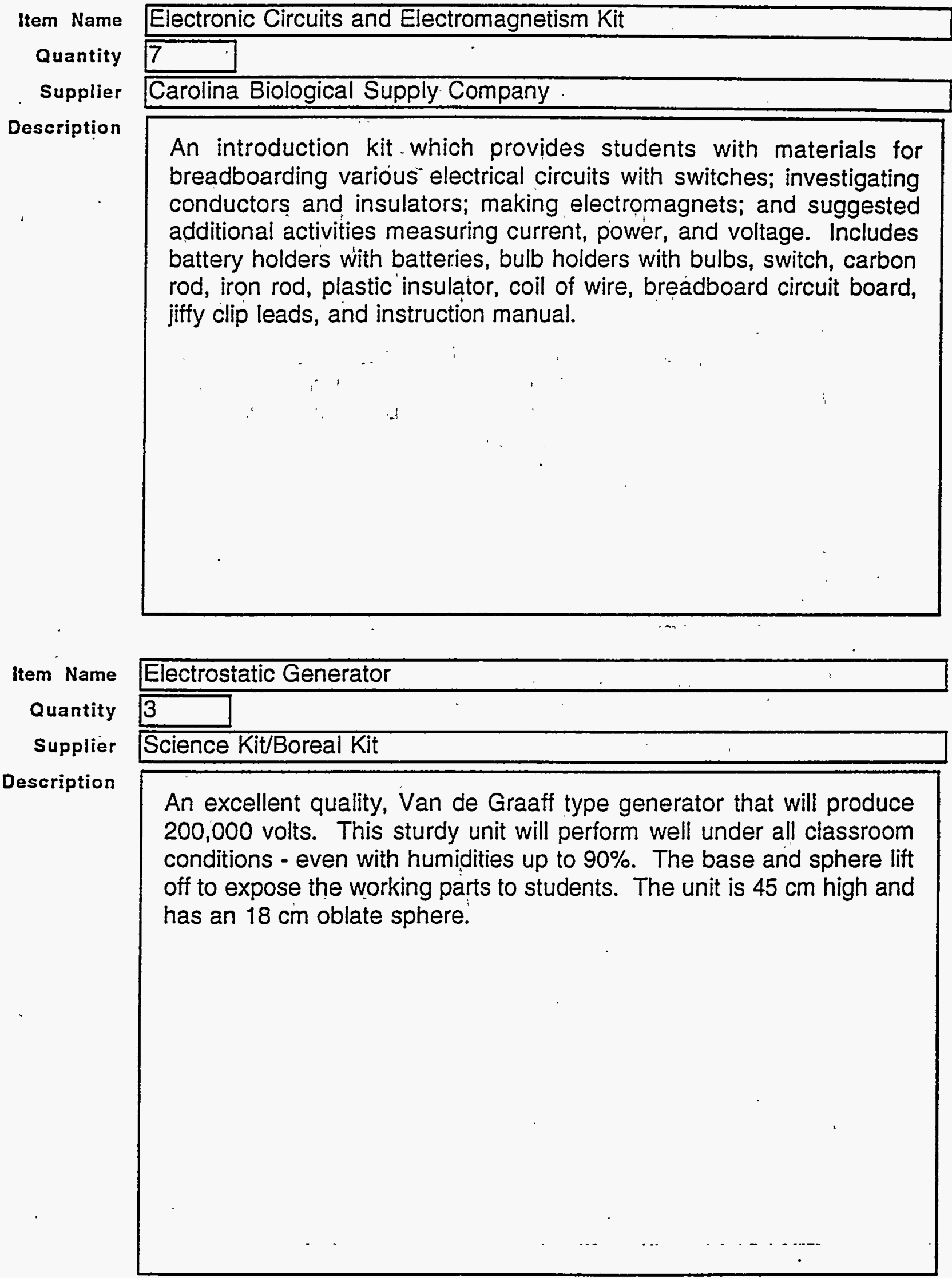




\section{INSTRUCTIONAL MATERIALS CÖLLECTION}

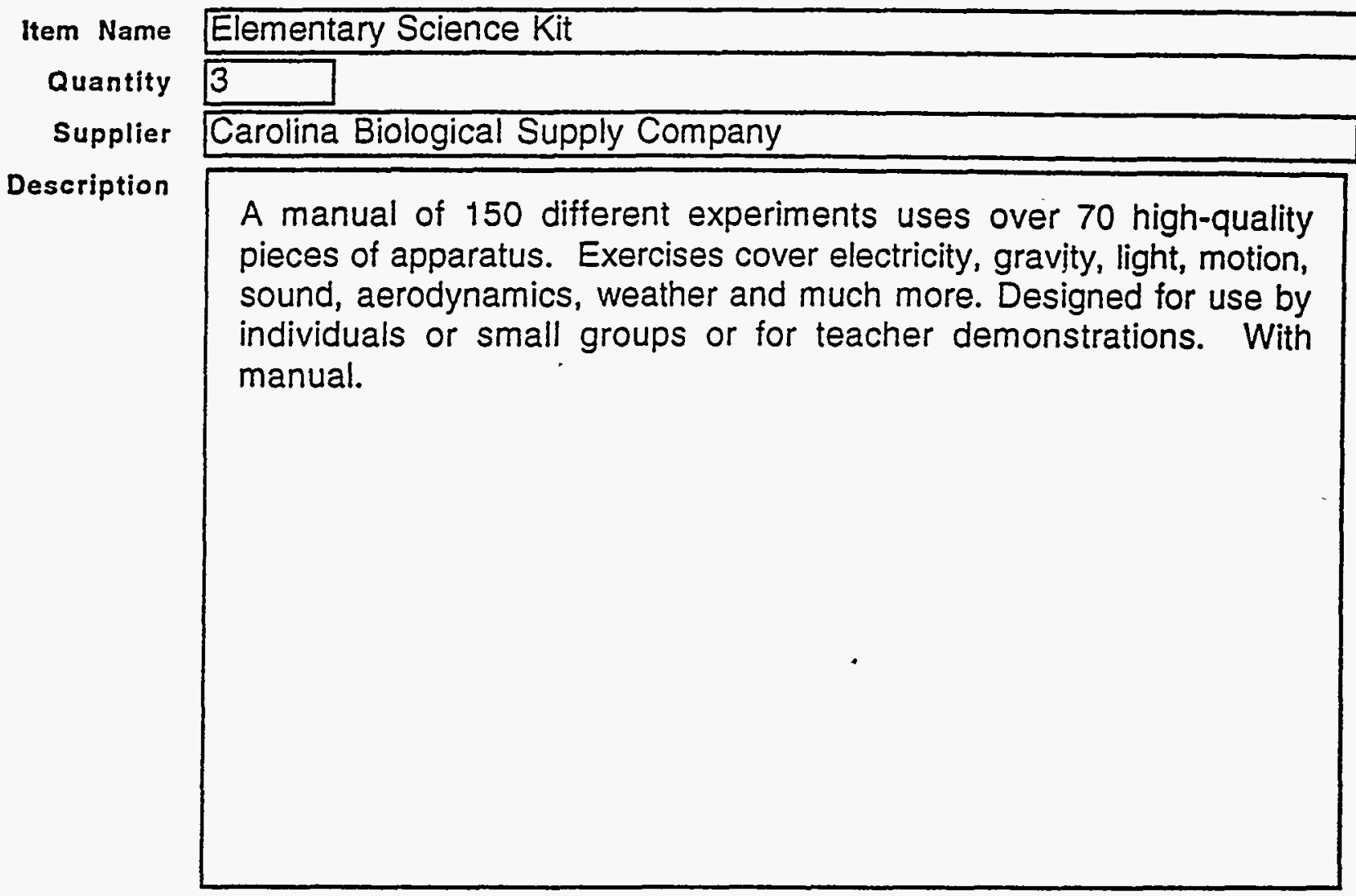

\section{Item Name \\ Quantity \\ Supplier}

Description

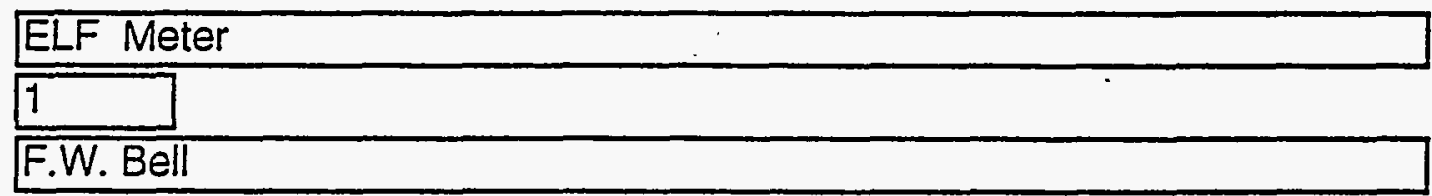

Extremely Low Frequency magnetic fields are generated by scores of electrical devices ranging from electrical transmission lines to electric blankets. The F.W. Bell Model 4060 ELF Meter measures these fields easily. The large $31 / 2$-digit readout indicates the field strength in either milligauss or gauss, depending on the setting. Model 4060 technology is based on the long line of industrial and laboratory grade gaussmeters (magnetic field measuring instruments) designed and manufactured by F.W. Bell. 


\author{
Item Name \\ Quantity \\ Supplier
}

Description

Item Name

Quantity

Supplier

Description
Faraday's Electromagnetic Induction

3

Science Kit/Boreal Lab

On the overhead are mounted three coils (20,40, and 80 turns) and a very sensitive milliammeter. Move a magnet in and out of any one of the coils and the meter responds accordingly. You can graphically demonstrate, how the number of coil turns, the speed with which the magnet moves, the magnet polarity, and its strength affect the milliammeter's behavior. The milliammeter is a center zero and reads to +2 milliamps. It also can be used independently. With complete instructions and teaching suggestions. Magnets are not included.

\section{Floating Magnet Demonstration}

1

Science Kit/Boreal"Lab

Demonstrated the repelling force of magnets. These magnets are made of alnico which is an extremely hard material composed of aluminum, iron, nickel, and cobalt. This alloy can be highly magnetized and is not easily demagnetized. The lower magnet is permanently fixed in place in the rugged yellow plastic frame, and the upper magnet can be removed by tilting the magnet down on one side and slipping it out of the upper side of the other groove. Length, 6.4 $\mathrm{cm}$. With instructions. 


\section{Item Name \\ Quantity \\ Supplier \\ Description}

Galvanometer and DC Volt-Ammeter

1

Sargent-Welch Scientific Company

Recommended for lecture and laboratory demonstrations. The combination galvanometer and volt-ammeter permits a wide range of voltages and currents to be measured. The movement is in clear view behind the glass window. It uses a double magnet and is built with extra ruggedness but is otherwise constructed along conventional principles so that it may be used to explain standard D'Arsonval movements. The wiring diagram for converting from galvanometer mode to any one of the voltmeter or ammeter ranges is shown on the panel inside the case and indicates clearly how each change is made at the binding posts on the base. The large pointer is clearly visible from all parts of a large room and is trussed for proper rigidity. Voltmeter ranges of 25 millivolts, 5, 25, and 125 volts are obtained using series resistors. Ammeter ranges of 25 milliamperes, 1, 5, and 25 amperes are obtained by using shunts. The sensitivity without shunts or multipliers is $200 \mathrm{ohms} / \mathrm{volt}$. The galvanometer sensitivity is 100 microamperes per division, well suited to the usual classroom

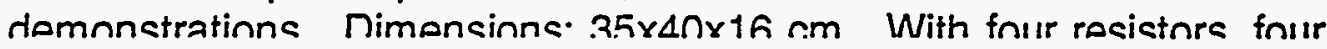

\section{Item Name \\ Quantity \\ Supplier}

Description

\section{Gauss/Tesla Meter, Hand-Held Digital}

1

F.W. Bell, Inc.

This hand-held instrument combines the basics of F.W. Bell Gaussmeter technology with state-of-the-art miniaturization to provide a compact, accurate, easy-to-use meter that reads in both gauss and tesla from $0.1 \mathrm{G}(10 \mathrm{mt})$ to $20 \mathrm{kG}(2 \mathrm{~T})$. A large LCD presents a readout of the field strength plus all other information relative to the reading and to instrument function and battery strength. The instrument is supplied with a transverse probe, probe extension cable, zero gauss chamber for zeroing, four "AA" alkaline batteries, an operation manual and a handy, soft-sided carrying pouch. A fold-away bail permits tabletop use. 


\section{InStructional MATERIALS Cóllection}

\section{Item Name \\ Quantity \\ Supplier}

Description

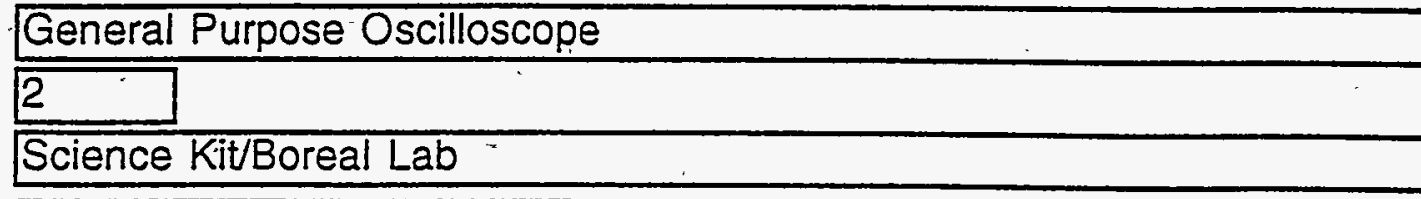

This well engineered, wideband oscilloscope analyzes waveforms present in electric and electronic circuits and devices. Recurrent sweep is useful for all applications at the introductory level as well as for many general laboratory level as well as for many general laboratory procedures. The unit features a $10 \mathrm{MHz}$ bandwidth. includes operation manual, lead wires, and three-wire cord and plug.

\section{Item Name \\ Quantity \\ Supplier}

Description

\section{Hi-Strength Magnetizer with Keeper Set}

2

Science Kit/Boreal Lab

Creates a magnetic field in metals at the flip of switch: Select North or South pole, insert a metal in the $25 \times 25 \mathrm{~mm}$ hole, and the metal becomes magnetized. This unit can be used to re-vitalize bar magnets and horseshoe magnets. Included with the Magnetizer is a threepiece Keeper Set which assures uniform magnetization. The unit measures $13.5 \times 8 \times 8.5 \mathrm{~cm}$ and has an on/off switch with pilot light." Furnished with a three-wire grounded cord for operation on 115 $V$, ac. Instructions included. 


\section{INSTRUCTIONAL MATERIALS CoLLECTION}

Item Name
Quantity
Supplier
Description

Item Name

Quantity

Supplier

Description
Holography Kit, Sandbox (Metrologic)

5

Sargent-Welch Scientific Company

Consists of optical accessories, film, and instructions to make reflection and transmission holograms. It is called a sandbox holography kit because a sandbox, although not included, is recommended to provide the vibrationless base needed for creating clear holograms. Plans for constructing such a sandbox of the required size are included. A comprehension book, "Holography Using a Helium-Neon Laser" is supplied with each kit.

\section{How Strong is a Magnet?}

3

Science Kit/Boreal Laboratory

Students assemble and use a sensitive magnetometer to measure the strength of magnets. An assortment of magnets together with instructions for four separate experiments are included. 


\section{INSTRUGTIONAL MATERIALS COLLËCTION}

Item Name

Quantity

Supplier

Description

\footnotetext{
Item Name

Quantity

Supplier

Description
}

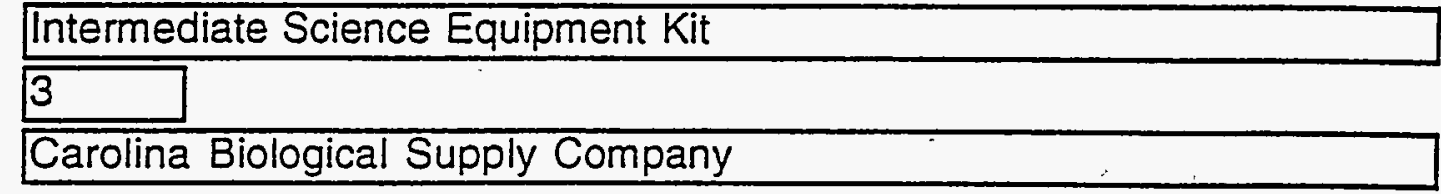

The comprehensive kit contains all equipment necessary for experiments and demonstrations to challenge and motivate students. Included are more than 50 items, plus 100 activity cards describing the experiments. The handy, reusable storage container includes alcohol burner, two beakers, glass plates, magnets, insect net, three pencil compasses, protractor, spring scale, tape measure, test tube, tongs, wire, and more.

\begin{tabular}{|l|l|}
\hline Large Cloud Chamber, Diffusion &. \\
\hline 4 & \\
\hline VWR Scientific & \\
\hline
\end{tabular}

Some of the remarkable properties of radioactive materials and the spectacular interactions of cosmic rays with matter may be presented to a large group of students with this diffusion cloud chamber. Radiation particles shooting out of the completely safe radiation source, and the variety of tracks produced by cosmic rays, fascinate all students - whether in elementary school, secondary school, or college. 


\section{INSTRUCTIONAL MATERIALS COLLECTION}

\section{Item Name \\ Quantity \\ Supplier}

Description
Laser, Helium/Neon (Metrologic)

1

Sargent-Welch Scientific Company

Useful in the laboratory for applications in holography and interferometry. It has a key switch, provisions for optional remote control operation, pilot light and mechanical beam shut off as well as a built-in time delay between application of power and lasing. Higher output power sufficient for holography or experiments where optical alignment must be made.
Item Name

Quantity

Supplier

Description

\section{Laser Lissajous Figure Apparatus}

\section{5}

Science Kit/ Boreal Lab

Try bouncing fascinating geometric Lissajous patterns off the walls, created with your laser beam and this cleaver device. The unit features two round mirrors each mounted on small motors across from one another. Power is supplied to the motors by two $D$ cell batteries: the speed of the motors is controlled by two rheostats mounted on the unit, the beam is projected onto one of the mirrors, bounced onto the other mirror, and then projected onto the wall. When one of the mirrors is set into motion, the reflected beam will appear on the wall as a circle. When the second motor starts to spin, the difference in the frequencies of the two motors creates Lissajous or frequency patterns on the wall. For an even greater challenge, determine the frequency ratio of the two mirrors by $\mathrm{cm}$ and is constructed of stained hardwood. 


\section{INSTRUCTIONAL MATEAIALS COLLECTION}

\section{Item Name \\ Quantity \\ Supplier \\ Description}

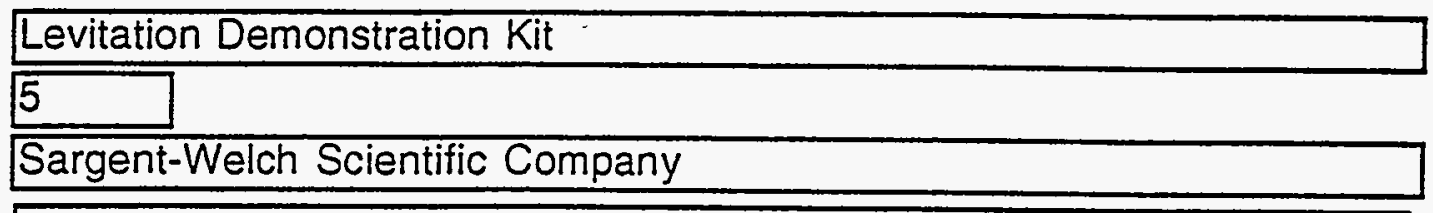

A perfect introductory kit. Economically priced and perfect for demonstrating levitation. The kit includes a mounted YBCO superconductor disc, a liquid nitrogen dish, a copper pedestal, a neodymium-iron-boron magnet, non-magnetic tweezers, and the manual.

\section{Item Name \\ Quantity \\ Supplier \\ Description}

Magnet Model, Projection Type

5

Science Kit/ Boreal Lab

For demonstrating the molecular nature of magnetism either by direct observation of the model or by observing its image on a screen with the aid of an overhead projector.

It consists of 20 bright red, freely turning compass needles, each 30 $\mathrm{mm}$ long with glass bearing resting on a needle point pivot, and with the north pole having a cutout letter $N$ to indicate its polarity when viewed directly or in the projected image. The needles hold a random orientation but tend to align themselves when placed in a magnetic field. The pivots re mounted in a transparent base plate. A transparent cover plate prevents the needles from coming off their pivots, yet leaves them accessible from the sides for any adjustment desired. Base dimensions (IXW):23×19 cm. ideal for any standard projector stage. 


\section{INSTHUGTIONAL MATEHILS COLLECTION}

Item Name

Quantity

Supplier

Description
Magnetic Earth Model

5

Science Kit/Boreal Lab

A unique apparatus for demonstrating the nature of the Earth's magnetic field. A half sphere containing an embedded magnet is mounted in a transparent container filled with a clear viscous liquid and iron fillings. As the iron fillings trace the lines of force around the magnetic sphere, a dramatic demonstration is provided of the field around the earth. This model is great for use with an overhead projector. Instructions included.

\section{Item Name \\ Quantity \\ Supplier \\ Description}

Magnetic Effect of Current

5

Science Kit/ Boreal Lab

A current-carrying wire rises vertically through this projectual. When iron fillings are sprinkled on the acrylic sheet and current is turned on, the circular magnetic field becomes immediately clear. Three compasses indicate the polarity. Also included is a transparent insert, used to illustrate Ampere's left hand rule, that slides easily into place even after the iron fillings have been applied. Complete instructions and teaching suggestions are included. Note: The projectual requires iron fillings and $1.5 \mathrm{~V}$, dc power source for operation. 


\section{INSTRUCTIONAL MATERIALS COLLECTION}

\section{Item Name \\ Quantity \\ Supplier \\ Description}

Metre Stick Optical Bench, with Accessories

5

Sargent-Welch Scientific Company

A complete set of equipment for performing experiments in elementary optics in an economical manner. The optical axis is at the same height for all components. The optics are compatible in quality, and produce acceptable data for accurate calculations. The holders support optical elements securely, and they are easy to adjust and remove. The bench is easy to set up or disassemble; it also stores compactly.

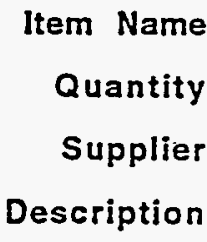

Millikan Apparatus

2

Science Kit/Boreal Lab

Compact, lightweight and ready to use, this apparatus lets your students determine (e) by one of two methods: allowing a selected sphere to fall through a measured distance with no electric field present - then applying an electric field and observing the velocity of the rising sphere; and by allowing a sphere to fall freely, then administering a high-voltage field until the sphere is suspended. The unit's all-in-one construction includes everything needed for a Millikan experiment: Microscope, illuminator, 0-500 VAC. 


\section{Item Name \\ Quantity \\ Supplier}

Description
Newtonian Demonstrator

5

Carolina Biological Supply Company

Dramatically illustrates Newton's Third Law of Motion. Completely assembled with instructions.

\section{Item Name \\ Quantity \\ Supplier \\ Description}

\section{Parabolic Collision Apparatus}

1

Science Kit/Boreal Lab

Even the most cynical student will be amazed by this demonstration of the classic "Monkey and the Hunter" problem. An electromagnet operated by a $1.5 \mathrm{~V}$ dry cell battery holds a bright yellow plastic ball (The Monkey). An adjustable-speed launcher (The Hunter Gun) is placed a few feet away. Launching a projectile from the "gun" causes the target "monkey" to drop. Since the projectile and the target fall at the same rate, they will almost always collide. A truly smashing demonstration of parabolic collision. Includes metal launcher, electromagnetic free fall unit, plastic balls, a special angle mirror for adjusting the sight, and instructions. Please note: Requires support stand and $1.5 \mathrm{~V}$ dry cell battery. 


\section{INSTRUCTIONAL MATERIALS COLLECTION}

\section{Item Name \\ Quantity \\ Supplier}

Description

Item Name

Quantity

Supplier

Description

\section{Pith Ball Electroscope}

7

Science Kit/Boreal Lab

Demonstrate the attraction and repulsion of electrostatic charges. An aluminum stand is used to suspend two pith balls of different colors. The stand is $21 \mathrm{~cm}$ high. Pith balls are included.

\section{Sargent-Welch}

The Portable Demonstration Hood is lightweight, easily movable, and can be set up: on your existing work counter, demonstration table, or mounted for use on movable tables. Front and rear panels are transparent plastic glazing secured with thumbscrews. The hood is provided completely wired, with integra! exhaust blower, vapor-tight light fixture, on-off switch, and 6 feet of ilexible hose with end coupling and clamps. A power cord is included. Easily assembled with ordinary hand tools. 


\section{Item Name \\ Quantity \\ Supplier}

Description

\section{Potential-Kinetic Energy Tracks}

5

Science Kit/Boreal Lab

Here is a new twist to inclined plane experiments - marble races, down this four track roller coaster. Each track is the same height, but has a different slope. Students calculate the average velocity of each marble as it travels down the slope. By marking the place on the floor where the marbles land, students also learn that no matter what their velocity, if objects of equal mass receive the same amount of potential energy (height), they will produce the same amount of kinetic energy (distance traveled). The catch-cup fits into a separate track with measurements marked on one side. No matter which of the four tracks a marble is caught from, the force of the moving marble causes the catch-cup to slide back the same distance in its track. The slide track is $37 \mathrm{~cm}$ long. The four-track unit measures $86 \times 28 \mathrm{~cm}$ and is made of varnished hardwood, with flexible plastic $19 \mathrm{~mm}$ wide grooved tracks. The unit is completely assembled. Also included are two $19 \mathrm{~mm}$ diameter steel marbles, instructions, a discussion of results, and suggestions for follow-up activities.

\section{Item Name \\ Quantity \\ Supplier \\ Description}

\section{Power Supply}

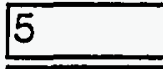

Sargent-Welch

Power Supply 0-10 V 0-5A. This is a recommended accessory to go with the Resistivity/Persistent Current Laboratory Kit-Model 1000. 


\section{INSTHUCTIONAL MATERIALS COLLECTION}

Item Name
Quantity
Supplier
Description

Item Name

Quantity

Supplier

Description
Power Supply, DC, Dual Station

3

Sargent-Welch Scientific Company

Two adjacent laboratory stations can be served simultaneously with this power supply. When the device is properly used, one station will not interfere with the other. Each has a separate set of binding posts providing six different voltages. The 0 to 5 volt variable voltage in this power supply is an electronic switching type with voltage regulation and current limiting capabilities.

\section{Random Molecular Motion Demo Kit}

5

Science Kit/Boreal Lab

A teacher-developed apparatus that dramatically demonstrates molecular motion. Demonstrations include the random kinetic motion of gas particles, the relatively stationary position of atomic particles in a crystalline lattice, the conservation of energy, motion, nuclear decay, osmosis, and many other phenomena. Designed for Van de Graaff generator, the kit simulates random molecular motion via the random motion of spheres resulting from electrical charges. An excellent teacher's manual that discusses each demonstration is included. 


\section{INSTRUCTIONAL MATERIALS COLLECTION}

\section{Item Name \\ Quantity \\ Supplier}

Description

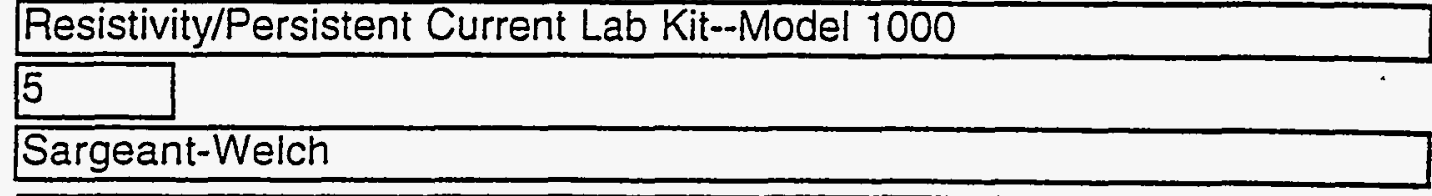

A unique kit that gives you the tools to perform superconductivity experiments in all the key areas. Experiments cover resistivity, critical temperature, critical current density, and persistent currents. The kit includes a superconductor probe with a $\mathrm{YBCO}$ ring, a temperature sensor, plus power and signal interfaces; a printed circuit board with a signal amplifier and other circuits for easy data acquisition; and a magnet holder/magnetic field coil board. The latter is used for inducing and calibrating currents in the superconductor. Also included are a signal interface cable, a neodymium-iron-boron magnet, a compass, two liquid nitrogen containers, and the manual. The unique electronics in the PC board enable both resistance and temperature measurements to be taken using one low cost voltmeter, with the voltage output such that a reading of $273 \mathrm{mV}$ equals $273 \mathrm{~K}$. In addition to liquid nitrogen and equipment to handle it, you will also need a high impedance voltmeter that reads to $0.1 \mathrm{mV}$ and $a 0-10 \mathrm{~V}$ power supply with a capacity of $5 \mathrm{~A}$.

\section{Item Name \\ Quantity \\ Supplier \\ Description}

\section{Ripple Tank/ Wave Generator}

Science Kit/ Boreal Lab

Our Ripple Tank/Wave Generator is designed specifically for use with an overhead projector. You can show your entire class experiments demonstrating wave propagation, reflection, diffraction, frequency-wavelength-velocity relationships, and interference and phase differences. All of these general wave phenomena become much more dramatic when projected on a screen. The package includes the specially designed ripple tank, a wave generator, and four barriers. 


\section{INSTRUCTIONAL MATERIALS COLLECTION}

\section{Item Name \\ Quantity \\ Supplier}

Description

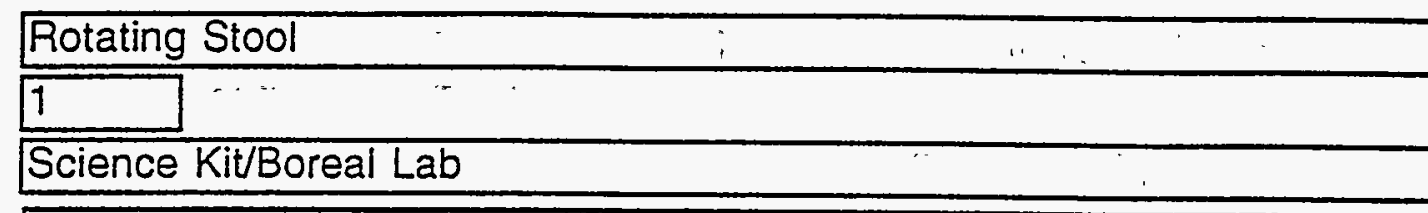

The forces involved in conservation of angular momentum, centripetal force, and gyroscopic precession can be experienced by the student using this sturdy stool and our Bicycle Wheel Gyroscope. The seat height adjusts from 46 to $66 \mathrm{~cm}$. The five steel legs give secure support. A footrest is proved for comfort; greater rotational force can be achieved by lifting the feet slightly off the footrest during experiments.
Item Name

Quantity

Supplier

Description

\section{Scattering Apparatus}

\section{4}

VWR Scientific

Simulates the scattering of atomic particles by a target nucleus. It introduced beginning physics students to some of the mechanics of computing cross sections of nuclear particles. The diameter of a target "nùcleus" is calculated from scatter patterns obtained during elastic collisions between steel balls and a plastic target, simulating interaction between atomic particles. The path of each projectile, after glancing from the target, is determined from the spot it makes on a strip of waxed recording paper attached to the inner surface of the scattering chamber. The target diameter-considered to be the "unknown" quantity-is deduced from the projectile diameter, the scattering angle, and the impact parameter, which is adjustable. Experimental results are easily checked by measuring the target diameter with calipers. 


\section{INSTRUCTIONAL MATERIALS COLLECTION}

\section{Item Name \\ Quantity \\ Supplier \\ Description}

\section{Item Name}

Quantity

Supplier

Description

\section{Sine/Square Wave Generator}

3

Science Kit/Boreal Lab

A professional solid-state signal generator that provides simultaneous sine and square-wave outputs. Its wide frequency range makes it perfect for testing all types of high-fidelity as well as sonar equipment. The unique low-distortion design provides clean signals over the entire frequency range for all types of testing. Since coverage is continuous, this generator is excellent for evaluating speaker systems.

\section{Speed of Light Laser Video Kit}

5

Science Kit/Boreal Lab

Make the most of your modulated laser. measure the speed of light within one percent, and transmit voice and video over a laser beam. This kit includes a beam splitter, two lenses, a microphone, a two-channel photodetector amplifier, and an instructional manual - all fitted into a reusable heavy cardboard carrying case. 


\section{INSTRUCTIONAL MATERIALS COLLEGTION}

\section{Item Name \\ Quantity \\ Supplier}

Description
Student Laser $0.8 \mathrm{~mW}$ Modulated

6

Science Kit/Boreal Lab

The laser is ideal for classroom demonstrations of diffraction and interference patterns and for making small holograms and can be modulated using built in connectors to transmit voice or video, and perform light speed experiments. (Power range when modulated is 85-100 percent of full rated power.)
Item Name
Quantity
Supplier
Description

Student Laser, $0.8 \mathrm{~mW}$ Unmodulated

5

Science Kit/Boreal Lab

The inexpensive laser is ideal for classroom demonstrations of diffraction and interference patterns and for making small holograms. 


\section{INSTRUCTIONAL MATERIALS COLLLECTION}

\section{Item Name \\ Quantity \\ Supplier}

Description

\section{Item Name \\ Quantity}

Supplier

Description
Student Laser $2.0 \mathrm{~mW}$ Unmodulated

2

Metrologic Instruments

Provides extra power for making larger holograms with shorter exposure times, better fringe visibility in interferometry, greater irradiance when the beam is spread, and brightness to spare when you set up optic paths using several lenses.

\section{Suburban Vacuum Pump}

1

MSC Industrial Supply Company

Suburban's solidly built rotary vane vacuum pumps are motor mounted. They are the oil-less type which provide nearly maintenance free operation. Each pump includes a muffler, filter support base, and proper fittings with 6 feet of reinforced vacuum hose. Built-in thermal overload protection is provided. 


\section{Instructional MATERIALS Collection}

\section{Item Name \\ Quantity \\ Supplier \\ Description}

Item Name

Quantity

Supplier

Description

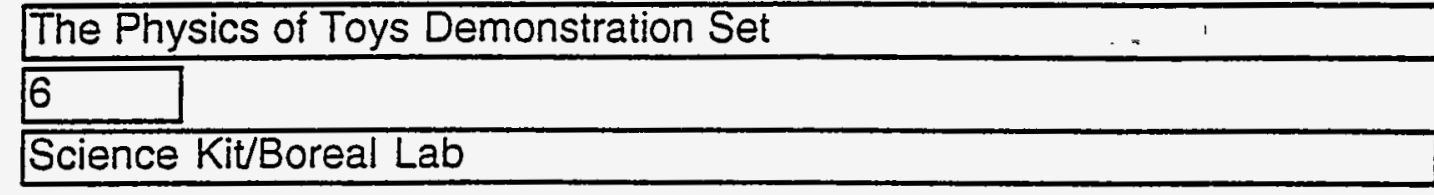

Surprise your students with a toy chest full of physics fun! The 23 toys in this set offer an unintimidating approach to learning about the principles of physics. Show the principle of vapor behavior via the Dunking Duck. Illustrate Newton's second law through the Wobbly Spaceman, Point out the spring dynamics of a Slinky. The 23 toys can be used to demonstrate sophisticated principles in classroom studies from basic to advanced. Convenient storage in a sturdy, two-drawer cardboard box. The accompanying manual, "Physics Fun and Demonstrations", gives complete instructions for performing experiments with each toy, the theory behind each phenomenon, and a work section for students. For "children" of all ages. \begin{tabular}{l} 
Three-Dimensional Magnetic Field Model \\
5 \\
\hline Science Kit/Boreal Lab
\end{tabular}

Produce a dramatic demonstration of magnetic fields. This $8 \times 11 \times 8$ $\mathrm{cm}$ hard acrylic unit is filled with a viscous fluid containing metal filings. It has a hollow center core so that a cylindrical magnet can be inserted from either end. Insert one magnet to illustrate the lines of magnetic force; insert two magriets and then switch poles to graphically demonstrate attractions and repulsion. Electrical currents can be demonstrated by passing copper wire through the center of the apparatus. The unit is designed for overhead projections and comes complete with a high-strength magnet set and keepers. 


\section{INSTRUCTIONAL MATERIALS COLLECTION}

Item Name
Quantity
Supplier
Description

Item Name

Quantity

Supplier

Description
TS-24 Registered Software License

1

Santa Barbara Instrument Group

A computer program that simulates the actual use of an observatory with a 24" research telescope. Features:

- realistic telescope eyepiece viewing

- atmospheric effects including weather simulation

- realistic data generated by simulated scientific instrumentation

-data analysis and graphics presentation programs for reporting scientific findings

-an unknown universe containing many unusual objects to be discovered and studied

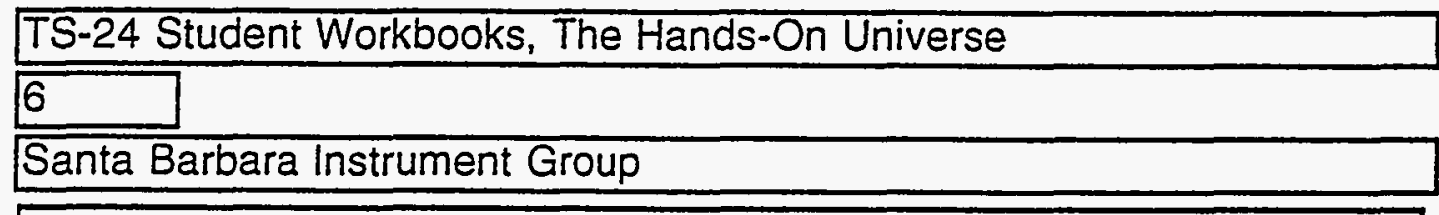

An introductory course to astronomy and astrophysics. It begins by introducing the student to the TS-24 telescope and observatory. It covers basic functions such as how to use the observatory and its instruments, how to use Right Ascension and Declination coordinates to find objects, how to keep records of scientific experiments. 


\section{Instructional Mateaials Collection}

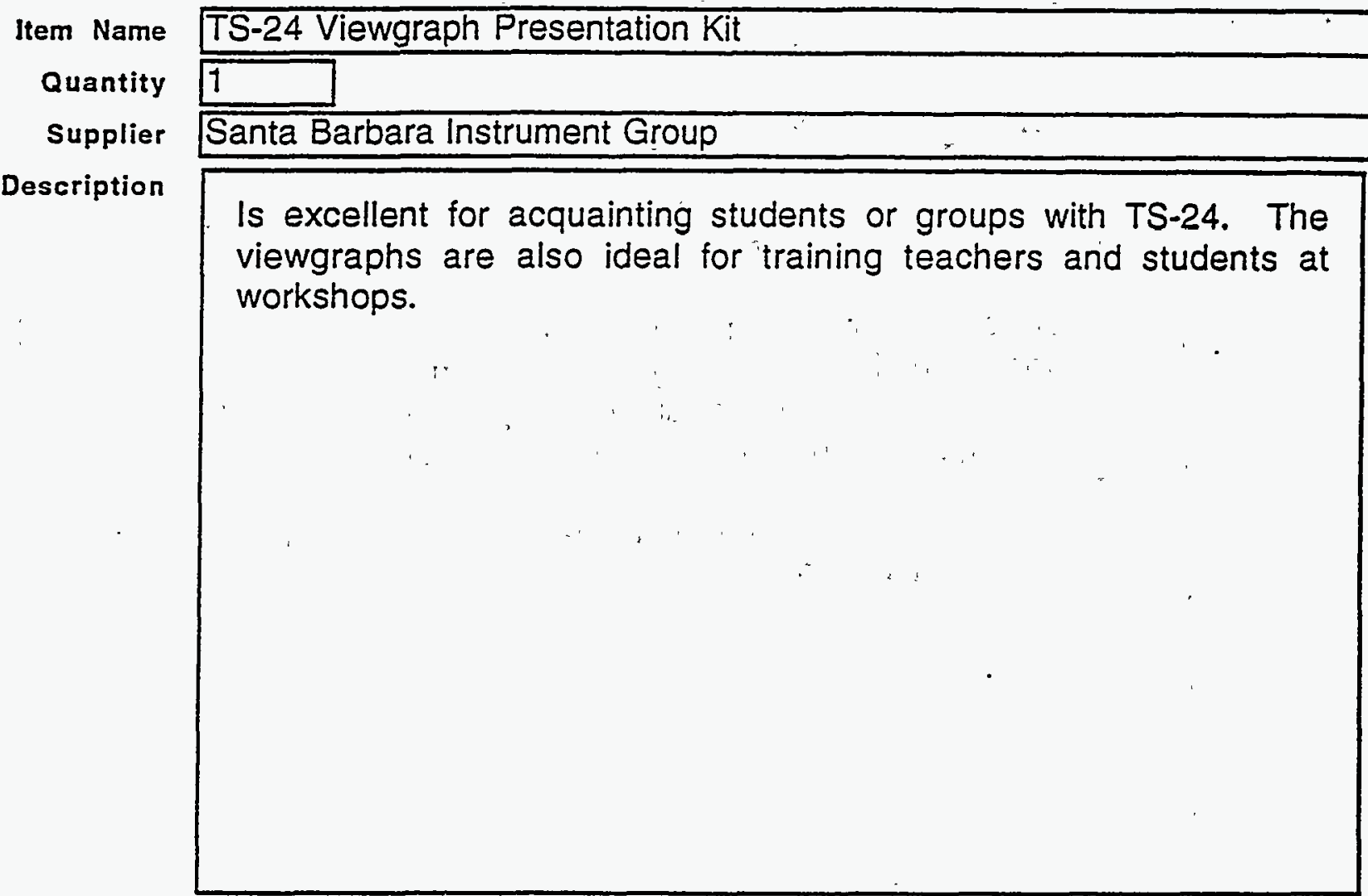




\author{
Market Analysis for a \\ Joint Texas Facility \\ for Research, Training and \\ Science Education
}

\author{
Daniel J. Howard \\ Associate Professor of Marketing \\ on the Marilyn and Leo F. Corrigan Endowment \\ Southern Methodist University
}


Executive Summary ................................................................................................................... v

Section 1: Overview...................................................................................................

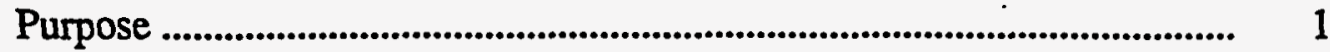

Sample Frame .................................................................................................... 2

Assessment of Sample Bias ................................................................................... 3

Questionnaire Development .............................................................................. 4

Stratification Variables ..................................................................................... 6

Statistical Decision Making.................................................................................. 10

Section 2: Results for the Total Sample......................................................................... 11

Research Value Scores............................................................................ 11

Training Value Scores ................................................................................. 14

Overall Asset Usage for Research and Training............................................ 17

Types of Asset Usage Anticipated .................................................................. 19

Anticipated Users of Asset Usage..................................................................... 22

Principal Benefit Derived ............................................................................. 24

Annual Rental Costs ........................................................................... 26

Resource Availability..................................................................................... 28

Market Potential.......................................................................................... $\quad 30$

Section 3: Results Stratified by Employment Group ................................................. 32

Research Value Scores................................................................................ 33

Training Value Scores ................................................................................... 35

Overall Asset Usage for Research and Training ......................................... . 37

Types of Asset Usage Anticipated................................................................. 39

Estimated Weeks of Asset Usage ................................................................ 43

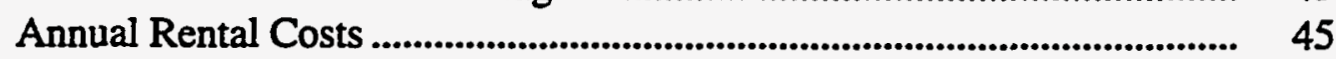

Section 4: Results Stratified by Area of Specialization ............................................... 47

Anticipated Asset Usage for Research Purposes .......................................... 48

Anticipated Asset Usage for Training Purposes ............................................ 52

Estimated Weeks of Asset Usage ................................................................... 55

Annual Rental Costs ............................................................................. 57

Section 5: Results Stratified by Type of Business ..................................................... 59

Anticipated Asset Usage for Research Purposes .......................................... 61

Anticipated Asset Usage for Training Purposes ......................................... $\quad 65$

Estimated Weeks of Asset Usage .................................................................. 67

Annual Rental Costs ................................................................................ 69 
Section 6: Other Stratifications ............................................................................ 71

Decision Making Responsibilities ................................................................. 71

Miles From Workplace to Waxahachie .......................................................... 73

Annual Corporate Revenues ........................................................................... 75

Externally Funded Research ........................................................................... 77

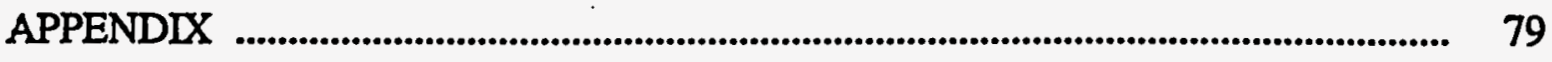


2 Principal Orientation and Area of Specialization.

Average Research Value Scores and Percent Usage Anticipated for the Total Sample

Average Training Value Scores and Percent Usage Anticipated for the Total Sample

Research and Training Use for the Total Sample

Percent of Total Sample Citing Types of Use Anticipated

Average Weeks of anticipated Use for the Total Sample

Principal Benefit Provided by Access to the SSC Assets

Average Research Value Scores and Percent Usage Anticipated by Employment Group

Average Training Value Scores and Percent Usage Anticipated by Employment Group.

14 Research and Training Use by Employment Group 


\section{List of Tables (Continued)}

Table

Page

Average Weeks of Anticipated Usage by Employment Group

44

Estimated Annual Rental Costs by Employment Group.. 46

Average Research Value Scores and Percent Usage Anticipated by Area of Specialization.

Percent of Area Specialization Target Group Citing Types of Asset

Usage Anticipated.

Average Training Value Scores and Percent Usage Anticipated

by Area of Specialization.

Average Weeks of Anticipated Usage by Area of Specialization.

Estimated Annual Rental Costs by Area of Specialization

Description of Other Businesses.

Average Research Value Scores and Percent Usage Anticipated

by Type of Business.

Percent of Business Target Group Citing Types of Asset

Usage Anticipated.

Average Training Value Scores and Percent Usage Anticipated

by Type of Business.

Estimated Annual Rental Costs by Type of Business. 


\section{Executive Summary}

This study examined marketplace needs for a Joint Texas Facility for Research, Training and Science Education. The study purpose was to measure potential demand for equipment and services for research and training purposes at such a Facility. The equipment and services would be developed using existing assets of the Superconducting Super Collider near Waxahachie, Texas. The study objective was to determine the types of equipment/services with the highest demand for inclusion in the Facility and the characteristics of the groups with the greatest needs.

The survey sample $(N=2505)$ was comprised of Texas physicists $(N=1044)$, employees of technology firms in Texas $(\mathrm{N}=1330)$ and Texas university deans of schools of science $(\mathrm{N}=$ 131). Five-hundred forty-two $(\mathrm{N}=542)$ usable surveys were returned for a response rate of 21.6\%. The response rate for the sub-samples was as follows: Texas physicists, $32.7 \%, N=$ 341 ; employees of technology firms, $13.2 \%, N=177$; deans, $18.3 \%, N=24$. An assessment of possible sample bias was conducted and not supported. The response rates for the survey were judged to be adequate for making population generalizations.

Seven assets were described for possible inclusion in the Facility: high performance computing, information technology, mechanical shops, cryogenics, magnet fabrication, electronics and data acquisition. Most respondents (65.7\%) indicated a willingness to use at lease one asset within the Facility for either research or training purposes. The use of assets for both research and training was most common (35.4\%), followed by research use (23.1\%) and training use (6.8\%). 
Estimates of high performance computing use for research ranged from $40.2-45.8 \%$ of the respondents. Estimated utilization of the information technology, mechanical shops, electronics and data acquisition assets ranged (over two measures) from $26.6-31.8 \%$ and 27.5 $34.7 \%$ of the respondents. Estimated use of the cryogenics and magnet fabrication assets were lowest and ranged (over two measures) from $8.2-11.9 \%$ and $10.0-12.5 \%$ of the respondents.

Estimates of asset usage for training purposes revealed a ranking similar to research although the anticipated usage levels were lower. High performance computing was ranked first (33.3\% of the respondents), followed by information technology, electronics and data acquisition (average of 25.5\%), mechanical shops (16.6\%) and cryogenics and magnet fabrication (average of $10.1 \%)$.

The manner in which assets would be utilized was examined. Across assets in general, use of assets for design, as opposed to fabrication, purposes was preferred.

No such differences were observed for Facility "support" versus direct "use" options. On the individual asset level, several preference differences were observed. Design support and design use is preferred for high performance computing, information technology and data acquisition. Fabrication support is most desired for mechanical.shops. Both design and fabrication support are preferred for electronics.

The "extent" of asset usage was examined. Respondents estimated using the high performance computing asset on average of 16.26 weeks annually. Information technology had the next highest average estimate (11.87 weeks). Small differences were observed for remaining assets and ranged from 7.95 to 9.86 weeks. 
Data was obtained on annual rental costs for comparable assets if Facility use is not provided. Those estimates varied widely and ranged from $\$ 152,714$ for magnet fabrication to $\$ 39,111$ for data acquisition. A mid-range estimate of $\$ 91,065$ was provided for high performance computing.

Results were stratified by employment group. Corporate respondents anticipated less research and training use on every asset than university respondents. Nevertheless, $50.8 \%$ of the corporate respondents still indicated use of at least one asset in the Facility for either research or training purposes. Higher percentages of both university faculty/staff (78.6\%) and deans (83.4\%) provided such indications.

Corporate respondents estimated fewer weeks ( 9.14 wks.) of high performance computing use than either university faculty/staff (19.27 wks.) or deans (16.53 wks.). Estimates on remaining assets were not significantly different across groups. Thus, although the proportion of the corporate population expected to utilize Facility assets may be less than the university population, the "extent" (amount) of usage is likely to be similar between customers from both groups on most assets.

Estimated annual rental costs revealed substantially higher estimates by corporate respondents, relative to university faculty/staff, most assets. Faculty/staff has higher estimates of magnet fabrication costs.

Data were stratified by principal orientation and area of specialization for the Texas physicist sub-sample. The intent was to identify groups with the highest likelihood of using Facility assets. A higher likelihood of asset use for research was found for respondents with 
experimental, design or training orientations. A higher likelihood of asset use for training was found for respondents with experimental or training orientations.

Higher anticipated asset use for research was indicated for the following specializations: astrophysics, biophysics, high energy physics, nuclear physics, physics of beams, superconductivity and mechanical engineering. Higher anticipated asset use for training was indicated for the following specializations: astrophysics, biophysics, condensed matter, high energy physics, nuclear physics and superconductivity. In general, the higher asset use among these target specializations was reflected in both higher percentages of respondents and a higher number of weeks of usage. The target specializations also estimated higher annual rental costs across assets.

Data were stratified by type of business for corporate respondents. The intent was to identify business with the highest likelihood of using Facility assets. For research purposes, those target businesses were as follows: computers, parts and equipment, electrical equipment and components, industrial chemicals, drugs and medicines, plastic and synthetic materials, optical and medical instruments and a variety of "additional" businesses (see Table 25). For training purposes, the target businesses were as follows: computers, parts and equipment, electrical equipment and components and aircraft and parts. However, higher research usage (percentage of respondents) among target businesses was not found for the cryogenics or magnet fabrication assets; higher usage for training purposes was not found for the cryogenics, magnet fabrication or data acquisition assets. The estimated number of weeks of usage were higher for target businesses across all assets except data acquisition. 
Data were stratified by respondent responsibilities for making decisions on use of the Facility assets. Respondents with "sole" decision making responsibilities were found to be less likely to utilize the assets, relative to other levels of responsibility.

Analyses were conducted to determine if the asset use results varied by the number of miles from respondent workplace to Waxahachie, Texas. They did not. One possible explanation is that respondents anticipate use of the Facility assets for non-routine and specialized projects that negate the opportunity costs associated with travel within the state of Texas.

Analyses were conducted to determine if the asset usage results varied by annual corporate revenues. The highest revenue group (greater than $\$ 400$ million) was more likely than other groups to indicate use of the high performance computing, cryogenics, magnet fabrication, information technology and data acquisition assets for research purposes; and the high performance computing and magnet fabrication assets for training purposes.

Analyses were conducted to determine if asset usage varied as a function of the amount of externally funded research obtained by universities. Results revealed a consistent tendency for greater asset use (for both research and training purposes) at universities with high external funding.

A synthesis of available information was utilized to approximate the market potential (dollar revenues) for Facility use. Across assets, the total market potential was estimated to be $\$ 72,600,139$. Given a variety of constraints, a substantially lower figure is probably more reasonable, at least for the first year of operation. Still, given effective management and 
implementation of the Facility concept, first year gross revenues of several million dollars can be conservatively anticipated.

Finally, various members of the Joint Facility team provided advice concerning the questionnaire and sample frame utilized in this study. The analyses and conclusions contained in this report, however, were independently derived by, and are the responsibility of, this investigator 
Section 1: Overview

\section{Purpose}

The purpose of this study was to measure the needs for equipment and services at a Joint Texas Facility for Research, Training and Science Education. The equipment and services would be developed using existing assets of the Superconducting Super Collider located near Waxahachie, Texas. Needs were separately examined across different assets with respect to a variety of issues, including anticipated use for research and training, the probable extent of such use, and market (price) value. The objective was to determine the types of equipment/services with the highest demand for inclusion within the Facility and the characteristics of the groups with the greatest equipment/service needs. 


\section{Sample Frame}

The principle target markets for the Facility were physicists and technology firms located in Texas. The survey sample was comprised of three groups: (1) Texas members of the American Physical Society; (2) employees of technology firms in Texas; and (3) Deans of schools of science at Texas universities. Five-hundred-forty-two $(\mathrm{N}=542)$ usable surveys were returned out of a total sample of $\mathrm{N}=2505$ for a response rate of $21.6 \%$. This response rate is quite consistent with the industry norm for responses to mail surveys, which is known to be approximately $20 \%$.

All members of the American Physical Society (APS) located in Texas were surveyed, with the exception of student and junior members. Members were surveyed regardless of their specialization within the APS. The total APS university surveys distributed numbered $\mathrm{N}=1044$. Three-hundred-forty-one were returned $(\mathrm{N}=341)$ for a response rate of $32.7 \%$. A $50 \%$ random sample of technology firms in Texas was obtained from Corptech and numbered $\mathrm{N}=1330$. Onehundred-seventy-seven $(\mathrm{N}=177)$ were returned for a response rate of $13.3 \%$. One-hundred-thirtyone $(N=131)$ university Deans at Texas universities were surveyed. Twenty-four $(N=24)$ were returned for a response rate of $18.3 \%$.

The response rates for the three sample groups was judged to be adequate for purposes of making population generalizations. However, the low response rate for the corporate survey in particular was a cause for concern and motivated an assessment of sample bias. 


\section{Assessment of Sample Bias}

People who are sampled but do not respond to surveys are sometimes different on a number of traits than those who do respond. One of the best predictors of the likely extent of such a bias is to examine differences in the survey answers of early versus late respondents. Slow responses to mail survey questionnaires are known to be sometimes predictive of the answers of those who do not respond at all. Although this relationship is not a perfect one, it can be revealing of the likely extent of a potential sample bias. In this study, the last (slowest) quartile of respondents for both the APS and corporate surveys was found not to be significantly different from earlier (faster) respondents on critical measures of research or training use of the SSC assets. These results argue against the likelihood of a strong sample bias. Survey research experience has shown that the lack of a sample bias represented by respondents vs. non-respondents is typically found with surveys of issues for which strong opinions are held. In such cases, respondents with positive and negative views of the survey issues are equally likely to complete the survey. This situation can be contrasted with less polarizing issues in which those favorably inclined to an idea are often most likely to respond. The fact that opposing views of the utility of the Facility are both represented within the survey responses is clear in the analysis. 


\section{Qnestionnaire Development}

The questionnaire was developed to measure the utility of SSC assets for research and training purposes and to define group differences in the perception of those utilities. Copies of the instruments and cover letters for the APS, corporate and dean surveys are presented in the Appendix.

The potential research and training utility of the Facility was examined across seven SSC assets: high performance computing, information technology, mechanical shops, cryogenics, magnet fabrication, electronics, and data acquisition. Each of these assets was defined on the first page of the survey questionnaire (prior to the survey questions), as well as in the survey supplement. A phone number was also provided to allow respondents to obtain additional information on the assets. These efforts were made to minimize the possibility of confusion or ambiguity over the asset classification scheme used in the survey.

The research utility of the assets was defined with items that measured the overall research and development value of each of the assets, the availability of the assets elsewhere, the anticipated extent of asset usage, the specific types of usage anticipated and the purchase and rental costs of the assets (in dollars). The training utility of the assets was defined with items that measured the overall value of each of the assets for training purposes and the preferred training format.

Group variability in survey responses was anticipated. Items were presented to allow stratifications across seven variables: principal place of employment, miles between workplace and Waxahachie, Texas, decision making responsibilities, amount of externally funded research in the previous year (for university respondents), company revenues for the previous year (for 
corporate respondents), principal orientation/area of specialization (for APS respondents), and type of business (for corporate respondents). 


\section{$\underline{\text { Stratification Variables }}$}

The data were stratified by three major variables to determine if the needs for equipment/services at the proposed Facility varied across market segments. Data on respondent principal place of employment are presented in Table 1. As seen, 93.3\% of the respondents are principally employed by either a university or a corporation. Those two classifications were utilized for stratification (group comparison) purposes.

Data on principal orientation and area of specialization were obtained from surveys sent to APS members (see Table 2). Data on products/services sold was obtained from surveys sent to employees of technology firms in Texas (see Table 3). Stratifications were defined using categories with maximum discrimination of use of the SSC assets. The intent here was to determine the university and corporate segments with the highest needs for the equipment and services being proposed for inclusion in the Facility. 
Table 1

Principal Place of Employment

Employment

University

Corporation

Government

Other
N

234

263

18

17 $\underline{\text { Percent }}$

44.0

49.3

3.4

3.2 
Table 2

Principal Orientation and Area of Specialization $(\mathrm{N}=363)$

Orientation

Theory

Experiment

Design

Product Development

Fabrication

Training

Specialization

Atomic Physics

Astrophysics

Biophysics

Chemical Physics

Condensed Matter

Computational Physics

High Energy Physics

Materials Science

Nuclear Physics

Physics of Beams

Plasma Physics

Other Physics

Superconductivity

Chemical Engineering

Electrical Engineering

Mechanical Engineering

Other Engineering

Other Specialization.

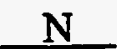

149

225

95

70

26

46
Percent

41.2

62.0

26.2

19.3

7.2

12.7
10.8

4.7

6.6

14.6

20.4

19.0

15.4

21.2

12.1

6.6

8.5

11.3

6.3

3.9

13.2

5.5

6.3

12.7

Missing or N.A. 
Table 3

Company Products and Services $(\mathrm{N}=178)$

Products/Services

Office, Accounting Machines

Computers, Parts and Equipment

Networking, Software Engineering and Related Services

Electrical Equipment and Components

Electronic Equipment and Components

Agricultural Chemicals

Industrial Chemicals

Drugs and Medicines

Plastic and Synthetic Materials

Optical and Medical Instruments

Professional and Scientific Instruments

Engines and Turbines

Aircraft and Parts

Other Transportation Equipment

Other Industrial Machinery and Equipment

Other
$\mathbf{N}$

5

25

52

15

54

2

2
Percent

2.8

14.0

29.2

8.4

30.3

1.1

1.1

2.8

3.9

5.1

11.2

1.1

2.8

1.1

24.7 


\section{Statistical Decision Making}

A variety of univariate and multivariate statistics were utilized to analyze the survey results. The specifics of those tests need not and will not be discussed in this report. However, the term "statistical significance" will often be used, especially in conjunction with mean and proportional difference tests. Statistical significance testing addresses the question of how different two or more means or proportions have to be in order to have confidence that the difference is a "true" and "reliable" distinction in the population of consumers represented by the survey respondents. A significant difference refers to a difference that would only be expected to occur under a chance distribution of scores in a small number of occurrences. Stated differently, a statistically significant difference is one the reader can have confidence did not occur by chance.

Traditionally, a probability level of 0.05 (i.e., $\mathrm{p}<0.05$ ) has been used as an accepted criterion level in statistical significance testing in scientific papers. A probability level of 0.10 (i.e., $\mathrm{p}<0.10$ ) has been accepted as indicative of "marginally" significant results. A finding of significance at the $\mathrm{p}<0.05$ or $\mathrm{p}<0.10$ levels would indicate that the observed results would only be expected to occur under a chance distribution of scores $5 \%$ and $10 \%$ of the time or less, respectively. Those criterion levels (based principally on Z-tests, discriminant function analysis and analysis of variance [ANOVA]) will be employed in this study whenever the terms "significant" and "marginally significant," "higher/greater" or "marginally higher/greater" are used. However, statistical significance testing is viewed by this analyst as a means of assisting, rather than determining, data interpretations. 
Section 2: Results for the Total Sample

\section{$\underline{\text { Research Value Scores }}$}

Respondents were asked to "please indicate the value to your research or development efforts the following SSC assets provide." A six point scale was provided (scored 0 to 5) with the following benchmarks: $0=$ no value; $1=$ little value; $3=$ moderate value; $5=$ high value. Each of the seven SSC assets were separately rated. The mean scores are provided in Table 4 where high performance computing is rated significantly higher than any other asset and cryogenics and magnet fabrication score significantly lower than other assets. No significant differences were found in the mean research value scores of the information technology, mechanical shops, electronics or data acquisition assets.

The mean scores across all of the assets "appear" low, ranging from 2.2 for high performance computing to 0.60 for magnet fabrication. However, low scores using such a scale are to be expected given the context of the present study. Experience has shown that respondents are typically hesitant to ascribe high value to something in situations of doubt or uncertainty. Although an adequate description of each asset was provided, the costs and contingencies associated with gaining access to those assets are unknown. Further, a precise formulation of the value of the existing SSC assets is difficult without knowledge of the organizational support structure encompassing those assets. In this analyst's view, the absolute size of the research value scores are less interpretable than the relative differences.

Problems with interpreting the absolute size of "evaluative" scores are common across disciplines. However, experience in the fields of marketing and advertising has shown that the percent of respondents who indicate "value" in the top half of the scale is highly predictive of the 
Table 4

Average Research Value Scores and Percent Usage Anticipated for the Total Sample

SSC Asset

High Performance Computing

Information Technology

Mechanical Shops

Cryogenics

Magnet Fabrication

Electronics

Data Acquisition
Mean Research Value

2.20

1.61

1.31

0.72

0.60

1.54

1.39
Total N

535

534

533

533

533

533

533
Percent Usage

Anticipated Usage N

45.8 248

31.8

170

26.6

142

13.5

72

10.5 56

32.6

174

29.3 
proportion likely to "act" on (i.e., purchase/use) an offering. This "top score" methodology was applied to the research value scores by calculating the percentage of respondents who rated each of the assets using one of the three highest scores $(3,4$ or 5$)$. That information is also presented in Table 4 where a more favorable perspective on the extent of probable use of the SSC assets emerges. This data suggests that $45.8 \%$ of the total respondents are likely to utilize the high performance computing facilities. The specialized cryogenics and magnet fabrication assets show the lowest levels of likely utilization ( $13.5 \%$ and $10.5 \%$ of the respondents respectively). For the overall sample, the significance of differences between mean value scores was found to equally hold true for differences between the sample proportions. In general, this was found to be true throughout data. Given the applied objective of this study, significance tests will only be reported for the usage proportions. The validity of the usage proportion statistics computed via the research value scores will be later assessed through comparisons with items that directly measured the likelihood of future asset utilization. 


\section{Training Value Scores}

A training value item was presented similar to the research value item just discussed.

Respondents were asked, "If vocational training in the use of some or all of the SSC assets were available, how valuable would that service be in the current or anticipated training of personnel in your organization?". The same six point scale (scored 0 to 5) used for the research value item was used again for each of the seven assets. Usage proportions were again calculated using the "top score" method. Results are presented in Table 5.

An examination of the usage percents reveals two important pieces of information. First, training use is directionally lower across assets relative to research use, although significantly lower only for high performance computing and mechanical shops. This suggests research, rather than training, is perceived to be the principal benefit associated with SSC asset utilization. Second, the training use rank order of the assets closely corresponds to the research value rank order of those assets. When considered in conjunction with the lower mean scores, this "halo effect" suggests that demand for training programs will vary partly as a function of demand for asset utilization in research (coefficient of determination $=0.36$ ).

On the other hand, the pattern of significant differences between assets is different than seen for research use. Anticipated use of high performance computing is significantly higher than remaining assets except information technology and electronics. Information technology and electronics use are higher than magnet fabrication, cryogenics and mechanical shops. Data acquisition use is higher than cryogenics and magnet fabrication. 
Table 5

Average Training Value Scores and Percent Usage Anticipated for the Total Sample

\begin{tabular}{|c|c|c|c|c|}
\hline SSC Asset & $\begin{array}{l}\text { Mean Training } \\
\text { Value }\end{array}$ & Total N & $\begin{array}{l}\text { Percent Usage } \\
\text { Anticipated }\end{array}$ & Usage $N$ \\
\hline High Performance Computing & 1.55 & 489 & 33.3 & 163 \\
\hline Information Technology & 1.22 & 488 & 26.0 & 127 \\
\hline Mechanical Shops & 0.84 & 487 & 16.6 & 81 \\
\hline Cryogenics & 0.58 & 486 & 11.9 & 58 \\
\hline Magnet Fabrication & 0.46 & 486 & 8.2 & 40 \\
\hline Electronics & 1.20 & 488 & 26.6 & 130 \\
\hline Data Acquisition & 1.11 & 489 & 23.9 & 117 \\
\hline
\end{tabular}


Respondents were also asked to indicate their preferences for a type of training format. An internship program was selected by $37.3 \%(\mathrm{~N}=202)$ of the respondents. A classroom format was preferred by $29.0 \%(\mathrm{~N}=157)$. Only 7\% $(\mathrm{N}=38)$ specified some "other" format. 


\section{Overall Asset Use for Research and Training}

The preceding analyses examined the proportion of respondents likely to use a particular SSC asset for either research or training purposes. Another question is whether respondents would use any of the assets for either research or training purposes. This question is an important one because the answer reflects the proportion of the overall market likely to use the Facility to some extent if all of the assets were provided. These data were derived through combining Tables 4-5 and are presented in Table 6. As seen, 65.3\% of the respondents appear likely to utilize the Facility for either research or training if all of the assets were made available. The most common use would be joint research and training (35.4\%) followed by research alone (23.1\%) and training (6.8\%). Note that the joint "research and training" statistic does not necessarily mean using the same asset for both research and training purposes; it indicates using at least one of the assets for research and one of the assets for training. 
Table 6

Research and Training Use for the Total Sample

Anticipated Use

Only for Research

Only for Training

For Both Research and Training
$\mathbf{N}$

135

37

192

\section{$\underline{\text { Percent }}$}

23.1

6.8

35.4

Total Usage 


\section{Type of Asset Usage Anticipated}

Respondents were asked to specify the manner in which they expected to utilize SSC assets for research purposes. Four options were provided: design support, fabrication support, design use and fabrication use. "Support" was defined as "experts at the facility would assist with your design or fabrication." "Use" was defined as "your personnel themselves [would] use the equipment for design or fabrication." The percent of respondents indicating each type of usage they anticipated are presented in Table 7. The last column ("asset usage anticipated") is a summary measure. It reflects that proportion of the total respondents likely to use each respective asset in at least one of the four possible ways. Assuming that design/fabrication support/use fairly well defines the research possibilities at the Facility, these figures should correspond closely to those derived using the "value" measures. A comparison between Tables 4 and 7 reveals that a close correspondence is indeed found. The discrepancies in asset utilization predictions range from a high of $5.6 \%$ for high performance computing to a low of $0.5 \%$ for magnet fabrication; the estimates across assets differ, on the average, by $3.9 \%$. When two separate items, making inquiries concerning related issues, provide similar predictions of an event, evidence of convergent validity is provided. Thus, those figures lend confidence to the estimations of likely asset utilization for research at the Facility. Further, given support for the validity of research utilization estimates using the "value" based measures, there is no reason to expect the training utilization estimates using the "value" measures are overly biased. However, in this analyst's view, the usage estimates are best regarded as indicative of the percent of the target populations willing to risk asset usage at the Facility on a "trial" basis. Whether any 
Table 7

Percent of Total Sample Citing Types of Use Anticipated $(\mathrm{N}=542)$

\begin{tabular}{|c|c|c|c|c|c|}
\hline SSC Asset & $\begin{array}{l}\text { Design } \\
\text { Support }\end{array}$ & $\begin{array}{l}\text { Fabrication } \\
\text { Support }\end{array}$ & $\begin{array}{l}\text { Design } \\
\text { Use } \\
\end{array}$ & $\begin{array}{l}\text { Fabrication } \\
\text { Use } \\
\end{array}$ & $\begin{array}{l}\text { Asset Usage } \\
\text { Anticipated }\end{array}$ \\
\hline High Performance Computing & 22.5 & 6.1 & 29.5 & 12.9 & 40.2 \\
\hline Information Technology & 15.9 & 5.0 & 18.8 & 7.6 & 29.0 \\
\hline Mechanical Shops & 15.5 & 24.2 & 9.2 & 15.5 & 31.5 \\
\hline Cryogenics & 7.4 & 9.0 & 5.5 & 5.4 & 12.5 \\
\hline Magnet Fabrication & 6.6 & 7.9 & 3.5 & 3.7 & 10.0 \\
\hline Electronics & 23.6 & 22.0 & 17.5 & 16.1 & 34.7 \\
\hline Data Acquisition & 17.7 & 11.3 & 15.9 & 9.6 & 27.5 \\
\hline
\end{tabular}


"repeat" usage occurs will depend, of course, on a host of organizational and cost related considerations.

Across assets, design support or use appears more likely than fabrication support or use: $52 \%$ of the respondents indicated design support/use would be requested on at least one asset; $42.1 \%$ indicated fabrication support/use on at least one asset. A significant difference between the mean number of assets cited is also consistent with this conclusion (design $=2.09$; fabrication $=1.56$ ). The percentages of "support" versus "usage" preferences are similar: $44.3 \%$ and $46.9 \%$ of the respondents indicated those respective options on at least one asset. The mean scores on the number of assets cited are also not significantly different (support $=1.95$; usage $=1.71$ ).

A pattern is also seen in the usage preferences for certain assets. Design support and design use is preferred for high performance computing, information technology, and data acquisition. Fabrication support is most desired for mechanical shops. Both design and fabrication support are preferred for electronics. 


\section{Anticipated Weeks of Asset Use}

The preceding analyses examined "whether" respondents would likely utilize the Facility if it provided particular assets. This section examines the likely "extent" of such usage.

Respondents were asked, "If you were provided access to the SSC assets at a 'fair price', on the average how many weeks out of the year (1 to 52) would you anticipate using those assets for your research or development?'. The number of weeks of use anticipated was obtained for each asset. The mean results are provided in Table 8. Respondents who indicated that an asset was not needed were eliminated from the analysis.

The average weeks of use for high performance computing $(M=16.25)$ is significantly higher than any other asset. The average weeks of use for information technology $(M=11.87)$ is higher than remaining assets, with the exception of electronics and data acquisition. No significant differences are seen in weeks of usage between mechanical shops, cryogenics, magnet fabrication, electronics and data acquisition (range of 7.95 to $9.86 \mathrm{wks}$.). 
Table 8

Average Weeks of Anticipated Use for the Total Sample

$\underline{\text { SSC Asset }}$

Mean Weeks of Use

$\mathrm{N}$

High Performance Computing

16.26

247

Information Technology

11.87

183

Mechanical Shops

7.95

167

Cryogenics

8.55

87

Magnet Fabrication

8.77

70

Electronics

9.22

189

Data Acquisition

9.86

162 


\section{Principal Benefit Derived}

Respondents were asked, "What principal benefit, if any, would access to the SSC assets provide to you beyond what is currently available through other resources?". The purpose of this question was to allow respondents to state in their own words what they hoped to gain by access to the assets. The results are presented in Table 9 where two issues are clear. First, mentions of research/training benefits $(78.8 \%)$ are far more frequent than mentions of cost or convenience benefits (21.2\%). Second, specific citations of high performance computing (36.0\%) are far more frequent than mentions of all other assets combined (21.6\%). 
Table 9

Principal Benefit Provided by Access to the SSC Assets

Benefits

Research/Training Facilitation in general

Access to High Performance Computing

Access to Other Assets

Lower Costs

Convenience
$\underline{N}$

62

105

63

33

29 $\underline{\text { Percent }}$

21.2

36.0

21.6

11.3

9.9 


\section{Annual Rental Costs}

Respondents were asked, "If you do not gain access to the SSC assets, what do you estimate it will cost to purchase or rent (contractual cost on a yearly basis) comparable assets for your research or development?". Insufficient data was provided for purchase costs. Data on the average yearly rental costs are provided in Table 10. As shown, the estimates range from a high of $\$ 152,714$ for magnet fabrication to a low of $\$ 39,111$ for data acquisition. A mid-range estimate is provided for high performance computing $(\$ 91,065)$. 


\section{Table 10}

Estimated Annual Rental Costs for the Total Sample

SSC Asset

High Performance Computing

Information Technology

Mechanical Shops

Cryogenics

Magnet Fabrication

Electronics

Data Acquisition
Mean Rental Costs

$\$ 91,065$

$\$ 53,764$

$\$ 48,463$

$\$ 68,767$

$\$ 152,714$

$\$ 58,675$

$\$ 39,111$
$\mathbf{N}$

92

68

95

30

21

83

63 


\section{Resource Availability}

Respondents were asked to state the extent to which they feel resources represented by the SSC assets "are available elsewhere to meet your research or development needs. A five point scale was used with the following benchmarks: $1=$ routinely available; $3=$ moderately available; $5=$ not available. The results are presented in Table 11. As shown, respondents indicate all of the assets are at least moderately available elsewhere. These results appear surprising given the specialized capabilities of the SSC assets and may indicate that respondents considered a very broad geographic scope when interpreting the phrase "available elsewhere." Again, the absolute value of the mean scores may be less interpretable than relative differences. Comparisons revealed the cryogenics and magnet fabrication units are rated as significantly less available than other assets. No significant differences were found between the means for remaining assets. 
Table 11

Average Resource Availability for the Total Sample

SSC Asset

High Performance Computing

Information Technology

Mechanical Shops

Cryogenics

Magnet Fabrication

Electronics

Data Acquisition
Mean Availability

2.58

2.34

2.19

3.03

3.45

2.31

2.40
$\mathrm{N}$

344

276

270

128

104

281

255 


\section{Market Potential}

The total market (dollar revenue) potential for use of the SSE assets within the proposed Facility can be estimated as a function of four parameters. Costs of renting comparable assets elsewhere were judged to be a reasonable equilibrium market entry price (see Table 10): These annual rental cost figures for each asset were adjusted to reflect the proportion of a year involved in asset use (see Table 8). These figures were then multiplied by the estimated total number of potential users. This number of "potential users" was defined by: (A) current APS members principally employed by Texas universities; and (B) the number of technology firms in Texas; it was assumed that "companies," rather than employees within those firms, would purchase Facility access. This number of "potential users" $(A+B)$ was 3322 . Finally, these figures were . multiplied by estimates of the population proportions likely to utilize the assets (see Table 5). Using this equation [(annual rental costs) $\mathrm{x}$ (percent year in use) $\mathrm{x}$ ( $\mathrm{N}$ of potential users) $\mathrm{X}$ (percent of population expected to use)], the estimated market potential for the assets is as follows:

$\begin{array}{llr}\text { High Performance Computing } & = & \$ 31,430,403 \\ \text { Information Technology } & = & \$ 10,587,645 \\ \text { Mechanical Shops } & = & \$ 4,088,928 \\ \text { Cryogenics } & = & \$ 4,458,312 \\ \text { Magnet Fabrication } & = & \$ 6,988,784 \\ \text { Electronics } & = & \$ 9,177,146 \\ \text { Data Acquisition } & = & \$ 5,868,921\end{array}$

Across assets, the total market potential is $\$ 72,600,139$. These figures should be regarded with . appropriate caution. Differences in assumptions in the development of the market potential parameters can greatly affect the resulting estimates. In this analyst's view, the market potential estimates are best regarded as exactly that -- market potential. They represent optimistic 
projections of what might be obtained in the absence of limiting circumstances (e.g., the need to provide a price discount significantly lower than competitors to attract customers, the resistance of key decision makers to use of assets at the Facility [see Section 6] etc.). Further, the possibility that respondents' statements of "intended" (or expected) use of assets may overstate their "actual" use needs to be considered when interpreting the market potential figures. Finally, approaching the market potential for Facility use will necessitate a highly effective and experienced management team in translating the Facility concept into practice.

Given these concerns, a first year revenue base substantially lower than indicated by the market potential figures might be realized. Still, given an effective management team and an adequate promotional campaign, this analyst would conservatively anticipate first year revenues of at least several million dollars. 
Section 3: Results Stratified by Employment Group

Data were stratified by three employment groups: University deans $(N=24)$; university faculty/staff as principal employment $(\mathrm{N}=210)$; and corporations as principal employment $(\mathrm{N}=$ 263). Government $(N=18)$ and "other" $(N=17)$ places of employment were not considered given their small sample sizes. Although the sample of university deans is also small, they were included given their position and answers reflecting the needs of their entire "organization". 


\section{Research Value Scores}

Average research value scores and percent usage anticipated (calculated using the "top score" method) by employment group are presented in Table 12. As stated in Section 2, the significance of differences between usage proportions generally correspond to those observed for mean value testing and only the former will be reported.

Deans anticipate using high performance computing $(79.2 \%)$ significantly more than any other asset. Information technology, mechanical shops, electronics, and data acquisition have more usage anticipated than cryogenics and magnet fabrication.

The asset preferences of university/staff members matched the total sample results. High performance computing has more anticipated usage $(61.8 \%)$ than any other asset. Cryogenics and magnet fabrication have less usage anticipated than all other assets. No significant differences were observed in the usage of the remaining four assets.

A less diversified view was reported by corporate respondents. Magnet fabrication and cryogenics have significantly less anticipated use than remaining five assets. However, no significant differences were found in the asset usage of any of those five assets with the exception of mechanical shops. Mechanical shops have significantly less anticipated usage than high performance computing.

An examination of individual asset usage percentages across employment groups revealed a clear picture. Corporate respondents anticipate significantly less use of every asset than either deans or faculty/staff. With the exception of mechanical shops, cryogenics and magnet fabrication, deans indicated significantly more asset usage than faculty/staff. 
Table 12

Average Research Value Scores and Percent Usage Anticipated by Employment Group

SSC ASSET

\begin{tabular}{llll}
\multicolumn{2}{c}{ DEANS* } & \multicolumn{2}{c}{ FACULTY/STAFF** } \\
Mean & Percent & Mean & Percent \\
Value & Usage & Value & Usage
\end{tabular}

CORPORATION*** Mean Percent

Value Usage

High Performance

3.42

79.2

2.93

61.8

1.38

28.0

Computing

Information

2.58

50.0

1.91

39.6

1.24

22.7

Technology

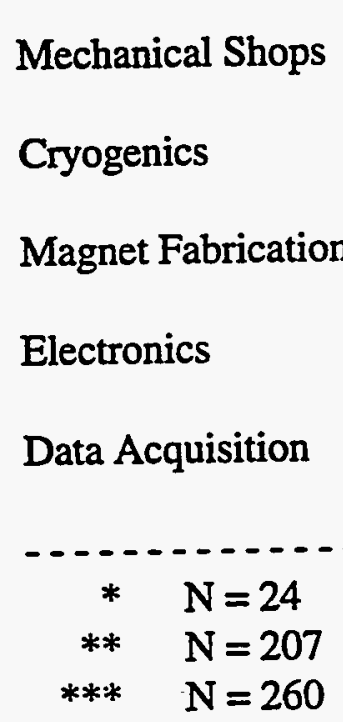

41.7

12.5

$16.7 \quad 0.85$

$48.8 \quad 1.68$

$58.3 \quad 1.60$
33.0

20.9

16.5

36.9

34.0
2.04

2.50

58.3

1.60




\section{Training Value Scores}

In general, the asset rank order of training value scores and usage percents corresponded across employment groups, to the pattern observed for research use. Training value and anticipated use data are provided in Table 13.

Deans anticipate using high performance computing (50.0\%) significantly more than all other assets. Information technology usage is higher than all remaining assets, except data acquisition and electronics. Data acquisition and electronics have higher usage than cryogenics and magnet fabrication.

Faculty/staff anticipate using high performance computing (46.3\%) significantly more than any other asset except information technology. Electronics and data acquisition usage are significantly higher than mechanical shops, cryogenics and magnet fabrication.

For corporate respondents, anticipated use of cryogenics and magnet fabrication is significantly lower than for the remaining five assets. No significant differences are found between those five assets.

An examination of individual assets across groups revealed the ratings of corporate respondents to be significantly lower than deans and faculty/staff on the high performance computing and information technology assets. No significant differences were seen for mechanical shops. Corporate respondents provided value ratings significantly lower than faculty/staff on remaining assets. 
Table 13

Average Training Value Scores and Percent Usage Anticipated by Employment Group

SSC ASSET

\begin{tabular}{llllll}
\multicolumn{2}{c}{ DEANS* } & \multicolumn{2}{c}{ FACULTYISTAFF** } & \multicolumn{2}{c}{ CORPORATION*** } \\
Mean & Percent & Mean & Percent & Mean & Percent \\
Value & Usage & Value & Usage & Value & Usage
\end{tabular}

High Performance

2.04

50.0

2.16

46.3

0.97

20.0

Computing

Information

1.63

$33.3 \quad 1.60$

45.1

0.84

17.1

Technology

Mechanical Shops

0.88

$20.8 \quad 0.93$

18.6

0.70

12.4

Cryogenics

0.63

$\begin{array}{ll}12.5 & 0.87\end{array}$

17.6

0.23

4.3

Magnet Fabrication

0.58

$12.5 \quad 0.64$

12.2

0.22

2.6

Electronics

1.08

25.0

1.44

31.4

0.99

21.4

Data Acquisition

1.33

25.0

1.46

31.2

0.78

15.3

$$
\begin{array}{rl}
* & N=24 \\
* * & N=235 \\
* * * & N=188
\end{array}
$$




\section{Overall Asset Usage for Research and Training}

The usage data in Tables 12 and 13 was analyzed to determine the proportion of respondents that would utilize any (at least one) of the assets and whether that usage would be only for research purposes, training purposes or both. The results are presented in Table 14. As seen, about half $(50.8 \%)$ of the corporate respondents are expected to use at least one of the SSC assets if made available in the Facility. Higher use should occur among university faculty/staff (78.6\%) and the organizations represented by the deans $(83.4 \%)$. As with the results for the overall sample, asset use for both research and training is the most common response across groups (ranging from $25.4 \%$ for corporations to $50.0 \%$ for deans). Again, this statistic does not necessarily indicate use of the same asset for both research and training purposes. Rather, it refers to the use of one of the assets for research and one of the assets for training. 
Table 14

Research and Training Use by Employment Group

\begin{tabular}{|c|c|c|c|c|c|c|}
\hline \multirow{2}{*}{ ANTICIPATED USE } & \multicolumn{2}{|c|}{ DEANS } & \multicolumn{2}{|c|}{ FACULTY/STAFF } & \multicolumn{2}{|c|}{ CORPORATION } \\
\hline & $\mathbf{N}$ & Percent & $\mathbf{N}$ & Percent & $\mathbf{N}$ & Percent \\
\hline Only for Research & 7 & 29.2 & 56 & 26.7 & 47 & 17.8 \\
\hline Only for Training & 1 & 4.2 & 13 & 6.2 & 20 & 7.6 \\
\hline $\begin{array}{l}\text { Both for Research } \\
\text { and Training }\end{array}$ & 12 & 50.0 & 96 & 45.7 & 67 & 25.4 \\
\hline Total Usage & 20 & 83.4 & 165 & 78.6 & 134 & 50.8 \\
\hline No Use Anticipated & 4 & 16.6 & 45 & 21.4 & 130 & 49.2 \\
\hline
\end{tabular}




\section{Types of Asset Usage Anticipated}

Tables 15-17 provide data on the types of asset use anticipated across respondent groups. The types of use anticipated for both faculty/staff and corporate respondents correspond across assets to the results for the overall sample: design support and use are the most preferred options for high performance computing, information technology and data acquisition. Fabrication support is preferred for mechanical shops. Design and fabrication support are most preferred for electronics. Deans also reported more anticipated design use and design support for high performance computing and information technology.

The last column in Tables 15-17 refers to the percent of respondents who stated they anticipate using at least one of the four indicated options for each respective asset. These estimates of total asset usage were compared to the estimates derived using the research value data (see Table 13). Those comparisons reveal an average discrepancy of $9.1 \%$ for deans, $5.4 \%$ for faculty/staff and $2.4 \%$ for corporations. Again, these figures provide confidence in the utility of the usage estimates (particularly for the two largest sub-samples: faculty/staff and corporations) although they are probably best considered as indicative of a willingness to consider "trial" use of the assets at the Facility. 
Table 15

Percent of Deans Citing Types of Asset Use Anticipated (N=24)

\begin{tabular}{|c|c|c|c|c|c|}
\hline SSC ASSET & $\begin{array}{l}\text { Design } \\
\text { Support }\end{array}$ & $\begin{array}{l}\text { Fabrication } \\
\text { Support }\end{array}$ & $\begin{array}{l}\text { Design } \\
\text { Use } \\
\end{array}$ & $\begin{array}{l}\text { Fabrication } \\
\text { Use }\end{array}$ & $\begin{array}{l}\text { Asset Usage } \\
\text { Anticipated }\end{array}$ \\
\hline $\begin{array}{l}\text { High Performance } \\
\text { Computing }\end{array}$ & 37.5 & 12.5 & 41.7 & 25.0 & 62.5 \\
\hline $\begin{array}{l}\text { Information } \\
\text { Technology }\end{array}$ & 29.2 & 8.3 & 33.3 & 16.7 & 54.2 \\
\hline Mechanical Shops & 33.3 & 37.5 & 25.0 & 41.7 & 54.2 \\
\hline Cryogenics & 8.3 & 8.3 & 12.5 & 8.3 & 20.8 \\
\hline Magnet Fabrication & 12.5 & 16.7 & 8.3 & 12.5 & 20.8 \\
\hline Electronics & 33.3 & 37.5 & 37.5 & 37.5 & 54.2 \\
\hline Data Acquisition & 29.2 & 16.7 & 25.0 & 33.3 & 50.0 \\
\hline
\end{tabular}




\section{Table 16}

Percent of Faculty/Staff Citing Types of Asset Use Anticipated (N=210)

\begin{tabular}{|c|c|c|c|c|c|}
\hline SSC ASSET & $\begin{array}{l}\text { Design } \\
\text { Support }\end{array}$ & $\begin{array}{l}\text { Fabrication } \\
\text { Support }\end{array}$ & $\begin{array}{l}\text { Design } \\
\text { Use } \\
\end{array}$ & $\begin{array}{l}\text { Fabrication } \\
\text { Use } \\
\end{array}$ & $\begin{array}{l}\text { Asset Usage } \\
\text { Anticipated }\end{array}$ \\
\hline $\begin{array}{l}\text { High Performance } \\
\text { Computing }\end{array}$ & 24.8 & 5.7 & 38.1 & 20.0 & 48.6 \\
\hline $\begin{array}{l}\text { Information } \\
\text { Technology }\end{array}$ & 18.1 & 5.7 & 23.3 & 9.5 & 33.8 \\
\hline Mechanical Shops & 17.1 & 27.6 & 10.0 & 15.2 & 36.7 \\
\hline Cryogenics & 8.6 & 12.9 & 6.7 & 6.7 & 17.1 \\
\hline Magnet Fabrication & 7.1 & 9.0 & 4.3 & 3.3 & 11.9 \\
\hline Electronics & 24.3 & 23.8 & 16.7 & 14.8 & 34.8 \\
\hline Data Acquisition & 19.0 & 14.3 & 16.7 & 10.0 & 29.5 \\
\hline
\end{tabular}


Table 17

Percent of Corporate Respondents Citing Types of Asset Usage Anticipated (N=264)

\begin{tabular}{|c|c|c|c|c|c|}
\hline SSC ASSET & $\begin{array}{l}\text { Design } \\
\text { Support }\end{array}$ & $\begin{array}{l}\text { Fabrication } \\
\text { Support }\end{array}$ & $\begin{array}{l}\text { Design } \\
\text { Use } \\
\end{array}$ & $\begin{array}{l}\text { Fabrication } \\
\text { Use } \\
\end{array}$ & $\begin{array}{l}\text { Asset Usage } \\
\text { Anticipated }\end{array}$ \\
\hline $\begin{array}{l}\text { High Performance } \\
\text { Computing }\end{array}$ & 18.6 & 4.9 & 18.2 & 5.3 & $\begin{array}{c}28.4 \\
.\end{array}$ \\
\hline $\begin{array}{l}\text { Information } \\
\text { Technology }\end{array}$ & 13.3 & 3.4 & 12.5 & 4.5 & 22.3 \\
\hline Mechanical Shops & 11.0 & 17.4 & 7.6 & 12.5 & 23.1 \\
\hline Cryogenics & 4.5 & 4.2 & 2.3 & 1.9 & 5.3 \\
\hline Magnet Fabrication & 4.5 & 4.5 & 1.9 & 1.9 & 5.3 \\
\hline Electronics & 20.8 & 18.2 & 15.5 & 13.3 & 31.1 \\
\hline Data Acquisition & 14.4 & 6.8 & 12.5 & 6.4 & 21.6 \\
\hline
\end{tabular}




\section{Estimated Weeks of Asset Use}

The average estimated number of weeks of asset use by employment group are presented in Table 18.

Deans estimate significantly more extensive use for high performance computing $(M=$ 16.53) than for any other asset. Electronics $(M=13.20)$ and data acquisition $(M=13.74)$ estimates are higher than for remaining assets with the exception of magnet fabrication. No significant differences are found among remaining assets.

Faculty/staff also estimate more extensive use of computing $(M=19.27)$ than other assets. Information technology $(M=11.51)$ and data acquisition $(M=10.42)$ estimates are higher than for remaining assets. No other differences are found.

Corporations estimate use of cryogenics $(M=6.05)$, magnet fabrication $(M=6.04)$ and data acquisition $(M=6.49)$ to be less than other assets with the exception of electronics $(M=$ 8.51). No other differences are found.

An analysis of individual assets by employment group reveals that corporations $(M=9.14)$ estimate less weeks of high performance computing use than either faculty/staff $(M=19.27)$ or deans $(M=16.53)$. No significant differences are found on other assets. Thus, although the proportion of the corporate population expected to utilize the assets may be less than the university population, the extent of usage within that segment is likely to be high as university users across most assets. 


\section{Table 18}

Average Weeks of Anticipated Usage by Employment Group

SSC ASSET

High Performance

Computing

Information

Technology

Mechanical Shops

Cryogenics

Magnet Fabrication

Electronics
10

12

DEANS

N Mean

$17 \quad 16.53$

$17 \quad 10.00$

$11 \quad 10.09$

$\begin{array}{ll}8 & 9.88\end{array}$

$5 \quad 11.80$

13.20

13.74
32

78

FACULTYISTAFF

N Mean

127

82

78

45

7.82

8.31

7.51

10.42
CORPORATION

N Mean

$77 \quad 9.14$

$\begin{array}{ll}68 & 10.00\end{array}$

$55 \quad 10.09$

$21 \quad 6.05$

$21 \quad 6.04$

$80 \quad 8.51$

$\begin{array}{ll}59 & 6.49\end{array}$ 


\section{Annual Rental Costs}

Average estimated annual asset rental costs by employment group are presented in Table 19. The key finding of interest is that corporations estimate rental costs significantly higher than faculty/staff on all assets except magnet fabrication and data acquisition. Faculty/staff estimate costs for magnet fabrication ( $M=\$ 215,250)$ substantially higher than corporations $(M=$ $\$ 27,375$ ). The tendency for deans to estimate higher costs than other groups (in three out of five assets) possibly reflects estimates made for their organizations as a whole. 
Table 19

Estimated Annual Rental Costs by Employment Group

\begin{tabular}{|c|c|c|c|c|c|c|}
\hline \multirow[t]{2}{*}{ SSC ASSET } & \multicolumn{2}{|c|}{ DEANS } & \multicolumn{2}{|c|}{ FACULTYISTAFF } & \multicolumn{2}{|c|}{ CORPORATION } \\
\hline & $\mathbf{N}$ & Mean & $\mathbf{N}$ & Mean & $\mathbf{N}$ & Mean \\
\hline $\begin{array}{l}\text { High Performance } \\
\text { Computing }\end{array}$ & 9 & $\$ 242,111$ & 43 & $\$ 53,209$ & 29 & $\$ 110,379$ \\
\hline $\begin{array}{l}\text { Information } \\
\text { Technology }\end{array}$ & 5 & $\$ 260,200$ & 31 & $\$ 25,161$ & 26 & $\$ 52,038$ \\
\hline Mechanical Shops & 6 & $\$ 84,666$ & 47. & $\$ 18,042$ & 29 & $\$ 86,620$ \\
\hline Cryogenics & - & - & 17 & $\$ 20,764$ & 7 & $\$ 35,000$ \\
\hline Magnet Fabrication & - & - & 8 & $\$ 215,250$ & 8 & $\$ 27,375$ \\
\hline Electronics & 7 & $\$ 100,000$ & 33 & $\$ 16,515$ & 35 & $\$ 95,286$ \\
\hline Data Acquisition & 6 & $\$ 109,373$ & 23 & $\$ 30,217$ & 28 & $\$ 33,321$ \\
\hline
\end{tabular}




\section{Section 4: Results Stratified by Area of Specialization}

A series of discriminatory analyses (discriminant function analysis and analysis of variance) were conducted to identify groups with the highest likelihood of utilizing the SSC assets. Respondents were asked to identify "Which of the following best describes your principal orientation and area of specialization?". Those descriptions were used to identify target groups for use of SSC assets for research and training purposès.

For research purposes the target group orientations were: experiment, design and training. For training purposes the target group orientations were: experiment and training. Separate analyses are not presented here for target group orientations since area of specialization appears to present an easier method of identifying potential users. However, it should be noted that the target orientation groups revealed significantly higher anticipated usage rates across assets, when compared to respondents with other orientations (theory, product development or fabrications).

The target group specializations for research purposes were as follows: astrophysics, biophysics, high energy physics, nuclear physics, physics of beams, superconductivity and mechanical engineering. Respondents in these specializations (labeled "target group") were generally more likely to indicate anticipated asset use for research purposes than those in remaining specializations (labeled "others").

The target group specializations for training purposes were as follows: astrophysics, biophysics, condensed matter, high energy physics, nuclear physics and superconductivity. Respondents in these specializations (labeled "target group") were generally more likely to indicate anticipated asset usage for training purposes than those in remaining specializations. 


\title{
Anticipated Asset Usage for Research Purposes
}

Table 20 presents the mean research value and percent usage statistics for SSC assets stratified by target group. The key finding is that the anticipated usage for the target group is significantly higher than for "others" across every asset. Table 21 provides a breakdown of the type of use anticipated, along with a second asset usage estimate. As in previous analyses, the two asset usage estimates (scored on different measures) were-compared and found to reasonably correspond. On the average, the asset usage estimates differ by $5.3 \%$.

An analysis of percent usage differences across assets (using Table 20) revealed results for the target group that matched those for the total sample. Anticipated use of high performance computing (73.3\%) is significantly higher than for any other asset and use of cryogenics and magnet fabrication is significantly lower than other assets. No significant differences exist in the usage percents for information technology, mechanical shops, electronics or data acquisition.

Separate analyses were conducted to identify the individual assets with significantly higher anticipated use for each specialization (relative to those in other specializations) within the target group. Those findings are as follows:

\author{
Astrophysics \\ High Performance Computing \\ Information Technology \\ Biophysics \\ High Performance Computing \\ Information Technology \\ Electronics \\ Data Acquisition \\ High Energy Physics
}

All seven assets 
Table 20

Average Research Value Scores and Percent Use Anticipated by Area of Specialization

SSC ASSET

High Performance

Computing

Information

Technology

Mechanical Shops

Cryogenics

Magnet Fabrication

Electronics

Data Acquisition

\section{TARGET GROUP*}

Mean Percent Usage

3.44 .

73.3

52.3

50.0

27.7

23.6

52.7

50.7

1.45

1.20

2.42

2.30

\section{OTHERS**}

Mean Percent Usage

2.34

50.4

1.42

27.6

1.09

20.9

0.59

11.4

0.52

8.1
1.24

25.2

1.24

23.8

$$
\begin{aligned}
* \quad N=148 \\
* \quad N=210
\end{aligned}
$$


Table 21

Percent of Area Specialization Target Group Citing Types of Asset Use Anticipated ( $\mathrm{N}=151)$

\begin{tabular}{|c|c|c|c|c|c|}
\hline SSC ASSET & $\begin{array}{l}\text { Design } \\
\text { Support }\end{array}$ & $\begin{array}{l}\text { Fabrication } \\
\text { Support }\end{array}$ & $\begin{array}{l}\text { Design } \\
\text { Use }\end{array}$ & $\begin{array}{l}\text { Fabrication } \\
\text { Use }\end{array}$ & $\begin{array}{l}\text { Asset Usage } \\
\text { Anticipated }\end{array}$ \\
\hline $\begin{array}{l}\text { High Performance } \\
\text { Computing }\end{array}$ & 33.1 & 8.6 & 47.7 & 26.5 & 62.9 \\
\hline $\begin{array}{l}\text { Information } \\
\text { Technology }\end{array}$ & 22.5 & 7.9 & 34.4 & 15.9 & 47.0 \\
\hline Mechanical Shops & 25.2 & 39.1 & 14.6 & 27.8 & 51.0 \\
\hline Cryogenics & 11.3 & 15.9 & 10.6 & 12.6 & 23.2 \\
\hline Magnet Fabrication & 9.9 & 13.9 & 6.0 & 8.6 & 18.5 \\
\hline Electronics & 35.8 & 36.4 & 28.5 & 27.8 & 50.3 \\
\hline Data Acquisition & 28.5 & 17.9 & 25.8 & 18.5 & 42.4 \\
\hline
\end{tabular}




\section{Nuclear Physics}

High Performance Computing

Mechanical Shops

Magnet Fabrication

Electronics

Data Acquisition

\section{Superconductivity}

\section{Information Technology \\ Mechanical Shops \\ Cryogenics \\ Magnet Fabrication \\ Electronics \\ Data Acquisition}

\section{Mechanical Engineering \\ Electronics \\ Data Acquisition \\ Mechanical Shops}

Note that for the target specializations the non-significant assets all showed directionally

higher usage. This may suggest that the target specializations are favorably inclined, in general, to the idea of a central facility providing access to the SSC assets. 


\section{Anticipated Asset Usage for Training Purposes}

Table 22 provides average training value scores and percent usage statistics for SSC assets by target group. Two points are clear. First, usage by target group specializations is significantly higher than other specializations across all assets. Second, estimates of asset use for training purposes are lower than the research use estimates for all assets except cryogenics and magnet fabrication.

Comparisons between assets for the target group reveal higher anticipated use of high performance computing than all other assets. No differences are observed between information technology, mechanical shops, electronics and data acquisition. Magnet fabrication use is lower than those four assets. Anticipated use of cryogenics is lower than information technology, electronics and data acquisition.

Analyses were again conducted to determine the individual assets with significantly higher training use for each specialization within the target group (relative to those with other specializations). The results were as follows:

\section{Astrophysics}

Magnet Fabrication

Cryogenics

Mechanical Shops 
Table 22

Average Training Value Scores and Percent Usage Anticipated by Area of Specialization

\begin{tabular}{lcccr} 
SSC ASSET & \multicolumn{2}{c}{ TARGET GROUP } & \multicolumn{2}{c}{ OTHERS } \\
\cline { 2 - 5 } & 2.29 & Mean & Mean \\
$\begin{array}{l}\text { High Performance } \\
\text { Computing }\end{array}$ & 1.64 & 35.9 & 1.63 & 34.9 \\
$\begin{array}{l}\text { Information } \\
\text { Technology }\end{array}$ & 1.23 & 27.9 & 1.25 & 27.1 \\
Mechanical Shops & 1.09 & 23.2 & 0.60 & 9.6 \\
Cryogenics & 0.89 & 17.1 & 0.47 & 9.6 \\
Magnet Fabrication & 1.73 & 40.6 & 0.34 & 6.6 \\
Electronics & 1.75 & 39.4 & 0.95 & 19.9 \\
Data Acquisition & & & 0.98 & 20.5
\end{tabular}

$\begin{aligned} * \quad N & =165 \\ * * \quad N & =166\end{aligned}$ 
Biophysics

High Performance Computing

Information Technology

Mechanical Shops

Cryogenics

Electronics

High Energy Physics

High Performance Computing

Mechanical Shops

Electronics

Data Acquisition

Nuclear Physics

High Performance Computing

Mechanical Shops

Magnet Fabrication

Electronics

Data Acquisition

Condensed Matter

Mechanical Shops

Cryogenics

Electronics

$\underline{\text { Superconductivity }}$

All seven assets 


\section{Estimated Weeks of Asset Usage}

Table 23 provides estimated weeks of asset use by target group. The target group specializations report higher mean weeks of usage than other specializations across all assets except magnet fabrication and data acquisition. Thus, not only are target specializations more likely to use the assets, they are also more likely to use most of them for a longer period of time. 
Table 23

Average Weeks of Anticipated Usage by Area of Specialization

SSC ASSET

TARGET GROUP

N Mean

OTHERS

High Performance

109

19.04

N $\quad \underline{\text { Mean }}$

Computing

Information

79

13.83

62

9.00

Technology

Mechanical Shops

81

8.79

54

5.52

Cryogenics

44

10.47

28

7.32

Magnet Fabrication

36

9.83

20

8.45

Electronics

79

10.95

63

5.01

Data Acquisition

74

11.12

55

9.18 


\section{Annual Rental Costs}

Table 24 presents estimated annual rental costs by target group. One clear finding emerged. The estimated costs by respondents in the target specializations are significantly higher (and hopefully more accurate) than those in other specializations across all assets. 
Table 24

Estimated Annual Rental Costs by Area of Specialization

SSC ASSET

High Performance

Computing

Information

Technology

Mechanical Shops

Cryogenics

Magnet Fabrication

Electronics

Data Acquisition

\section{TARGET GROUP}

N $\quad \underline{\text { Mean }}$

$46 \$ 96,652$

30

$\$ 69,733$

45

$\$ 43,755$

$\$ 99,176$

$\$ 268,700$

$\$ 45,642$

$\$ 47,629$

17

10

28

27

\section{OTHERS \\ N \\ Mean}

35 . $\$ 81,114$

22

$\$ 21,045$
35

10

7

34

22
$\$ 21,028$

$\$ 31,900$

$\$ 54,857$

$\$ 31,205$

$\$ 30,909$ 
Section 5: Results Stratified by Type of Business

A series of discriminatory analyses were also conducted to determine the types of businesses with the highest likelihood of using the SSC assets. Corporate respondents were asked, "Which of the following best describes your company's business?". Those answers were used to identify target groups for use of SSC assets for both research and training purposes.

For research purposes the target group businesses were as follows:

Computers, parts and equipment

Electrical equipment and components

Industrial chemicals

Drugs and medicines

Plastic and synthetic materials

Optical and medical instruments

Additional

Respondents generally provided a description of their "additional" business. Those descriptions are provided in Table 25. Note that in most cases respondents marked another business type along with the "additional" category. Respondents in the "target group" specializations were generally more likely to indicate anticipated asset use for research purposes, relative to those in all remaining businesses (the "other" category in Table 26).

Three target businesses for training purposes were identified:

Computers, parts and equipment Electrical equipment and components Aircraft and parts

Respondents in these three businesses were generally more likely to indicate anticipated asset use for training purposes than those in other businesses. 
Table 25

Descriptions of "Additional" Businesses

Training Systems

Avionics, Test and Measurement Electronics

Department of Defense Contractor

Research and Development in Intelligent Computing

Software Development and Sales

Satellite Systems Integration

Finance

Telecommunications

Custom Plastic Injection and Blown Molding

Information Research

Education

Ultraviolet Energy Sources

Market Research

Geophysical Measurement Systems

High Speed Document Sorting Equipment

Integrated Circuits

Video Conferencing

Industrial Material Analysis

Stock Sampling for Stationary Sources 


\section{Anticipated Asset Usage for Research Purposes}

Table 26 provides the mean research value scores and percent usage statistics for SSC assets stratified by target group. The target group is seen to have significantly higher anticipated use than other businesses for all assets except cryogenics and magnet fabrication. Table 27 provides a breakdown of the types of usage anticipated for the target businesses along with a second asset usage estimate. As in previous analyses, the two usage estimates for each asset were compared (compare Tables 26 and 27 ) and found to be very similar. On the average, the usage estimates vary by $3.6 \%$.

An analysis of percent usage differences between assets (using Table 26) was conducted for the target group. Anticipated use of cryogenics and magnet fabrication is significantly lower than other assets. No differences in anticipated usage are seen for high performance computing, information technology, electronics or data acquisition. Anticipated electronics use is significantly higher than mechanical shops.

Separate analyses were conducted to identify the individual assets with significantly higher anticipated use for each type of business (relative to all other businesses) within the target group. Those findings are as follows:

\section{Computers, Parts and Equipment}

High Performance Computing Information Technology Magnet Fabrication Electronics Data Acquisition 
Table 26

Average Research Value Scores and Percent Usage Anticipated by Type of Business

SSC ASSET

High Performance

Computing

Information

Technology

Mechanical Shops

Cryogenics

Magnet Fabrication

Electronics

Data Acquisition
TARGET GROUP*

Mean Percent Usage

1.21

1.47

1.06

0.40

0.33

1.40

1.06

25.9

25.9

19.8

7.4

4.9

32.1

25.0

$0.71 \quad 11.7$

$0.71 \quad 11.7$

OTHERS**

Mean Percent Usage

0.80

13.8

0.52

7.4

0.13

1.0

0.07

0

0.93

18.1

0.59

11.7

$$
\begin{array}{r}
* \quad N=81 \\
* * \quad N=94
\end{array}
$$


Table 27

Percent of Business Target Group Citing Types of Asset

Usage Anticipated ( $N=82)$

\begin{tabular}{|c|c|c|c|c|c|}
\hline SSC ASSET & $\begin{array}{l}\text { Design } \\
\text { Support }\end{array}$ & $\begin{array}{l}\text { Fabrication } \\
\text { Support }\end{array}$ & $\begin{array}{l}\text { Design } \\
\text { Use } \\
\end{array}$ & $\begin{array}{l}\text { Fabrication } \\
\text { Use } \\
\end{array}$ & $\begin{array}{l}\text { Asset Usage } \\
\text { Anticipated }\end{array}$ \\
\hline $\begin{array}{l}\text { High Performance } \\
\text { Computing }\end{array}$ & 24.4 & 6.1 & 14.6 & 3.7 & 31.7 \\
\hline $\begin{array}{l}\text { Information } \\
\text { Technology }\end{array}$ & 19.5 & 2.24 & 12.2 & 4.9 & 26.8 \\
\hline Mechanical Shops & 18.3 & 20.7 & 14.6 & 22.0 & 31.7 \\
\hline Cryogenics & 6.1 & 6.1 & 2.4 & 1.2 & 7.3 \\
\hline Magnet Fabrication & 6.1 & 7.3 & 2.4 & 2.4 & 8.5 \\
\hline Electronics & 25.6 & 18.3 & 20.7 & 15.9 & 34.1 \\
\hline Data Acquisition & 17.1 & 9.8 & 13.4 & 7.3 & 25.6 \\
\hline
\end{tabular}


Electrical Equipment and Components

Mechanical Shops

Magnet Fabrication

Electronics

Data Acquisition

Industrial Chemicals

Information Technology

Mechanical Shops

Electronics

Data Acquisition

Drugs and Medicine

Information Technology

Mechanical Shops

Cryogenics

Data Acquisition

Optical and Medical Instruments

Information Technology

Mechanical Shops

Electronics

Data Acquisition

Aircraft Parts

Mechanical Shops

Cryogenics

Electronics

Plastic and Synthetic Materials

Mechanical Shops

Data Acquisition

Other

Cryogenics

Data Acquisition 


\section{Anticipated Asset Usage for Training Purposes}

Table 28 provides average training value scores and percent usage statistics for SSC assets by target group. Anticipated target group use is significantly higher than for other businesses on all assets except cryogenics, magnet fabrication and data acquisition.

Surprisingly, anticipated training usage is not significantly different than research usage across assets, except for data acquisition. Anticipated research use of data acquisition is significantly higher than for training. The lack of significant differences on other assets may reflect the small target group sample size available for the training measures $(N=38)$.

Analyses were again conducted to determine the individual assets with significantly higher training use for each specialization within the target group (relative to all other types of business). The results were as follows:

\section{Computers, Parts and Equipment}

High Performance Computing Magnet Fabrication

Mechanical Shops

\section{Electrical Equipment and Components}

High Performance Computing Information Technology

Mechanical Shops

Magnet Fabrication

Electronics

Data Acquisition

Aircraft and Parts

Mechanical Shops

Electronics

Data Acquisition 
Table 28

Average Training Value Scores and Percent Usage Anticipated by Type of Business

SSC ASSET

High Performance

Computing

Information

Technology

Mechanical Shops

Cryogenics

Magnet Fabrication

Electronics

Data Acquisition

\section{TARGET GROUP*}

$\underline{N} \quad \underline{\text { Mean }}$

1.16

1.13

1.24

21.0

2.6

2.6

28.2

10.5

0.37

1.29

0.74
0.51

0.13

2.5

\section{OTHERS**}

N

Mean

0.55

10.8

12.6

8.4

0

16.1

11.7

$$
\begin{aligned}
& \text { * } \quad N=38 \\
& \text { ** } \quad \mathrm{N}=120
\end{aligned}
$$




\section{Estimated Weeks of Asset Usage}

Table 29 provides estimated weeks of asset use for research purposes by target group. The target group businesses report significantly higher mean weeks of use than other businesses across all assets except data acquisition. Thus, not only is the target group more likely than other businesses to use the assets, they are also more likely to use most of them for a longer period of time. 
Table 29

Average Weeks of Anticipated Use by Type of Business

\begin{tabular}{|c|c|c|c|c|}
\hline \multirow{2}{*}{ SSC ASSET } & \multicolumn{2}{|c|}{ TARGET GROUP } & \multicolumn{2}{|c|}{ OTHERS } \\
\hline & $\mathbf{N}$ & Mean & $\mathbf{N}$ & Mean \\
\hline $\begin{array}{l}\text { High Performance } \\
\text { Computing }\end{array}$ & 23 & 13.00 & 14 & 2.36 \\
\hline $\begin{array}{l}\text { Information } \\
\text { Technology }\end{array}$ & 24 & 15.75 & 18 & 8.00 \\
\hline Mechanical Shops & 19 & 14.42 & 13 & 3.31 \\
\hline Cryogenics & 8 & 9.25 & 7 & 0.57 \\
\hline Magnet Fabrication & 8 & 10.13 & 6 & 3.61 \\
\hline Electronics & 25 & 13.28 & 22 & 10.41 \\
\hline Data Acquisition & 19 & 8.16 & 14 & 8.21 \\
\hline
\end{tabular}


Annual Rental Costs

Table 30 provides estimated annual rental costs by target group. These data may or may not provide insight concerning target group valuation of the assets. Caution is advised in the interpretation of the figures given the small sample sizes available. 
Table 30

Estimated Annual Rental Costs by Type of Business

SSC ASSET

TARGET GROUP
$N$

OTHERS

N Mean

N $\quad$ Mean

High Performance

7

$\$ 102,142$

4

$\$ 94,500$

Computing

Information

8

$\$ 73,125$

8

$\$ 64,500$

Technology

Mechanical Shops

10

$\$ 124,400$

5

$\$ 131,000$

Cryogenics

[Insufficient Data]

Magnet Fabrication

[Insufficient Data]

Electronics

11

$\$ 158,000$

10

$\$ 79,300$

Data Acquisition

7

$\$ 16,714$

7

$\$ 54,428$ 
Section 6: Other Stratifications

\section{Decision Making Responsibilities}

Respondents were asked, "In your current position, how would you describe your likely responsibilities for making a decision to utilize SSC assets?". Five response categories were provided: sole responsibility, major input, moderate input, minor input and no input. The three classifications used for stratification purposes are presented in Table 31 and were made on the basis of cell size equality considerations. The frequency count within the "moderate to no input" group $(N=152)$ was as follows: moderate input, $N=81 ;$ minor input, $N=47$; no input, $N=24$.

Anticipated asset use for research and training purposes was examined as a function of the decision making groups. Results revealed that respondents with "sole" decision making responsibilities were significantly less likely to utilize the assets. No differences were found between the other two groups (major input and moderate to no input respondents). These results can be partly explained by the fact that corporate respondents, in general, indicated a lesser likelihood of asset use than university respondents and 57\% of the "sole" decision making group are corporate respondents. The need to educate and market the Facility to key decision makers is clearly indicated. 
Table 31

Decision Making Responsibilities for Use of SSC Assets

Responsibility

Sole Responsibility

Major Input

Moderate to No Input
$\mathbf{N}$

166

201

152
Percent

32.0

38.7

29.3

Missing 


\section{Miles From Workplace to Waxahachie}

Data on miles from respondent workplace to Waxahachie, Texas are presented in Table 32. The four categories utilized for stratification purposes were determined through an examination of "breaks" in the frequency distribution of the data.

No significant differences between the four categories were found in the asset utilization data. These results were quite surprising. One possible explanation is that respondents anticipate use of the SSC assets for non-routine and specialized projects that negate the opportunity costs represented by travel, at least within the state of Texas. 


\section{Table 32}

Miles from Workplace to Waxahachie, Texas

\begin{tabular}{|c|c|c|}
\hline Miles & $\mathbf{N}$ & Percent \\
\hline 1 to 35 & 117 & 23.6 \\
\hline 36 to 138 & 96 & 19.4 \\
\hline 139 to 184 & 103 & 20.8 \\
\hline 185 to 560 & 179 & 36.2 \\
\hline Missing & 47 & - \\
\hline
\end{tabular}




\section{Annual Corporate Revenues}

An approximate quartile split was utilized for stratifying results by company revenues.

These data are presented in Table 33. Results revealed that anticipated asset use for research was significantly higher for the highest revenue group, relative to the other three, for the high performance computing, cryogenics, magnet fabrication and data acquisition assets; a marginally higher usage was seen for the information technology asset. This effect was particularly strong for high performance computing. The highest revenue group was also significantly more likely to use the high performance computing and marginally more likely to use the magnet fabrication assets for training purposes. 
Table 33

Company Revenues for the Previous Year

\section{Amount}

Less than $\$ 1,000,000$ to $\$ 2,000,000$

$\$ 3,000,000$ to $\$ 14,000,000$

$\$ 15,000,000$ to $\$ 325,000,000$

$\$ 400,000,000$ to $\$ 120,000,000,000$

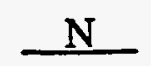

55

48

52

54
Percent

26.3

23.0

24.9

25.8 


\section{Externally Funded Research}

Only twenty-one respondents provided information on the amount of externally funded research their university obtained last year. Stratification (comparison group definition) was performed using an approximate 50/50 frequency split. These data are presented in Table 34. Results revealed a consistent directional tendency for greater asset usage for both research and training purposes in universities with more external research funding. However, no significant difference in the use of information technology for research purposes was seen. Significant effects on asset usage for training purposes were only seen for electronics and data acquisition. 


\section{Table 34}

Dollar Amount of Externally Funded Research Last Year

Amount

$\$ 1,000$ to $\$ 100,000$

$\$ 500,000$ to $\$ 40,000,000$
$N$

11

10
Percent

52.4

47.6

Missing or N.A. 
APPENDIX - 

AC MEMBER SURVEY 

Evaluation of

\title{
Superconducting Super Collider
}

\author{
assets for use in a
}

\section{Joint Texas Facility}

for Research, Training and Education 



\section{Overview of SSC assets}

The main SSC assets are located at two sites south of the Dallas Fort-Worth Metroplex, near Waxahachie. The first site, near I 35E and US 287 , is a 550,000 square feet facility. It provides office space, conference rooms, computer rooms, electronics laboratories, mechanical shops and warehouse space. This site also has an excellent technical library and extensive publication facilities.

The second site consists of several industrial buildings located 6 miles east from I35 on FM 1447. It houses a cryogenic facility and test and production capabilities for superconducting magnets.

A core of trained operators, engineers, technicians and scientists would be available at the Facility to provide support with design, research, development, testing and production. Scientific and technical activities at the Facility would provide an ideal environment for vocational training and scientific education.

The following describes the assets to be evaluated. The "SSC Assets Supplement" describes these assets in more detail.

\section{High Performance Computing}

The SSC High Performance Computer Center provides 12,000 MIPS computing power on a UNIX workstation farm. Workstations are tightly coupled on FDDI rings. The center can be used for massively parallel technical and scientific applications, as well as for advanced distributed databases. Four file servers provide 240 GBytes of disk space. Tape robots are available for archiving. The center also has a 64-node Hypercube.

\section{Information Technology}

Both sites have an excellent communications infrastructure. The internal network connects thousands of PCs, Macintoshes, workstations and servers. Connections with regional and national data networks are assured by T1 links. Extensive audio-visual capabilities allow for video recording, digital image processing and video conferencing.

\section{Mechanical Shops}

SSC mechanical workshops are well equipped with numerically controlled machinery. Capabilities include high precision prototype work, vacuum technology and small scale light industrial manufacturing. CAD/CAM is used to take ideas from concept through drawing directly to numerically controlled fabrication.

\section{Cryogenics}

The SSC has the world's largest cryogenic capabilities. Three helium refrigerators each provide $4000 \mathrm{~W}$ cooling at 4.5 degrees Kelvin. The system is capable of meeting multiple simultaneous cryogenic users.

\section{Magnet Fabrication}

The SSC magnet laboratories are equipped to design and produce superconducting and resistive dipoles. and more complex magnets. Magnets of up to 16 meters in length can be built in-house. Cryogenic and a warm test stands are used for precision magnetic measurements.

\section{Electronics}

The SSC electronics shops are equipped for small and medium size production. Shops can handle analog and digital design, surface mount, programmable logic, $R F$ and high power. Sophisticated CAD software is available for the design and simulation of electronics at the VISI, component, board and system levels. High precision equipment is used for testing, measurement and verification.

\section{Data Acquisition}

Extensive capability and expertise is available in the area of data acquisition, readout and control. It allows for development of multiprocessor real-time systems, embedded control, digital signal processing and complete readout systems. Evaluation and test equipment exists for network and high bandwidth connection studies. A large pool of modular NIM, CAMAC, VME and VXI test and measurement equipment is available. 



\section{Evaluation of Superconducting Super Collider assets}

1. Please tell us how valuable the SSC assets would be in your current or anticipated research or development. If needed, review the descriptions of SSC assets on the prior page or in the supplement. You may also call Rebekah DeLaughter at 214-708-6197 for additional asset information.

Using the following scale, please indicate the value to your research or development efforts that the following SSC assets provide. Give an asset a score of " 0 " if it is unlikely that your company would use it in research or development.

\begin{tabular}{cccccc} 
No Value & Little Value & - & Moderate & - & High Value \\
\hline 0 & 1 & 2 & 3 & 4 & 5
\end{tabular}

\begin{tabular}{|lc|}
\hline SSC Asset & $\begin{array}{c}\text { Research Value } \\
\text { (write in appropriate number) }\end{array}$ \\
\hline High Performance Computing & \\
Information Technology & \\
Mechanical Shops & \\
Cryogenics & \\
Magnet Fabrication & \\
Electronics & \\
\hline Data Acquisition & \\
\hline
\end{tabular}

2. If you were provided access to the SSC assets at a "fair price," on the average how many weeks out of the year ( 1 to 52 ) would you anticipate using those assets being used for your research or development?

\begin{tabular}{|lcc|}
\hline SSC Asset & No Use Anticipated & $\begin{array}{c}\text { Number of Weeks } \\
\text { (write in number) }\end{array}$ \\
\hline High Performance Computing & $\square$ & - \\
Information Technology & $\square$ & - \\
Mechanical Shops & $\square$ \\
Cryogenics & $\square$ & \\
Magnet Fabrication & $\square$ & \\
Electronics & $\square$ & \\
Data Acquisition & $\square$ & \\
\hline
\end{tabular}


3. : If you de not gain access to the SSC assets, what do you estimate it will cost to purchase or rent (contractual cost on a yearly basis) comparable assets for your research or development? If you have no intention of using a particular asset, leave the space blank.

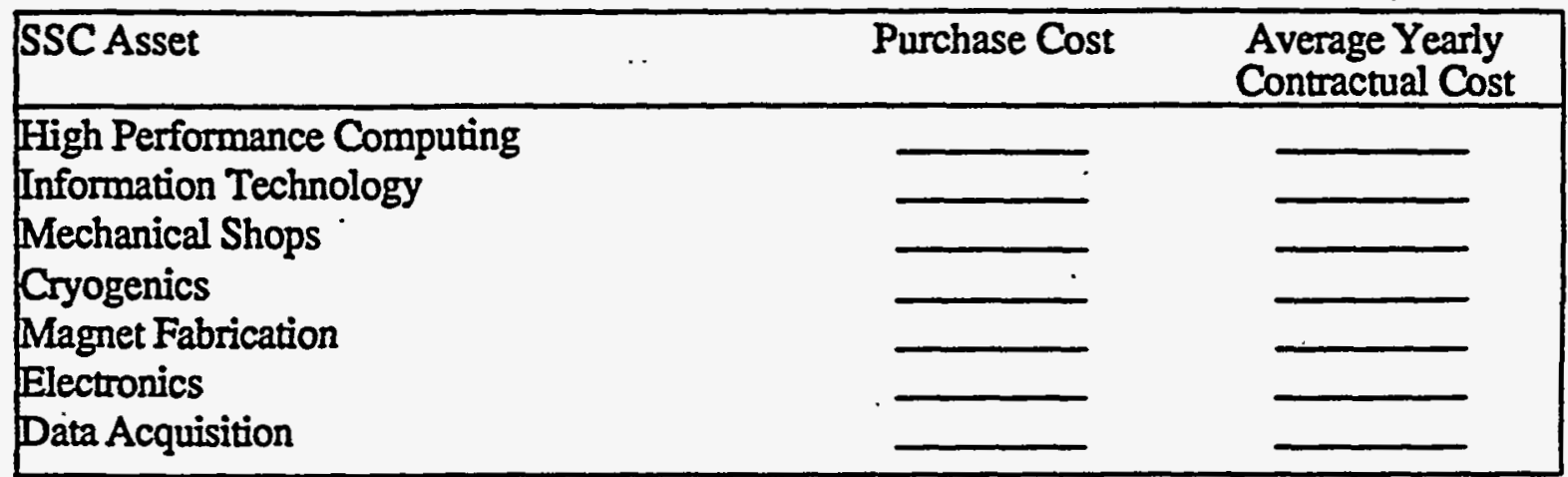

4. What principal benefit, if any, would access to the SSC assets provide to you beyond what is currently available through other resources. Please summarize that principal benefit in one or two sentences:

5a. For each of the following SSC asset areas, please state the extent to which you feel those resources are available elsewh.ere to meet your research or development needs:

\begin{tabular}{ccccc} 
Routinely Available & - & Moderately Available & - & Not Available \\
\hline & 2 & 3 & 4 & 5
\end{tabular}

\begin{tabular}{|lcc|}
\hline SSC Asset & $\begin{array}{c}\text { Resource } \\
\text { Not Needed }\end{array}$ & $\begin{array}{c}\text { Resource Availability } \\
\text { (write in number) }\end{array}$ \\
\hline High Performance Computing & $\square$ & - \\
Information Technology & $\square$ & - \\
Mechanical Shops & $\square$ & \\
Cryogenics & $\square$ & - \\
Magnet Fabrication & $\square$ & \\
Electronics & $\square$ & \\
Data Acquisition & $\square$ & \\
\hline
\end{tabular}

5b. For the assets that you indicated as available elsewhere, please list their locations. 
6. How do you anticipate using SSC assets:

SSC assets may be used for design and/or for fabrication. Experts at the Facility would assist with your design or fabrication (called "Support"). Also, you may want your personnel themselves to use the equipment or software for design or fabrication (called "Use").

Please indicate anticipated methods of usage, by checking all appropriate boxes.

\begin{tabular}{|lcccc|}
\hline SSC Asset & $\begin{array}{c}\text { Design } \\
\text { Support }\end{array}$ & $\begin{array}{c}\text { Fabrication } \\
\text { Support }\end{array}$ & $\begin{array}{c}\text { Design } \\
\text { Use }\end{array}$ & $\begin{array}{c}\text { Fabrication } \\
\text { Use }\end{array}$ \\
\hline High Performance Computing & $\square$ & $\square$ & $\square$ & $\square$ \\
Information Technology & $\square$ & $\square$ & $\square$ & $\square$ \\
Mechanical Shops & $\square$ & $\square$ & $\square$ & $\square$ \\
Cryogenics & $\square$ & $\square$ & $\square$ & $\square$ \\
Magnet Fabrication & $\square$ & $\square$ & $\square$ & $\square$ \\
Electronics & $\square$ & $\square$ & $\square$ & $\square$ \\
Data Acquisition & $\square$ & $\square$ & $\square$ & $\square$ \\
\hline
\end{tabular}

7a. If vocational training in the use of some or all of the SSC assets were available, how valuable would that service be in the current or anticipated training of personnel in your organization? Using the following scale, please indicate the value of the following SSC assets for training. Give an asset a score of " 0 " if it is unlikely that you would use it for training purposes.

\begin{tabular}{cccccc} 
No Value & Little Value & - & Moderate & - & High Value \\
\hline 0 & 1 & 2 & 3 & 4 & 5
\end{tabular}

SSC Asset

Training Value

High Performance Computing

Information Technology

Mechanical Shops

Cryogenics

Magnet Fabrication

Electronics

Data Acquisition

(write in appropriate number)

7b. Would you prefer that training be conducted using $a(n)$ :

(check all that apply)

$\square$ Internship format $\square$ Classroom format $\square$ Other:

8a. Where is your principal place of employment?
$\square \quad$ University
Government Agency
Corporation
Other Organization 
8b. If you answered "Corporation" to the previous question, what were the approximate annual revenues of your company last year (in millions)?

8c. In what city and state do you work?

9. In your current position, how would you describe your likely responsibilities for making a decision to utilize SSC assets?

I would be solely responsible for the decision.

I would have major input to the decision.

I would have moderate input to the decision.

I would have minor input to the decision.

I would have no input to the decision.

10. Which of the following best describes your principal orientation and area of specialization?? (Please check all that apply)

Orientation:

$\square$ Theory

$\square$ Experiment

$\square$ Design

Specialization:

$\square$ Atomic Physics

Astrophysics

Biophysics

Chemical Physics

Condensed Matter

Computational Physics

High Energy Physics

Materials Science

Nuclear Physics $\square$ Product Development

Fabrication

Training $\square$ Physics of Beams

$\square$ Plasma Physics

$\square$ Other Physics

$\square$ Superconductivity

$\square$ Chemical Engineering

D Electrical Engineering

$\square$ Mechanical Engineering

$\square$ Other Engineering

$\square$ Other Specialization

Thank you for your help. If you want us to contact you concerning your use of the SSC assets, please enclose your name, position and phone number with this survey. Also enclose a project description if you wish to discuss that project with us. 
TECHNOLOGY FIRM SURVEY 



\title{
Evaluation of
}

\section{Superconducting Super Collider}

\author{
assets for use in a
}

\section{Joint Texas Facility}

for Research, Training and Education 

The main SSC assets are located at two sites south of the Dallas Fort-Worth Metroplex, near Waxahachie. The first site, near I 35E and US 287 , is a 550,000 square feet facility. It provides office space, conference rooms, computer rooms, electronics laboratories, mechanical shops and warehouse space. This site'also has an excellent technical library and extensive publication facilities.

The second site consists of several industrial buildings located 6 miles east from I35 on FM 1447. It houses a cryogenic facility and test and production capabilities for superconducting magnets.

A core of trained operators, engineers, technicians and scientists would be available at the Facility to provide support with design, research, development, testing and production. Scientific and technical activities at the Facility would provide an ideal environment for vocational training and scientific education.

The following describes the assets to be evaluated. The "SSC Assets Supplement" describes these assets in more detail.

\section{High Performance Computing}

The SSC High Performance Computer Center provides 12,000 MIPS computing power on a UNIX workstation farm. Workstations are tightly coupled on FDDI rings. The center can be used for massively parallel technical and scientific applications, as well as for advanced distributed databases. Four file servers provide 240 GBytes of disk space. Tape robots are available for archiving. The center also has a 64-node Hypercube.

\section{Information Technology}

Both sites have an excellent communications infrastructure. The internal network connects thousands of PCs, Macintoshes, workstations and servers. Connections with regional and national data networks are assured by $\mathrm{T} 1$ links. Extensive audio-visual capabilities allow for video recording, digital image processing and video conferencing.

\section{Mechanical Shops}

SSC mechanical workshops are well equipped with numerically controlled machinery. Capabilities include high precision prototype work, vacuum technology and small scale light industrial manufacturing. CAD/CAM is used to take ideas from concept through drawing directly to numerically controlled fabrication.

\section{Cryogenics}

The SSC has the world's largest cryogenic capabilities. Three helium refrigerators each provide $4000 \mathrm{~W}$ cooling at 4.5 degrees Kelvin. The system is capable of meeting multiple simultaneous cryogenic users.

\section{Magnet Fabrication}

The SSC magnet laboratories are equipped to design and produce superconducting and resistive dipoles and more complex magnets. Magnets of up to 16 meters in length can be built in-house. Cryogenic and a warm test stands are used for precision magnetic measurements.

\section{Electronics}

The SSC electronics shops are equipped for small and medium size production. Shops can handle analog and digital design, surface mount, programmable logic, $\mathrm{RF}$ and high power. Sophisticated CAD software is available for the design and simulation of electronics at the VLSI, component, board and system levels. High precision equipment is used for testing, measurement and verification.

\section{Data Acquisition}

Extensive capability and expertise is available in the area of data acquisition, readout and control. It allows for development of multiprocessor real-time systems, embedded control, digital signal processing and complete readout systems. Evaluation and test equipment exists for network and high bandwidth connection studies. A large pool of modular NIM, CAMAC, VME and VXI test and measurement equipment is available. 



\section{Evaluation of Superconducting Super Collider assets}

1. Please tell us how valuable the SSC assets would be in your company's current or anticipated research or development. If needed, review the descriptions of SSC assets on the prior page or in the supplement. You may also call Rebekah DeLaughter at 214-708-6197 for additional asset information.

Using the following scale, please indicate the value to your company's research or development efforts that the following SSC assets provide. Give an asset a score of " 0 " if it is unlikely that your company would use it in research or development.

\begin{tabular}{cccccc} 
No Value & Litle Value & - & Moderate & - & High Value \\
\hline 0 & 1 & 2 & 3 & 4 & 5
\end{tabular}

SSC Asset

Research Value

High Performance Computing

Information Technology

Mechanical Shops

Cryogenics

Magnet Fabrication

Electronics

Data Acquisition

(write in appropriate number)

2. If your company were provided access to the SSC assets at a "fair price," on the average how many weeks out of the year ( 1 to 52) would you anticipate those assets being used for research or development?

\begin{tabular}{|lcc|}
\hline SSC Asset & No Use Anticipated & $\begin{array}{c}\text { Number of Weeks } \\
\text { (write in number) }\end{array}$ \\
\hline High Performance Computing & $\square$ & - \\
Information Technology & $\square$ & - \\
Mechanical Shops & $\square$ & - \\
Cryogenics & $\square$ & - \\
Magnet Fabrication & $\square$ & \\
Electronics & $\square$ & \\
Data Acquisition & $\square$ & \\
\hline
\end{tabular}


3. If your company does not gain access to the SSC assets, what do you estimate it will cost to purchase or rent (contractual cost on a yearly basis) comparable assets for research or development purposes? If your company is unlikely to use a particular asset, leave the space blank.

\begin{tabular}{|lll|}
\hline SSC Asset & Purchase Cost & $\begin{array}{c}\text { Average Yearly } \\
\text { Contractual Cost }\end{array}$ \\
\hline High Performance Computing & - \\
Information Technology & - \\
Mechanical Shops & - \\
Cryogenics & \\
Magnet Fabrication & \\
Electronics & \\
Data Acquisition & & \\
\hline
\end{tabular}

4. What principal benefit, if any, would access to the SSC assets provide to your company beyond what is currently available through other resources. Please summarize that principal benefit in one or two sentences:

5a. For each of the following SSC asset areas, please state the extent to which you feel those resources are available elsewhere to meet your company's research or development needs:

\begin{tabular}{ccccc} 
Routinely Available & - & Moderately Available & - & Not Available \\
\hline 1 & 2 & 3 & 4 & 5
\end{tabular}

\begin{tabular}{|lcc|}
\hline SSC Asset & $\begin{array}{c}\text { Resource } \\
\text { Not Needed }\end{array}$ & $\begin{array}{c}\text { Resource Availability } \\
\text { (write in number) }\end{array}$ \\
\hline High Performance Computing & $\square$ & - \\
Information Technology & $\square$ & - \\
Mechanical Shops & $\square$ & - \\
Cryogenics & $\square$ & - \\
Magnet Fabrication & $\square$ & - \\
Electronics & $\square$ & - \\
\hline Data Acquisition & $\square$ & \\
\hline
\end{tabular}

5b. For the assets that you indicated as available elsewhere, please list their locations. 
6. How do you anticipate your company would use SSC assets:

SSC assets may be used for design and/or for fabrication. Experts at the Facility could assist with your design or fabrication (called "Support"). Also, you may want your per-sonnel themselves to use the equipment or software for design or fabrication (called "Use").

Please indicate anticipated methods of usage, by checking all appropriate boxes.

\begin{tabular}{|lcccc|}
\hline SSC Asset & $\begin{array}{c}\text { Design } \\
\text { Support }\end{array}$ & $\begin{array}{c}\text { Fabrication } \\
\text { Support }\end{array}$ & $\begin{array}{c}\text { Design } \\
\text { Use }\end{array}$ & $\begin{array}{c}\text { Fabrication } \\
\text { Use }\end{array}$ \\
\hline High Performance Computing & $\square$ & $\square$ & $\square$ & $\square$ \\
Information Technology & $\square$ & $\square$ & $\square$ & $\square$ \\
Mechanical Shops & $\square$ & $\square$ & $\square$ & $\square$ \\
Cryogenics & $\square$ & $\square$ & $\square$ & $\square$ \\
Magnet Fabrication & $\square$ & $\square$ & $\square$ & $\square$ \\
Electronics & $\square$ & $\square$ & $\square$ & $\square$ \\
Data Acquisition & $\square$ & $\square$ & $\square$ & $\square$ \\
\hline
\end{tabular}

7a. If vocational training in the use of some or all of the SSC assets were available, how valuable would that service be in the current or anticipated training of personnel in your organization? Using the following scale, please indicate the value of the following SSC assets for training. Give an asset a score of " 0 " if it is unlikely that you would use it for training purposes.

\begin{tabular}{cccccc} 
No Value & Litule Value & - & Moderate & - & High Value \\
\hline 0 & 1 & 2 & 3 & 4 & 5
\end{tabular}

SSC Asset

Training Value (write in appropriate number)

High Performance Computing

Information Technology

Mechanical Shops

Cryogenics

Magnet Fabrication

Electronics

Data Acquisition

7b. Would your company prefer that training be conducted using $\mathrm{a}(\mathrm{n})$ : (check all that apply)

$\square \quad$ Internship format $\square$ Classroom format $\square$ Other:

8a. What were the approximate annual revenues of your company last year (in millions)? 
8b. In what city and state is your company located?

or check here if your company has multiple city locations

9. This question is directed specifically at the individual completing this survey: In your current position, how would you describe your likely responsibilities for making a decision to utilize SSC assets?

$\square \quad$ I would be solely responsible for the decision.

I would have major input to the decision.

I I would have moderate input to the decision.

I I would have minor input to the decision.

I I would have no input to the decision.

10. Which of the following best describes your company's business? (Please check all that apply)

$\begin{array}{ll}\square & \text { Office, Accounting Machines } \\ \square & \text { Computers, Parts and Equipment } \\ \square & \text { Networking, Software Engineering and Related Services } \\ \square & \text { Electrical Equipment and Components } \\ \square \quad \text { Electronic Equipment and Components } \\ \square \quad \text { Agricultural Chemicals } \\ \square \quad \text { Industrial Chemicals } \\ \square \quad \text { Drugs and Medicines } \\ \square \quad \text { Plastic and Synthetic Materials } \\ \square \quad \text { Optical and Medical Instruments } \\ \square \quad \text { Professional and Scientific Instruments } \\ \square \quad \text { Engines and Turbines } \\ \square \quad \text { Aircraft and Parts } \\ \square \quad \text { Other Transportation Equipment } \\ \square \quad \text { Other Industrial Machinery and Equipment } \\ \square \quad \text { Other }\end{array}$

Thank you for your help. If you want us to contact you concerning your use of the SSC assets, please enclose your name, position and phone number with this survey. Also enclose a project description if you wish to discuss that project with us. 
UNIVERSITY DEAN SURVEY

$\bullet$ 



\section{Evaluation of}

\section{Superconducting Super Collider}

assets for use in a

\section{Joint Texas Facility}

for Research, Training and Education 


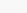


The main SSC assets are located at two sites south of the Dallas Fort-Worth Metroplex, near Waxahachie. The first site, near I 35E and US 287 , is a 550,000 square feet facility. It provides office space, conference rooms, computer rooms, electronics laboratories, mechanical shops and warehouse space. This site also has an excellent technical library and extensive publication facilities.

The second site consists of several industrial buildings located 6 miles east from I35 on FM 1447. It houses a cryogenic facility and test and production capabilities for superconducting magnets.

A core of trained operators, engineers, technicians and scientists would be available at the Facility to provide support with design, research, development, testing and production. Scientific and technical activities at the Facility would provide an ideal environment for vocational training and scientific education.

The foilowing describes the assets to be evaluated. The "SSC Assets Supplement" describes these assets in more detail.

\section{High Performance Computing}

The SSC High Performance Computer Center provides 12,000 MIPS computing power on a UNIX workstation farm. Workstations are tightly coupled on FDDI rings. The center can be used for massively parallel technical and scientific applications, as well as for advanced distributed databases. Four file servers provide 240 GBytes of disk space. Tape robots are available for archiving. The center also has a 64-node Hypercube.

\section{Information Technology}

Both sites have an excellent communications infrastructure. The internal network connects thousands of PCs, Macintoshes, workstations and servers. Connections with regional and national data networks are assured by T1 links. Extensive audio-visual capabilities allow for video recording, digital image processing and video conferencing.

\section{Mechanical Shops}

SSC mechanical workshops are well equipped with numerically controlled machinery. Capabilities include high precision prototype work, vacuum technology and small scale light industrial manufacturing. CAD/CAM is used to take ideas from concept through drawing directly to numerically controlled fabrication.

\section{Cryogenics}

The SSC has the world's largest cryogenic capabilities. Three helium refrigerators each provide $4000 \mathrm{~W}$ cooling at 4.5 degrees Kelvin. The system is capable of meeting multiple simultaneous cryogenic users.

\section{Magnet Fabrication}

The SSC magnet laboratories are equipped to design and produce superconducting and resistive dipoles and more complex magnets. Magnets of up to 16 meters in length can be built in-house. Cryogenic and a warm test stands are used for precision magnetic measurements.

\section{Electronics}

The SSC electronics shops are equipped for small and medium size production. Shops can handle analog and digital design, surface mount, programmable logic, $\mathrm{RF}$ and high power. Sophisticated CAD software is available for the design and simuiation of electronics at the VLSI, component, board and system levels. High precision equipment is used for testing, measurement and verification.

\section{Data Acquisition}

Extensive capability and expertise is available in the area of data acquisition, readout and control. It allows for development of multiprocessor real-time systems, embedded control, digital signal processing and complete readout systems. Evaluation and test equipment exists for network and high bandwidth connection studies. A large pool of modular NIM, CAMAC, VME and VXI test and measurement equipment is available. 



\section{Evaluation of Superconducting Super Collider assets}

1. Please tell us how valuable the SSC assets would be in your organization's current or anticipated research or development. If needed, review the descriptions of SSC assets on the prior page or in the supplement. You may also call Rebekah DeLaughter at 214-708-6197 for additional asset information.

Using the following scale, please indicate the value to your organization's research or development efforts that the following SSC assets provide. If your organization is unlikely to use a particular asset, give it a score of " 0 ".

\begin{tabular}{cccccc} 
No Value & Little Value & - & Moderate & - & High Value \\
\hline 0 & 1 & 2 & 3 & 4 & 5
\end{tabular}

SSCAsset

Research Value

High Performance Computing

Information Technology

Mechanical Shops

Cryogenics

Magnet Fabrication

Electronics

Data Acquisition

2. If your organization were provided access to the SSC assets at a "fair price," on the average how many weeks out of the year (1 to 52) would you anticipate those assets being used for research or development?

\begin{tabular}{|lcc|}
\hline SSC Asset & No Use Anticipated & $\begin{array}{c}\text { Number of Weeks } \\
\text { (write in number) }\end{array}$ \\
\hline High Performance Computing & $\square$ & - \\
Information Technology & $\square$ & - \\
Mechanical Shops & $\square$ & - \\
Cryogenics & $\square$ & - \\
Magnet Fabrication & $\square$ & \\
Electronics & $\square$ & \\
Data Acquisition & $\square$ & \\
\hline
\end{tabular}


3. If your organization does not gain access to the SSC assets, what do you estimate it will cost to purchase or rent (contractual cost on a yearly basis) comparable assets for research or development purposes? If your organization is unlikely to use a particular asset, leave the space blank.

\begin{tabular}{|lcc|}
\hline SSC Asset & Purchase Cost & $\begin{array}{c}\text { Average Yearly } \\
\text { Contractual Cost }\end{array}$ \\
\hline High Performance Computing & - \\
Information Technology & - \\
Mechanical Shops & - \\
Cryogenics & - \\
Magnet Fabrication & - \\
Electronics & - \\
Data Acquisition & - \\
\hline
\end{tabular}

4. What principal benefit, if any, would access to the SSC assets provide to your organization beyond what is currently available through other resources. Please summarize that principal benefit in one or two sentences:

5a. For each of the following SSC asset areas, please state the extent to which you feel those resources are available elsewhere to meet your organization's research or development needs:

\begin{tabular}{ccccc} 
Routinely Available & - & Moderately Available & - & Not Available \\
\hline 1 & 2 & 3 & 5
\end{tabular}

\begin{tabular}{|lcc|}
\hline SSC Asset & $\begin{array}{c}\text { Resource } \\
\text { Not Needed }\end{array}$ & $\begin{array}{c}\text { Resource Availability } \\
\text { (write in number) }\end{array}$ \\
\hline High Performance Computing & $\square$ & - \\
Information Technology & $\square$ & - \\
Mechanical Shops & $\square$ & - \\
Cryogenics & $\square$ & - \\
Magnet Fabrication & $\square$ & - \\
Electronics & $\square$ & - \\
Data Acquisition & $\square$ & - \\
\hline
\end{tabular}

5b. For the assets that you indicated as available elsewhere, please list their locations. 
6. How do you anticipate your organization would use SSC assets:

SSC assets may be used for design and/or for fabrication. Experts at the Facility could assist with your design or fabrication (called "Support"). Also, you may want your per-sonnel themselves to use the equipment or software for design or fabrication (called "Use").

Please indicate anticipated methods of usage, by checking all appropriate boxes.

\begin{tabular}{|lcccc|}
\hline SSC Asset & Design & Fabrication & Design & Fabrication \\
& Support & Support & Use & Use \\
\hline High Performance Computing & $\square$ & $\square$ & $\square$ & $\square$ \\
Information Technology & $\square$ & $\square$ & $\square$ & $\square$ \\
Mechanical Shops & $\square$ & $\square$ & $\square$ & $\square$ \\
Cryogenics & $\square$ & $\square$ & $\square$ & $\square$ \\
Magnet Fabrication & $\square$ & $\square$ & $\square$ & $\square$ \\
Electronics & $\square$ & $\square$ & $\square$ & $\square$ \\
Data Acquisition & $\square$ & $\square$ & $\square$ & $\square$ \\
\hline
\end{tabular}

7a. If vocational training in the use of some or all of the SSC assets were available, how valuable would that service be in the current or anticipated training of personnel in your organization?

Using the following scale, please indicate the value of the following SSC assets for training. Give an asset a score of " 0 " if it is unlikely that you would use it for training purposes.

\begin{tabular}{cccccc} 
No Value & Litlle Value & - & Moderaie & - & High Value \\
\hline 0 & 1 & 2 & 3 & 4 & 5
\end{tabular}

\begin{tabular}{|l|c|}
\hline SSC Asset & $\begin{array}{c}\text { Training Value } \\
\text { (write in appropriate number) }\end{array}$ \\
\hline High Performance Computing & \\
Information Technology & \\
Mechanical Shops & \\
Cryogenics & \\
Magnet Fabrication & \\
Electronics & \\
Data Acquisition & \\
\hline
\end{tabular}

7b. Would your organization prefer that training be conducted using $a(n)$ :

(check all that apply)

$\square$ Internship format $\square$ Classroom format $\square$ Other:

8a. In what city and state is your university located? 
8b. What was the approximate dollar amount of externally funded research your university obtained last year:

9. This question is directed specifically at the individual completing this survey: In your current position, how would you describe your likely responsibilities for making a decision to utilize SSC assets?

$\square \quad$ I would be solely responsible for the decision.

$\square$ I would have major input to the decision.

$\square$ I would have moderate input to the decision.

$\square$ I would have minor input to the decision.

$\square$ I would have no input to the decision.

10. Which of the following best describes your organization's principal orientation and area of specialization? (Please check all that apply)

Orientation:

$\begin{array}{llll}\square & \text { Theory } & \square & \text { Product Development } \\ \square & \text { Experiment } & \square & \text { Fabrication } \\ \square & \text { Design } & \square & \text { Training }\end{array}$

Specialization:

Atomic Physics

$\square \quad$ Physics of Beams

$\square$ Astrophysics

Plasma Physics

$\square$ Biophysics

$\square$ Other Physics

$\square$ Chemical Physics

[ Superconductivity

$\square$ Condensed Matter

$\square$ Chemical Engineering

$\square$ Computational Physics

$\square \quad$ Electrical Engineering

$\square$ High Energy Physics

$\square$ Mechanical Engineering

$\square$ Materials Science

$\square$ Other Engineering

$\square \quad$ Nuclear Physics

$\square$ Other Specialization

Thank you for your help. If you want us to contact you concerning your use of the SSC assets, please enclose your name, position and phone number with this survey. Also enclose a project description if you wish to discuss that project with us. 
SSC ASSETS SUPPLEMENT 

This supplement gives more details concerning the assets available at the SSC. If further information is needed, please contact Rebekah at (214) 708-6197*.

\section{Facilities}

Most SSC assets are located at two sites near Waxahachie. The largest one, called the Central Facility, is a 550,000 square feet building on 46 acres of land. A warehouse storage facility uses $100,000 \mathrm{sq}$. $\mathrm{ft}$. of the building; laboratories and mechanical shops occupy 160,000 sq. ft. and the remainder is used as offices, conference rooms, computer rooms and a food service area. The facility is located a few miles from I35E, the main Texas north-south corridor, one mile north of US 287. The site has excellent accessibility by road and is adjacent to a railroad.

Electrical power of up to $15,700 \mathrm{kVA}$ is available in the building, as well as low conductivity cooling water and compressed air. Nine computer rooms provide UPS capability.

Machine shops and assembly areas are organized in 10 high bays with crane capacities varying from 3 to 25 Tons. Some of the cranes also serve covered loading docks.

The Central Facility houses an excellent technical library. It has a collection of 10,000 books and 700 journals. The main collection areas are physics, accelerator theory, design and construction and magnet technology. Supporting collections cover computing, software engineering, mathematics, science education, EH\&S, and Total Quality Management (TQM).

The second site, called N15, is located 6 miles west from I35E on FM 1446. It has several industrial buildings with a total area of 90,000 square feet. They house cryogenics facilities and magnet construction and testing laboratories.

\footnotetext{
-(214) $935-9000$ ext. 6197 after September 12. However, surveys
} need to be retumed within the next 10 days.

\section{High Performance Computing}

The SSC High Performance Computer Center was established for the simulation of SSC physics experiments and the design of the accelerator systems. It provides 12,000 MIPS computing power on a UNIX workstation farm. A total of 120 workstations are organized in groups that are tightly coupled by FDDI and Ethernet. Several types of stations are used, such as HP 9000/735, SUN SPARC 10 , and SGI $4 D / 360$ with 6 processors each. Each processor has at least $64 \mathrm{MB}$ RAM and 1 GByte of disk. Four SGI Challenge L file servers provide an additional 150 GBytes of disk space. Two Summus STL-2300-12 tape robots are used for archiving.

The center is being used for technical and scientific applications, and is easily accessible via Internet. All computer equipment is housed in secure, air conditioned and fire proof computer rooms.

The workstations in the farm normally run in course grain parallelism and are available for batch and interactive use. Batch queuing is provided using NQS. Applications that require fine grain parallelism can run under PVM. The large amount of disk space allows use of advanced distributed databases and information retrieval systems. Due to its modular architecture the system is easily upgradable and expandable. It can be used as a test bed for emerging hard and software technologies and new interoperability concepts.

The center has an Intel iP860 Hypercube with 64 tightly connected nodes. It can be used for massively parallel scientific and technical applications in areas of image processing, ray tracing, climatology and hydro-dynamics, etc.

\section{Information Technology}

The SSC has an excellent internal and external communications infrastructure. Extensive capabilities in areas of data processing, network- 
ing and multi media make it an ideal facility to develop and exploit the emerging information technologies.

\section{Voice Systems}

Each SSC office has at least 4 connections for phone and data. Voice communication relies on AT\&T PBX equipment able to serve 10,000 connections. Redundant long distance links are available and buildings are connected with T1 lines. Pagers are also available and radio links assure contact with mobile crews.

\section{Data Network}

On-site networking is typically done using Ethernet. Ethernet concentrators are in secure equipment rooms. They are wired by fiber or copper to CISCO routers, connected on a FDDI backbone. The different buildings are linked using T1 connections. Software for network monitoring and management is installed throughout.

The internal networks connect thousands of PCs, Macintoshes and workstations. Tens of servers are installed throughout the facility and used for name servers, file servers, databases, compute servers, centralized plotting, mail distribution, backup and interactive information retrieval.

Wide Area Network connections with regional and national networks are assured by three $\mathrm{T} 1$ links. The site is directly connected to the Texas Higher Education network (THEnet) and ESnet, and has access to Internet and Texas Education network (TEnet). The excellent bandwidth of the connections and the availability of powerful servers, ample mass storage and the High Performance Computer Center make the site very attractive for information storage, interactive retrieval, and 'distance learning'.

Several workstations are set up as servers for the Word Wide Net. This allows information browsing using multi media viewers like NCSA's Mosaic.

\section{Audio-Visual}

The SSC laboratory has extensive facilities for video teleconferencing. Several complete systems currently support connections with, for example, the National Laboratories, universities in the US, and sites in Italy and Japan. More primitive, multi-party, global video conferencing between workstations is now possible using Internet.

Sophisticated video production capabilities include preproduction planning, script writing, professional camera teams, videotaping and post-production editing. They are used for documentation, instruction, information, training, public awareness and educational purposes.

The SSC has professional still-camera equipment and photo lab equipment with a throughput of up to 360 prints per hour. High resolution color scanners are used for digitization. Software is installed for digital image treatment. Part of the photographic collection is accessible via Internet.

An integrated publishing system allows for the conversion of various word processing standards and computer assisted translation. Document control systems are accessible via the network. A complete publishing department can handle document preparation and high throughput printing.

\section{Mechanical shops}

Most of the mechanical shop capabilities are located at the Central Facility. The shops would have the personnel and equipment to manufacture hardware and instrumentation for a wide range of applications. Shop capabilities include machining, forming, fabrication, welding and assembly processes and specialized techniques for the production of a wide variety of prototype components, systems and expeiments.

CAD/CAM program systems provide the capability to take ideas from concept through drawing directly into the proper machine language for the individual machines with Computer Numerical Control (CNC).

\section{Machining Capabilities}

Most conventional equipment has the ability to attain a tolerance level of $0.025 \mathrm{~mm}(0.001 ")$, while some of the more sophisticated CNC units reach $0.002 \mathrm{~mm}$ (0.0002"). Most machine tools have the capability of reading in metric or English units.

The shops contain over 150 major pieces of equipment. Machining capabilities include: lathes with working envelopes of 24 " swing 
and 60" length, fully programmable milling machines, a planer that can handle work pieces of up to $144^{\prime \prime}$ length, and a $6^{\prime \prime}$ by $18^{\prime \prime}$ grinder which can satisfy exceptional surface finish requirements. In addition, there is a CNC turning/milling center that swings a maximum diameter of $18^{\prime \prime}$. It has a 16 position automatic tool changing magazine; all tool positions are live and can operate in the horizontal or vertical position. Parts up to 39 " length can be machined. All functions are controlled by microprocessor to within 0.001 degree.

\section{Welding Capability}

The welding shop capability includes the equipment to perform a complete range of welding procedures and techniques i.e. Gas Tungsten Arc Welding (TIG), Gas Metal Arc Welding (MIG), Shielded Metal Arc Welding (SMAW). The shop fabricates complex structural and tubing configurations in a variety of materials. It also has the capability to perform soldering, brazing and cutting with oxyacetylene and plasma systems.

TIG machines are used for the complex and delicate welding of thin wall $0.005^{\prime \prime}$ thick stainless steel bellows.

\section{Quality Control}

Testing and inspection capabilities cover a wide assortment of precision measurements. A QA group would have sophisticated equipment, such as: CNC optical comparators, CNC coordinate measuring machines, a dead weight tester, a vacuum gauge calibration system, a super-micrometer and a laser alignment system.

\section{Cryogenics}

The cryogenics facility is located at the N15 site east from I35. It houses the world's largest cryogenic capability. Three helium refrigerators each provide $4000 \mathrm{~W}$ cooling at $4.5^{\circ}$ Kelvin and $37 \mathrm{~g} / \mathrm{s}$ liquefaction. A smaller refrigerator cools $500 \mathrm{~W}$ at $4^{\circ} \mathrm{K}$. Large 40,000 liter dewars intrinsically handle sudden, major load upsets.

The facility is designed to provide maximum flexibility and to handle the requirements of multiple large or small-scale loads. Automatic control is implemented to improve system ef- ficiency and quick turnaround. The large cooling power provides a unique opportunity to create a world-class $1.8 \mathrm{~K}$ superfluid helium facility. It can also be used for testing at intermediate temperatures.

\section{Magnet Fabrication}

The magnet development and test laboratories at the N15 site are dedicated to the advancement of superconducting devices and the associated manufacturing technologies. They are equipped to design and produce superconducting and resistive dipoles and more complex magnets. Magnets of up to 16 meters in length can be built and tested in-house. The capabilities of facilities have been demonstrated by the successful manufacturing of the world's premier superconducting magnets.

The site has 47,000 square feet of mechanical shops, served by two 25 ton cranes. The buildings provide a quasi clean room environment for specialized equipment used for magnet construction, such as fully automated cablers, cable wrappers and wedge wrappers; gantry style coil winders for coils of 2-16 meter length; and curing and collaring presses with up to 300 tons per foot capacity. A 16 meter long shell welding press allows for fully automated TIG welding.

The magnet laboratories also provide $\mathrm{CAD} /$ CAM, factory simulation software, sophisticated general purpose machining equipment and Quality Control inspection. Cryogenic and a warm test stand are used for precision magnetic measurements.

\section{Electronics}

Ten specialized laboratories at the SSC are equipped for research, development and production of electronics and data acquisition systems. All have excellent connectivity to the network. Some of the shops have special high power provisions, while others are RF shielded for ultra-sensitive measurements. The electronics shops can handle analog and digital design, surface mount, programmable logic, $\mathrm{RF}$ and high power. 
VLSI design and testing

Computer Aided Design software is available for design of analog and digital chips. Simulation at chip level is done using HSpice, for analog electronics, and VERILOG, VHDL for digital, behavioral simulation. A 100channel $100 \mathrm{MHz}$ pin-by-pin digital chip tester is used for IC verification. Combined with analog digital test \& measurement equipment it can be used for the evaluation of mixed analog/digital designs.

\section{Board level systems}

Electronics capabilities meet a wide range of requirements in the areas of low noise, low power, radiation hardness, digital signal processing, VME, VXI, and system design. Alternative CAD software is available for design, simulation, layout and production of board level systems of varying complexity and functionality. E-size plotters and copiers are available for documentation. State-of-the-art programmers could be available for PALs, FPGAs, EPROMs and ROM.

Prototype fabrication and small scale production are possible using through-hole mounting and infra-red refold surface mount soldering systems with automated component placement, cleaning and Quality Control. A sheet metal workshop is used for the production of chassis and rack assemblies.

\section{RF capabilities}

Extensive capability has been developed in the area of Radio Frequency design and testing. A 5300 square feet facility specializes in testing of high power RF equipment. It has separate 3-phase, $1000 \mathrm{kVA}$ power feeds that provide $16-20 \mathrm{kV}$ DC output power. Low conductivity cooling water is available at more than 1000 gallons/minute.

A second 5000 square feet RF shielded room specializes in low level RF testing. Capability also exists for high precision impedance testing of RF structures.

\section{Test \& Measurement}

All laboratories are well equipped with up-todate measurement equipment, such as network analyzers, spectrum analyzers, oscilloscopes, sweepers, synthesizers and state analyzers. Extensive capability exists for measurements beyond $1 \mathrm{GHz}$ and in the $430 \mathrm{MHz}$ and 60 $\mathrm{MHz}$ ranges. Much of the equipment is computer controlled via GPIB, VME or VXI.

Electronics Quality Assurance is provided by the metrology/calibration laboratory that serves as a standard reference traceable to NIST. The laboratory is designed to perform incoming inspection, periodic calibration and repairs of the electronic equipment used at the SSC.

\section{Data Acquisition}

Extensive capability and expertise would be available in the area of data acquisition, readout and control. Numerous real-time multi-processor systems have been developed, based on VME and VXI. Large setups are normally controlled by UNIX workstations, while agile small scale readout systems are based on Macs or PCs running LabView. Expertise would be available with real-time UNIX operating systems like VxWorks and Lynx.

Specialized evaluation and test equipment exists for network and for high bandwidth connection studies. Experience with measurement, control, readout and digital signal processing allows for the design of small or high bandwidth systems with throughputs of up to $40 \mathrm{~GB} / \mathrm{s}$.

A large pool of commercial modular NIM, CAMAC, GPIB, VME and VXI test and measurement equipment is available to tackle the most difficult control and readout problems.

\section{Training \& Education}

The diverse activities at the Faculty would make it an ideal place for training and education. Efficient vocational training is possible using the most up-to-date equipment and expertise. The presence of scientists, mathematicians, engineers and information technologists would create a stimulating environment for the enhancement of science education. 
APS SURVEY COVER LETTER 

August 1, 1994

«FName» «LName»«Ext»

«Add》

Dear Dr. «LName»:

To assist decisions regarding the future use of Superconducting Super Collider assets, Dr. S. Peter Rosen, Dean of Science at the University of Texas at Arlington, and Dr. Vigdor L. Teplitz, Chair of the Physics Department at Southern Methodist University, have received DoE funding to study the feasibility of a Joint Texas Facility for Support of Research, Training, and Education. In turn, I have been asked to survey impartially your evaluations of SSC assets that might be included in such a Texas Facility. Specifically, this survey is intended to measure the extent to which potential research users perceive utility (or a lack of utility) in those assets.

Your name has been selected from a small group of Texas based academic and industrial physicists. Thus, your feedback is critical. The survey contains 10 questions that will take about 10 minutes to answer. Please return the survey within the next 10 days. Your prompt input will be important in helping to make decisions on what to do with the SSC assets. Regardless of your position, if those decisions are important to you, it is in your interest to complete this survey. A pre-paid business reply envelope is enclosed for your convenience. If you would like us to send you a summary of the results, enclose your name and address.

As indicated by the recent Texas-DoE "settlement," something is going to happen to the SSC assets. Be a part of the process. Complete the survey now. Thank you for your help.

Sincerely,

Daniel J. Howard

Associate Professor and Chair

Department of Marketing 

TECHNOLOGY FIRM SURVEY COVER LETTER 

August 8, 1994

«FName» «LName»

«Add»

Dear «Title» «LName»:

To assist decisions regarding the future use of Superconducting Super Collider assets, Dr. S.

Peter Rosen, Dean of Science at the University of Texas at Arlington, and Dr. Vigdor L. Teplitz, Chair of the Physics Department at Southern Methodist University, have received DoE funding to study the feasibility of a Joint Texas Facility for Support of Research, Training, and Education. In turn, I have been asked to survey impartially evaluations of SSC assets that might be included in such a Texas Facility. Specifically, this survey is intended to measure the extent to which potential research organizations perceive utility (or a lack of utility) in those assets.

Your company has been selected from a small group of Texas based academic and industrial institutions. Thus, your feedback is critical. This survey should be completed by a person who has s:gnificant influence over decisions regarding your company's use of SSC assets. The survey contains 10 questions that will take about 10 minutes to answer. Please return the survey within the next 10 days. Your prompt input will be important in helping to make decisions on what to do with the SSC assets. Regardless of your position, if those decisions are important to your company, it is in your interest to complete this survey. A pre-paid business reply envelope is enclosed for your convenience. If you would like us to send you a summary of the results, enclose your name and address.

As indicated by the recent Texas-DoE "settlement," something is going to happen to the SSC assets. Be a part of the process. Complete the survey now. Thank you for your help.

Sincerely,

Daniel J. Howard

Associate Professor and Chair

Department of Marketing 

DEAN'S SURVEY COVER LETTER 

August 8, 1994

«FName» «LName»«Ext»

«Add»

Dear «LName»:

To assist decisions regarding the future use of Superconducting Super Collider assets, Dr. S. Peter Rosen, Dean of Science at the University of Texas at Arlington, and Dr. Vigdor L. Teplitz, Chair of the Physics Department at Southern Methodist University, have received DoE funding to study the feasibility of a Joint Texas Facility for Support of Research, Training, and Education. In turn, I have been asked to survey impartially evaluations of SSC assets that might be included in such a Texas Facility. Specifically, this survey is intended to measure the extent to which potential research organizations perceive utility (or a lack of utility) in those assets.

Your university has been selected from a small group of Texas based academic and industrial institutions. Thus, your feedback is critical. This survey. should be completed by a person who has significant influence over decisions regarding your university's use of SSC assets. The survey contains 10 questions that will take about 10 minutes to answer. Please return the survey within the next 10 days. Your prompt input will be important in helping to make decisions on what to do with the SSC assets. Regardless of your position, if those decisions are important to your university, it is in your interest to complete this survey. A pre-paid business reply envelope is enclosed for your convenience. If you would like us to send you a summary of the results, enclose your name and address.

As indicated by the recent Texas-DoE "settlement," something is going to happen to the SSC assets. Be a part of the process. Complete the survey now. Thank you for your help.

Sincerely,

Daniel J. Howard

Associate Professor and Chair

Department of Marketing 



\section{APPENDIX N}

Dr. Thomas N. Pyke, Director

The GLOBE Program

744 Jackson Place, N.W.

Washington, DC 20503

SUBJECT: Expression of Interest in a Joint Project Agreement Supporting the GLOBE (Global

Learning and Observations to Benefit the Environment) Program

Dear Dr. Pyke:

In fulfilling concomitant designations as Land-Grant, Sea-Grant and Space-Grant institutions, Texas A\&M University has established a tradition of and continues to demonstrate a leadership role in cutting-edge research and education related to the environment and appropriate uses of Earth's resources.

As an extension of its ongoing responsibilities within both the national and international environmental education infrastructure, Texas A\&M can team with appropriate partners to serve as a primary focal point for collaborative, joint. initiatives benefiting the GLOBE Program.

For example, in the wake of the shutdown of the Superconducting Super Collider (SSC), strong state and federal interest has been expressed in applying resources of that project to the enhancement of science education. One of the Department of Energy (DoE) project definition studies currently underway at the SSC, "The Joint Texas Facility Supporting Research, Training and Science Education," is developing the operational framework for a CYBERSCIENCE COALITION, using Internet to link active scientists and engineers in the enhancement of science education in $\mathrm{K}-12$ classrooms, as well as university coursework.

Teaming with the leaders of this evolving CYBERSCIENCE COALITION, Texas A\&M University's College of Science proposes activities such as the following:

- Use of the extensive hardware and software resources at the SSC High Performance Computer Center in Waxahachie, Texas, to serve as GLOBE's central processing site, at which global environmental images will be created and relayed back to the students and environmental scientists through Internet on existing networking nodes and infrastructure.

- Use of existing SSC high-bandwidth connectivity to the Texas Educational Network (TENET) and the Texas Higher Education Network (TheNET) to demonstrate delivery to and partcipation of a variety of constituents in diverse, multicultural settings across the state and in Mexico.

- Providing expertise in computational modeling and visualization available through TAMU's Institute for Scientific Computation.

- Involving teachers at the Maypearl ISC (10 miles from the SSC) in a GLOBE demonstration project, which capitalizes upon several years of student collected data and experience running an educational environmental program monitoring the local creeks, pollen counts and bird populations.

- Targeting another DoE project definition study at the SSC, The Blackland Prairie Restoration Project, as an appropriate research environment for GLOBE data collection. Planned to start in 1995, the Blackland Prairie Restoration Project (5000+ acres) involves DoE and the Texas Department of Parks $\&$ Wildlife, and could be interesting pilot project subject matter for broad public school involvement and collaboration with the existing Blackland Restoration Project at FermiLab. 
- Drawing upon expertise in interactive educational methods existing at The Multimedia Development Laboratory, College of Education, Texas A\&M to facilitate the evolution of new curriculum and educational tools.

- Working with researchers from the Houston Adranced Research Center (HARC) in The Woodlands, Texas and TAMU to create a rescarch test bed demionstrating commerical viability for new tclecommunications technologies which might be used immediately to optimize bandwidth into the classroom.

Given the short notice of the request for expressions of interest and the advice of staff within the GLOBE program office, I am forwarding the information above in order to alcrt you of capabilities to respond with new and interesting ideas, and to assure that our team is eager to respond in greater detail when needed.

Respectfully submitted,

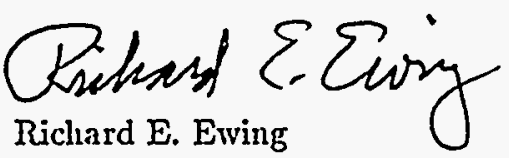

Dean, College of Science

Texas Enginecring Experiment Station (TEES)

Distinguished Research Chair

Director, Institute for Scientific Computation

Professor of Mathematics and Engineering

cc: Jane Armstrong

Andy Blanchard

Jheroen Dorenbosch

Evelyn Restivo

Peter Rosen

Mike Snith

Vic Teplitz

Jim Zuhn 
